Technical Report

March 1997

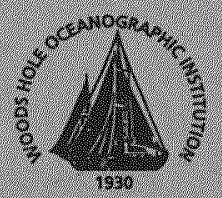

\title{
Acquisition, Description and Evaluation of Atmospheric Model Products for the Coastal Mixing and Optics Experiment
}

by

Mark F. Baumgartner

Steven P. Anderson
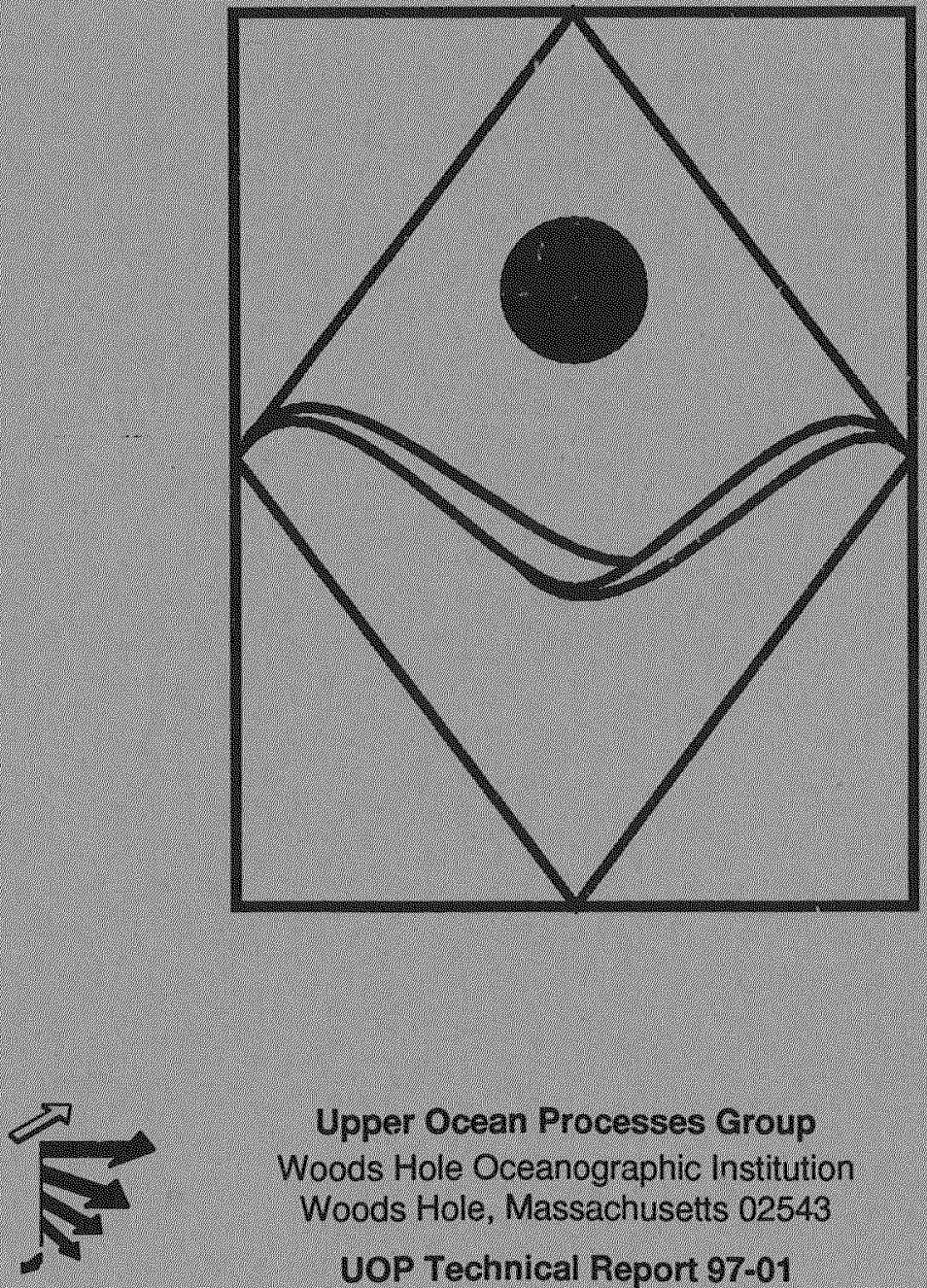
WHOI-97-02

UOP Report 97-01

\title{
Acquisition, Description and Evaluation of Atmospheric Model Products for the Coastal Mixing and Optics Experiment
}

\author{
by \\ Mark F. Baumgartner \\ Steven P. Anderson \\ Upper Ocean Processes Group \\ Woods Hole Oceanographic Institution \\ Woods Hole, Massachusetts 02543-1541
}

March 1997

\section{Technical Report}

Funding provided by the Office of Naval Research under

Contract No. N00014-95-1-0339

Reproduction in whole or in part is permitted for any purpose of the United States

Government. This report should be cited as:

Woods Hole Oceanog. Inst. Tech. Rept., WHOI-97-02

Approved for publication; distribution unlimited.

Approved for Distribution:

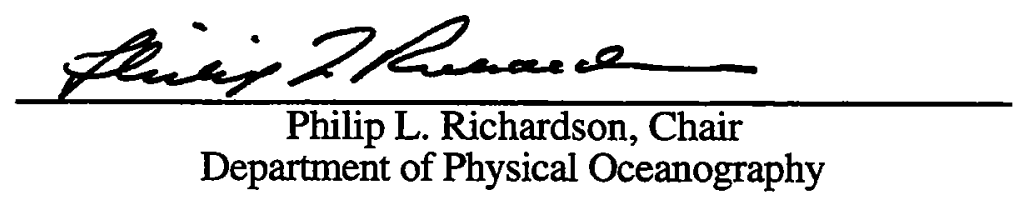




\section{Abstract}

Numerical weather forecasting model products were acquired for use in the Coastal Mixing and Optics (CMO) Experiment to augment in situ observations of meteorological parameters (e.g., wind speed and direction, air temperature and relative humidity) at a moored array of buoys in the Middle Atlantic Bight. In this report, the Eta and Rapid Update Cycle (RUC) regional models are described and the two methods of acquisition via the Internet, the Internet Data Distribution (IDD) system and file transfer (FTP) from the NOAA Information Center's data server, are discussed. Processing and archival of the model data are also addressed. Data from the CMO central mooring and six National Data Buoy Center (NDBC) buoys in the Middle Atlantic Bight were used to evaluate the accuracy of the model products. Comparisons between model and in situ wind speed, wind direction, barometric pressure, air temperature and sea surface temperature were possible for all seven of the buoys. Since no moisture measurement was made from the NDBC buoys, comparisons of relative and specific humidity were only possible at the CMO buoy. Sensible and latent heat fluxes and global (net) radiation from the models were compared to estimates of heat fluxes and net radiation from the CMO central buoy. 


\section{Table of Contents}

$\begin{array}{ll}\text { Abstract } & \text { i }\end{array}$

List of Figures iii

List of Tables $\quad$ ix

Section 1: Introduction $\quad 1$

Section 2: Model Descriptions $\quad 3$

$\begin{array}{ll}\text { Section 3: Data Acquisition } & 6\end{array}$

$\begin{array}{ll}\text { Section 4: Data Summary } & 10\end{array}$

Section 5: Evaluation of Model Products $\quad 16$

$\begin{array}{ll}\text { Literature Cited } & 29\end{array}$

Acknowledgments $\quad$. 29

Appendix A: Model versus In situ Comparisons $\quad 30$

Appendix B: Comparison of CMO buoy and NDBC buoy $44008 \quad 166$

Appendix C: NetCDF formats for archived model data $\quad 172$

Appendix D: Bibliography $\quad 180$

$\begin{array}{ll}\text { Appendix E: WWW Resources } & 181\end{array}$

$\begin{array}{ll}\text { Appendix F: Acronyms } & 182\end{array}$ 


\section{List of Figures}

Figure 1. Domains of the (a) 211 and (b) 87 grid. 4

Figure 2. Conceptual distribution scheme of the Internet Data Distribution 6 (IDD) system.

$\begin{array}{lll}\text { Figure 3. Coastal Mixing and Optics (CMO) moored array and surrounding } & 10\end{array}$ National Data Buoy Center (NDBC) buoys.

Figure 4. Coastal Mixing and Optics central 3m discus buoy. 11

Figure 5. (a) NDBC 3m discus buoy. (b) U.S. Coast Guard large navigational 13 buoy. (c) NDBC $6 \mathrm{~m}$ NOMAD buoy. Photos courtesy of National Data Buoy Center.

Figure 6. Locations of CMO buoys, NDBC buoys and (a) 211 and (b) 87 grid points.

$\begin{array}{lll}\text { Figure 7. Mean and standard deviations of [model - in situ] differences. } & 18\end{array}$

Figure 8. An example of anomalously high wind speeds at the edge of the 20 RUC domain.

Figure 9. (a) Sensible and (b) latent heat fluxes for CMO buoy, RUC Hourly 28 and from TOGA COARE flux algorithm using RUC Hourly observables as input.

Figure A1. Eta vs. CMO VAWR 0704 wind speed. $\quad 36$

$\begin{array}{lll}\text { Figure A2. . Eta vs. NDBC Buoy } 44004 \text { wind speed. } & 37\end{array}$

$\begin{array}{lll}\text { Figure A3. Eta vs. NDBC Buoy } 44008 \text { wind speed. } & 38\end{array}$

$\begin{array}{lll}\text { Figure A4. Eta vs. NDBC Buoy } 44009 \text { wind speed. } & 39\end{array}$

Figure A5. Eta vs. NDBC Buoy 44011 wind speed. $\quad 40$

Figure A6. Eta vs. NDBC Buoy 44025 wind speed. 41

Figure A7. Eta vs. NDBC Buoy 44028 wind speed. 42

Figure A8. RUC vs. CMO VAWR 0704 wind speed. 43

Figure A9. RUC vs. NDBC Buoy 44004 wind speed. 44

Figure A10. RUC vs. NDBC Buoy 44008 wind speed. 45

Figure A11. RUC vs. NDBC Buoy 44009 wind speed. 46 
Figure A12. RUC vs. NDBC Buoy 44011 wind speed. $\quad 47$

Figure A13. RUC vs. NDBC Buoy 44025 wind speed. 48

Figure A14. RUC vs. NDBC Buoy 44028 wind speed. 49

Figure A15. RUC Analysis vs. CMO VAWR 0704 wind speed. 50

Figure A16. RUC Analysis vs. NDBC Buoy 44004 wind speed. 51

Figure A17. RUC Analysis vs. NDBC Buoy 44008 wind speed. 52

Figure A18. RUC Analysis vs. NDBC Buoy 44009 wind speed. 53

Figure A19. RUC Analysis vs. NDBC Buoy 44011 wind speed. 54

Figure A20. RUC Analysis vs. NDBC Buoy 44025 wind speed. 55

Figure A21. RUC Analysis vs. NDBC Buoy 44028 wind speed. 56

Figure A22. RUC Hourly vs. CMO VAWR 0704 wind speed. 57

Figure A23. RUC Hourly vs. NDBC Buoy 44004 wind speed. $\quad 58$

Figure A24. RUC Hourly vs. NDBC Buoy 44008 wind speed. 59

Figure A25. RUC Hourly vs. NDBC Buoy 44009 wind speed. 60

Figure A26. RUC Hourly vs. NDBC Buoy 44011 wind speed. 61

Figure A27. RUC Hourly vs. NDBC Buoy 44025 wind speed. 62

Figure A28. RUC Hourly vs. NDBC Buoy 44028 wind speed. 63

Figure A29. Eta vs. CMO VAWR 0704 wind direction. 64

Figure A30. Eta vs. NDBC Buoy 44004 wind direction.

Figure A31. Eta vs. NDBC Buoy 44008 wind direction. 66

$\begin{array}{lll}\text { Figure A32. Eta vs. NDBC Buoy } 44009 \text { wind direction. } & 67\end{array}$

$\begin{array}{lll}\text { Figure A33. Eta vs. NDBC Buoy } 44011 \text { wind direction. } & 68\end{array}$

$\begin{array}{lll}\text { Figure A34. Eta vs. NDBC Buoy } 44025 \text { wind direction. } & 69\end{array}$

$\begin{array}{lll}\text { Figure A35. Eta vs. NDBC Buoy } 44028 \text { wind direction. } & 70\end{array}$

Figure A36. RUC vs. CMO VAWR 0704 wind direction. 71

$\begin{array}{lll}\text { Figure A37. RUC vs. NDBC Buoy } 44004 \text { wind direction. } & 72\end{array}$

Figure A38. RUC vs. NDBC Buoy 44008 wind direction. 73 
Figure A39. RUC vs. NDBC Buoy 44009 wind direction.

Figure A40. RUC vs. NDBC Buoy 44011 wind direction. 75

Figure A41. RUC vs. NDBC Buoy 44025 wind direction. 76

Figure A42. RUC vs. NDBC Buoy 44028 wind direction. 77

Figure A43. RUC Analysis vs. CMO VAWR 0704 wind direction. 78

Figure A44. RUC Analysis vs. NDBC Buoy 44004 wind direction. 79

Figure A45. RUC Analysis vs. NDBC Buoy 44008 wind direction. 80

Figure A46. RUC Analysis vs. NDBC Buoy 44009 wind direction. $\quad 81$

Figure A47. RUC Analysis vs. NDBC Buoy 44011 wind direction. 82

Figure A48. RUC Analysis vs. NDBC Buoy 44025 wind direction. 83

Figure A49. RUC Analysis vs. NDBC Buoy 44028 wind direction. 84

Figure A50. RUC Hourly vs. CMO VAWR 0704 wind direction. $\quad 85$

Figure A51. RUC Hourly vs. NDBC Buoy 44004 wind direction. 86

Figure A52. RUC Hourly vs. NDBC Buoy 44008 wind direction. 87

Figure A53. RUC Hourly vs. NDBC Buoy 44009 wind direction. 88

Figure A54. RUC Hourly vs. NDBC Buoy 44011 wind direction. 89

Figure A55. RUC Hourly vs. NDBC Buoy 44025 wind direction. 90

Figure A56. RUC Hourly vs. NDBC Buoy 44028 wind direction. 91

Figure A57. Eta vs. CMO VAWR 0704 barometric pressure. 92

Figure A58. Eta vs. NDBC Buoy 44004 barometric pressure. 93

$\begin{array}{lll}\text { Figure A59. Eta vs. NDBC Buoy } 44008 \text { barometric pressure. } & 94\end{array}$

Figure A60. Eta vs. NDBC Buoy 44009 barometric pressure. 95

Figure A61. Eta vs. NDBC Buoy 44011 barometric pressure. 96

$\begin{array}{lll}\text { Figure A62. Eta vs. NDBC Buoy } 44025 \text { barometric pressure. } & 97\end{array}$

$\begin{array}{lll}\text { Figure A63. Eta vs. NDBC Buoy } 44028 \text { barometric pressure. } & 98\end{array}$

Figure A64. RUC vs. CMO VAWR 0704 barometric pressure. 99

Figure A65. RUC vs. NDBC Buoy 44004 barometric pressure. 100 
Figure A66. RUC vs. NDBC Buoy 44008 barometric pressure. 101

Figure A67. RUC vs. NDBC Buoy 44009 barometric pressure. 102

$\begin{array}{lll}\text { Figure A68. } & \text { RUC vs. NDBC Buoy } 44011 \text { barometric pressure. } & 103\end{array}$

$\begin{array}{lll}\text { Figure A69. } & \text { RUC vs. NDBC Buoy } 44025 \text { barometric pressure. } & 104\end{array}$

Figure A70. RUC vs. NDBC Buoy 44028 barometric pressure. 105

Figure A71. RUC Analysis vs. CMO VAWR 0704 barometric pressure. 106

Figure A72. RUC Analysis vs. NDBC Buoy 44004 barometric pressure. $\quad 107$

Figure A73. RUC Analysis vs. NDBC Buoy 44008 barometric pressure. 108

Figure A74. RUC Analysis vs. NDBC Buoy 44009 barometric pressure. 109

Figure A75. RUC Analysis vs. NDBC Buoy 44011 barometric pressure. 110

Figure A76. RUC Analysis vs. NDBC Buoy 44025 barometric pressure. 111

Figure A77. RUC Analysis vs. NDBC Buoy 44028 barometric pressure. 112

Figure A78. RUC Hourly vs. CMO VAWR 0704 barometric pressure. 113

Figure A79. RUC Hourly vs. NDBC Buoy 44004 barometric pressure. 114

Figure A80. RUC Hourly vs. NDBC Buoy 44008 barometric pressure. 115

Figure A81. RUC Hourly vs. NDBC Buoy 44009 barometric pressure. 116

Figure A82. RUC Hourly vs. NDBC Buoy 44011 barometric pressure. _ $\quad 117$

Figure A83. RUC Hourly vs. NDBC Buoy 44025 barometric pressure. 118

Figure A84. RUC Hourly vs. NDBC Buoy 44028 barometric pressure. 119

$\begin{array}{lll}\text { Figure A85. Eta vs. CMO VAWR } 0704 \text { air temperature. } & 120\end{array}$

$\begin{array}{lll}\text { Figure A86. Eta vs. NDBC Buoy } 44004 \text { air temperature. } & 121\end{array}$

Figure A87. Eta vs. NDBC Buoy 44008 air temperature. 122

$\begin{array}{lll}\text { Figure A88. Eta vs. NDBC Buoy } 44009 \text { air temperature. } & 123\end{array}$

$\begin{array}{lll}\text { Figure A89. Eta vs. NDBC Buoy } 44011 \text { air temperature. } & 124\end{array}$

$\begin{array}{lll}\text { Figure A90. Eta vs. NDBC Buoy } 44025 \text { air temperature. } & 125\end{array}$

$\begin{array}{lll}\text { Figure A91. Eta vs. NDBC Buoy } 44028 \text { air temperature. } & 126\end{array}$

$\begin{array}{lll}\text { Figure A92. } & \text { RUC vs. CMO VAWR } 0704 \text { air temperature. } & 127\end{array}$ 
$\begin{array}{lll}\text { Figure A93. } & \text { RUC vs. NDBC Buoy } 44004 \text { air temperature. } & 128\end{array}$

Figure A94. RUC vs. NDBC Buoy 44008 air temperature. 129

Figure A95. RUC vs. NDBC Buoy 44009 air temperature. 130

Figure A96. RUC vs. NDBC Buoy 44011 air temperature. 131

Figure A97. RUC vs. NDBC Buoy 44025 air temperature. 132

Figure A98. RUC vs. NDBC Buoy 44028 air temperature. 133

Figure A99. RUC Analysis vs. CMO VAWR 0704 air temperature. 134

Figure A100. RUC Analysis vs. NDBC Buoy 44004 air temperature. 135

Figure A101. RUC Analysis vs. NDBC Buoy 44008 air temperature. 136

Figure A102. RUC Analysis vs. NDBC Buoy 44009 air temperature. 137

Figure A103. RUC Analysis vs. NDBC Buoy 44011 air temperature. 138

Figure A104. RUC Analysis vs. NDBC Buoy 44025 air temperature. 139

Figure A105. RUC Analysis vs. NDBC Buoy 44028 air temperature. 140

Figure A106. RUC Hourly vs. CMO VAWR 0704 air temperature. 141

Figure A107. RUC Hourly vs. NDBC Buoy 44004 air temperature. 142

Figure A108. RUC Hourly vs. NDBC Buoy 44008 air temperature. 143

Figure A109. RUC Hourly vs. NDBC Buoy 44009 air temperature. 144

Figure A110. RUC Hourly vs. NDBC Buoy 44011 air temperature. 145

Figure A111. RUC Hourly vs. NDBC Buoy 44025 air temperature. 146

Figure A112. RUC Hourly vs. NDBC Buoy 44028 air temperature. 147

$\begin{array}{ll}\text { Figure A113. Eta vs. CMO VAWR } 0704 \text { relative humidity. } & 148\end{array}$

Figure A114. RUC vs. CMO VAWR 0704 relative humidity. 149

Figure A115. RUC Analysis vs. CMO VAWR 0704 relative humidity. 150

Figure A116. RUC Hourly vs. CMO VAWR 0704 relative humidity. 151

Figure A117. Eta vs. CMO VAWR 0704 specific humidity. 152

Figure A118. RUC vs. CMO VAWR 0704 specific humidity. 153

Figure A119. RUC Analysis vs. CMO VAWR 0704 specific humidity. 154 
Figure A120. RUC Hourly vs. CMO VAWR 0704 specific humidity. 155

Figure A121. RUC Hourly vs. CMO VAWR 0704 sea surface temperature. 156

Figure A122. RUC Hourly vs. NDBC Buoy 44004 sea surface temperature. 157

Figure A123. RUC Hourly vs. NDBC Buoy 44008 sea surface temperature. 158

Figure A124. RUC Hourly vs. NDBC Buoy 44009 sea surface temperature. 159

Figure A125. RUC Hourly vs. NDBC Buoy 44011 sea surface temperature. 160

Figure A126. RUC Hourly vs. NDBC Buoy 44025 sea surface temperature. 161

Figure A127. RUC Hourly vs. NDBC Buoy 44028 sea surface temperature. 162

Figure A128. RUC Hourly vs. CMO VAWR 0704 sensible heat flux. 163

Figure A129. RUC Hourly vs. CMO VAWR 0704 latent heat flux. 164

Figure A130. RUC Hourly vs. CMO VAWR 0704 global radiation. 165

Figure B1. NDBC Buoy 44008 vs. CMO VAWR 0704 wind speed. 167

Figure B2. NDBC Buoy 44008 vs. CMO VAWR 0704 wind direction. 168

Figure B3. NDBC Buoy 44008 vs. CMO VAWR 0704 barometric pressure. 169

Figure B4. NDBC Buoy 44008 vs. CMO VAWR 0704 air temperature. 170

Figure B5. NDBC Buoy 44008 vs. CMO VAWR 0704 sea surface temperature. $\quad 171$ 


\section{List of Tables}

Table 1. Model products acquired for the CMO experiment. 3

Table 2. Model domain parameters. 5

Table 3. RUC model output files available from the NIC. 7

Table 4. Archived forecast hours and filenames for each model. 8

$\begin{array}{ll}\text { Table 5. VAWR sensor specifications. } & 12\end{array}$

Table 6. Locations, depths and hull types of NDBC buoys. 12

$\begin{array}{ll}\text { Table 7. NDBC DACT payload sensor specifications. } & 14\end{array}$

$\begin{array}{ll}\text { Table 8. Rotation angles for wind vectors. } & 15\end{array}$

Table 9. Average and range of mean [model - in situ] wind speed differences and 16 range of model versus in situ wind speed correlation coefficients for all buoys.

Table 10. Average and range of mean [model - in situ] wind direction differences and range of model versus in situ wind direction correlation coefficients for all buoys.

Table 11. Mean differences of [model $\left.\mathrm{NDBC}_{\mathrm{NBC}}-\operatorname{model}_{\mathrm{CMO}}\right]$ wind directions in degrees. 22

Table 12. Average and range of mean [model - in situ] barometric pressure differences and range of model versus in situ barometric pressure correlation coefficients for all buoys.

Table 13. Average and range of mean [model - in situ] air temperature differences and range of model versus in situ air temperature correlation coefficients for all buoys.

Table 14. Mean differences of [model - in situ] relative and specific humidity and model versus in situ relative and specific humidity correlation coefficients for the CMO central buoy

Table A1. Statistical summary of model vs in situ comparisons of wind speed.

Table A2. Statistical summary of model vs in situ comparisons of wind direction.

Table A3. Statistical summary of model vs in situ comparisons of barometric pressure.

Table A4. Statistical summary of model vs in situ comparisons of air temperature.

Table A5. Statistical summary of model vs in situ comparisons of relative humidity. 
Table A6. Statistical summary of model vs in situ comparisons of specific humidity.

Table A7. Statistical summary of RUC Hourly vs in situ comparisons of sea surface temperature.

Table A8. Statistical summary of RUC Hourly model vs in situ comparisons of heat fluxes. 


\section{Section 1: Introduction}

The scientific objective of the moored array component of the ONR Coastal Mixing and Optics (CMO) Experiment is to identify and understand the oceanic mixing processes influencing the evolution of the vertical temperature stratification on the continental shelf. To address this objective, four moorings were deployed at mid-shelf in the Middle Atlantic Bight; a central mooring on the $70 \mathrm{~m}$ isobath and three surrounding moorings located $\sim 10 \mathrm{~km}$ inshore along the $60 \mathrm{~m}$ isobath, $\sim 10 \mathrm{~km}$ offshore along the $80 \mathrm{~m}$ isobath and $\sim 25 \mathrm{~km}$ alongshore to the east in 70m of water. These buoys were deployed in August 1996 and will be recovered in June of 1997. This observing period spans the destruction of the thermal stratification in fall and redevelopment of the thermal stratification in spring. The moorings support instrumentation to measure the ocean temperature, salinity and velocity structure and variability as well as the surface meteorology. The observations from this moored array will be used to investigate changes in the stratification in response to atmospheric forcing, surface gravity wave variability, surface and bottom boundary layer mixing, current shear, internal waves and advection.

The oceanic variability on the continental shelf is closely tied to temporal and spatial variability in the atmospheric forcing. To characterize the local atmospheric forcing, a surface buoy at the central mooring site contains redundant Vector Averaging Wind Recorder (VAWR) meteorological instrumentation (Weller et al., 1990). Both VAWR packages measure wind speed and direction, incoming short-wave and long-wave radiation, relative humidity, air temperature, sea-surface temperature, barometric pressure. In addition, two stand-alone, internally logging precipitation gauges are on the buoy. The buoy observations will provide the various parameters necessary for estimating the local surface momentum, heat and buoyancy fluxes. The three surrounding mooring sites each support a WeatherPak 2000 meteorological package (Coastal Environmental Systems, Seattle, Washington) which records wind speed and direction, air temperature, relative humidity and barometric pressure.

The surface meteorological observations from the moored array provide limited information about the remote atmospheric forcing. Gridded products from numerical weather forecasting models can offer more complete descriptions of the spatial variability over the ocean. Surface flux estimates from European Centre for Medium-Range Weather Forecasts (ECMWF) and National Centers for Environmental Prediction (NCEP) global numerical models are commonly used by oceanographers to force basin-scale ocean models. However, the resolutions of these global analysis fields are too low both in time and space to be useful in understanding the 
oceanic response on the continental shelf. In addition, the accuracy of these flux fields near the coast is questionable.

The regional numerical weather models, such as NCEP's Eta and Rapid Update Cycle (RUC) models, offer surface fields with higher spatial and temporal resolutions. The domain of these two models in particular covers much of the U.S. continental shelf. The coastal ocean community does not typically use the surface fields from these weather forecasting models and little work has been done to validate these surface fields over the ocean. The CMO program provides a good opportunity to both validate and utilize these surface fields.

The first part of this report (Sections 2, 3 and 4) briefly describes the Eta and RUC numerical weather prediction models and the methods by which the model and in situ data were acquired and archived. The final section (Section 5) provides a preliminary comparison of the surface model products with the meteorological observations from the CMO central site and six National Data Buoy Center (NDBC) buoys located in the Middle Atlantic Bight. 


\section{Section 2: Model Descriptions}

Data from two regional NCEP models, the Eta and Rapid Update Cycle (RUC), were acquired for the CMO experiment. Each model's native domain is shown in Figure 1 and the features of each, including domain parameters, model run and forecast times and surface data availability, are provided in Tables 1 and 2. Although the RUC model is run on the 87 grid (Table 2), it is interpolated to the 211 grid by NCEP so that it can be compared to other models. Note that the list of variables in Table 1 are a subset of the variables available in each model. References for documentation of all the model products are given in Appendices D and $\mathrm{E}$.

Table 1. Model products acquired for the CMO experiment. A "D" denotes the variable can be derived from other variables.

\begin{tabular}{|c|c|c|c|c|}
\hline & Eta & RUC & $\begin{array}{c}\text { RUC } \\
\text { Analysis }\end{array}$ & $\begin{array}{c}\text { RUC } \\
\text { Hourly }\end{array}$ \\
\hline Data Source & $\mathrm{IDD}$ & $\mathrm{IDD}$ & NIC & NIC \\
\hline Native Domain & 211 & 87 & 87 & 87 \\
\hline Distributed Domain & 211 & 211 & 87 & 87 \\
\hline Model Run Interval (hours) & 12 & 3 & 3 & 3 \\
\hline Forecast Hours & $0-48$ & $0-12$ & - & $0-12$ \\
\hline Forecast Interval (hours) & 6 & 3 & - & 1 \\
\hline \multicolumn{5}{|l|}{ Variables } \\
\hline East Wind $\left(\mathrm{m} \mathrm{s}^{-1}\right)$ & $\mathrm{X}$ & $\mathrm{X}$ & $\mathrm{X}$ & $\mathrm{X}$ \\
\hline North Wind $\left(\mathrm{m} \mathrm{s}^{-1}\right)$ & $\mathrm{X}$ & $\mathrm{X}$ & $\mathrm{X}$ & $\mathrm{X}$ \\
\hline Air Temperature $\left({ }^{\circ} \mathrm{C}\right)$ & $\mathrm{X}$ & $\mathrm{X}$ & $\mathrm{D}$ & $\mathrm{D}$ \\
\hline Relative Humidity (\%) & $\mathrm{X}$ & $x$ & $\mathrm{D}$ & $\mathrm{D}$ \\
\hline Surface Pressure (mbar) & $X$ & X & & \\
\hline Mean Sea Level Pressure (mbar) & $\mathrm{X}$ & $\mathbf{X}$ & $\mathbf{X}$ & $\mathrm{X}$ \\
\hline Condensation Pressure (mbar) & & & $\mathbf{X}$ & $\mathrm{X}$ \\
\hline Potential Temperature $\left({ }^{\circ} \mathrm{C}\right)$ & & & $\mathbf{X}$ & $\mathbf{x}$ \\
\hline Convective Inhibition $\left(\mathrm{J} \mathrm{kg}^{-1}\right)$ & $\mathrm{X}$ & $\mathrm{X}$ & & $\mathbf{X}$ \\
\hline Convective Available Potential Energy $\left(\mathrm{J} \mathrm{kg}^{-1}\right)$ & $\mathbf{X}$ & $\mathrm{X}$ & & $\mathrm{X}$ \\
\hline Precipitation over Accumulation Interval $\left(\mathrm{kg} \mathrm{m}^{-2}\right)$ & $\mathrm{X}$ & $\mathrm{X}$ & & \\
\hline Large Scale Precipitation (non-convective) $\left(\mathrm{kg} \mathrm{m}^{-2}\right)$ & & & & $\mathrm{x}$ \\
\hline Convective Precipitation $\left(\mathrm{kg} \mathrm{m}^{-2}\right)$ & & & & $\mathrm{X}$ \\
\hline Precipitable Water $\left(\mathrm{kg} \mathrm{m}^{-2}\right)$ & & & & $\mathrm{X}$ \\
\hline Latent Heat $\left(\mathrm{W} \mathrm{m}^{-2}\right)$ & & & & $\mathbf{X}$ \\
\hline Sensible Heat $\left(\mathrm{W} \mathrm{m}^{-2}\right)$ & & & & $X$ \\
\hline Global Radiation (W m $\left.{ }^{-2}\right)$ & & & & $\mathrm{X}$ \\
\hline Sea Surface Temperature $\left({ }^{\circ} \mathrm{C}\right)$ & & & & $\mathbf{X}$ \\
\hline Precipitation Rate $\left(\mathrm{kg} \mathrm{m}^{-1} \mathrm{~s}^{-1}\right)$ & & & & $\mathrm{X}$ \\
\hline
\end{tabular}

The Eta model (also known as the Early Eta) is a 38-level eta-coordinate model run on the 211 grid. It is run every 12 hours and produces forecasts up to 48 hours into the future. The 

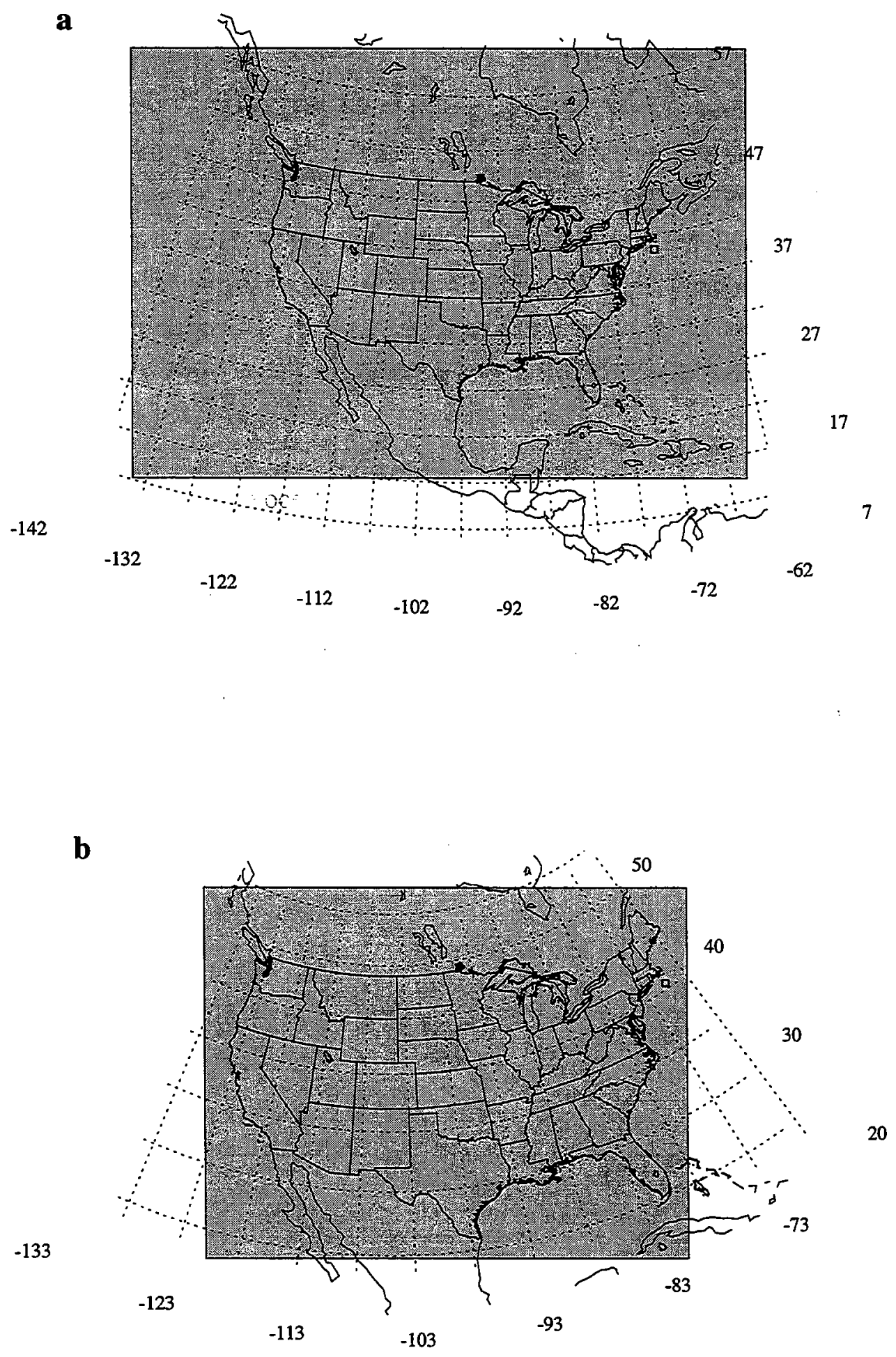

Figure 1. Domains of the (a) 211 and (b) 87 grids. 
Eta model is initialized with output from the Global Data Assimilation System (GDAS) and the Eta optimal interpolation (OI) scheme. The 0 (initialized), 6, 12, 18, 24, 30, 36, 42 and 48 hour forecasts from this model are available from the Internet Data Distribution (IDD) system on the native 211 grid in GRIB format.

Table 2. Model domain parameters.

\begin{tabular}{lcc}
\hline \hline & Grid 87 & Grid 211 \\
\cline { 2 - 3 } Projection & Polar stereographic & Lambert Conformal Conic \\
Horizontal Resolution & $60 \mathrm{~km}\left(\right.$ at $\left.40^{\circ} \mathrm{N}\right)$ & $80 \mathrm{~km}\left(\right.$ at $\left.35^{\circ} \mathrm{N}\right)$ \\
Dimensions & $81 \times 62$ & $93 \times 65$ \\
NW Corner & $52.489^{\circ} \mathrm{N}, 136.546^{\circ} \mathrm{W}$ & $54.536^{\circ} \mathrm{N}, 152.856^{\circ} \mathrm{W}$ \\
NE Corner & $46.017^{\circ} \mathrm{N}, 60.828^{\circ} \mathrm{W}$ & $57.290^{\circ} \mathrm{N}, 49.385^{\circ} \mathrm{W}$ \\
SW Corner & $22.876^{\circ} \mathrm{N}, 120.491^{\circ} \mathrm{W}$ & $12.190^{\circ} \mathrm{N}, 133.459^{\circ} \mathrm{W}$ \\
SE Corner & $20.128^{\circ} \mathrm{N}, 81.243^{\circ} \mathrm{W}$ & $14.335^{\circ} \mathrm{N}, 65.091^{\circ} \mathrm{W}$ \\
\hline
\end{tabular}

The RUC model is the operational version of the Mesoscale Analysis and Prediction System (MAPS) developed by the Forecast Systems Laboratory (FSL) of the National Oceanic and Atmospheric Administration (NOAA). This model is a 25-level, hybrid isentropic-sigma coordinate analysis and forecast system which is run on the 87 grid. The model is run every three hours and produces forecasts up to 12 hours into the future. Data from rawinsonde, commercial aircraft, profilers and surface stations are assimilated in an analysis before each model run. The model is initialized at the start of each three hour run with a filtered product of the analysis. This filtered product is distributed as the 0 hour forecast.

Data from the RUC model are available from both the IDD and the NOAA Information Center (NIC) server in GRIB format. The data from the IDD are available on the 211 grid and consist of the 0 (initialized), 3, 6, 9 and 12 hour forecasts only. Model data from the NIC server are available both on the native 87 grid and the 211 grid. These data include analysis, initialized and hourly (1-12 hour) forecasts fields. 


\section{Section 3: Data Acquisition}

NCEP and ECMWF model data are available through Unidata's Internet Data Distribution (IDD) system of which the Woods Hole Oceanographic Institution (WHOI) is a licensed member. The IDD is a distributed system, meaning that the data is not accessed at a single centralized server. There are three ways a computer can interact with the IDD; as a source, a relay or a sink. A source is a computer that inserts data into the system for use by an authorized group of computers called downstream hosts, a sink is a computer that accepts data from a source or a relay (i.e., its upstream host), and a relay is a computer that accepts data from its upstream host and then inserts that same data back into the system for its authorized group of downstream hosts (Figure 2). A workstation at WHOI is a sink, receiving data only from one upstream host. The flow of data within the IDD is managed by software on each computer in the system called the Local Data Manager (LDM) software.

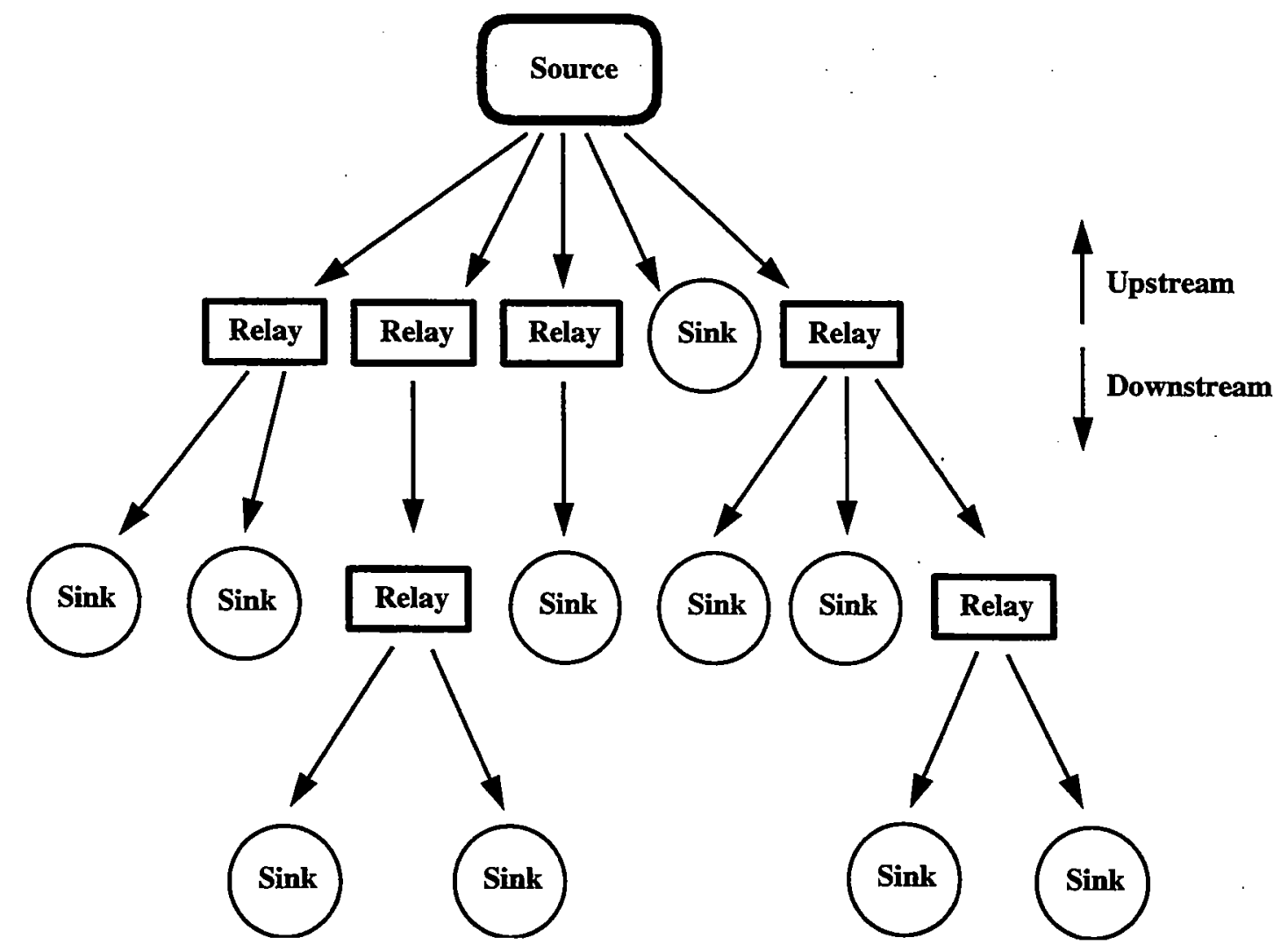

Figure 2. Conceptual distribution scheme of the Internet Data Distribution (IDD) system.

The LDM software is a daemon that runs in the background on a workstation. After initial configuration, the software requires no user input. For a source or a relay, the LDM 
coordinates the delivery of data to downstream hosts. On a relay or sink computer, the LDM delivers requests for data to an upstream host and then coordinates delivery and any additional processing of the data. Data requests sent from sinks to sources or relays specify the type of data the sink wishes to acquire from its upstream host. The entire National Weather Service (NWS) Family of Services (FOS) are available through the IDD, including weather bulletins, surface station observations, upper-air data, atmospheric model products and buoy reports. Also available are ECMWF model products, GOES imagery, NEXRAD radar mosaics and data from the National Lightning Detection Network, although some services require additional licensing agreements with institutions other than Unidata. For the CMO experiment, RUC and Eta model data are requested from an upstream host and as the data become available on the upstream host, it is delivered to a WHOI workstation running the LDM software.

Additional model data from NCEP are available on the NIC server and can be acquired via the anonymous file transfer program (FTP). The full suite of RUC model products on the native 87 grid are available from this server, including the analysis and 12 hourly forecast files. Similar RUC products are also available on the 211 grid. The files listed in Table 3 can be downloaded from the directory pub/ruc on the NIC server, nic . fb4 . noaa. gov. Currently, only products on the 87 grid are being obtained from the NIC for the CMO experiment, since the 211 grid products are being acquired from the IDD. Output from other models are also available from the NIC server, including the Eta, Nested Grid Model (NGM), Aviation and Medium Range Forecast (MRF) models.

\begin{tabular}{|c|c|}
\hline & File \\
\hline \multicolumn{2}{|l|}{87 Grid } \\
\hline Analysis Field & ruc. T\#\#Z.grbbanl \\
\hline Initialized Field ( 0 hour forecast) & ruc.T\#\#Z.grbb $\neq 00$ \\
\hline 1-12 hour Forecast & ruc. T\#\#Z.grbbfXX \\
\hline \multicolumn{2}{|l|}{211 Grid } \\
\hline Analysis Field & ruc.T\#\#Z.grb2anl \\
\hline Initialized Field ( 0 hour forecast) & ruc. $T \# \# Z . g r b 2 f 00$ \\
\hline 1-12 hour Forecast & ruc.T\#\#Z.grb2 $\mathrm{fXx}$ \\
\hline
\end{tabular}

Because of the large volume of model data available, only the surface variables for selected forecasts are archived. These variables are explicitly labeled as the surface variables in the Eta 
and RUC files distributed via the IDD. Since there are no separate surface variables distributed in the RUC Analysis and RUC Hourly datasets, the variables from the hybrid level closest to the surface (Level 1) in these datasets are treated as the surface variables. The forecast hours selected for archival are presented in Table 4. Once the model data are acquired from either the IDD or the NIC, the surface variables for the selected forecasts are extracted, reformatted from GRIB to NetCDF and archived.

Table 4. Archived forecast hours and filenames for each model. Year of century, month, day and hour are denoted as YY, MM, DD and HH, respectively. Italicized filename dates are the forecast times and nonitalicized dates are model run times.

\begin{tabular}{lllcc}
\hline \hline & & & & Forecast or \\
Model & Forecast Selection & Archived Filename & $\begin{array}{c}\text { Archive files } \\
\text { per model run }\end{array}$ & $\begin{array}{c}\text { palysis fields } \\
\text { per file }\end{array}$ \\
\hline Eta & $0,6,12,18$ and 24 hour & YYMMDDHHeta.nc & 1 & 5 \\
RUC & $0,3,6,9$ and 12 hour & YYMMDDHHruc.nc & 1 & 5 \\
RUC Analysis & Each 3 hour analysis & YYMMDDHHrucanl.nc & 1 & 1 \\
RUC Hourly & 1,2 , and 3 hour & YYMMDDHHrucflux.nc & 3 & 1 \\
\hline
\end{tabular}

Forecast data from each model run of the Eta model are archived as a single NetCDF file. The file contains the model output for each of the forecast hours listed in Table 4 and the NetCDF format is listed in Appendix C. The RUC model data from the IDD are archived in the same manner as the Eta model. The RUC Analysis data from the NIC are generated only once every model run, so the archived file contains only the analysis fields and no forecast fields. The RUC Hourly data from the NIC are archived as a single NetCDF file for each forecast hour. For each RUC model run, three NetCDF archive files of RUC Hourly data are generated for the 1,2 and 3 hour forecasts.

Acquisition of the models from both the IDD and NIC is entirely dependent on network availability. Data gaps in the time series of archived model products arise from network or power outages. Fortunately, these outages are infrequent and an uninterruptible power supply (UPS) serves the WHOI LDM workstation to protect against local transient power problems. Since the moored array is relatively close to Woods Hole, the most energetic events that may be scientifically significant (e.g., Hurricane Edouard in early September 1996) can knock power out at WHOI. During these events, model acquisition may become impossible. Data archives of the model data from the IDD are available, but these archives are not supported by Unidata and are available only as a courtesy to the IDD community by other users. The archive used for the CMO experiment at the University of Illinois at Urbana-Champaign only keeps the last 
36 hours of NCEP and ECMWF model data due to immense storage requirements. Data on the NIC server is, at most, 24 hours old. Because of outages and implementation problems, the data return of model products has been between 83 and $93 \%$. 


\section{Section 4: Data Summary}

\section{$\underline{\text { In situ }}$}

To evaluate the accuracy of the numerical weather forecasting models, the model products were compared with in situ observations from buoys in the Middle Atlantic Bight (Figure 3). These observations were collected from the CMO central mooring and six NDBC buoys from 1 August 1996 to 31 January, 1997.

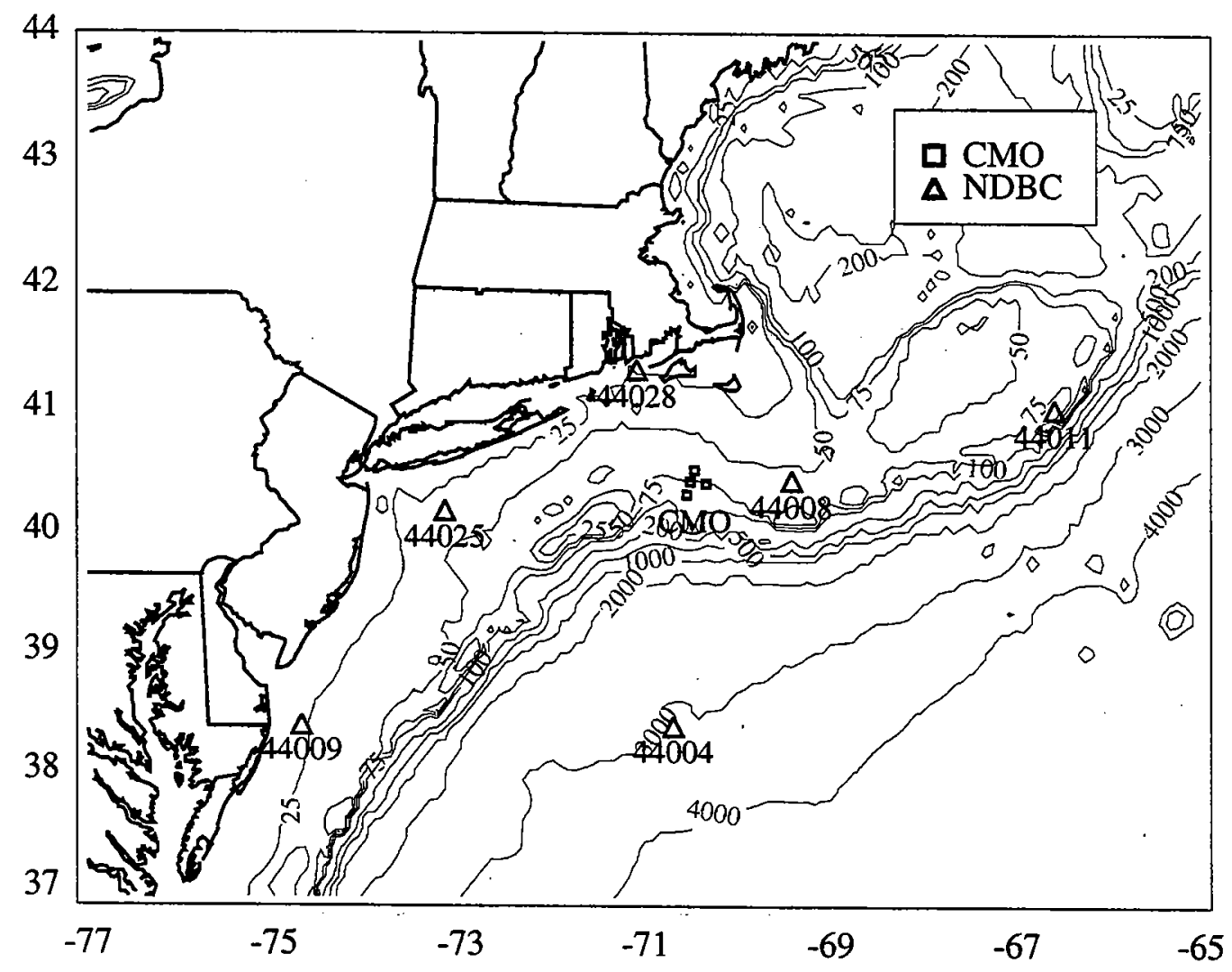

Figure 3. Coastal Mixing and Optics moored array and surrounding National Data Buoy Center buoys.

The CMO central mooring carried two, redundant Vector Averaging Wind Recorder (VAWR) meteorological packages (Weller et al., 1990) which measure wind speed and direction, incoming short-wave and long-wave radiation, air temperature, relative humidity, barometric pressure and sea surface temperature at a 15 minute sampling rate (Figure 4). The sensor specifications for this package are presented in Table 5. The VAWR telemeters the meteorological data to the NOAA-series polar orbiting satellites. The data can then be accessed by $\mathrm{CMO}$ investigators via Service Argos and once downloaded, the data are calibrated, quality 


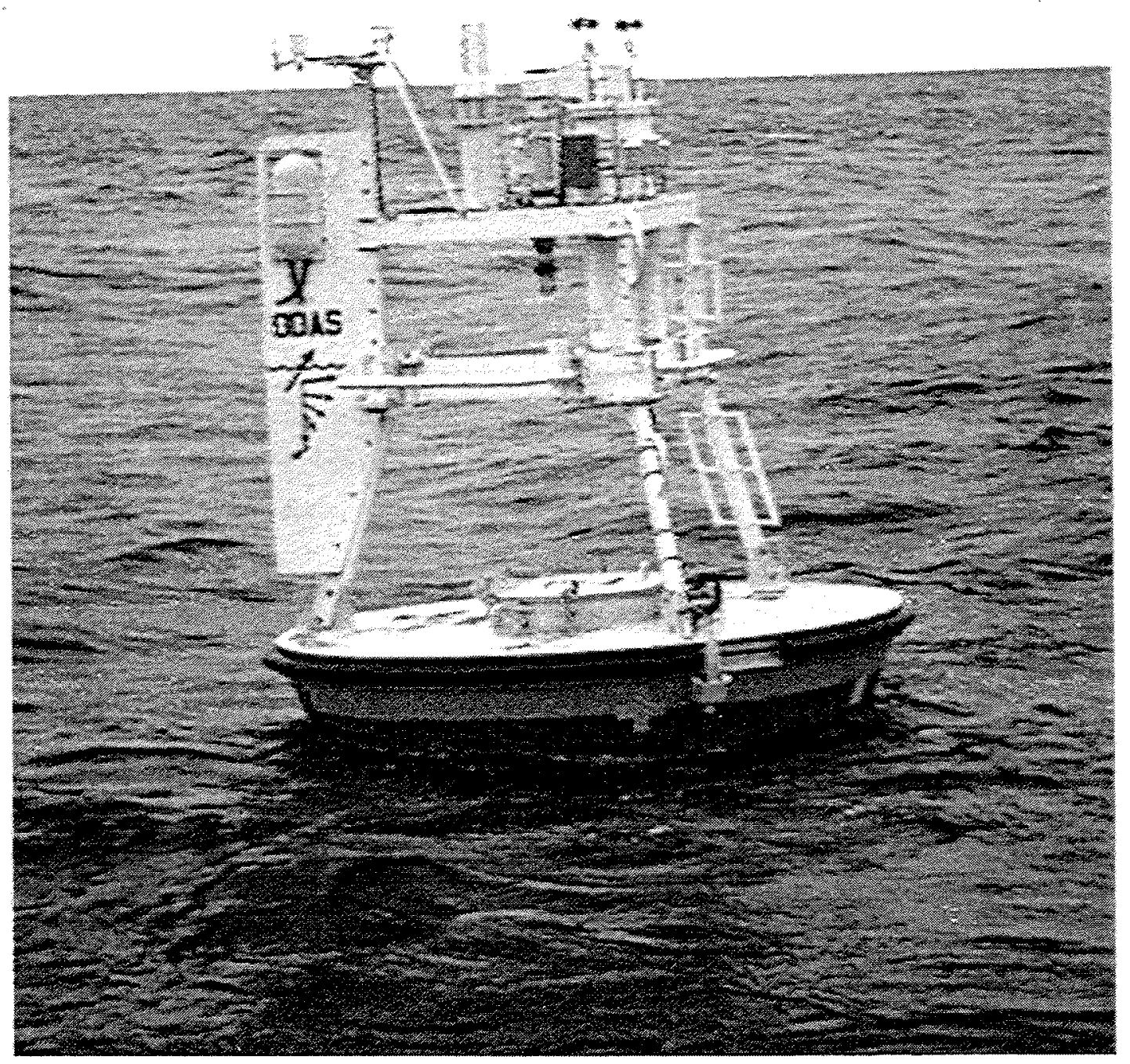

Figure 4. Coastal Mixing and Optics central $3 \mathrm{~m}$ discus buoy. 
controlled and reformatted to NetCDF before analysis. Heat and momentum fluxes were estimated from the telemetered meteorological observations using the TOGA COARE bulk flux algorithm (Fairall et al., 1996) with both the warm layer and cool skin adjustments omitted.

Table 5. VAWR sensor specifications. Wind speed and direction are vector averaged over the sampling interval. Heights are reported as meters above the mean water line.

\begin{tabular}{lcccc}
\hline \hline & Sampling Interval & Range & Accuracy & Height \\
\hline Parameter & 15 minute average & $0.2-50.0 \mathrm{~ms}^{-1}$ & $\pm 2 \%$ above $0.7 \mathrm{~ms}^{-1}$ & 3.30 \\
Wind speed & 15 minute average & $0-360^{\circ}$ & $\pm 5.6^{\circ}$ & 3.02 \\
Wind direction & 3.75 minute average & $-10-35^{\circ} \mathrm{C}$ & $\pm 0.2^{\circ} \mathrm{C}$ when wind $>5 \mathrm{~ms}^{-1}$ & 2.63 \\
Air temperature & 3.75 minute average & $-5-30^{\circ} \mathrm{C}$ & $\pm 0.005^{\circ} \mathrm{C}$ & -1.46 \\
Sea temperature & 2.5 second sample & $0-1034 \mathrm{mbar}$ & $\pm 0.2 \mathrm{mbar}$ when wind $<20 \mathrm{~ms}^{-1}$ & 2.72 \\
Barometric pressure & 3.5 second sample & $0-100 \%$ & $\pm 2 \%$ & 2.68 \\
Relative humidity & 15 minute average & $0-1400 \mathrm{Wm}^{-2}$ & $\pm 3 \%$ of value & 3.39 \\
Short-wave radiation & 15 minute average & $0-700 \mathrm{Wm}^{-2}$ & $\pm 10 \%$ & 3.40 \\
Long-wave radiation & 15
\end{tabular}

Six NDBC buoys deployed in the Middle Atlantic Bight near the CMO mooring were selected for evaluating the model products (Table 6). Each of these buoys carries a DACT sensor payload that measures wind speed and direction, wind gust speed, significant wave height, wave period, air and sea surface temperature and barometric pressure every hour. Sensor specifications for the DACT payload are presented in Table 7 and the buoy hull types are shown in Figure 5. The time series of these measurements is available on the NDBC anonymous FTP server, seaboard. ndbc noaa. gov. Heat fluxes were not computed at the NDBC buoy sites, since no moisture variable (e.g., relative humidity, specific humidity or dewpoint temperature) was measured.

Table 6. Locations, depths and hull types of NDBC buoys. Water depths are in meters.

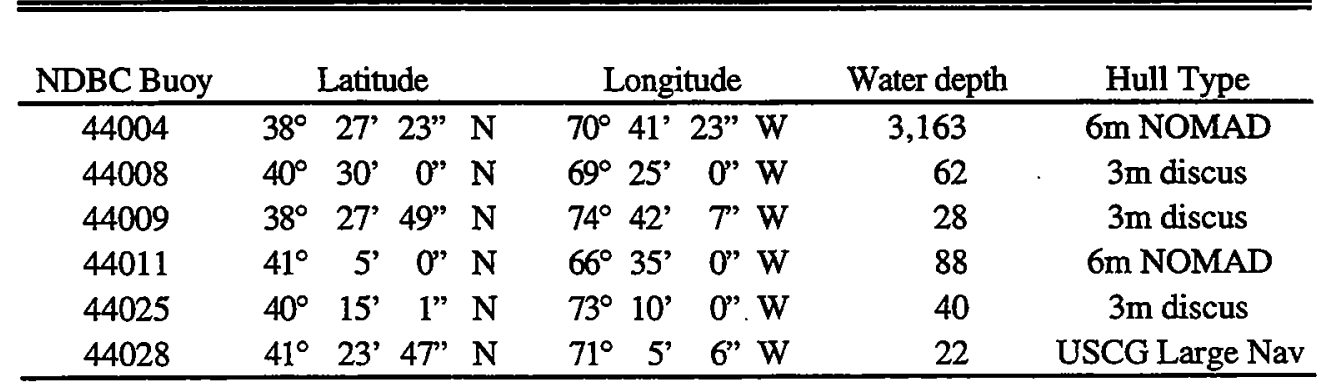



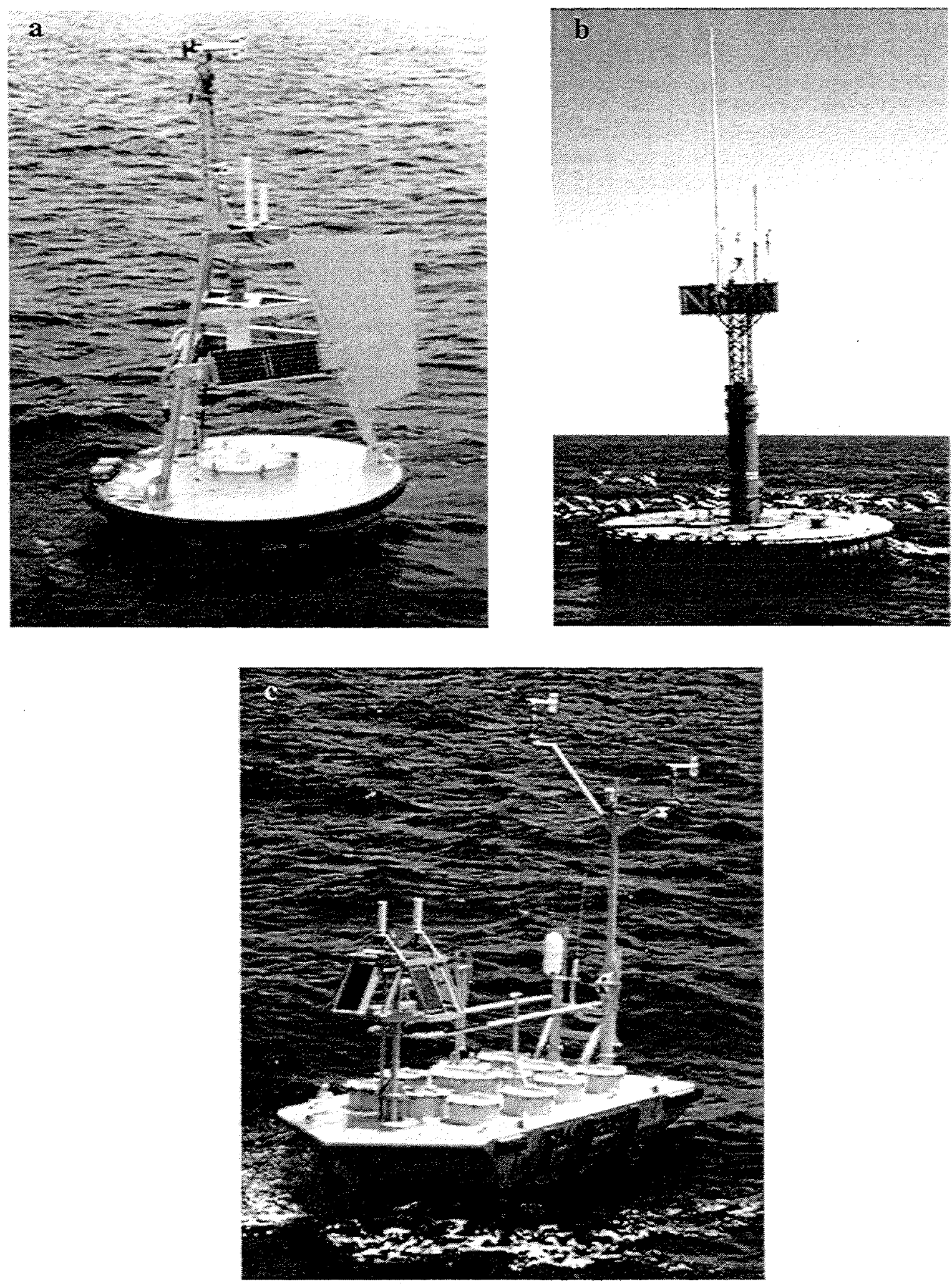

Figure 5. (a) NDBC $3 \mathrm{~m}$ discus buoy. (b) U.S. Coast Guard large navigational buoy. (c) NDBC $6 \mathrm{~m}$ NOMAD buoy. Photos courtesy of National Data Buoy Center. 
Table 7. NDBC DACT payload sensor specifications. Wind speed is scalar averaged over the sampling interval. Wind direction is calculated as $\arctan (\mathrm{u} / \mathrm{v})$ where $\mathrm{u}$ and $\mathrm{v}$ are averaged east and north components, respectively, of a unit vector oriented in the direction of the wind. Heights are in meters relative to the mean water line.

\begin{tabular}{lccccc}
\hline \hline & & & \multicolumn{3}{c}{ Height } \\
& & & & $3 \mathrm{~m}$ and $6 \mathrm{~m}$ & USCG \\
Parameter & Sampling Interval & Range & Accuracy & buoys & Large Nav \\
\hline Wind speed & 8 minute average & $0.0-61.8 \mathrm{~ms}^{-1}$ & $\pm 1 \mathrm{~ms}^{-1}$ or $\pm 10 \%$ & 5.0 & 13.8 \\
Wind direction & 8 minute average & $0-355^{\circ}$ & $\pm 10^{\circ}$ & 5.0 & 13.8 \\
Air temperature & 8 minute average & $-40-50^{\circ} \mathrm{C}$ & $\pm 1^{\circ} \mathrm{C}$ & 5.0 & 12.3 \\
Sea temperature & 8 minute average & $-6.7-40.6^{\circ} \mathrm{C}$ & $\pm 1^{\circ} \mathrm{C}$ & -1.0 & -1.5 \\
Barometric pressure & 8 minute average & $900-1100 \mathrm{mbar}$ & $\pm 1 \mathrm{mbar}$ & 0.0 & 0.0 \\
\hline
\end{tabular}

All in situ data were averaged to 6, 3,3 and 1 hours to match the time base of the Eta, RUC, RUC Analysis and RUC Hourly datasets, respectively. Averages were centered on the model forecast time.

\section{Model Products}

The atmospheric model data were extracted from the archived files at the grid point closest to each of the buoys. For each time series, several processing steps were necessary to obtain the most accurate set of model products at the buoy location. At any point in the time series, data from several forecasts and possibly an initialized field ( 0 hour forecast) may be available. A simple selection algorithm was implemented to choose data from either an initialized field if available or from the closest forecast time. For example, to find the best RUC data for 1800 hours on a particular day, data may be available from a 12 hour forecast generated at 0600 , a 9 hour forecast generated at 0900 , a 6 hour forecast generated at 1200, a 3 hour forecast generated at 1500 and an initialized field from the 1800 hour model run. Since the initialized field is assumed to be the most accurate, it would be selected. If the initialized field is not available, the 3 hour forecast would be selected and so on.

After selection, common variables were derived as necessary. In the case of the RUC Analysis and Hourly datasets, moisture and temperature are represented as condensation pressure and potential temperature, respectively, which were converted to relative humidity, specific humidity and air temperature for analysis. Wind vectors also required adjustment, since the components of the wind vectors were oriented toward the $+x$ and $+y$ directions in the model domain, not true east and north. To account for this, wind vectors were rotated by the angles reported in Table 8. Wind directions were computed from the vector components in oceanographic convention, i.e., the direction toward which the wind is blowing. 
Table 8. Rotation angles for wind vectors in degrees. All angles rotate east of north.

\begin{tabular}{ccc}
\hline & & \\
Buoy & Grid 211 & Grid 87 \\
\hline CMO Central & 10.2 & 34.7 \\
NDBC 44004 & 10.4 & 34.1 \\
NDBC 44008 & 11.0 & 35.7 \\
NDBC 44009 & 8.5 & 30.1 \\
NDBC 44011 & 11.9 & 38.0 \\
NDBC 44025 & 9.4 & 32.3 \\
NDBC 44028 & 10.3 & 33.9 \\
\hline
\end{tabular}

The time series of most archived model products spanned 1 August 1996 to 31 January 1997. The entire RUC Analysis dataset, however, and the potential temperature and condensation pressure of the RUC Hourly dataset were not collected for the first two and a half months of the experiment. After preliminary analyses of the acquired model data and many subsequent conversations with Lauren Morone of NCEP, acquisition and archival of these model products was initiated on 25 October 1996.

No attempts were made to account for possible differences in the measurement heights of the in situ observations and the model products. The designated heights of the model products distributed as the surface fields or as the gridded fields closest to the surface are unclear. These products are probably equivalent to $10 \mathrm{~m}$ winds and $2 \mathrm{~m}$ air temperature and humidity, however, for the sake of simplicity, the following analyses treat the in situ and model data as measured or forecast at the same height. 


\section{Section 5: Evaluation of Model Products}

In situ data from the CMO central mooring and the six NDBC buoys were compared to time series of model products at the grid points closest to each of these platforms (Figure 6). Evaluations of wind speed and direction, barometric pressure and air temperature were possible for all platforms while relative and specific humidity, sensible and latent heat fluxes and global radiation could only be evaluated at the CMO central buoy. Sea surface temperature from the RUC Hourly was evaluated at each buoy site. Detailed presentations of the comparisons are included in Appendix A. Summary information is provided below.

The mean and standard deviations of the difference between the model and the in situ observations are presented in Figure 7. Positive differences indicate that the model is higher or larger than the in situ data. The NDBC buoys are grouped as the offshore (44004, 44008 and $44011)$ and inshore $(44009,44025,44028)$ buoys. Positive heat flux and global radiation values indicate ocean heating.

\section{Wind Speed}

Analyses of the model wind speeds versus the observed in situ wind speeds are presented in Figures A1 through A28. The mean differences and correlation coefficients between the model and the in situ wind speeds are shown in Table Al and summarized in Table 9. The mean differences for the Eta model slightly exceed the accuracies of the sensors for the VAWR and NDBC buoys 44004, 44008 and 44009, however the overall mean difference (the average of the mean differences for all of the buoys) is comparatively small. This suggests that despite discrepancies at a few of the buoys, the wind speeds are reasonably accurate over the entire study area. The mean differences shown in Figure 7 also indicate that the Eta wind speeds may be a little too low near the coast and too high farther offshore.

Table 9. Average and range of mean [model - in situ] wind speed differences and range of model versus in situ wind speed correlation coefficients for all buoys.

\begin{tabular}{lccccc}
\hline \hline & \multicolumn{3}{c}{ Mean Differences $\left(\mathrm{m} \mathrm{s}^{-1}\right)$} & \multicolumn{2}{c}{ Correlation Coefficient } \\
Model & Average & Minimum & Maximum & Minimum & Maximum \\
\hline Eta & 0.13 & -1.62 & 1.35 & 0.80 & 0.88 \\
RUC & -0.64 & -2.17 & 0.33 & 0.74 & 0.83 \\
RUC Analysis & -1.27 & -1.85 & -0.73 & 0.72 & 0.85 \\
RUC Hourly & -0.78 & -1.50 & -0.26 & 0.77 & 0.85 \\
\hline
\end{tabular}



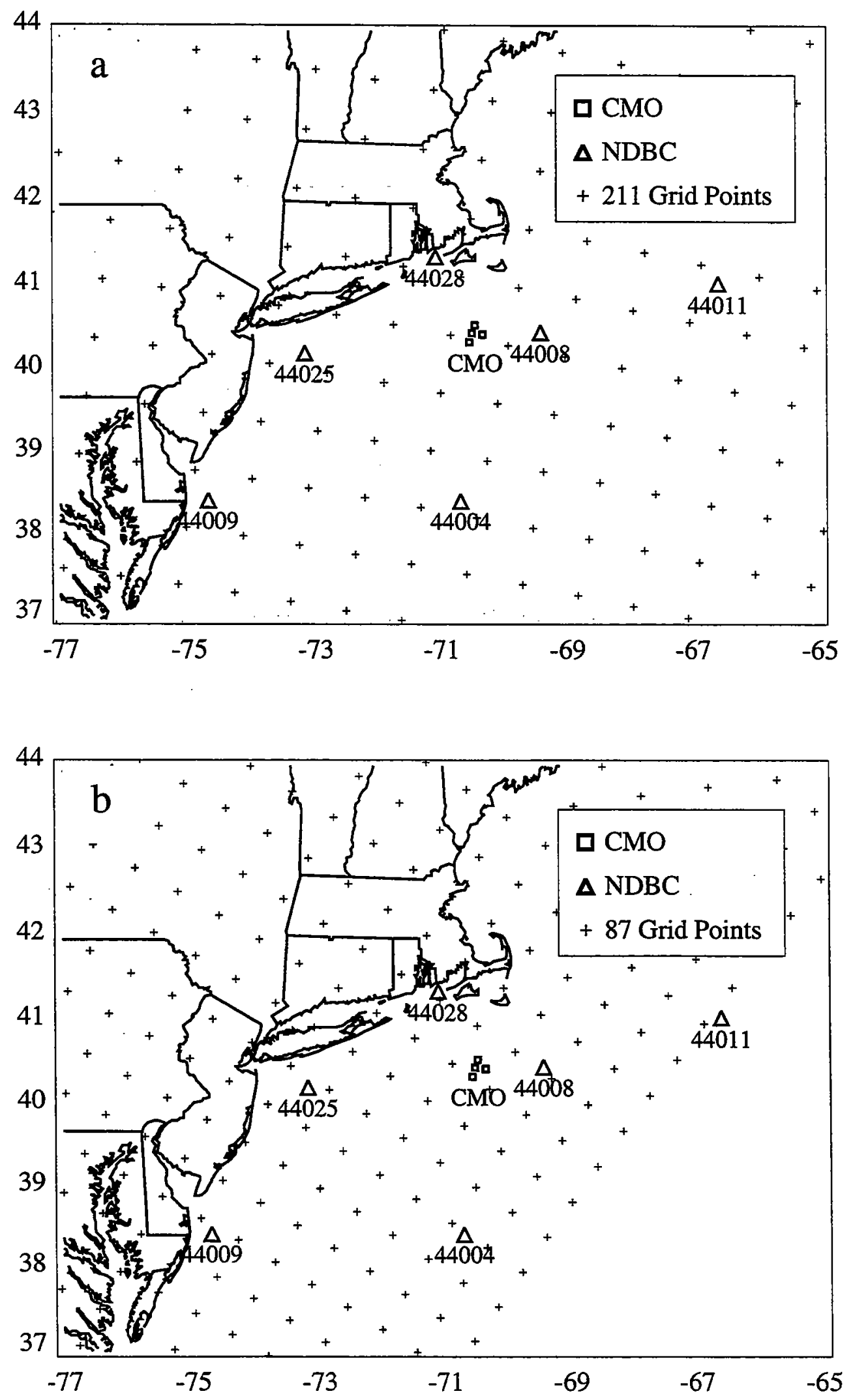

Figure 6. Locations of CMO buoys, NDBC buoys and (a) 211 and (b) 87 grid points. 

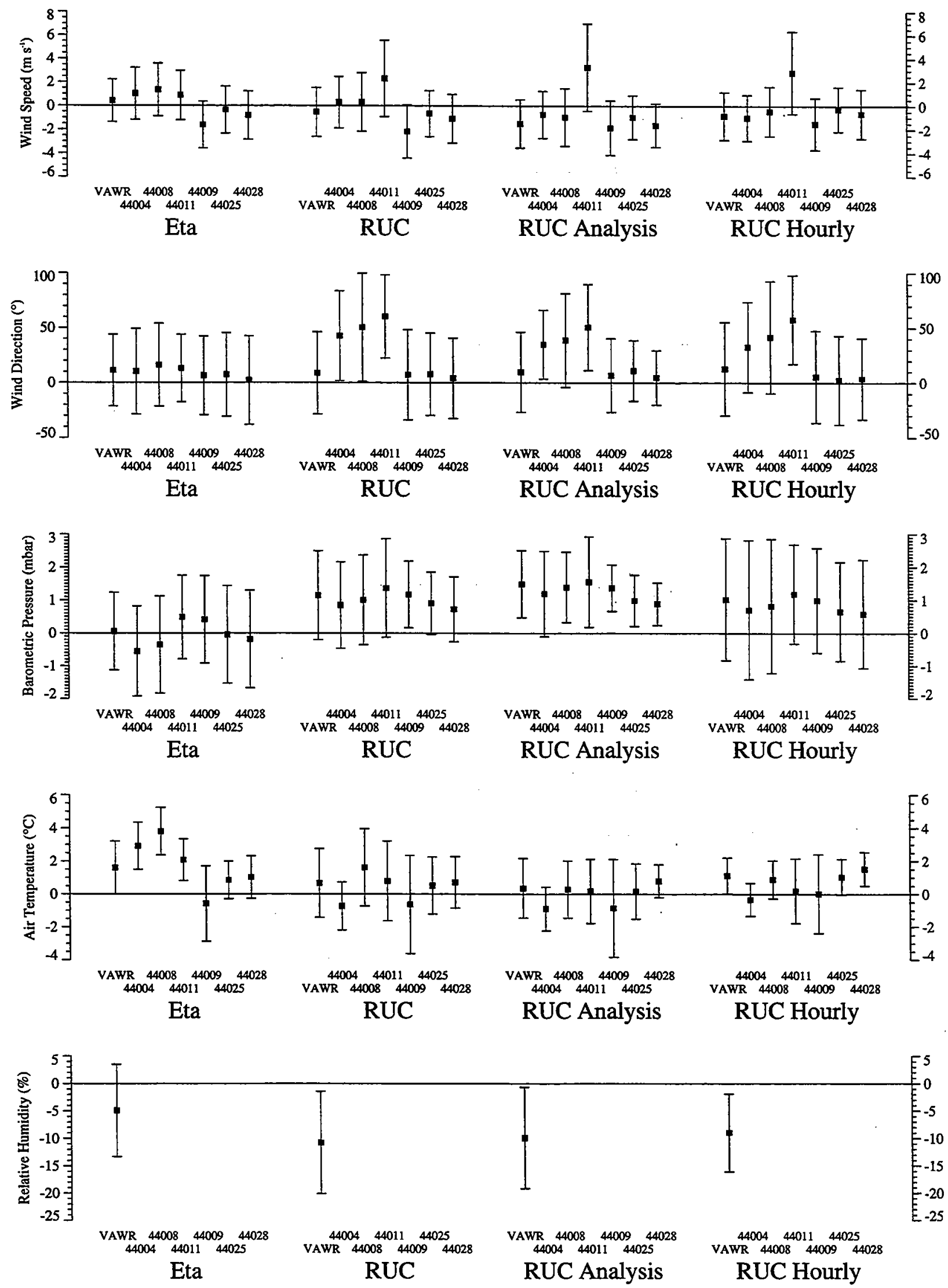

Figure 7. Mean and standard deviation of [model - in-situ] differences. Positive differences indicate the model is higher than the buoy. 

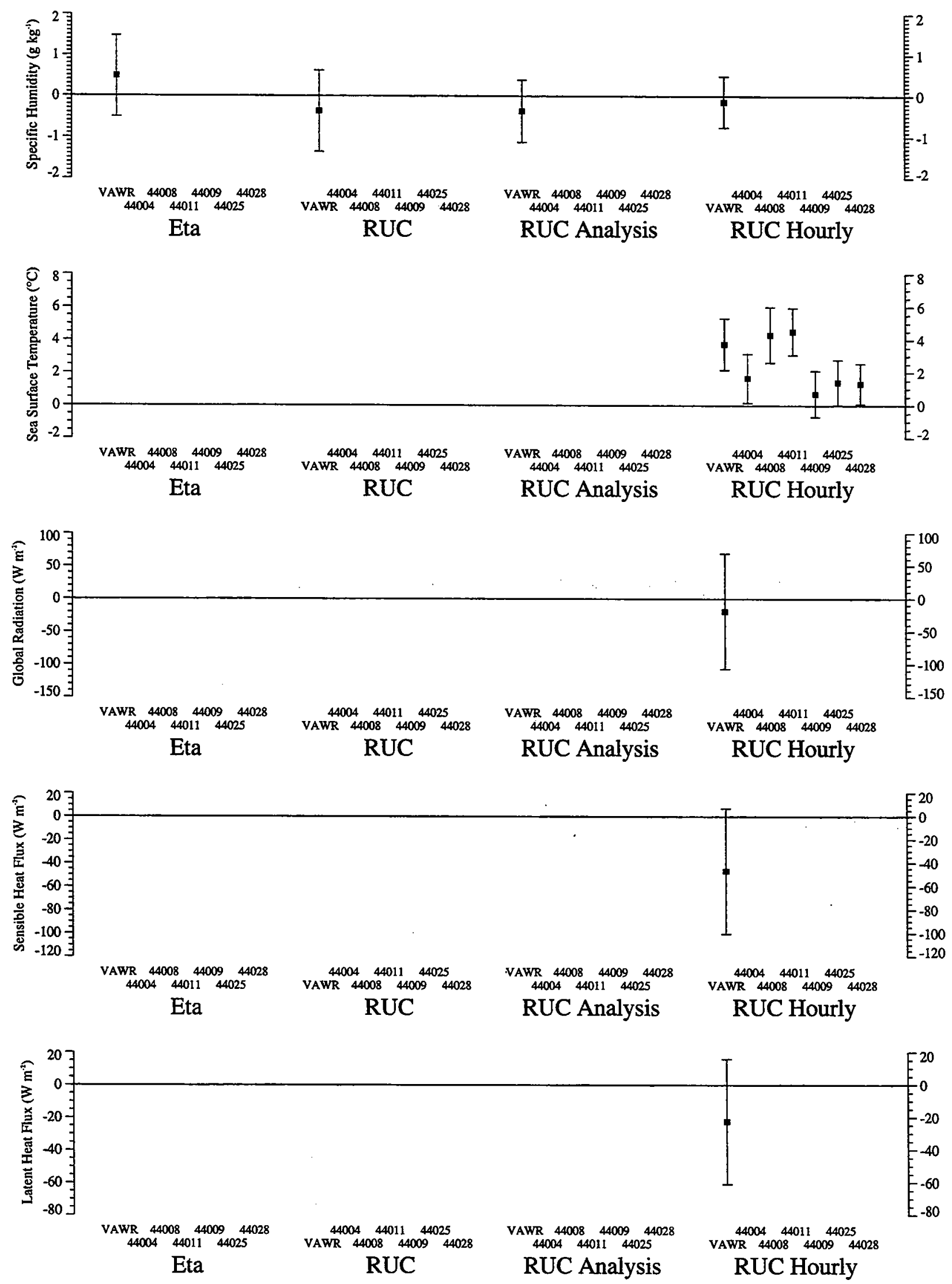

Figure 7 (continued) 
The overall means for the RUC, RUC Analysis and RUC Hourly in Table 9 suggest that the wind speeds in the RUC model are low by roughly $0.9 \mathrm{~m} \mathrm{~s}^{-1}$. Although this overall bias is within the accuracy of the NDBC anemometer, the mean differences for the CMO buoy are considerably larger than the accuracy of the VAWR wind measurement. These mean differences, $-0.53,-1.50$ and $-0.84 \mathrm{~m} \mathrm{~s}^{-1}$ for the RUC, RUC Analysis and RUC Hourly, respectively, indicate that there is indeed a bias in the RUC model winds.

The comparison data from NDBC buoy 44011 were not included in the summary statistics since this buoy is clearly an outlier. This buoy was compared with a grid point that is at the very edge of the RUC domain (Figure 6b). Because wind speeds along the boundary of the RUC domain are much higher than those of adjacent grid points in the interior (Figure 8), these data were considered unreliable and were omitted from the summary analysis.

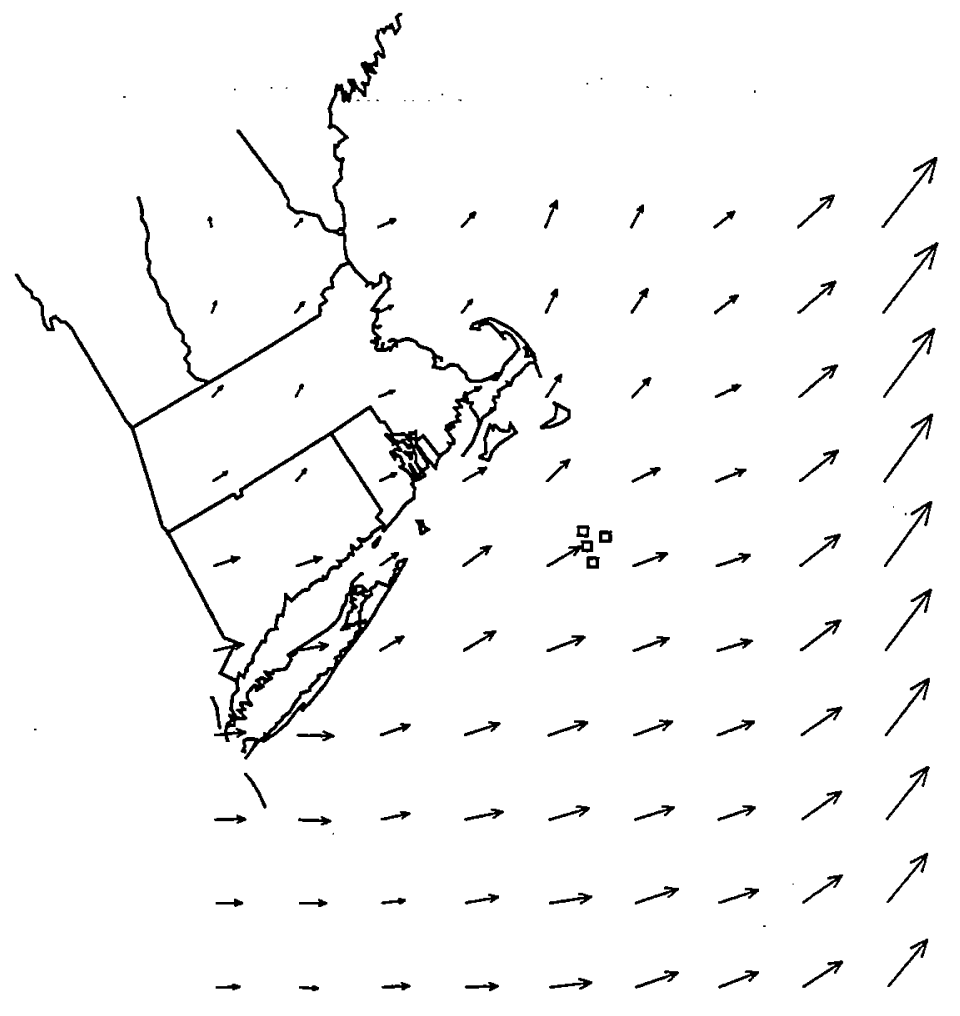

Figure 8. An example of anomalously high wind speeds at the edge of the RUC domain. 


\section{Wind Direction}

Analyses of the model wind directions versus the observed wind directions are presented in Figures A29 through A56 and Table A2. The mean differences and correlation coefficients from the analyses are summarized in Table 10. Positive differences indicate that the model is rotated east of north (clockwise) relative to the buoy wind direction. The Eta model wind directions at the inshore NDBC buoys $\left(44009,44025\right.$ and 44028) are within the $\pm 10^{\circ}$ accuracy of the NDBC anemometer, however the Eta winds at the offshore NDBC buoys show a mean offset of $13.2^{\circ}$ east of north relative to the observed wind direction. The Eta model winds at the CMO buoy are rotated well above the accuracy of the VAWR anemometer $\left( \pm 5.6^{\circ}\right)$. These results suggest that the Eta model winds have a mean bias of approximately $10^{\circ}$ east of north over the Middle Atlantic Bight.

Table 10. Average and range of mean [model - in situ] wind direction differences and range of model versus in situ wind direction correlation coefficients for all buoys.

\begin{tabular}{lccccc}
\hline \hline & \multicolumn{3}{c}{ Mean Differences $\left(^{\circ}\right)$} & \multicolumn{2}{c}{ Correlation Coefficient } \\
Model & Average & Minimum & Maximum & Minimum & Maximum \\
\hline Eta & 9.6 & 2.2 & 16.1 & 0.93 & 0.96 \\
RUC & 25.9 & 4.1 & 60.4 & 0.90 & 0.94 \\
RUC Analysis & 22.5 & 4.8 & 50.7 & 0.91 & 0.97 \\
RUC Hourly & 22.4 & 2.5 & 57.8 & 0.89 & 0.94 \\
\hline
\end{tabular}

The mean biases between the observed and RUC, RUC Analysis and RUC Hourly wind directions were $6.4,7.6$ and $4.0^{\circ}$ at the inshore NDBC buoys and 51.2, 41.5 and $44.1^{\circ}$ at the offshore NDBC buoys, respectively. All but one of the mean differences at the inshore NDBC buoys were within the $\pm 10^{\circ}$ accuracy of the NDBC anemometer, indicating good agreement. The mean biases between the RUC, RUC Analysis and RUC Hourly wind directions and those observed at the $\mathrm{CMO}$ buoy were $8.8,9.8$ and $12.8^{\circ}$, respectively. Table 11 shows the mean differences between the model and observed wind directions ordered by decreasing distance to the RUC domain boundary. The reported distance is between the RUC grid point closest to the buoy (i.e., the grid point from which the wind directions are selected for analysis) and the nearest boundary grid point. An inshore-offshore gradient in wind direction accuracy is evident, with the lowest biases occurring at the inshore sites and the largest biases (up to $60.4^{\circ}$ ) occurring at those sites closest to the domain boundary. 
Table 11. Mean [model - in situ] wind direction differences in degrees, ordered by distance to the RUC domain boundary.

\begin{tabular}{|c|c|c|c|c|}
\hline Buoy & $\begin{array}{l}\text { Distance from } \\
\text { boundary }(\mathrm{km})\end{array}$ & RUC & $\begin{array}{c}\text { RUC } \\
\text { Analysis }\end{array}$ & $\begin{array}{l}\text { RUC } \\
\text { Hourly }\end{array}$ \\
\hline 44009 & 412.2 & 7.3 & 6.9 & 5.7 \\
\hline 44025 & 358.2 & 7.9 & 11.2 & 2.5 \\
\hline 44028 & 301.4 & 4.1 & 4.8 & 3.8 \\
\hline CMO & 240.0 & 8.8 & 9.8 & 12.8 \\
\hline 44008 & 120.1 & 50.4 & 38.9 & 41.7 \\
\hline 44004 & 118.4 & 42.8 & 35.0 & 32.7 \\
\hline 44011 & 0.0 & 60.4 & 50.7 & 57.8 \\
\hline
\end{tabular}

The large biases in wind direction at the offshore sites in the RUC, RUC Analysis and RUC Hourly are a result of the boundary conditions used in the RUC analysis and model. The boundary of the RUC domain (up to 5 grid points from the edge) is relaxed to the output of another NCEP regional model, the Nested Grid Model (NGM). Since the offshore buoys are within this boundary, the corresponding intercomparisons do not necessarily reflect the accuracy of the RUC model itself, but instead, evaluate the use of the NGM as a boundary condition for the RUC (Stan Benjamin, personal communication). Because of the large discrepancies in the model wind field near the RUC domain boundary, these wind directions should be used with considerable caution.

\section{Barometric Pressure}

Analyses of the model barometric pressure versus the observed in situ pressure are presented in Figures A57 through A84. The mean differences and correlation coefficients between the model and the in situ pressure are shown in Table A3 and summarized in Table 12. The Eta barometric pressures agree with the in situ observations within the accuracy of both the VAWR ( $\pm 0.2 \mathrm{mbar}$ ) and the NDBC sensor ( $\pm 1 \mathrm{mbar}$ ), indicating that this model is accurately representing the pressure field. The RUC, RUC Analysis and RUC Hourly datasets have mean differences of $1.0,1.3$ and 0.9 mbars, respectively. These statistics suggest that the RUC pressure field is too high by roughly $1 \mathrm{mbar}$, which might explain this model's lower wind speeds. 
Table 12. Average and range of mean [model - in situ] barometric pressure differences and range of model versus in situ barometric pressure correlation coefficients for all buoys.

\begin{tabular}{lccccc}
\hline \hline & \multicolumn{3}{c}{ Mean Differences (mbar) } & \multicolumn{2}{c}{ Correlation Coefficient } \\
Model & Average & Minimum & Maximum & Minimum & Maximum \\
\hline Eta & 0.0 & -0.6 & 0.5 & 0.98 & 0.99 \\
RUC & 1.0 & 0.7 & 1.4 & 0.99 & 0.99 \\
RUC Analysis & 1.3 & 0.9 & 1.6 & 0.99 & 1.00 \\
RUC Hourly & 0.9 & 0.6 & 1.2 & 0.97 & 0.99 \\
\hline
\end{tabular}

Note that the high pressure events starting on 5 October 1996, 15 November 1996 and 27 January 1997 each exceeded the maximum measurement value for the VAWR barometric pressure sensor (Figures A57, A64, A71 and A78). The range of this instrument is 0 to $1034 \mathrm{mbar}$ (Table 5). Maximum pressures during these periods at NDBC buoy 44008 were 1037.3, 1037.9 and $1039.2 \mathrm{mbar}$, respectively.

\section{Air Temperature}

Analyses of model versus in situ air temperatures are presented in Figures A85 through A112 and Table A4. A summary of the mean differences and correlation coefficients is shown in Table 13. The Eta model air temperatures have an overall mean bias of $1.67^{\circ} \mathrm{C}$, however the time series (Figure A85-A91) indicates that larger differences exist between 1 August and 1 November than at any other time. The mean difference between the Eta model and the VAWR before 1 November is $2.52^{\circ} \mathrm{C}$ and $0.62^{\circ} \mathrm{C}$ after 1 November. These biases are especially large for the offshore NDBC buoys and the VAWR. A potential source for these differences might be enhanced ocean heat loss due to an incorrect sea surface temperature or inaccurate boundary layer parameterization.

Table 13. Average and range of mean [model - in situ] air temperature differences and range of model versus in situ air temperature correlation coefficients for all buoys.

\begin{tabular}{lccccc}
\hline \hline & \multicolumn{3}{c}{ Mean Differences $\left({ }^{\circ} \mathrm{C}\right)$} & \multicolumn{2}{c}{ Correlation Coefficient } \\
Model & Average & Minimum & Maximum & Minimum & Maximum \\
\hline Eta & 1.67 & -0.58 & 3.80 & 0.96 & 0.99 \\
RUC & 0.42 & -0.73 & 1.61 & 0.92 & 0.98 \\
RUC Analysis & 0.00 & -0.89 & 0.80 & 0.80 & 0.98 \\
RUC Hourly & 0.64 & -0.34 & 1.53 & 0.87 & 0.99 \\
\hline
\end{tabular}


The mean differences between the RUC Analysis and the in situ air temperatures are quite small. This would be expected if the NDBC buoy reports are regularly used in the data assimilation of the RUC Analysis. The model air temperatures from the RUC and RUC Hourly are slightly high, however. The mean differences across all the platforms average to 0.42 and $0.64^{\circ} \mathrm{C}$ for the RUC and RUC Hourly, respectively. Note that the standard deviations of the differences between all the models and NDBC buoy 44009 are high. This variability in the differences is due to the pronounced diurnal cycle in surface air temperature in the models near this buoy. The nearest grid point to this buoy is most likely treated as if it were over land in the models and not over the ocean. Consequently, the strong diurnal signal of daytime heating and nighttime cooling over land is evident in the time series of the model and is absent in the time series of air temperatures at the coastal buoy.

\section{Relative and Specific Humidity}

Comparisons of relative humidity differences between the models and in situ observations are presented in Figures A113 through A116 and Table A5. The analyses of model versus in situ specific humidity are presented in Figures A117 through A120 and Table A6. Since only the CMO VAWR measured moisture, only one comparison was possible for each model. The mean differences and correlation coefficients for both relative and specific humidity are shown in Table 14. The evaluation of relative humidity suggests that both models are too dry, however, relative humidity is influenced by temperature. The Eta model has a large bias in air temperature (Table 13) which "balances" the drier relative humidity. This causes a specific humidity which is, on average, slightly more moist than the in situ observations.

Table 14. Mean differences of [model - in situ] relative and specific humidity and model versus in situ relative and specific humidity correlation coefficients for the CMO central buoy.

\begin{tabular}{|c|c|c|c|c|}
\hline \multirow[b]{2}{*}{ Model } & \multicolumn{2}{|c|}{ Relative Humidity (\%) } & \multicolumn{2}{|c|}{ Specific Humidity $\left(\mathrm{g} \mathrm{kg}^{-1}\right)$} \\
\hline & $\begin{array}{c}\text { Mean } \\
\text { Difference }\end{array}$ & $\begin{array}{l}\text { Correlation } \\
\text { Coefficient }\end{array}$ & $\begin{array}{c}\text { Mean } \\
\text { Difference }\end{array}$ & $\begin{array}{l}\text { Correlation } \\
\text { Coefficient }\end{array}$ \\
\hline Eta & -4.9 & 0.75 & 0.49 & 0.97 \\
\hline RUC & -10.8 & 0.80 & -0.37 & 0.97 \\
\hline RUC Analysis & -9.9 & 0.83 & -0.36 & 0.95 \\
\hline RUC Hourly & -9.0 & 0.87 & -0.14 & 0.96 \\
\hline
\end{tabular}

The RUC Analysis air temperatures were reasonably accurate while those of the RUC and RUC Hourly were slightly high. These temperature differences are not large enough to have a 
significant influence on the specific humidity, however. The RUC model remains too dry in specific humidity, although only slightly so in the case of the RUC Hourly.

It is important to note that these conclusions are based on only one set of in situ observations. The analyses of the wind field, barometric pressure and air temperature benefited considerably from the inclusion of the NDBC buoy data. Since this was not possible in the evaluation of humidity, caution must be used in interpreting these results.

\section{Sea Surface Temperature}

Analyses of sea surface temperature are presented in Figures A121 through A127 and Table A7. The mean differences between the RUC Hourly and in situ sea surface temperatures ranged from 0.71 to $4.51^{\circ} \mathrm{C}$ and the overall average difference was $2.52^{\circ} \mathrm{C}$. Correlation coefficients ranged from 0.93 to 0.98 . The surface temperature over the ocean in the RUC Hourly dataset is a monthly climatological mean and is clearly a step function (Figures A121A127). Mean differences were lowest for the inshore NDBC buoys, however the model surface temperatures for these buoys were still, on average, $1.14^{\circ} \mathrm{C}$ too warm. These differences could potentially have a significant impact on the estimation of latent and sensible heat fluxes and outgoing long-wave radiation.

\section{Heat Fluxes}

Comparisons of the estimated heat flux components (sensible and latent heat flux and global radiation) from the RUC Hourly dataset and the CMO buoy are presented in Figures A128 through A130 and Table A8. Positive heat fluxes indicate ocean heating.

Global radiation is the sum of the net short-wave and net long-wave radiation components and mean differences between the RUC Hourly and the CMO estimates for this variable averaged $-18.9 \mathrm{~W} \mathrm{~m}^{-2}$. This indicates that the model prescribes too much ocean heat loss. The correlation coefficient was 0.91 . Since net short-wave falls to zero at night, biases in net longwave can be evaluated by examining only nighttime global radiation. Mean differences between the model and the in situ estimates of global radiation at night (i.e., net long-wave radiation) were $-47.1 \mathrm{~W} \mathrm{~m}^{-2}$ (standard deviation of $28.9 \mathrm{~W} \mathrm{~m}^{-2}$ ), indicating that the model was prescribing much larger oceanic heat loss than was observed. This bias may be due to either higher than observed outgoing long-wave radiation caused by higher sea surface temperatures or lower incoming long-wave radiation caused by lower boundary layer humidity or lower 
cloud cover. The RUC Hourly sea surface temperatures are indeed too high, however this accounts for an average of only $-19.7 \mathrm{~W} \mathrm{~m} \mathrm{~m}^{-2}$ (standard deviation of $8.8 \mathrm{~W} \mathrm{~m} \mathrm{~m}^{-2}$ ), less than half of the mean $-47.1 \mathrm{~W} \mathrm{\textrm {m } ^ { - 2 }}$ difference ${ }^{1}$. This suggests that not only is outgoing long-wave too high due to the model sea surface temperature being too warm, but incoming long-wave radiation is too low. This seems plausible, since the surface humidity in the RUC Hourly dataset is too dry (see above).

Since cloud cover can influence incoming long-wave radiation, daytime global radiation was examined to see if incoming short-wave radiation was too high, an indication that cloud cover is too low. To investigate this, an offset of $47.1 \mathrm{~W} \mathrm{~m} \mathrm{~m}^{-2}$ was applied to the global radiation as an average bias in the net long-wave radiation. Any errors in the global radiation after applying the net long-wave bias are then assumed to be in the incoming short-wave. Daytime mean differences in the adjusted global radiation were $68.2 \mathrm{~W} \mathrm{~m}^{-2}$, indicating that the model's incoming short-wave radiation was indeed too large. This suggests that the model cloud cover over the CMO buoy might be too low. An alternative explanation for the model's larger incoming short-wave radiation, however, is the selection of an atmospheric transmissivity in the model that is too large.

Mean differences between the RUC Hourly and the CMO sensible and latent heat flux estimates were $-46.8 \mathrm{~W} \mathrm{~m}^{-2}$ and $-22.5 \mathrm{~W} \mathrm{\textrm {m } ^ { - 2 }}$, respectively, indicating that the model overestimates the ocean heat loss. The estimation of the sensible heat flux is sensitive to the air-sea temperature difference while the estimation of the latent heat flux is sensitive to the airsea humidity gradient. Both are sensitive to the parameterization of the boundary layer in the aerodynamic bulk formulae. To examine the effect of errors in the air-sea temperature and humidity gradients and the sensitivity of the fluxes to the parameterization of the boundary layer, the model fluxes were re-computed with the TOGA COARE flux algorithm (i.e., the same algorithm used to compute the buoy fluxes) using the model observables as the input variables. The model fluxes, buoy fluxes and the re-computed fluxes are shown in Figure 9.

The differences between the model and re-computed fluxes demonstrate that the parameterization of the boundary layer is clearly different between the model and the TOGA COARE algorithm. The mean difference between the re-computed model sensible heat flux and that of the CMO buoy is $-14.1 \mathrm{~W} \mathrm{~m}^{-2}$ (standard deviation of $20.6 \mathrm{~W} \mathrm{~m} \mathrm{~m}^{-2}$ ), indicating good

1 The outgoing long-wave is computed as $\varepsilon \sigma \mathrm{T}^{4}$, where $\varepsilon$ is the emissivity of the sea surface, $\sigma$ is the StefanBoltzmann constant and $\mathrm{T}$ is the sea surface temperature in ${ }^{\circ} \mathrm{K}$. An emissivity of 0.97 was used for this analysis. 
agreement between the two. The re-computed latent heat fluxes, however, are less accurate than the model's original latent heat fluxes. The mean difference between the re-computed and CMO buoy latent heat fluxes is $-36.2 \mathrm{~W} \mathrm{~m}^{-2}$ (standard deviation of $44.0 \mathrm{~W} \mathrm{~m}^{-2}$ ).

Note that in Figure 9b, the model latent heat flux never exceeds zero, meaning that there is never condensation on the sea surface. Excluding times when the CMO latent heat fluxes become positive, the mean difference between the model and CMO buoy latent heat fluxes is $-13.6 \mathrm{~W} \mathrm{~m}^{-2}$ (standard deviation of $36.8 \mathrm{~W} \mathrm{~m}^{-2}$ ). This suggests that the model latent heat fluxes are in good agreement with the estimated latent heat fluxes from the CMO buoy. 

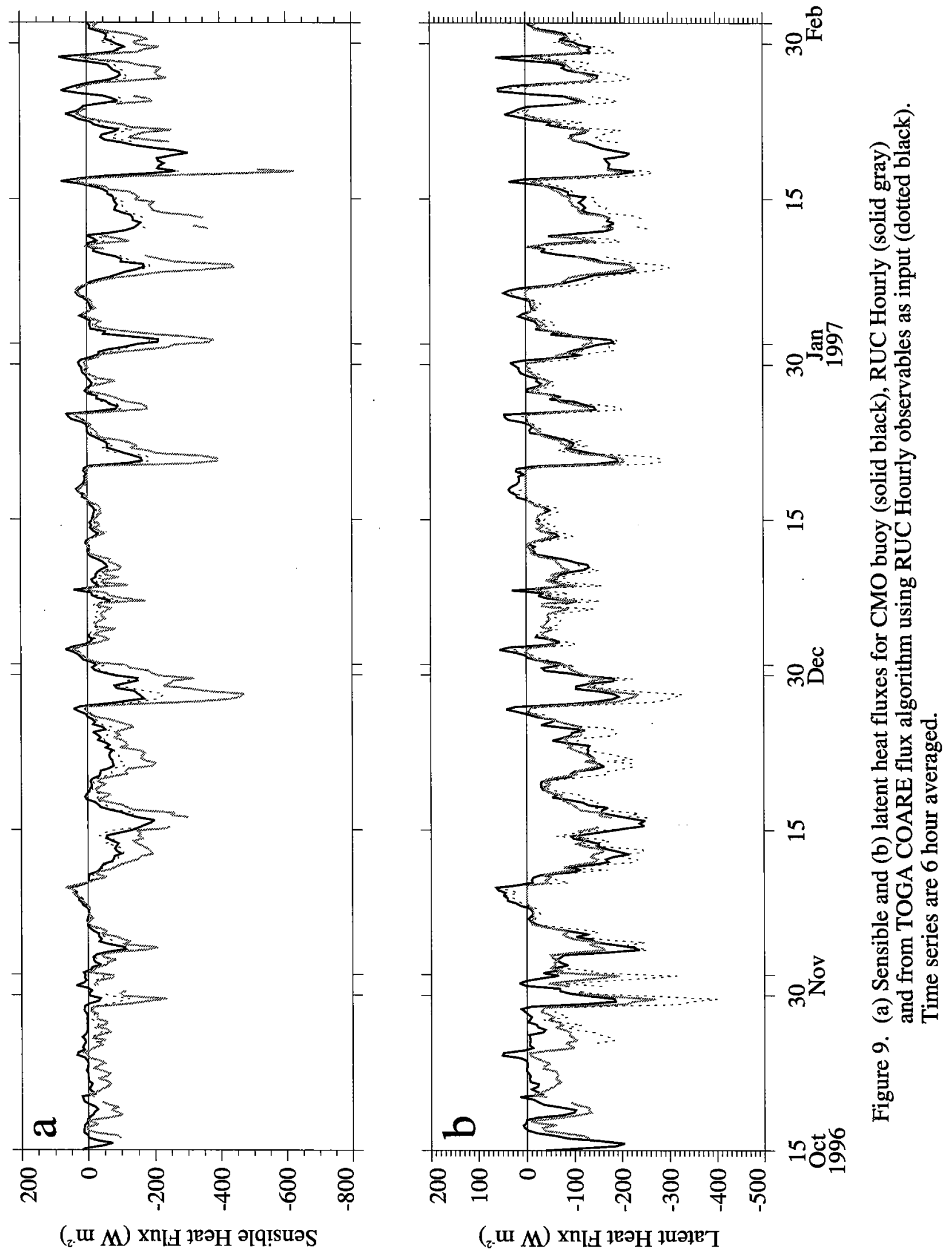


\section{Literature Cited}

Fairall, C.W., E.F. Bradley, D.P. Rogers, J.B. Edson and G.S. Young, 1996. Bulk parameterization of air-sea fluxes for TOGA COARE. Journal of Geophysical Research. 101, 3747-3764.

Weller, R.A., D.L. Rudnick, R.E. Payne, J.P. Dean, N.J. Pennington and R.P. Trask, 1990. Measuring near-surface meteorology over the ocean from an array of surface moorings in the subtropical convergence zone. Journal of Atmospheric and Oceanic Technology. 7, 85-103.

\section{Acknowledgments}

The success of the moored array is due to the efforts of the Woods Hole Oceanographic Institution's Upper Ocean Processes (UOP) group, particularly Nancy Brink, Nancy Galbraith, Steve Lentz, Craig Marquette, Will Ostrom, Dick Payne, Al Plueddemann, Rick Trask, Jonathan Ware and Bryan Way. At Unidata, Linda Miller and Sandra Nilsson guided us through the site licensing process and Steve Chiswell provided valuable advice on the implementation of various Unidata products. David Wojtowicz at the University of Illinois at Urbana-Champaign graciously provided access to their IDD recovery data. The staff of the National Data Buoy Center are gratefully acknowledged for their efforts in data collection, quality control and distribution. The NDBC web site is an exemplary data server which greatly facilitates the acquisition and understanding of NDBC's buoy data. Lauren Morone of the National Centers for Environmental Prediction provided guidance on the acquisition and use of RUC model data from the NOAA Information Center's data server. Stan Benjamin pointed us toward useful references and helped further our understanding of the model products. The Coastal Mixing and Optics moored array experiment was supported by the Office of Naval Research under contract N00014-95-1-0339. 


\section{Appendix A: Model versus In situ Comparisons}

In the following tables and figures, positive differences indicate the model is higher or larger than the in situ observations. The figures include a time series of the model and in situ variables, a scatterplot, a histogram of the differences and a statistics box. The statistics box displays the sample size, statistics of the [model - in situ] difference (median, mean, standard deviation and standard error), the correlation coefficient and two linear regressions. The first linear regression is denoted by a superscript 1 and is a simple linear regression. The second is forced through the origin and is denoted by a superscript 2 . The sample size, statistics of the difference and correlation coefficient are summarized for all the variables in Tables A1 through A8. 
Table A1. Statistical summary of model vs in situ comparisons of wind speed. Units for the mean, standard deviation, standard error and median are $\mathrm{m} \mathrm{s}^{-1}$. The comparison sample size is $\mathrm{N}$ and the correlation coefficient is $\mathrm{r}$.

\begin{tabular}{|c|c|c|c|c|c|c|c|}
\hline Model & Buoy & $\mathbf{N}$ & Mean & Std. Dev. & Std. Err. & Median & $r$ \\
\hline \multirow[t]{7}{*}{ Eta } & $\mathrm{CMO}$ & 706 & 0.42 & 1.80 & 0.07 & 0.28 & 0.88 \\
\hline & 44004 & 739 & 1.02 & 2.21 & 0.08 & 1.02 & 0.85 \\
\hline & 44008 & 736 & 1.35 & 2.24 & 0.08 & 1.18 & 0.82 \\
\hline & 44009 & 759 & -1.62 & 1.98 & 0.07 & -1.57 & 0.80 \\
\hline & 44011 & 774 & 0.88 & 2.10 & 0.08 & 0.69 & 0.87 \\
\hline & 44025 & 774 & -0.35 & 1.99 & 0.07 & -0.41 & 0.82 \\
\hline & 44028 & 771 & -0.81 & 2.03 & 0.07 & -0.86 & 0.82 \\
\hline \multirow[t]{7}{*}{ RUC } & CMO & 1367 & -0.53 & 2.07 & 0.06 & -0.51 & 0.82 \\
\hline & 44004 & 1435 & 0.29 & 2.18 & 0.06 & 0.25 & 0.83 \\
\hline & 44008 & 1430 & 0.33 & 2.48 & 0.07 & 0.27 & 0.74 \\
\hline & 44009 & 1474 & -2.17 & 2.24 & 0.06 & -2.12 & 0.75 \\
\hline & 44011 & 1503 & 2.32 & 3.25 & 0.08 & 1.81 & 0.76 \\
\hline & 44025 & 1507 & -0.66 & 1.95 & 0.05 & -0.61 & 0.83 \\
\hline & 44028 & 1499 & -1.09 & 2.05 & 0.05 & -1.04 & 0.83 \\
\hline \multirow[t]{7}{*}{ RUC Analysis } & CMO & 725 & -1.50 & 2.05 & 0.08 & -1.47 & 0.80 \\
\hline & 44004 & 663 & -0.73 & 2.00 & 0.08 & -0.91 & 0.83 \\
\hline & 44008 & 658 & -0.95 & 2.45 & 0.10 & -1.18 & 0.72 \\
\hline & 44009 & 702 & -1.85 & 2.30 & 0.09 & -1.89 & 0.77 \\
\hline & 44011 & 725 & 3.29 & 3.72 & 0.14 & 2.45 & 0.73 \\
\hline & 44025 & 728 & -0.96 & 1.84 & 0.07 & -0.84 & 0.84 \\
\hline & 44028 & 728 & -1.64 & 1.84 & 0.07 & -1.57 & 0.85 \\
\hline \multirow[t]{7}{*}{ RUC Hourly } & CMO & 4097 & -0.84 & 2.02 & 0.03 & -0.77 & 0.82 \\
\hline & 44004 & 4145 & -1.00 & 1.94 & 0.03 & -1.01 & 0.83 \\
\hline & 44008 & 4063 & -0.45 & 2.09 & 0.03 & -0.42 & 0.80 \\
\hline & 44009 & 4302 & -1.50 & 2.19 & 0.03 & -1.43 & 0.77 \\
\hline & 44011 & 4293 & 2.85 & 3.50 & 0.05 & 2.25 & 0.75 \\
\hline & 44025 & 4330 & -0.26 & 1.89 & 0.03 & -0.28 & 0.85 \\
\hline & 44028 & 4286 & -0.65 & 2.08 & 0.03 & -0.57 & 0.82 \\
\hline
\end{tabular}


Table A2. Statistical summary of model vs in situ comparisons of wind direction. Units for the mean, standard deviation, standard error and median are degrees. The comparison sample size is $N$ and the correlation coefficient is $r$.

\begin{tabular}{|c|c|c|c|c|c|c|c|}
\hline Model & Buoy & $\mathbf{N}$ & Mean & Std. Dev. & Std. Err. & Median & $I$ \\
\hline \multirow[t]{7}{*}{$\overline{\text { Eta }}$} & $\mathrm{CMO}$ & 706 & 11.3 & 32.6 & 1.2 & 11.3 & 0.96 \\
\hline & 44004 & 739 & 10.3 & 38.9 & 1.4 & 9.3 & 0.94 \\
\hline & 44008 & 736 & 16.1 & 37.7 & 1.4 & 15.8 & 0.94 \\
\hline & 44009 & 759 & 6.5 & 35.8 & 1.3 & 7.5 & 0.94 \\
\hline & 44011 & 774 & 13.1 & 30.7 & 1.1 & 14.1 & 0.96 \\
\hline & 44025 & 774 & 7.3 & 38.1 & 1.4 & 9.7 & 0.93 \\
\hline & 44028 & 771 & 2.2 & 40.4 & 1.5 & 5.9 & 0.93 \\
\hline \multirow[t]{7}{*}{ RUC } & $\mathrm{CMO}$ & 1367 & 8.8 & 37.3 & 1.0 & 9.3 & 0.94 \\
\hline & 44004 & 1435 & 42.8 & 41.0 & 1.1 & 45.5 & 0.93 \\
\hline & 44008 & 1430 & 50.4 & 49.4 & 1.3 & 51.3 & 0.90 \\
\hline & 44009 & 1474 & 7.3 & 41.1 & 1.1 & 6.9 & 0.92 \\
\hline & 44011 & 1503 & 60.4 & 37.9 & 1.0 & 61.5 & 0.93 \\
\hline & 44025 & 1507 & 7.9 & 37.5 & 1.0 & 11.2 & 0.93 \\
\hline & 44028 & 1499 & 4.1 & 36.6 & 0.9 & 7.0 & 0.94 \\
\hline \multirow[t]{7}{*}{ RUC Analysis } & CMO & 725 & 9.8 & 36.5 & 1.4 & 10.2 & 0.93 \\
\hline & 44004 & 663 & 35.0 & 31.4 & 1.2 & 36.4 & 0.95 \\
\hline & 44008 & 658 & 38.9 & 42.7 & 1.7 & 38.5 & 0.91 \\
\hline & 44009 & 702 & 6.9 & 33.6 & 1.3 & 6.1 & 0.94 \\
\hline & 44011 & 725 & 50.7 & 39.3 & 1.5 & 51.7 & 0.93 \\
\hline & 44025 & 728 & 11.2 & 27.5 & 1.0 & 13.1 & 0.96 \\
\hline & 44028 & 728 & 4.8 & 24.7 & 0.9 & 6.3 & 0.97 \\
\hline \multirow[t]{7}{*}{ RUC Hourly } & $\mathrm{CMO}$ & 4097 & 12.8 & 42.5 & 0.7 & 14.2 & 0.91 \\
\hline & 44004 & 4144 & 32.7 & 41.1 & 0.6 & 35.1 & 0.93 \\
\hline & 44008 & 4063 & 41.7 & 51.0 & 0.8 & 42.7 & 0.89 \\
\hline & 44009 & 4302 & 5.7 & 41.9 & 0.6 & 4.2 & 0.92 \\
\hline & 44011 & 4288 & 57.8 & 40.4 & 0.6 & 59.7 & 0.92 \\
\hline & 44025 & 4330 & 2.5 & 40.4 & 0.6 & 6.9 & 0.92 \\
\hline & 44028 & 4282 & 3.8 & 37.0 & 0.6 & 5.5 & 0.94 \\
\hline
\end{tabular}


Table A3. Statistical summary of model vs in situ comparisons of barometric pressure. Units for the mean, standard deviation, standard error and median are millibars. The comparison sample size is $\mathrm{N}$ and the correlation coefficient is $\mathrm{r}$.

\begin{tabular}{|c|c|c|c|c|c|c|c|}
\hline Model & Buoy & $\mathrm{N}$ & Mean & Std. Dev. & Std. Err. & Median & $\mathrm{r}$ \\
\hline \multirow[t]{7}{*}{ Eta } & $\mathrm{CMO}$ & 680 & 0.1 & 1.2 & 0.0 & -0.1 & 0.99 \\
\hline & 44004 & 741 & -0.6 & 1.4 & 0.1 & -0.7 & 0.98 \\
\hline & 44008 & 748 & -0.4 & 1.5 & 0.1 & -0.6 & 0.98 \\
\hline & 44009 & 749 & 0.4 & 1.3 & 0.0 & 0.2 & 0.99 \\
\hline & 44011 & 747 & 0.5 & 1.3 & 0.0 & 0.4 & 0.99 \\
\hline & 44025 & 748 & 0.0 & 1.5 & 0.1 & -0.2 & 0.98 \\
\hline & 44028 & 749 & -0.2 & 1.5 & 0.1 & -0.4 & 0.99 \\
\hline \multirow[t]{7}{*}{ RUC } & CMO & 1366 & 1.1 & 1.3 & 0.0 & 1.0 & 0.99 \\
\hline & 44004 & 1491 & 0.8 & 1.3 & 0.0 & 0.9 & 0.99 \\
\hline & 44008 & 1505 & 1.0 & 1.4 & 0.0 & 1.0 & 0.99 \\
\hline & 44009 & 1505 & 1.2 & 1.0 & 0.0 & 1.1 & 0.99 \\
\hline & 44011 & 1501 & 1.4 & 1.5 & 0.0 & 1.3 & 0.99 \\
\hline & 44025 & 1506 & 0.9 & 0.9 & 0.0 & 0.9 & 0.99 \\
\hline & 44028 & 1505 & 0.7 & 1.0 & 0.0 & 0.8 & 0.99 \\
\hline \multirow[t]{7}{*}{ RUC Analysis } & $\mathrm{CMO}$ & 732 & 1.5 & 1.0 & 0.0 & 1.5 & 0.99 \\
\hline & 44004 & 723 & 1.2 & 1.3 & 0.0 & 1.1 & 0.99 \\
\hline & 44008 & 735 & 1.4 & 1.1 & 0.0 & 1.4 & 0.99 \\
\hline & 44009 & 735 & 1.4 & 0.7 & 0.0 & 1.3 & 1.00 \\
\hline & 44011 & 731 & 1.6 & 1.4 & 0.1 & 1.5 & 0.99 \\
\hline & 44025 & 735 & 1.0 & 0.8 & 0.0 & 0.9 & 1.00 \\
\hline & 44028 & 735 & 0.9 & 0.6 & 0.0 & 0.9 & 1.00 \\
\hline \multirow[t]{7}{*}{ RUC Hourly } & CMO & 4084 & 1.0 & 1.9 & 0.0 & 1.0 & 0.98 \\
\hline & 44004 & 4279 & 0.7 & 2.1 & 0.0 & 0.8 & 0.97 \\
\hline & 44008 & 4270 & 0.8 & 2.0 & 0.0 & 0.8 & 0.98 \\
\hline & 44009 & 4368 & 1.0 & 1.6 & 0.0 & 1.0 & 0.99 \\
\hline & 44011 & 4284 & 1.2 & 1.5 & 0.0 & 1.0 & 0.99 \\
\hline & 44025 & 4317 & 0.7 & 1.5 & 0.0 & 0.7 & 0.99 \\
\hline & 44028 & 4331 & 0.6 & 1.6 & 0.0 & 0.6 & 0.99 \\
\hline
\end{tabular}


Table A4. Statistical summary of model vs in situ comparisons of air temperature. Units for the mean, standard deviation, standard error and median are ${ }^{\circ} \mathrm{C}$. The comparison sample size is $\mathrm{N}$ and the correlation coefficient is $\mathrm{r}$.

\begin{tabular}{|c|c|c|c|c|c|c|c|}
\hline Model & Buoy & $\mathbf{N}$ & Mean & Std. Dev. & Std. Err. & Median & $\mathrm{r}$ \\
\hline \multirow[t]{7}{*}{$\overline{\text { Eta }}$} & $\mathrm{CMO}$ & 691 & 1.60 & 1.61 & 0.06 & 1.54 & 0.98 \\
\hline & 44004 & 751 & 2.92 & 1.42 & 0.05 & 2.89 & 0.98 \\
\hline & 44008 & 758 & 3.80 & 1.44 & 0.05 & 3.64 & 0.97 \\
\hline & 44009 & 588 & -0.58 & 2.29 & 0.09 & -0.24 & 0.96 \\
\hline & 44011 & 758 & 2.08 & 1.26 & 0.05 & 2.04 & 0.98 \\
\hline & 44025 & 758 & 0.85 & 1.14 & 0.04 & 0.77 & 0.99 \\
\hline & 44028 & 341 & 1.02 & 1.29 & 0.07 & 0.99 & 0.98 \\
\hline \multirow[t]{7}{*}{ RUC } & CMO & 1367 & 0.66 & 2.09 & 0.06 & 0.75 & 0.97 \\
\hline & 44004 & 1493 & -0.73 & 1.46 & 0.04 & -0.68 & 0.98 \\
\hline & 44008 & 1506 & 1.61 & 2.34 & 0.06 & 1.42 & 0.96 \\
\hline & 44009 & 1168 & -0.64 & 2.98 & 0.09 & -0.45 & 0.92 \\
\hline & 44011 & 1503 & 0.79 & 2.42 & 0.06 & 0.62 & 0.97 \\
\hline & 44025 & 1507 & 0.52 & 1.74 & 0.04 & 0.62 & 0.98 \\
\hline & 44028 & 643 & 0.72 & 1.57 & 0.06 & 0.75 & 0.97 \\
\hline \multirow[t]{7}{*}{ RUC Analysis } & $\mathrm{CMO}$ & 725 & 0.36 & 1.82 & 0.07 & 0.57 & 0.94 \\
\hline & 44004 & 717 & -0.89 & 1.33 & 0.05 & -0.85 & 0.97 \\
\hline & 44008 & 728 & 0.28 & 1.74 & 0.06 & 0.32 & 0.95 \\
\hline & 44009 & 410 & -0.85 & 2.98 & 0.15 & -0.39 & 0.80 \\
\hline & 44011 & 726 & 0.18 & .1 .95 & 0.07 & -0.10 & 0.96 \\
\hline & 44025 & 728 & 0.16 & 1.69 & 0.06 & 0.36 & 0.95 \\
\hline & 44028 & 66 & 0.80 & 1.00 & 0.12 & 0.69 & 0.98 \\
\hline \multirow[t]{7}{*}{ RUC Hourly } & CMO & 2182 & 1.12 & 1.09 & 0.02 & 1.16 & 0.97 \\
\hline & 44004 & 2088 & -0.34 & 1.01 & 0.02 & -0.27 & 0.98 \\
\hline & 44008 & 2102 & 0.89 & 1.16 & 0.03 & 0.83 & 0.97 \\
\hline & 44009 & 1222 & 0.02 & 2.40 & 0.07 & 0.26 & 0.87 \\
\hline & 44011 & 2121 & 0.20 & 1.97 & 0.04 & -0.11 & 0.96 \\
\hline & 44025 & 2147 & 1.04 & 1.09 & 0.02 & 1.01 & 0.97 \\
\hline & 44028 & 204 & 1.53 & 1.02 & 0.07 & 1.70 & 0.99 \\
\hline
\end{tabular}


Table A5. Statistical summary of model vs in situ comparisons of relative humidity. Units for the mean, standard deviation, standard error and median are percent. The comparison sample size is $\mathrm{N}$ and the correlation coefficient is $\mathrm{r}$.

\begin{tabular}{llrccccc}
\hline \hline & & & & & & & \\
Model & Buoy & N & Mean & Std. Dev. & Std. Err. & Median & r \\
\hline Eta & CMO & 709 & -4.9 & 8.4 & 0.3 & -4.8 & 0.75 \\
RUC & CMO & 1367 & -10.8 & 9.3 & 0.3 & -9.9 & 0.80 \\
RUC Analysis & CMO & 725 & -9.9 & 9.2 & 0.3 & -9.5 & 0.83 \\
RUC Hourly & CMO & 2182 & -9.0 & 7.1 & 0.2 & -8.8 & 0.87 \\
\hline
\end{tabular}

Table A6. Statistical summary of model vs in situ comparisons of specific humidity. Units for the mean, standard deviation, standard error and median are $\mathrm{g} \mathrm{kg}^{-1}$. The comparison sample size is $\mathrm{N}$ and the correlation coefficient is $\mathrm{r}$.

\begin{tabular}{llrrrrrc}
\hline \hline & & & & & & \\
Model & Buoy & N & Mean & Std. Dev. & Std. Err. & Median & r \\
\hline Eta & CMO & 674 & 0.49 & 0.99 & 0.04 & 0.34 & 0.97 \\
RUC & CMO & 1366 & -0.37 & 0.99 & 0.03 & -0.49 & 0.97 \\
RUC Analysis & CMO & 725 & -0.36 & 0.76 & 0.03 & -0.49 & 0.95 \\
RUC Hourly & CMO & 2182 & -0.14 & 0.62 & 0.01 & -0.20 & 0.96 \\
\hline
\end{tabular}

Table A7. Statistical summary of RUC Hourly vs in situ comparisons of sea surface temperature. Units for the mean, standard deviation, standard error and median are ${ }^{\circ} \mathrm{C}$. The comparison sample size is $\mathbf{N}$ and the correlation coefficient is $\mathbf{r}$.

\begin{tabular}{llcccccc}
\hline \hline \multirow{2}{*}{ Model } & Buoy & N & Mean & Std. Dev. & Std. Err. & Median & r \\
\hline RUC Hourly & CMO & 4083 & 3.73 & 1.58 & 0.02 & 3.33 & 0.95 \\
& 44004 & 4280 & 1.65 & 1.50 & 0.02 & 1.55 & 0.93 \\
& 44008 & 4269 & 4.31 & 1.69 & 0.03 & 4.45 & 0.96 \\
& 44009 & 4367 & 0.71 & 1.40 & 0.02 & 0.75 & 0.98 \\
& 44011 & 4275 & 4.51 & 1.43 & 0.02 & 4.45 & 0.95 \\
& 44025 & 4316 & 1.40 & 1.39 & 0.02 & 1.25 & 0.97 \\
& 44028 & 4328 & 1.32 & 1.23 & 0.02 & 1.35 & 0.97 \\
\hline
\end{tabular}

Table A8. Statistical summary of RUC Hourly model vs in situ comparisons of heat fluxes. Units for the mean, standard deviation, standard error and median are $\mathrm{W} \mathrm{m}^{-2}$. The comparison sample size is $\mathrm{N}$ and the correlation coefficient is $\mathrm{r}$.

\begin{tabular}{llcccccc}
\hline \hline & & & & & & \\
Variable & Buoy & $\mathrm{N}$ & Mean & Std. Dev. & Std. Err. & Median & $\mathrm{r}$ \\
\hline Global Radiation & CMO & 4038 & -18.9 & 88.1 & 1.4 & -40.5 & 0.91 \\
Sensible Heat Flux & CMO & 4038 & -46.8 & 53.7 & 0.8 & -28.3 & 0.91 \\
Latent Heat Flux & CMO & 4038 & -22.5 & 38.4 & 0.6 & -19.6 & 0.81 \\
\hline
\end{tabular}




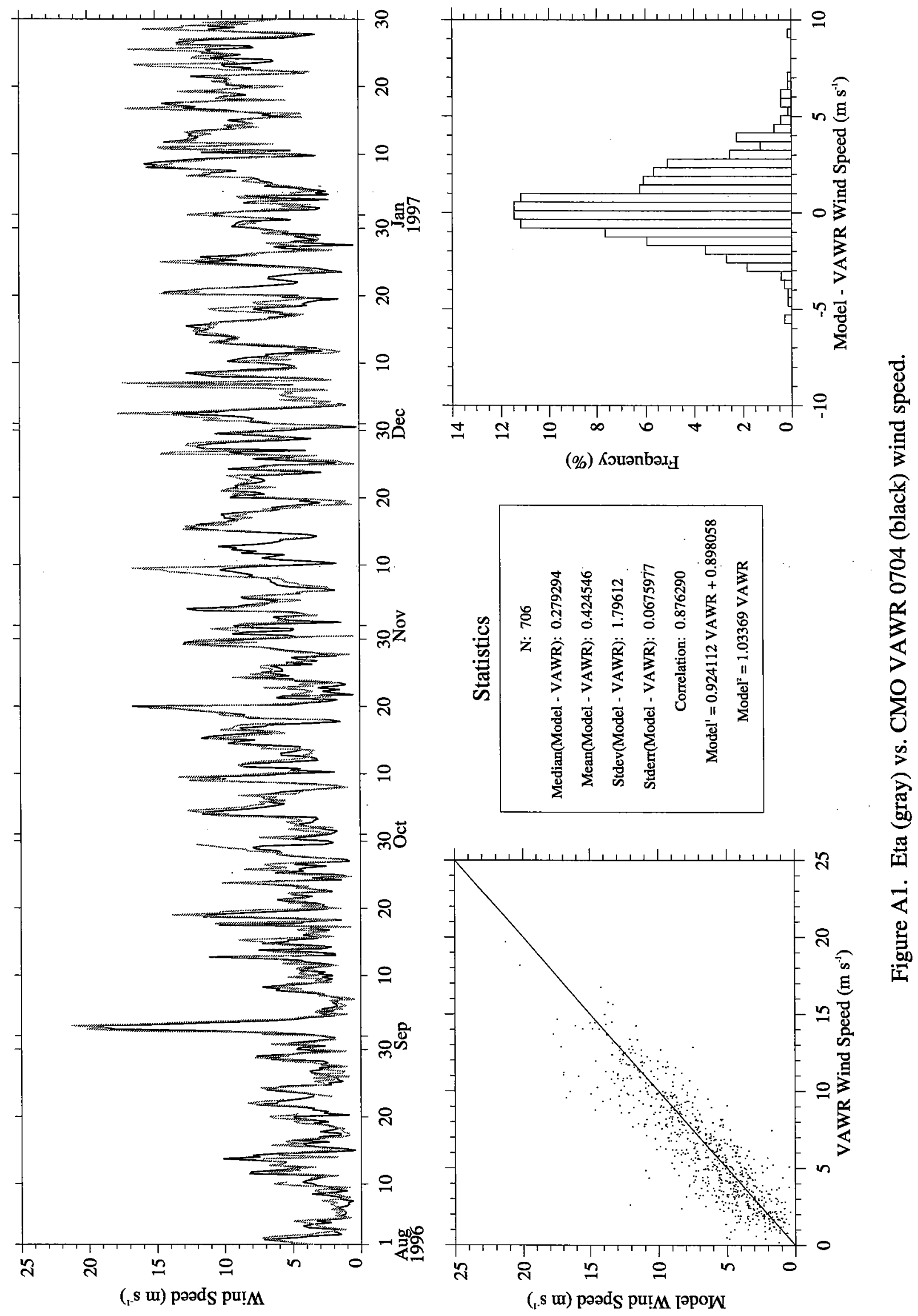



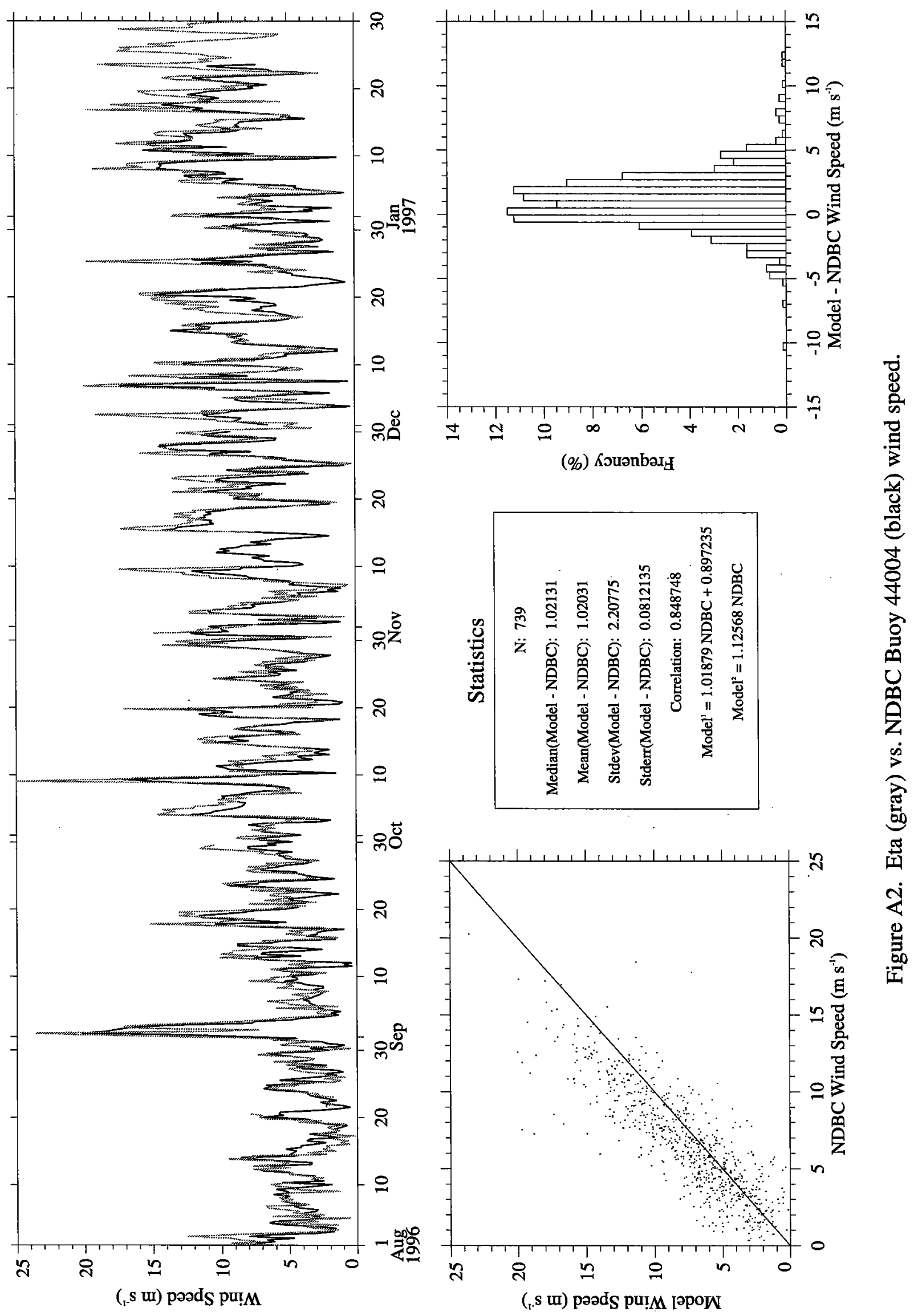


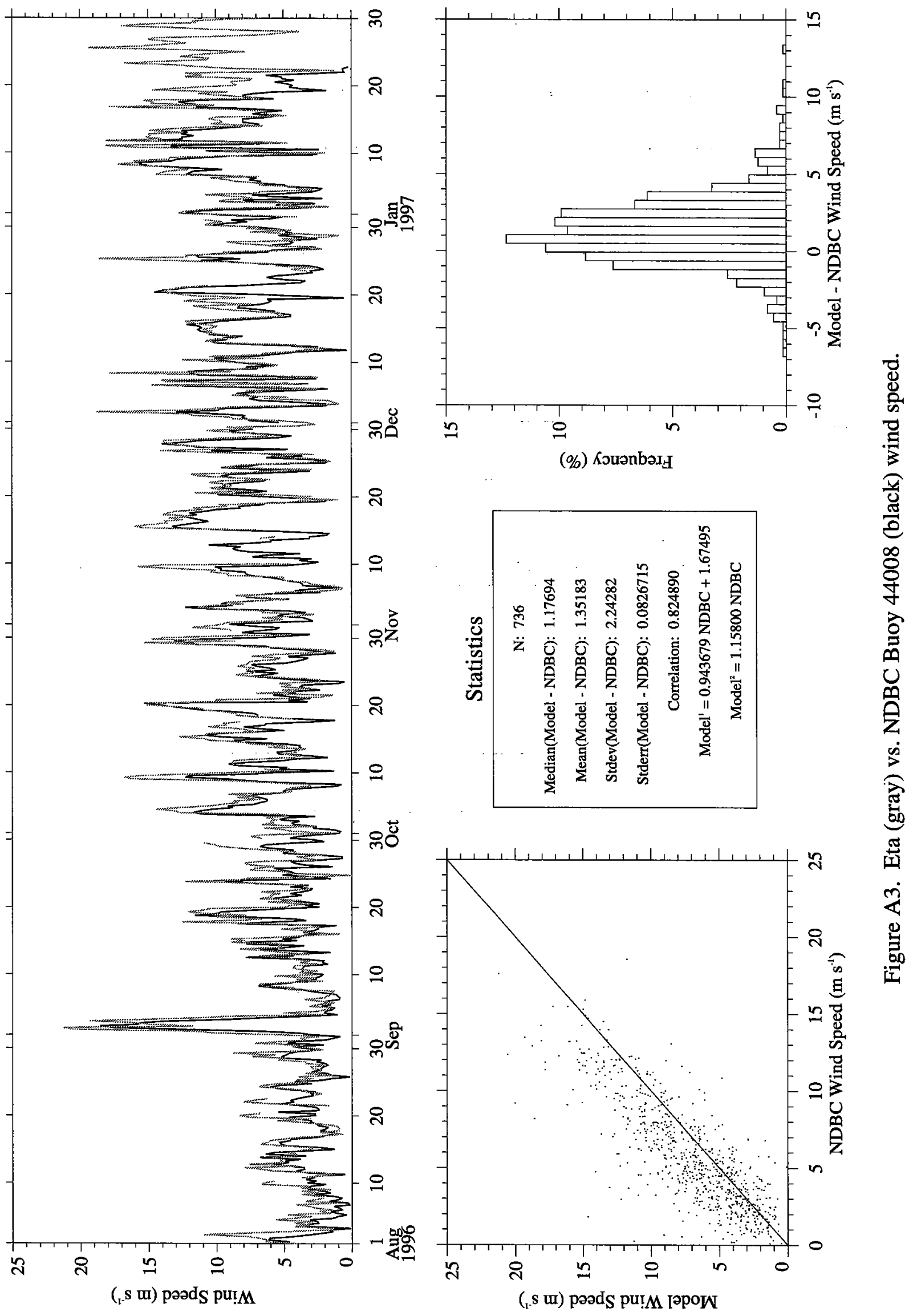



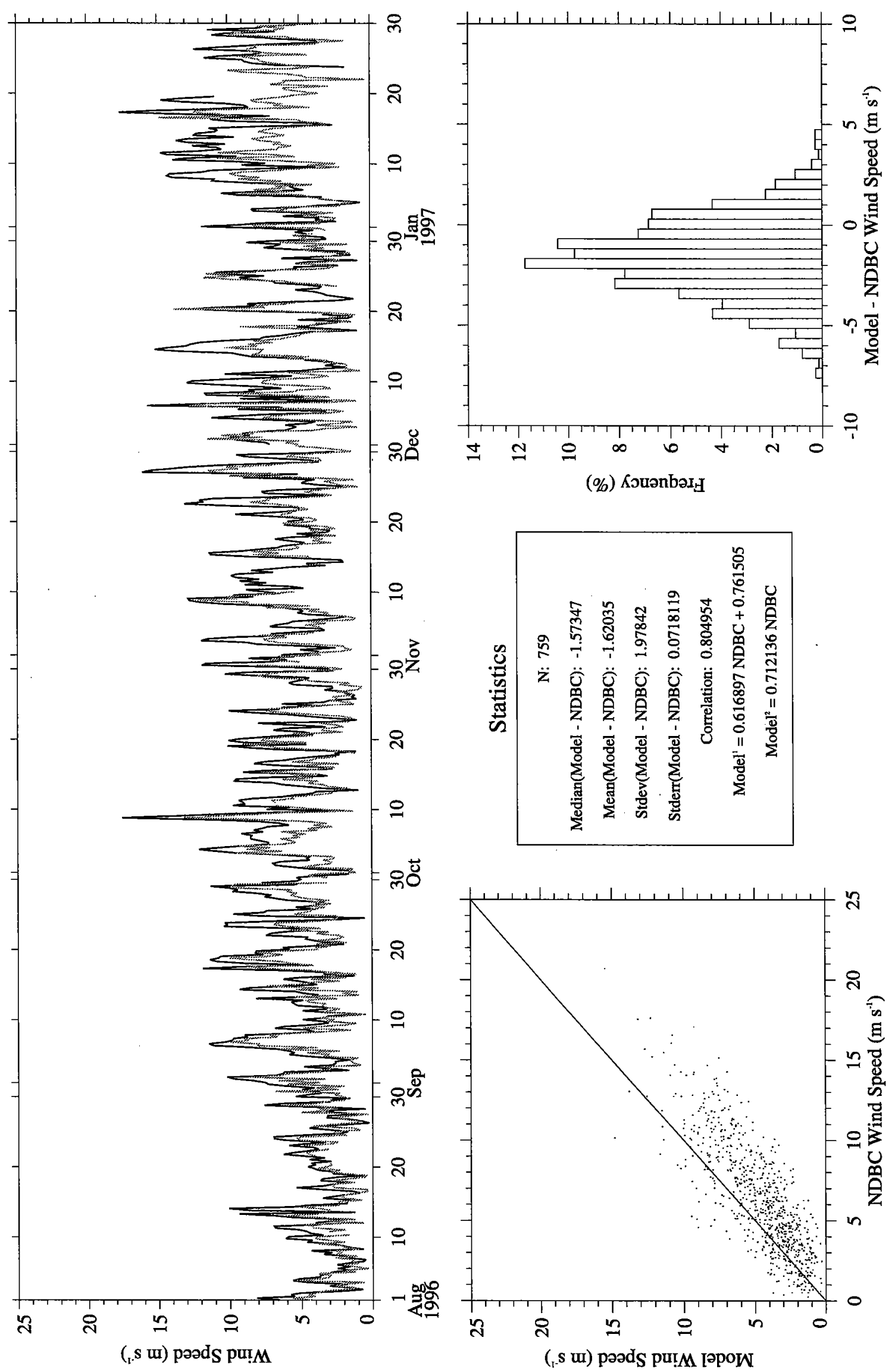

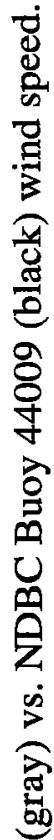

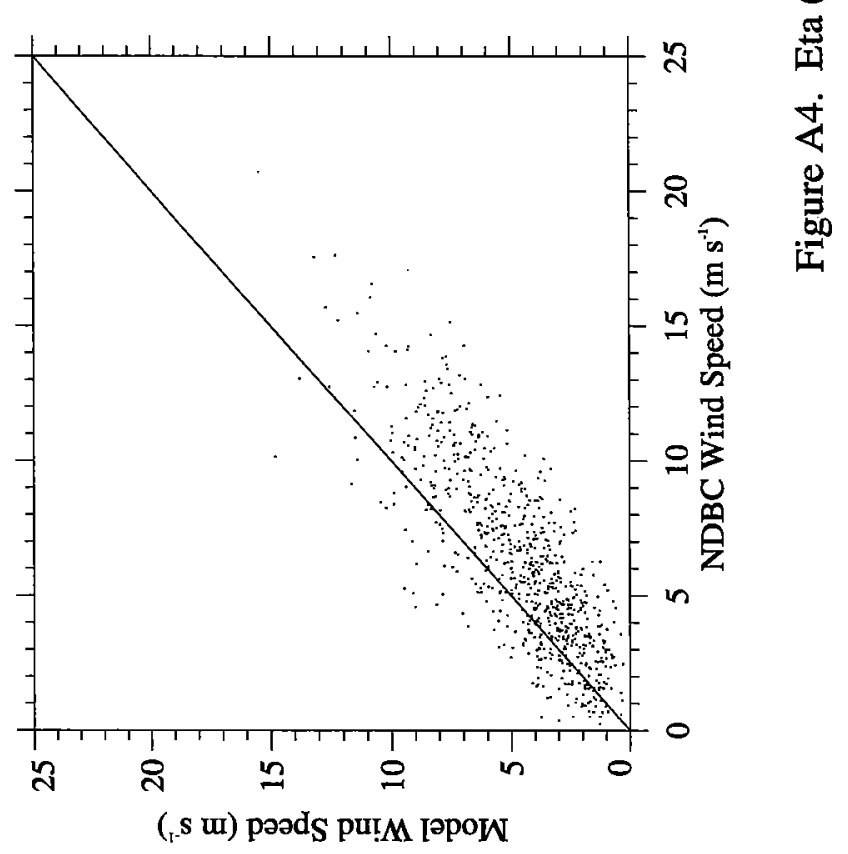



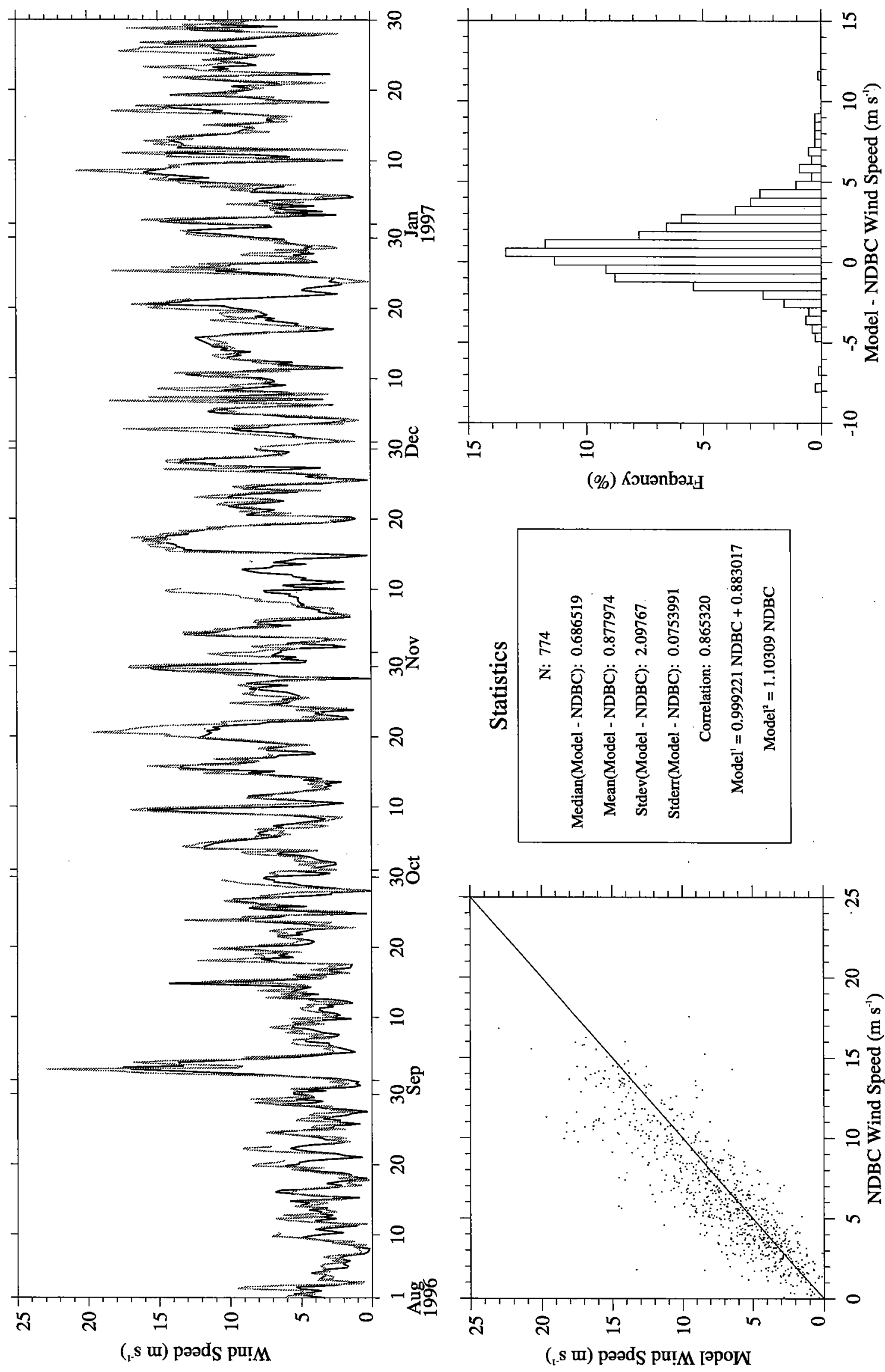

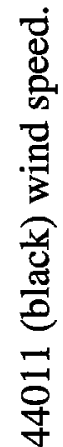
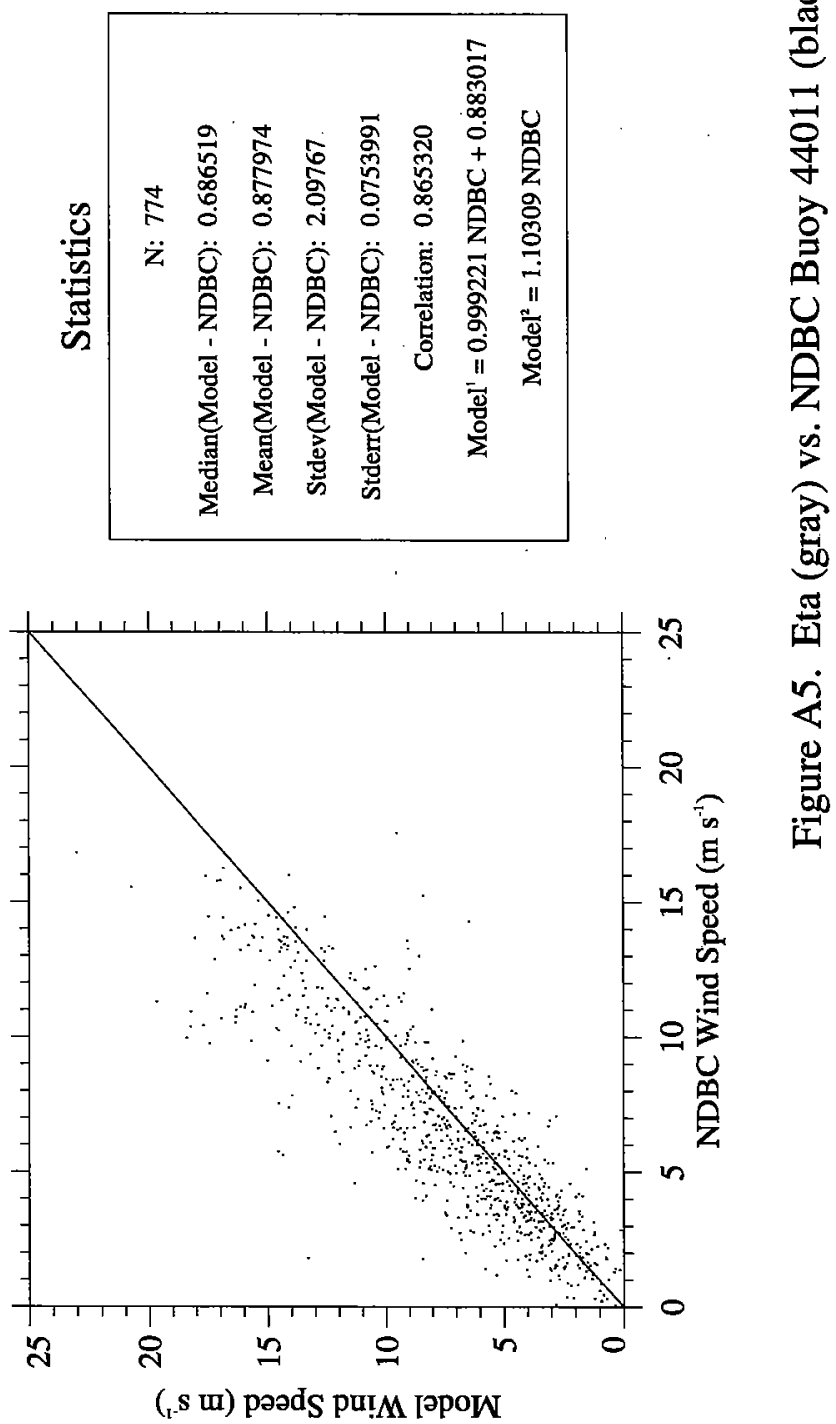


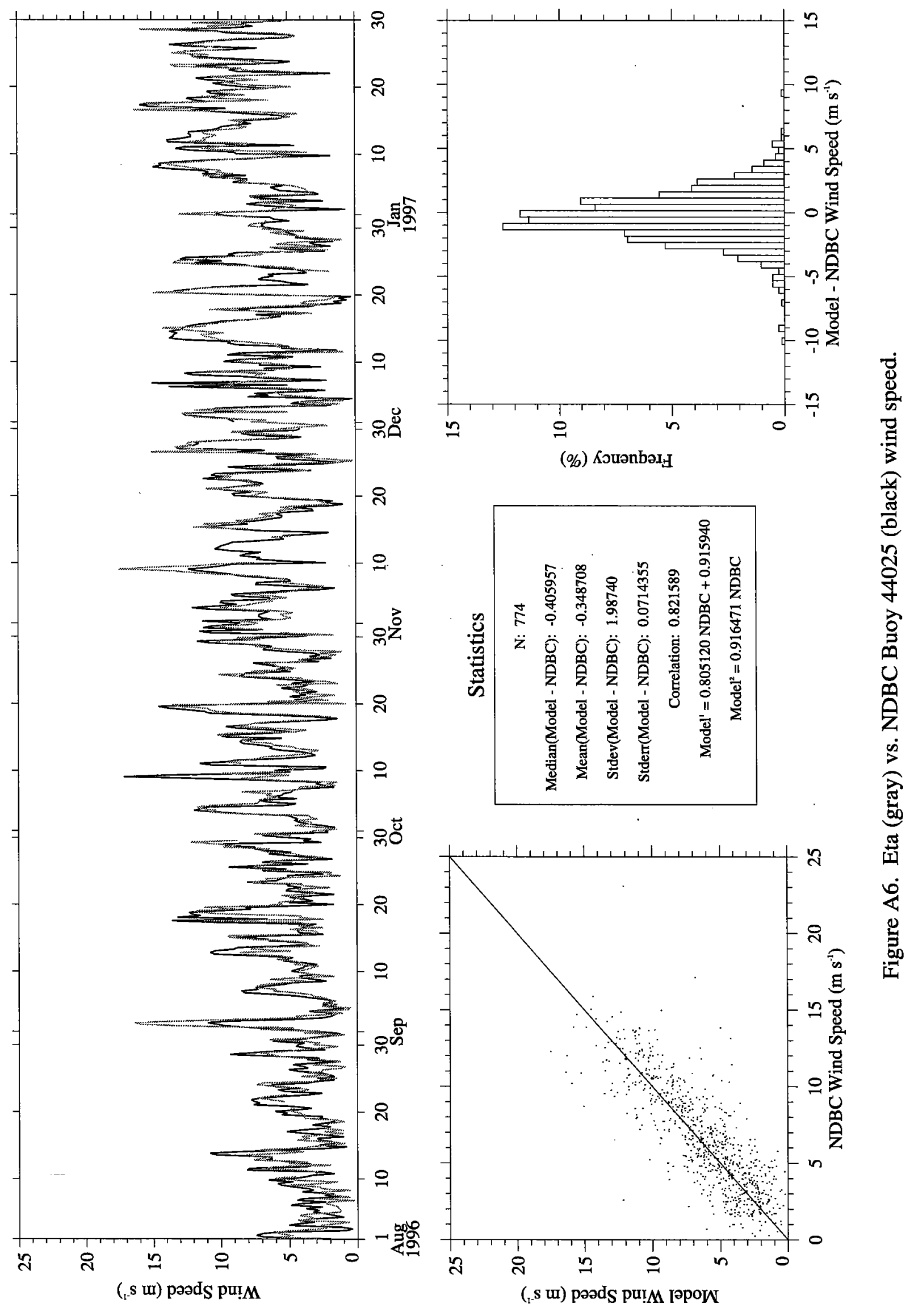



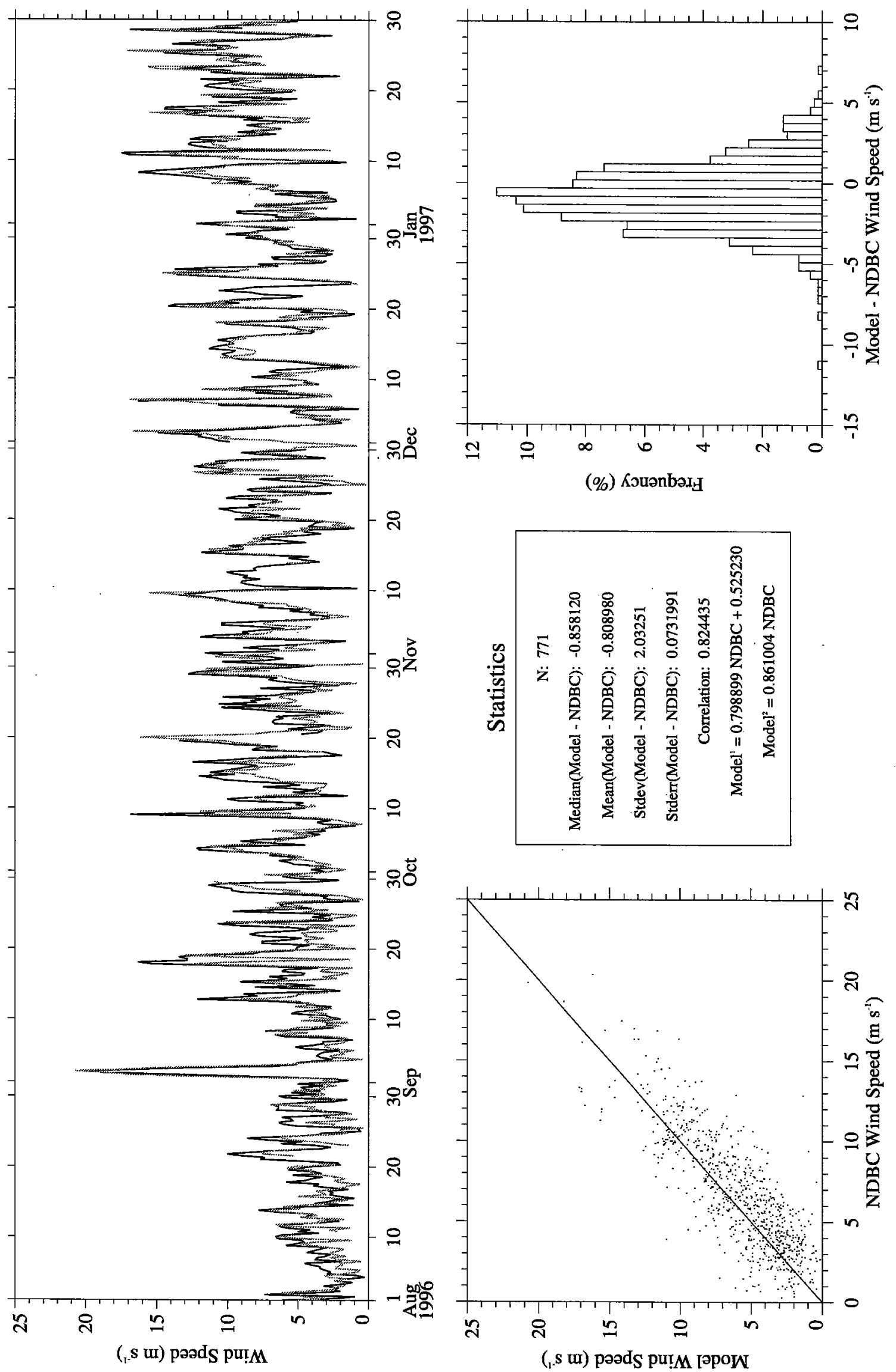

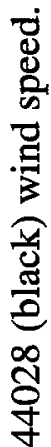

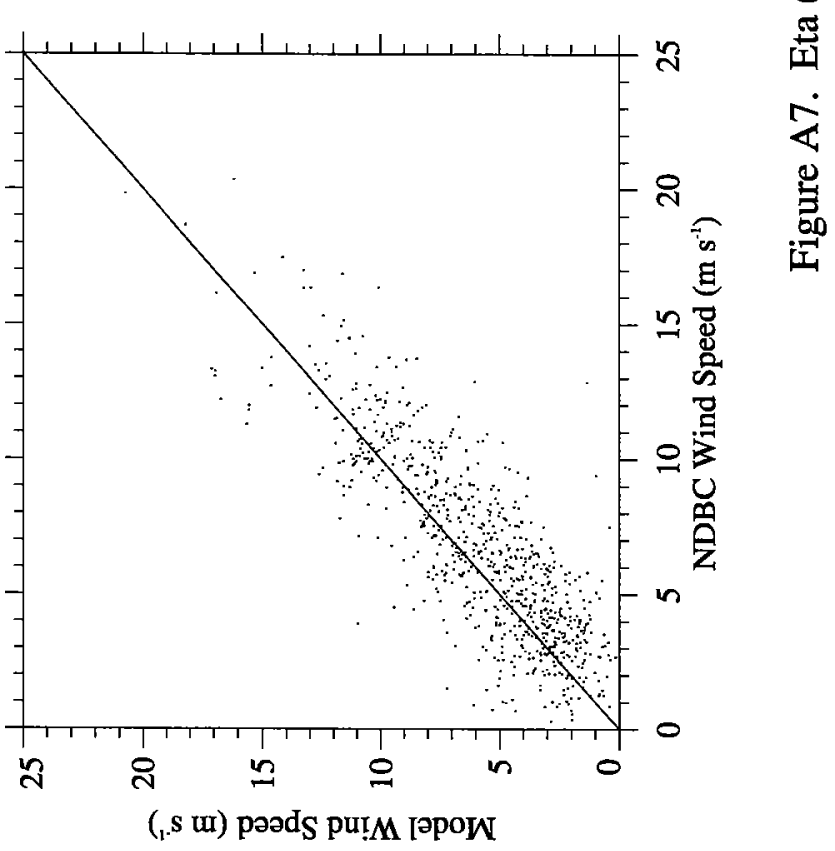



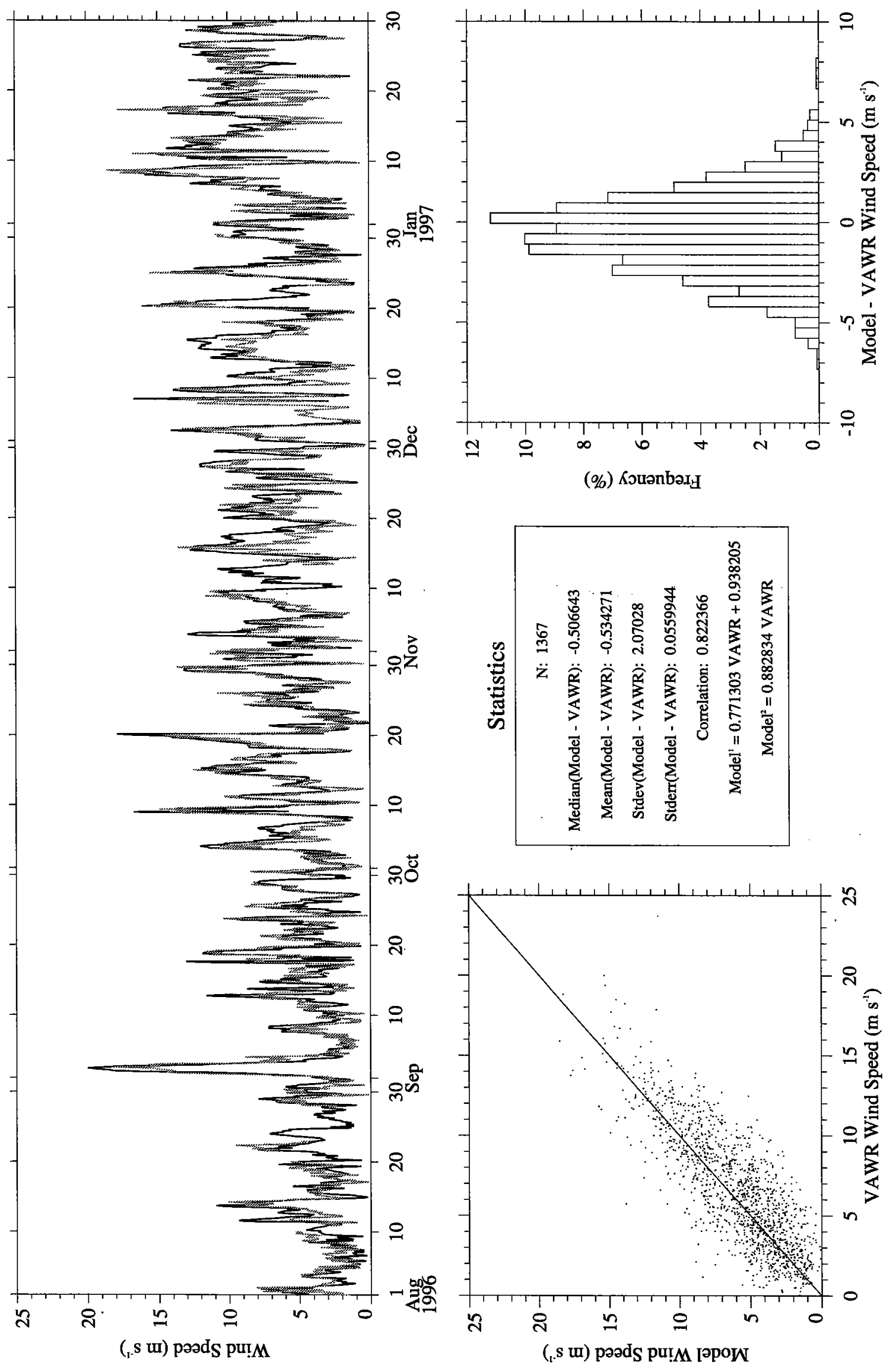

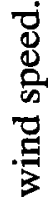
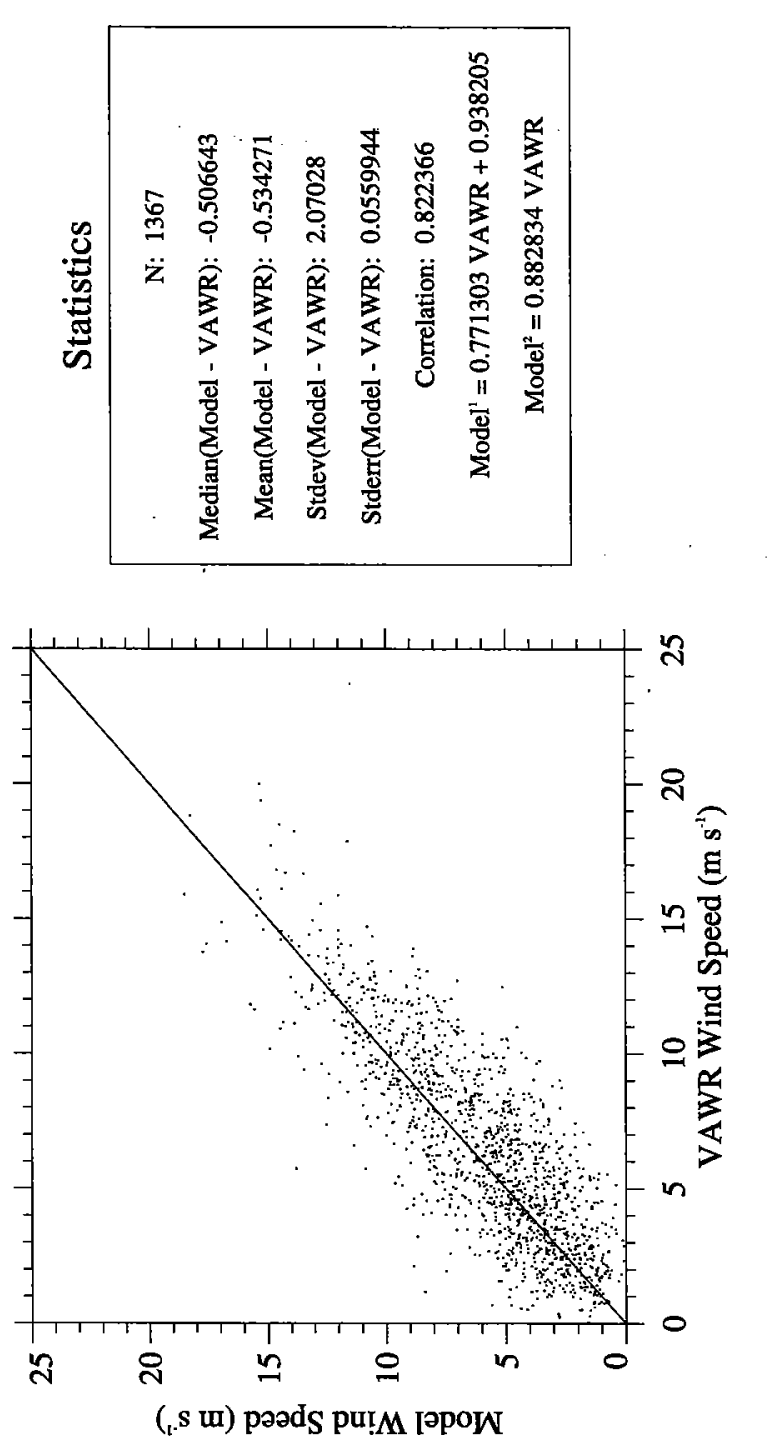


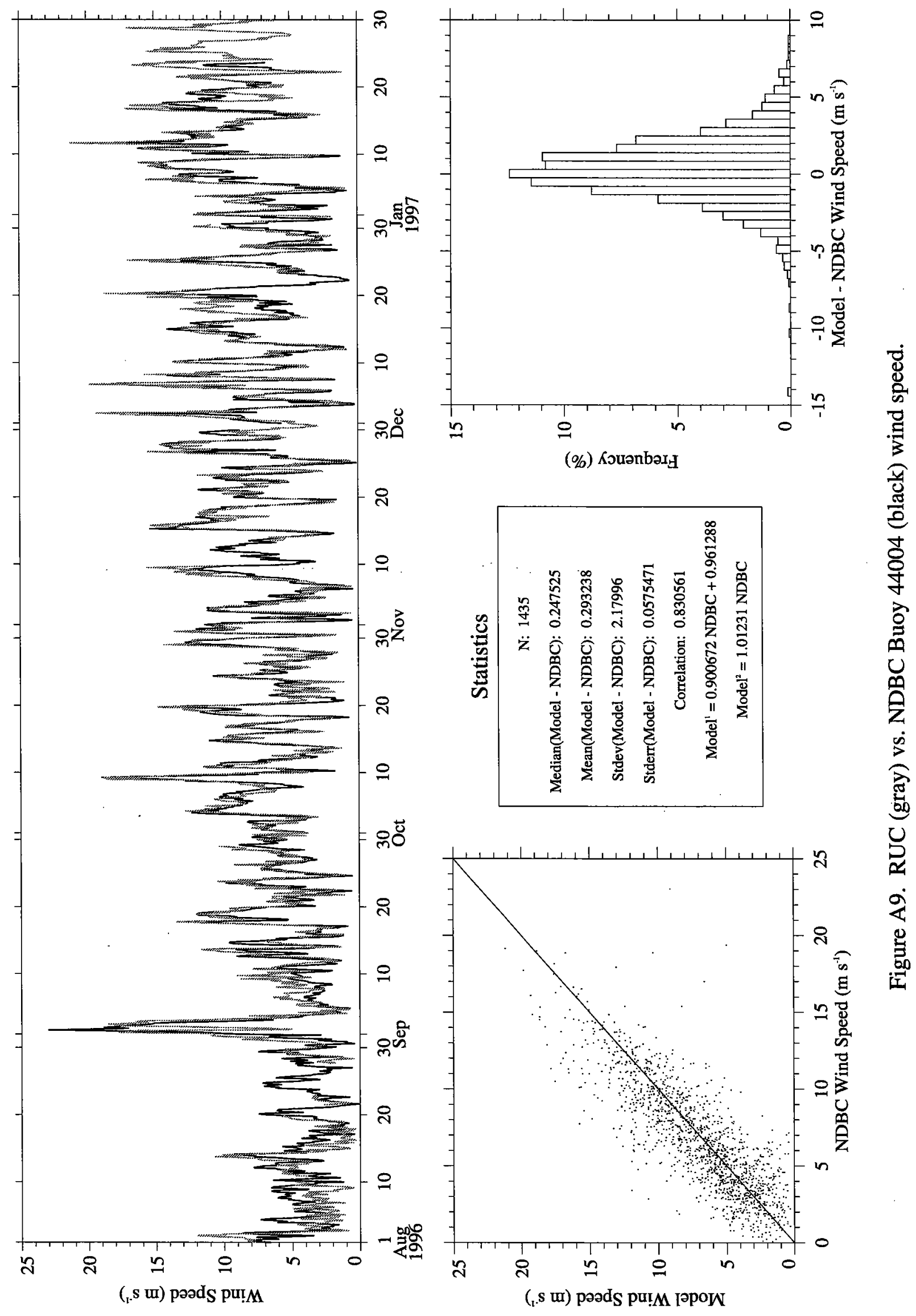




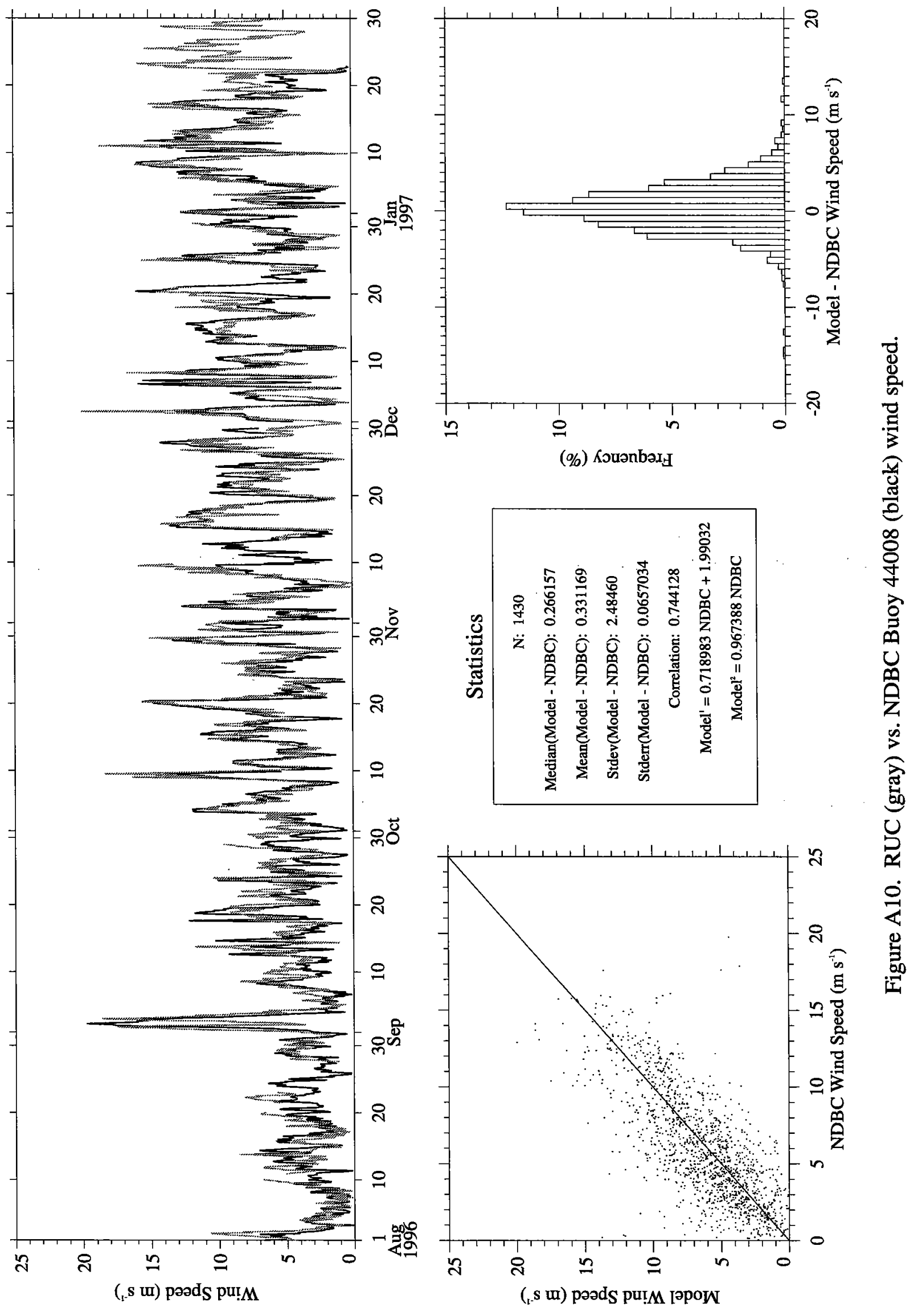



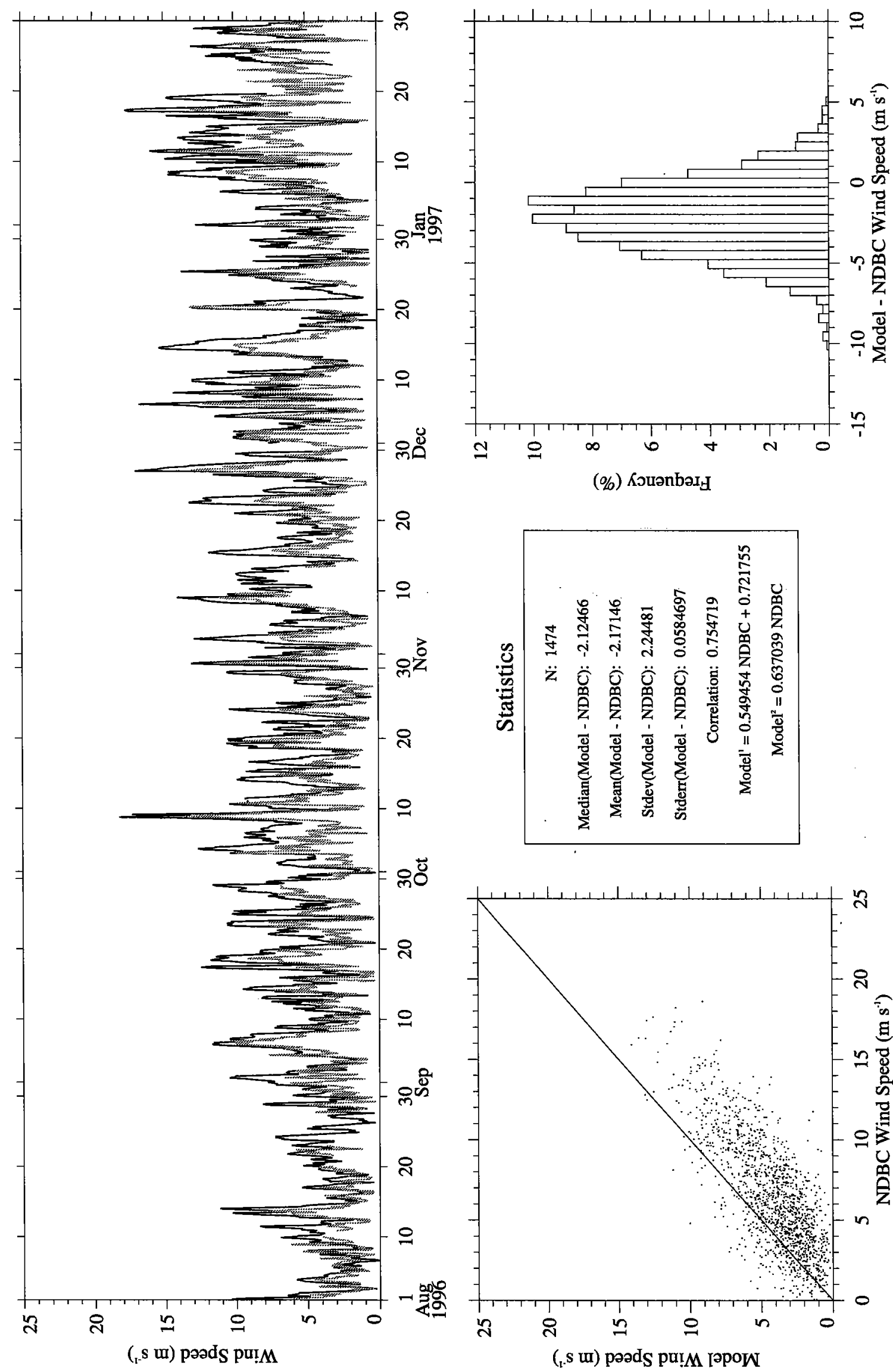

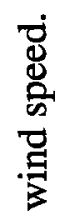

(\%) KouənbəI

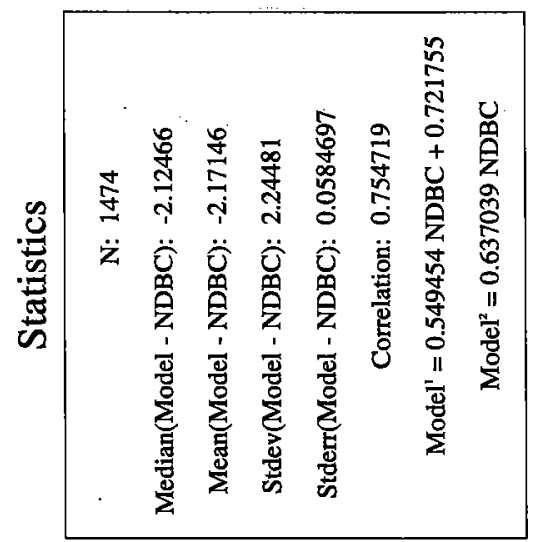

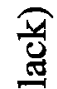

를

g

응

亩

$\dot{s}$

突
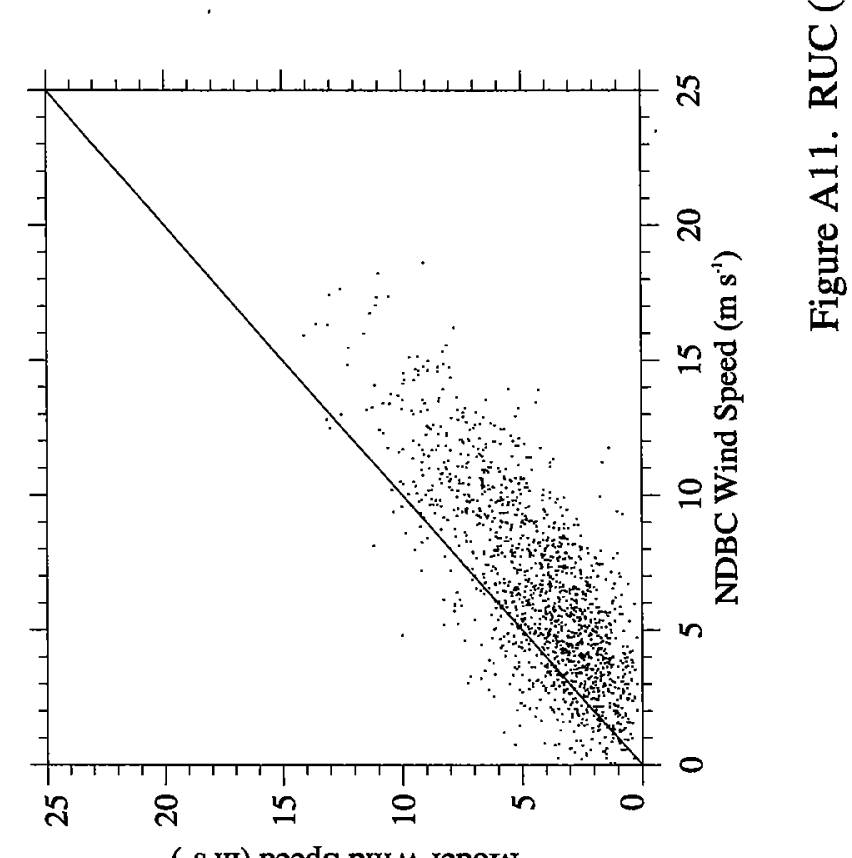

党

递

ह

魚

$(\mathrm{s}$. $\mathrm{u})$ pəads pu!M Iəpow 


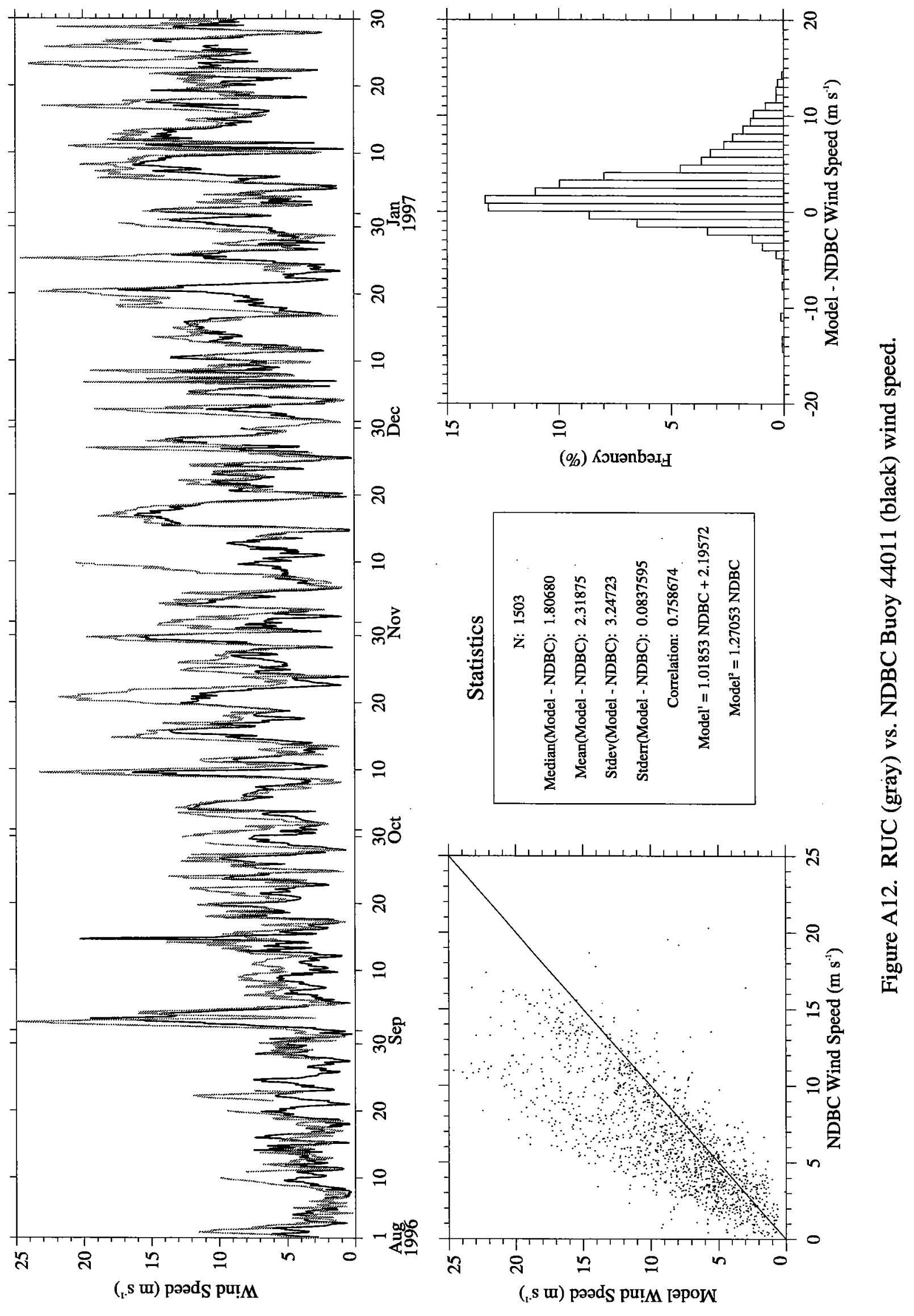



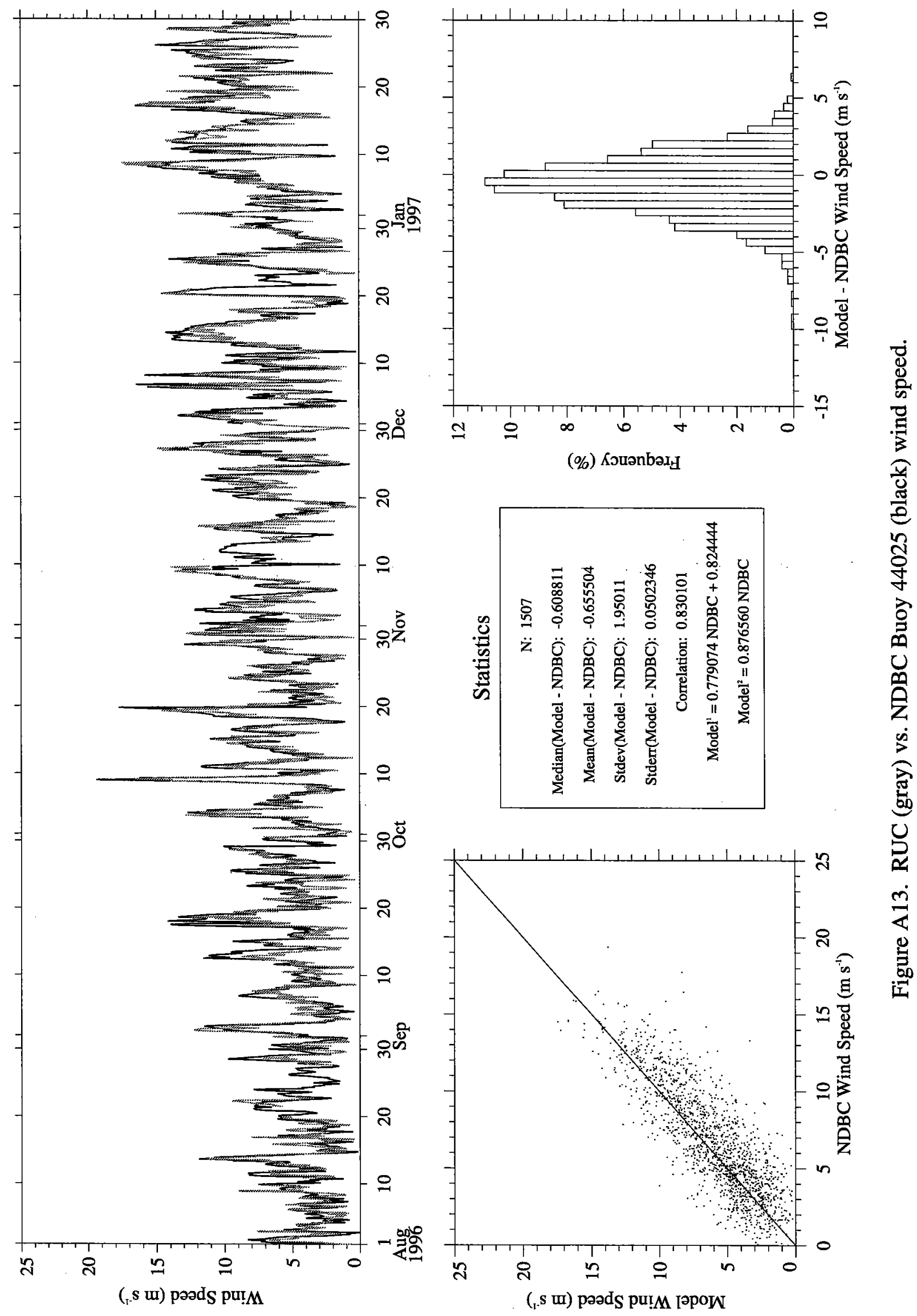

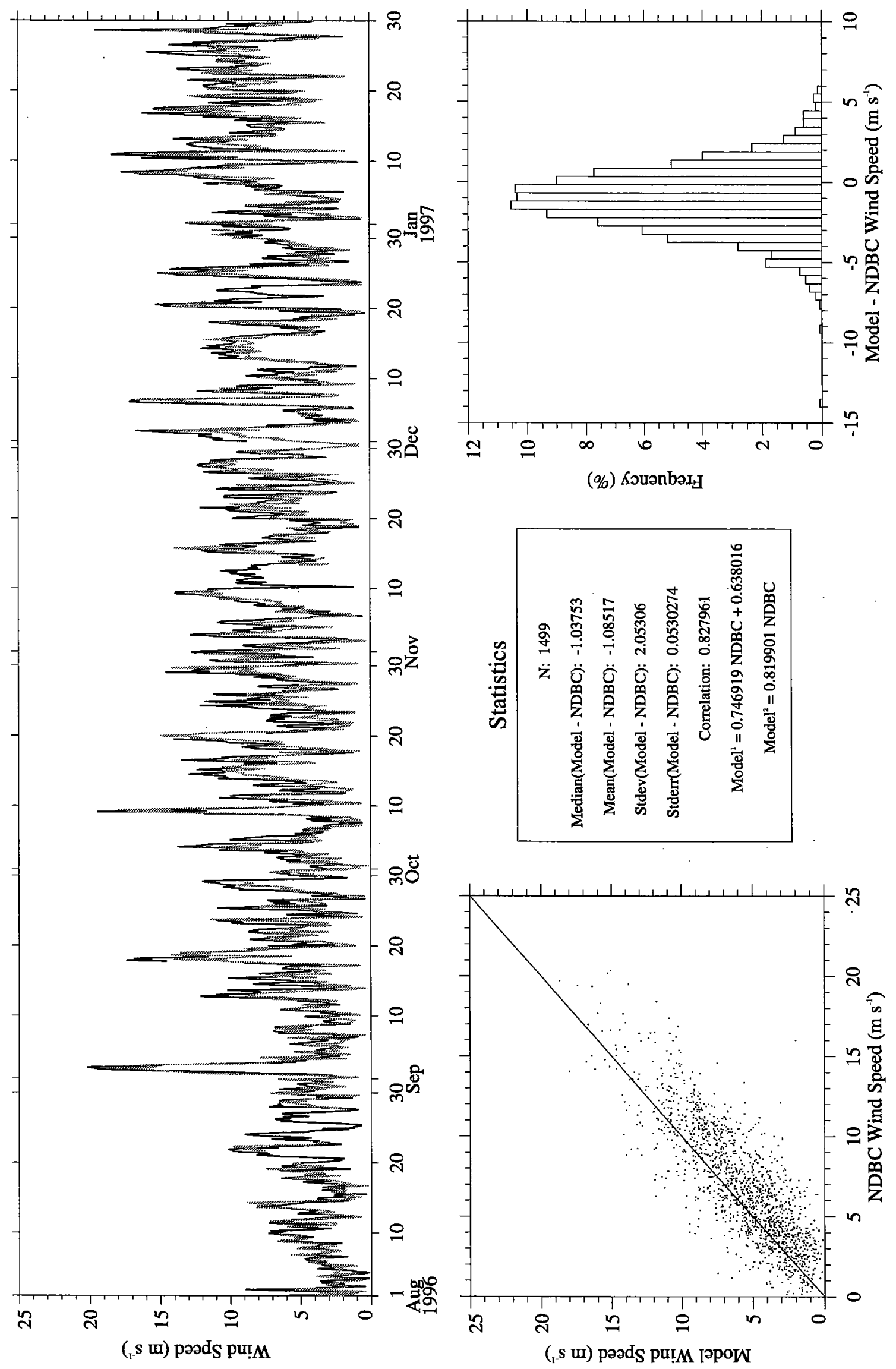

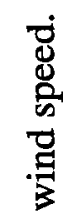

(\%) Кэuənbวג

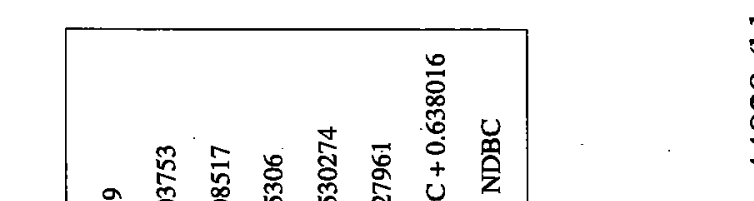

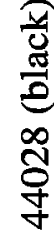

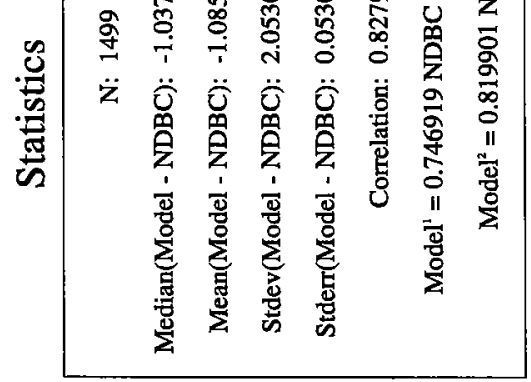

을

品

男

$\dot{m}$

สิ่

एक

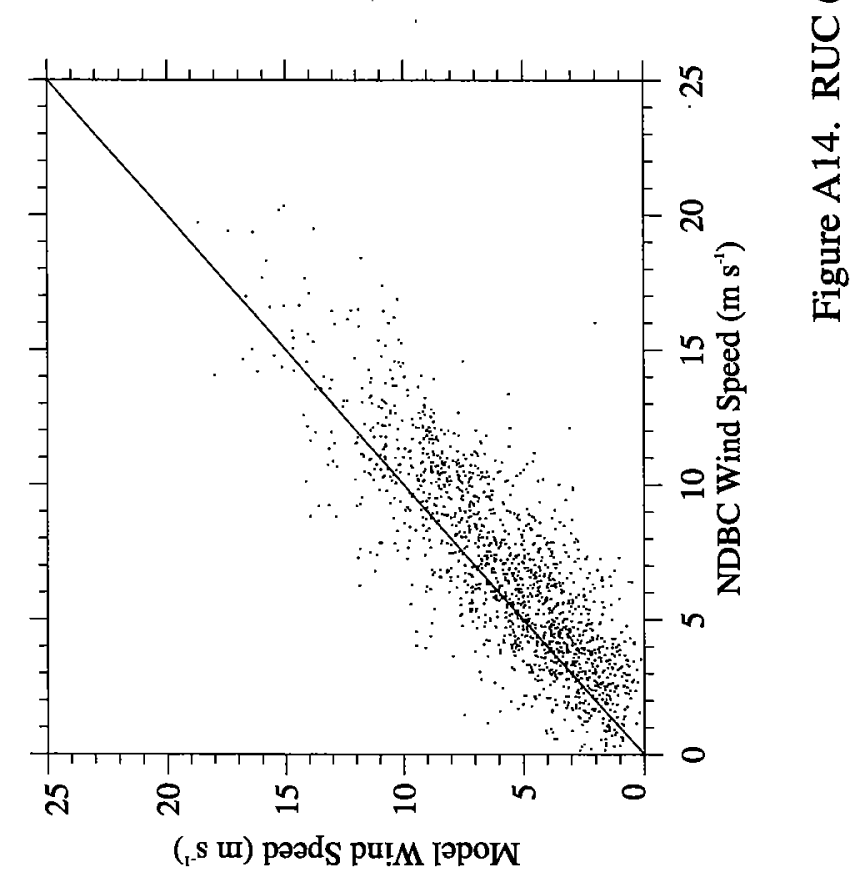



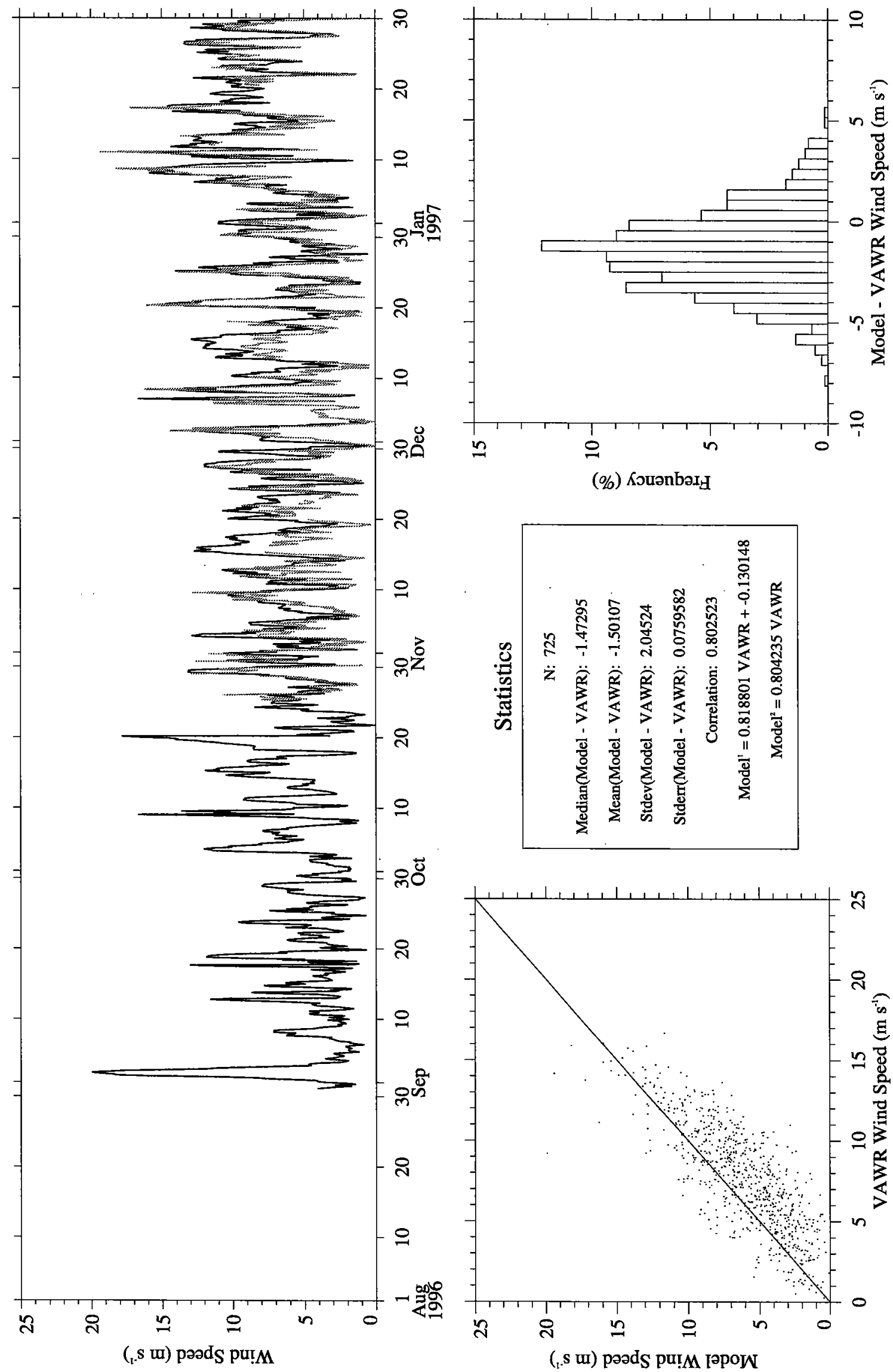

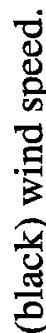

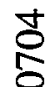

s

3

$\sum_{0}^{0}$

$\dot{2}$

ลิ

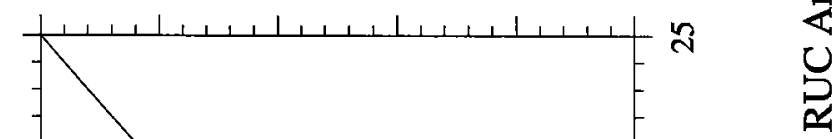

吕

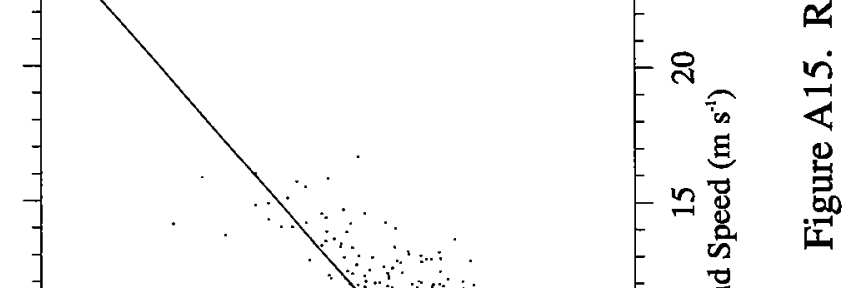




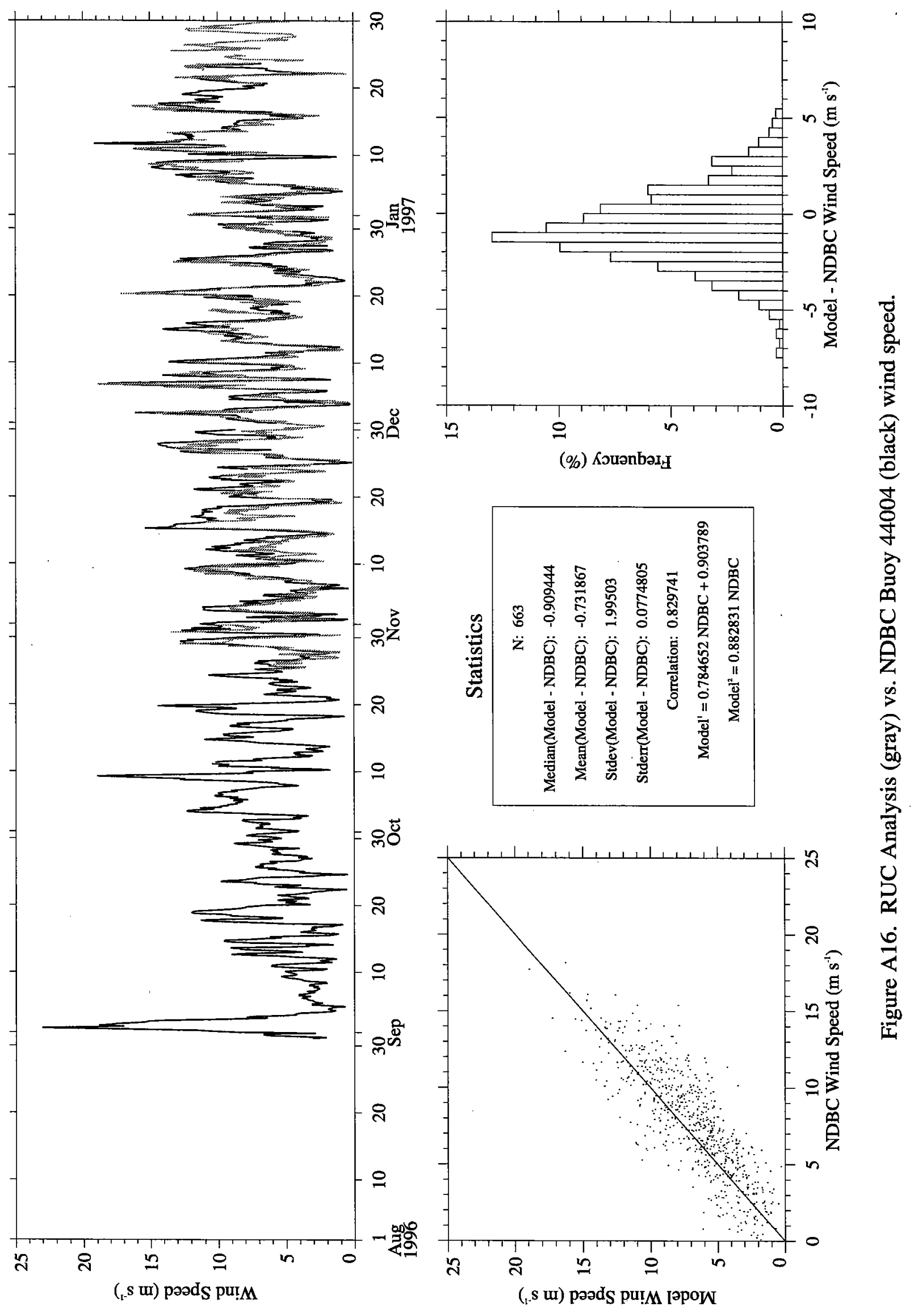




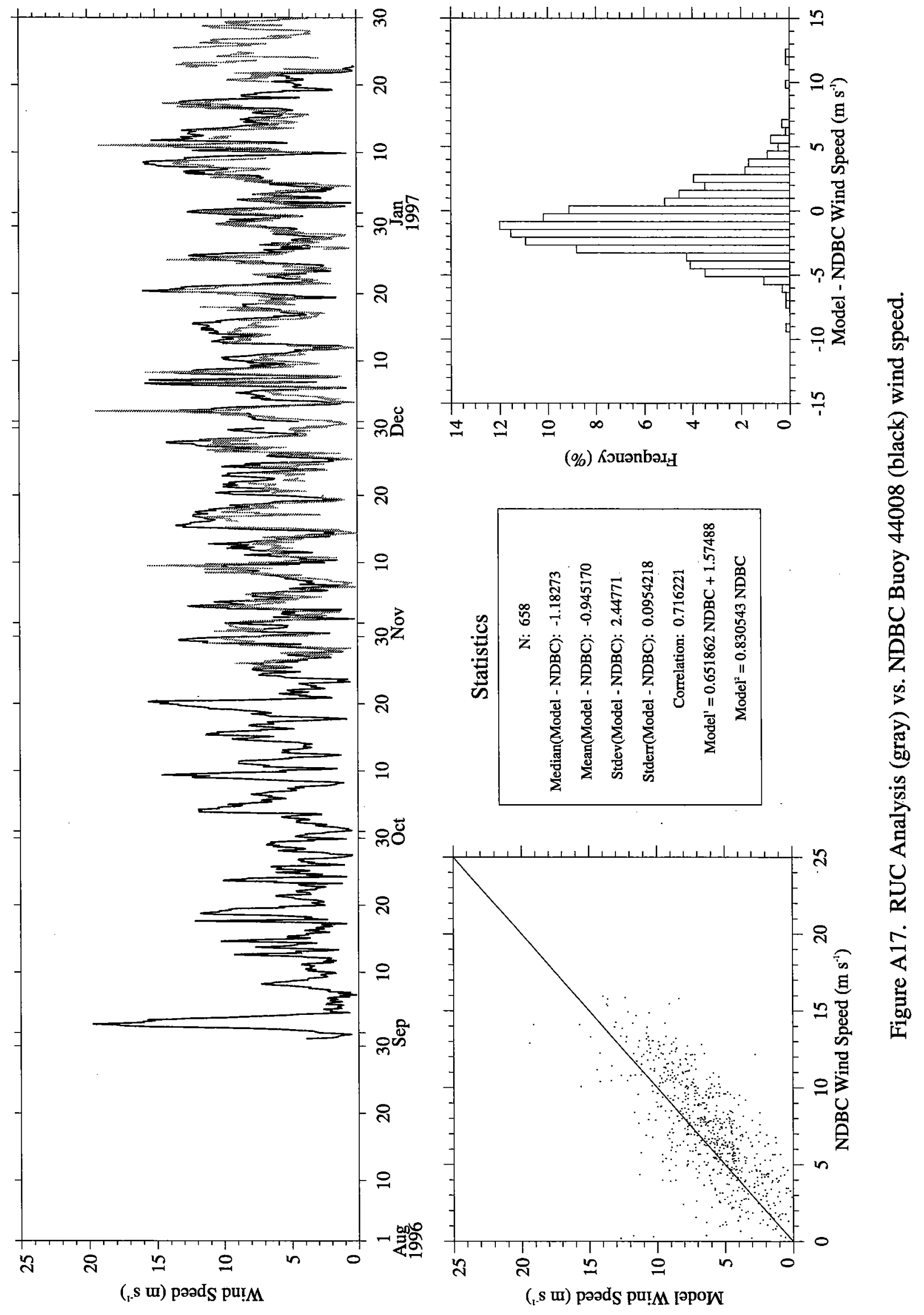




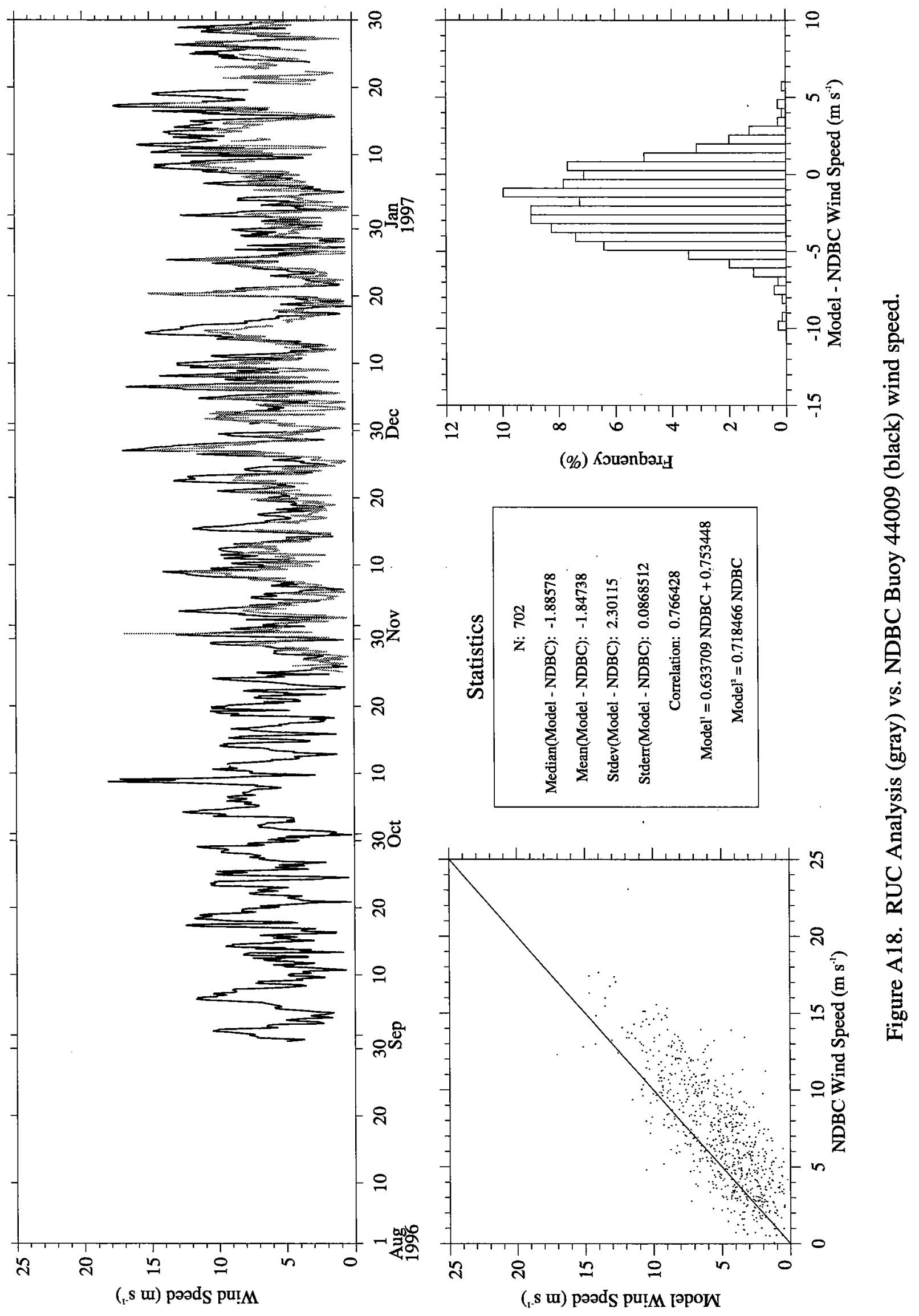



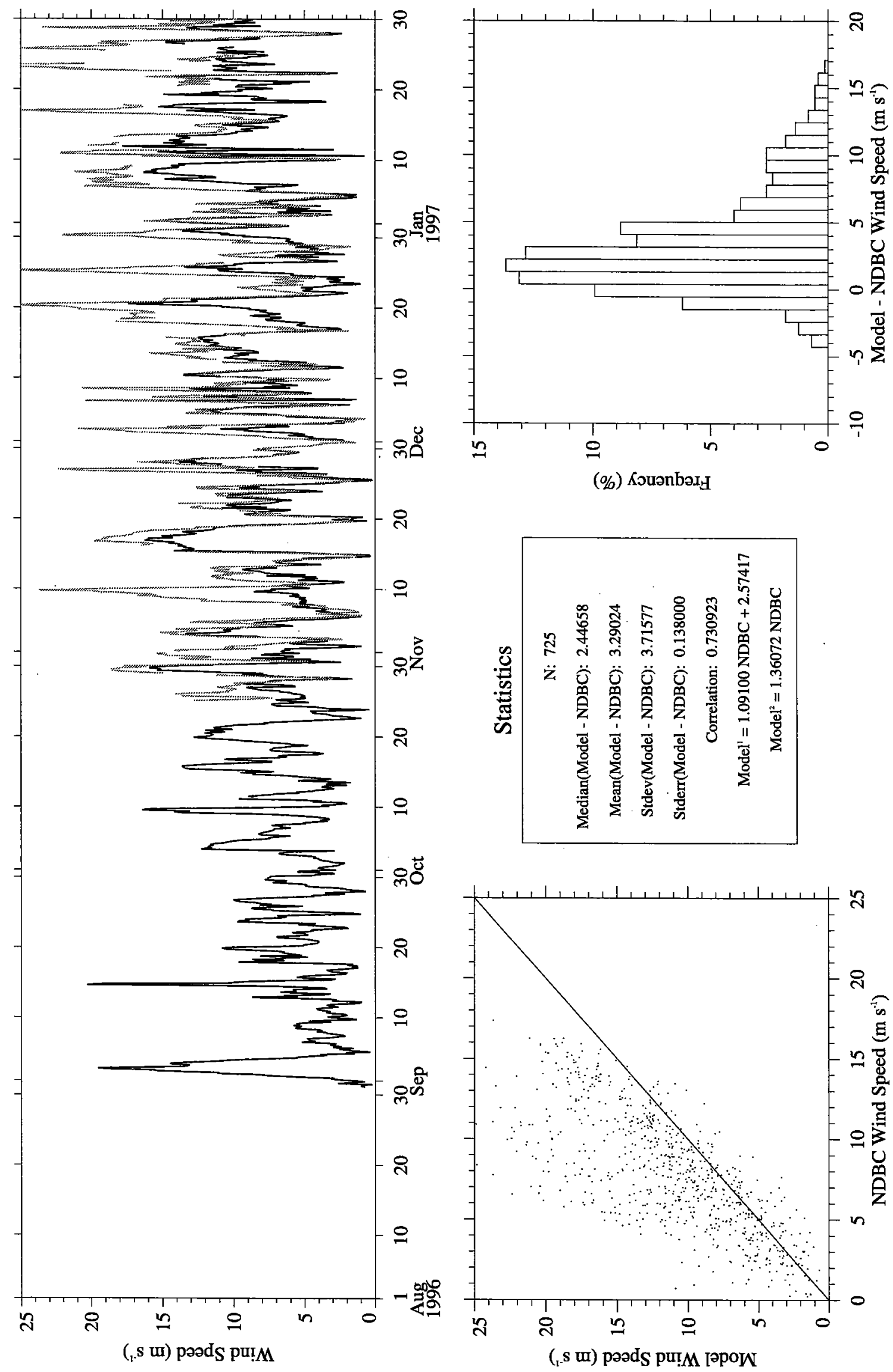

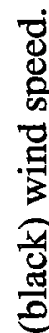

สิ

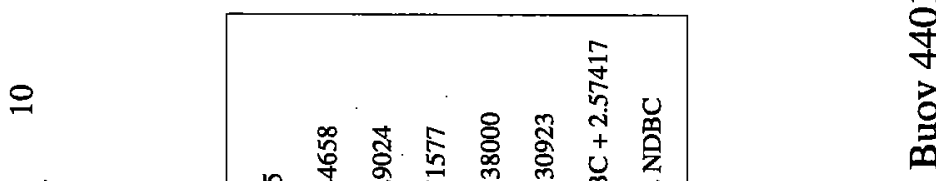

品

ㄴ.

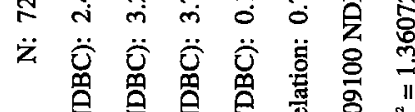

完

오

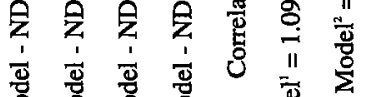

으

造

$\dot{m}$

命

5

$\frac{\infty}{5}$

ळัँ

요

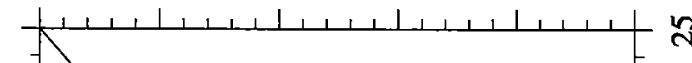

$+2$

帘

?
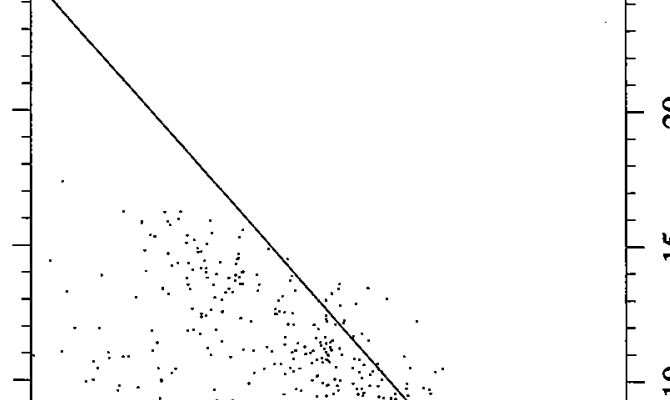

F 요

$\frac{9}{4}$

>

๙

오

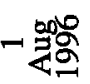

4
$y$ क $n$ in 0

( $\mathrm{s}$. u) paəds pu!M Iәpow 


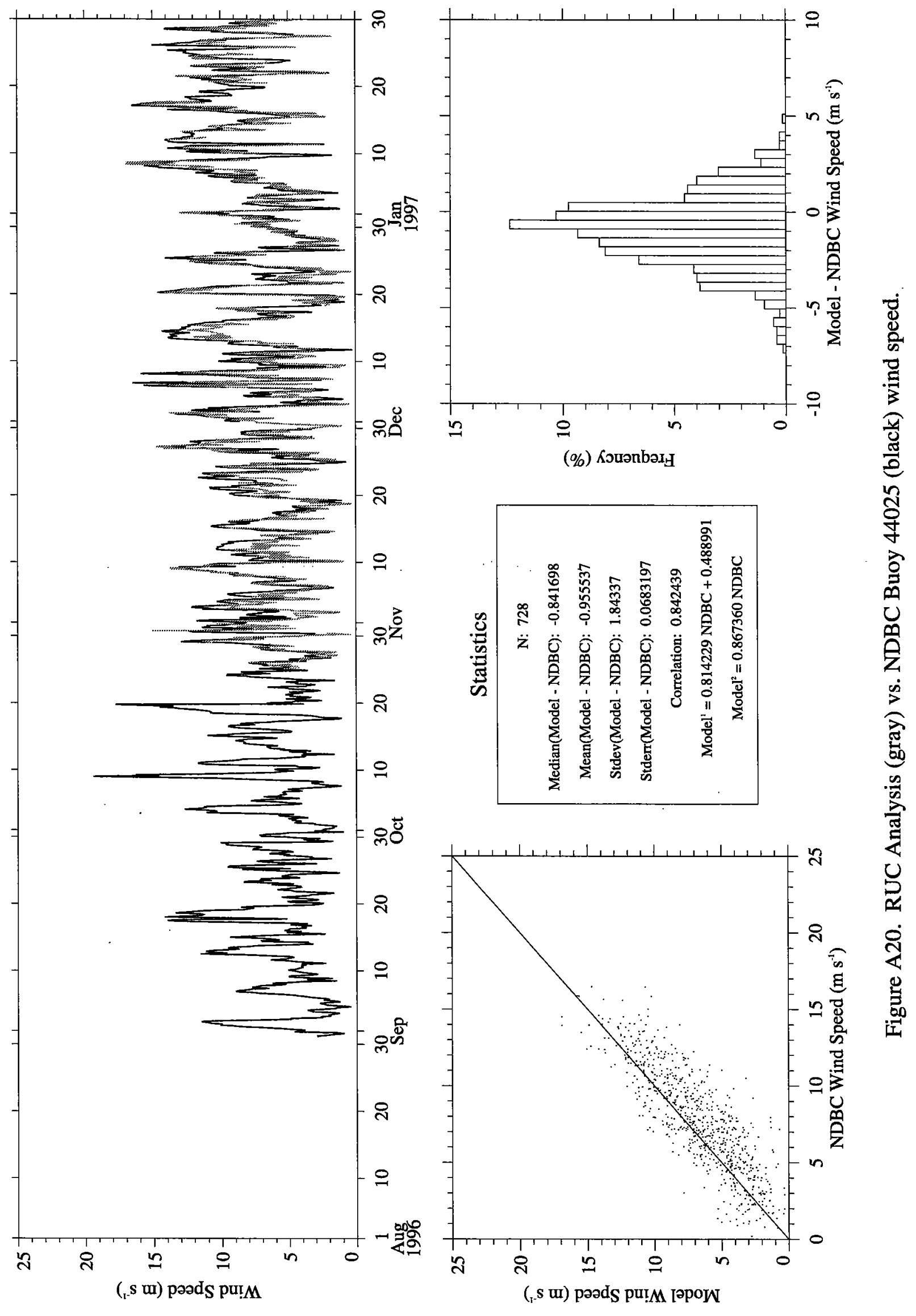



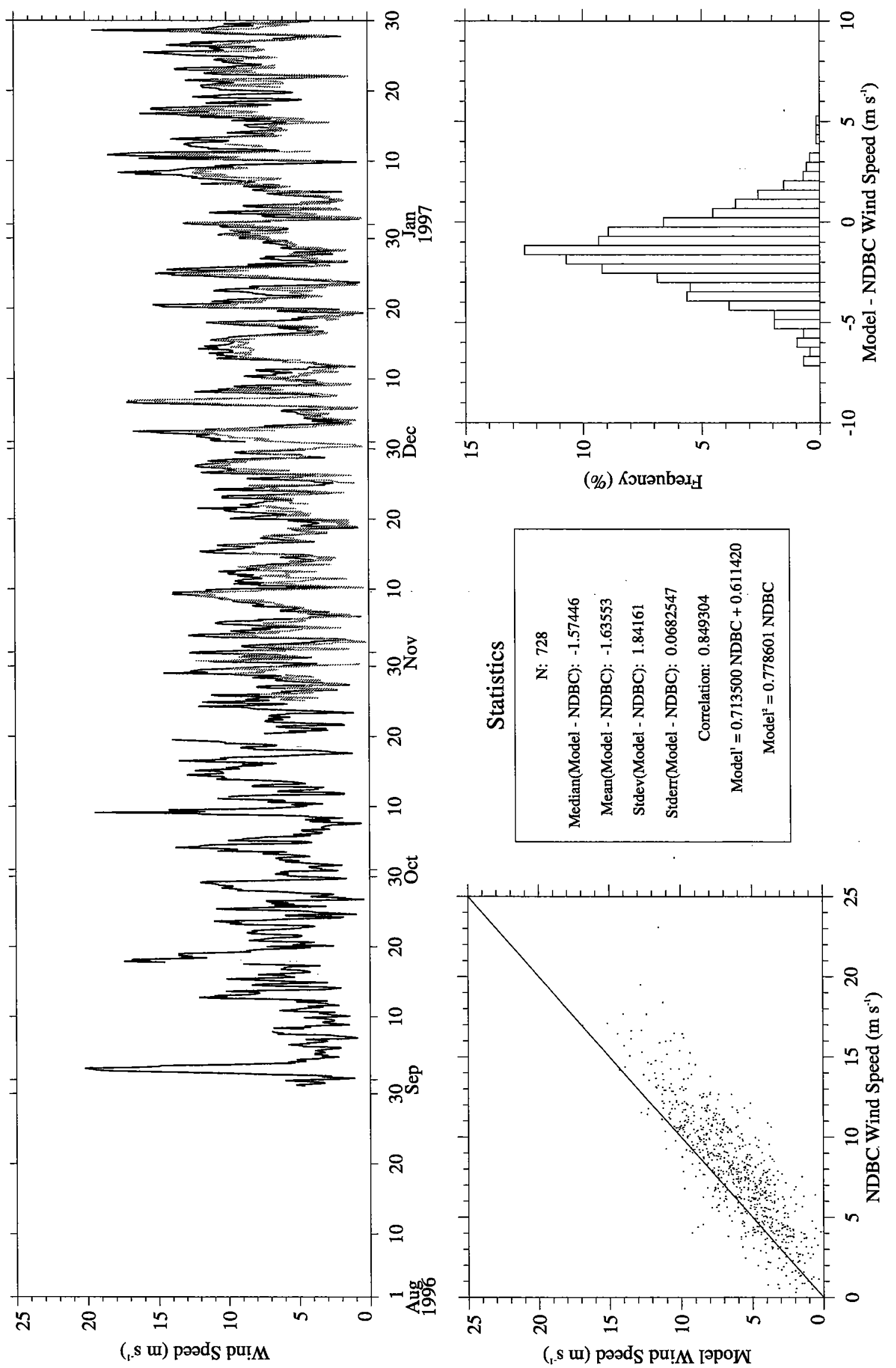

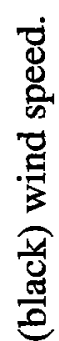

ণั
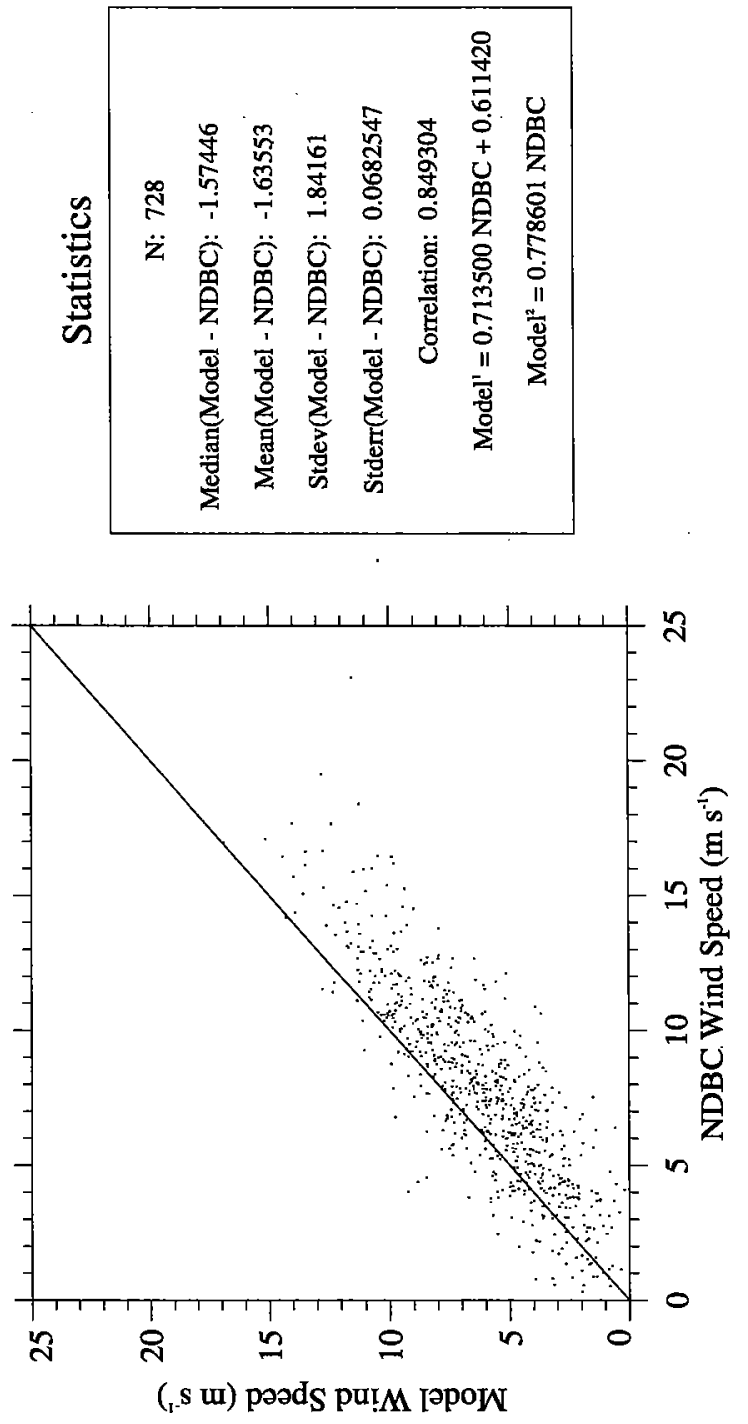

荅

걱

$\stackrel{0}{0}$

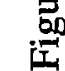




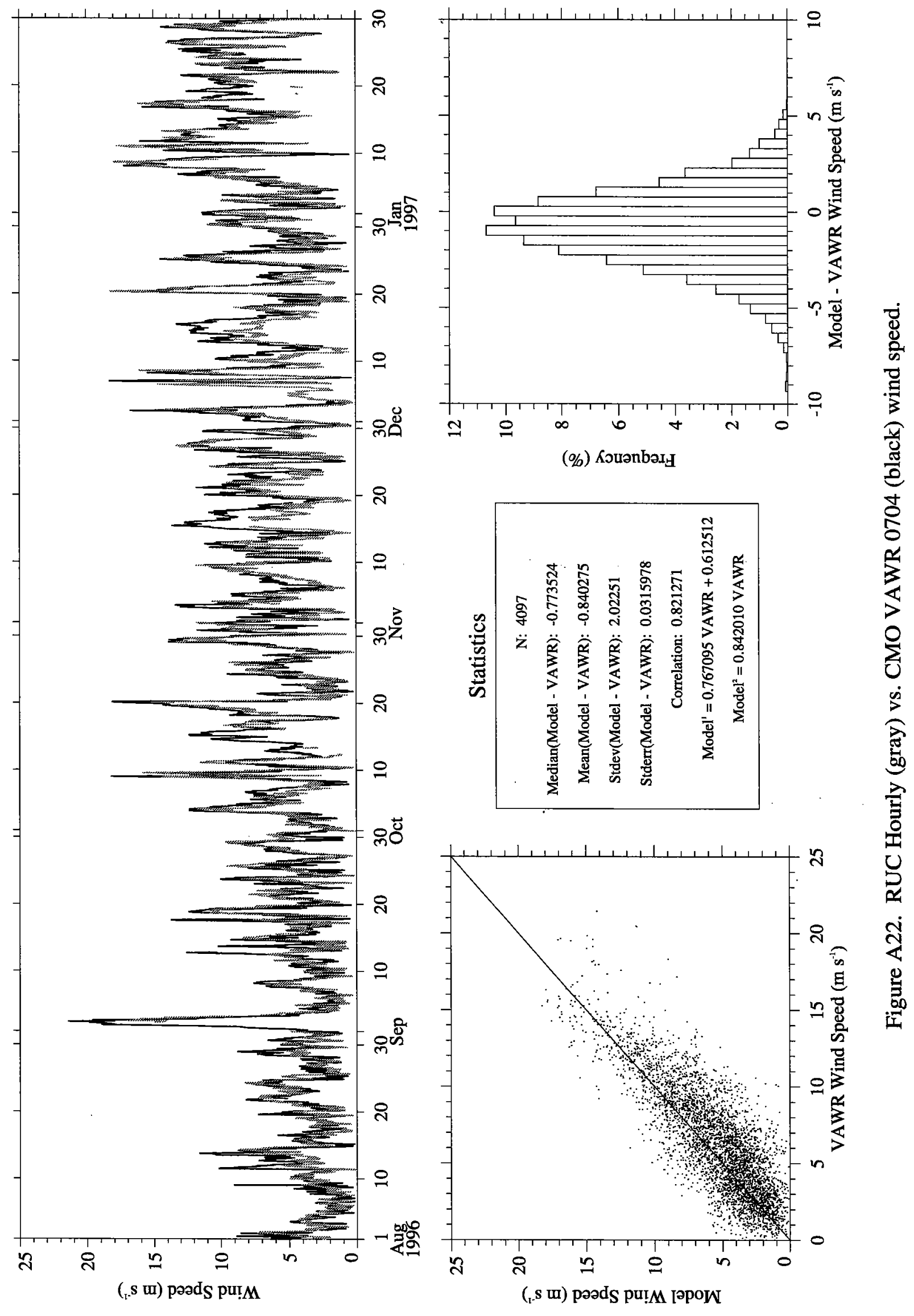



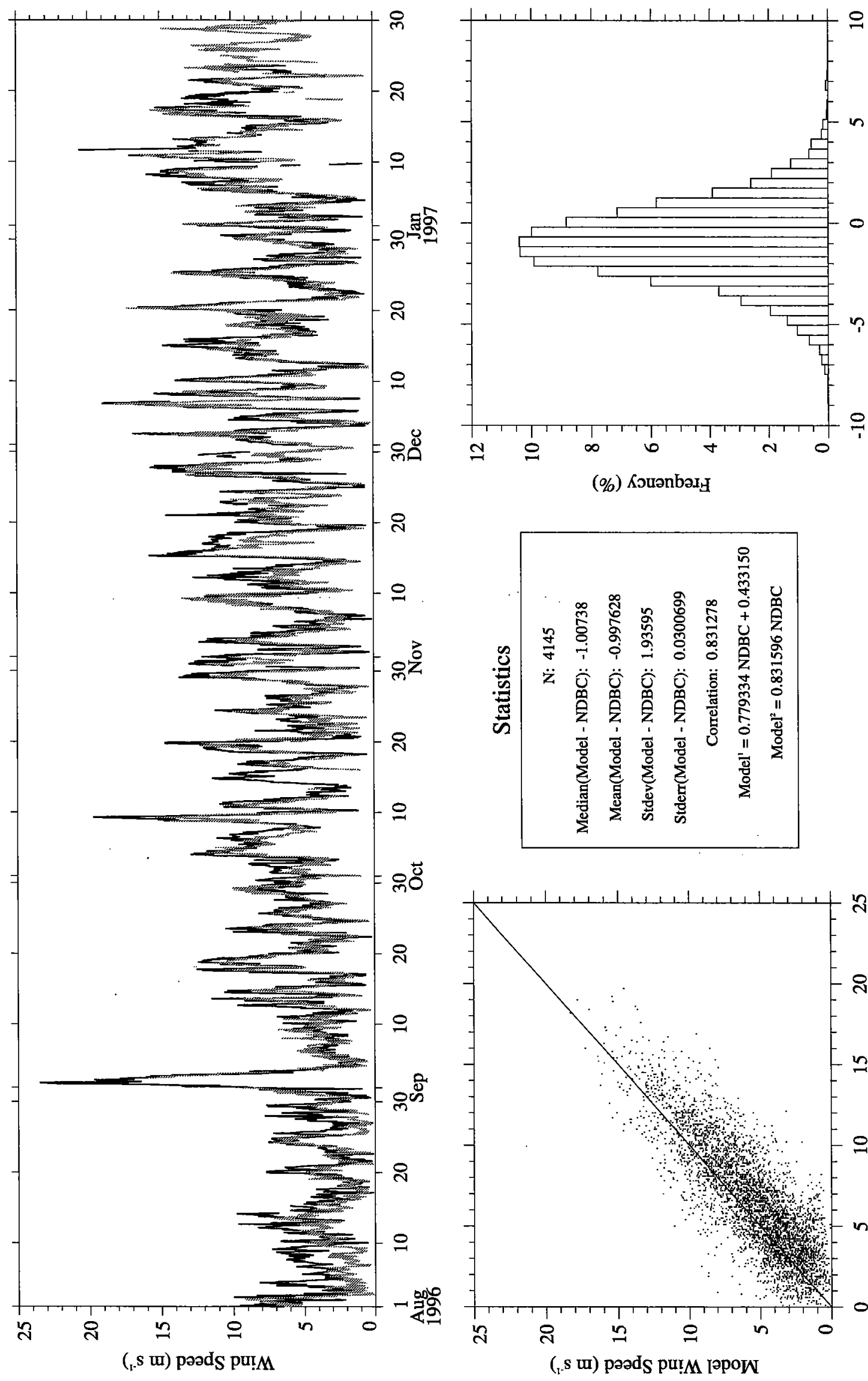

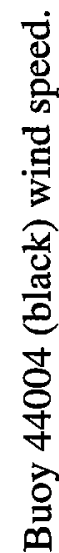

(\%) KouənbəxH
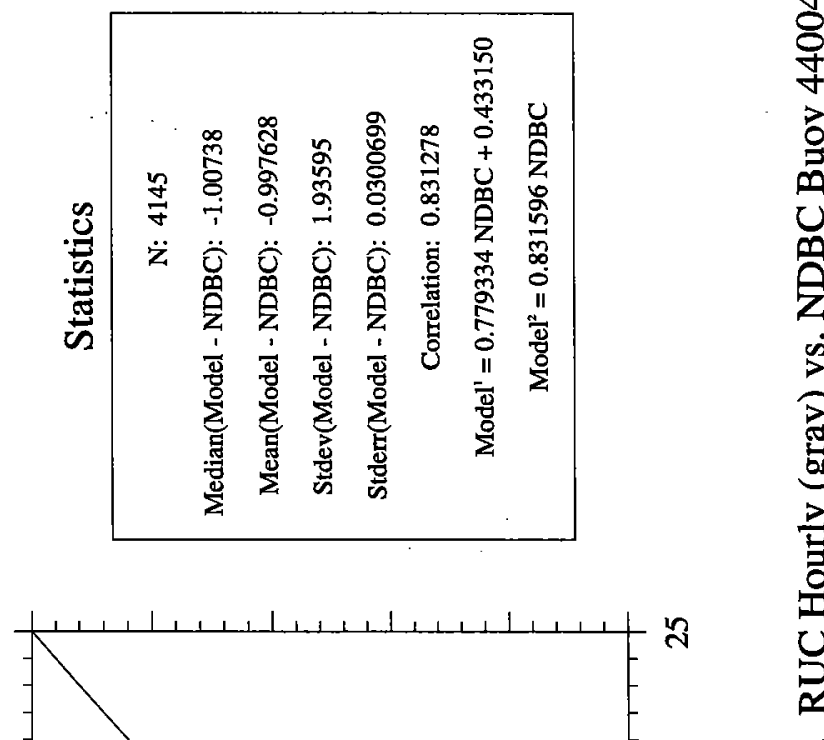

워

क 2
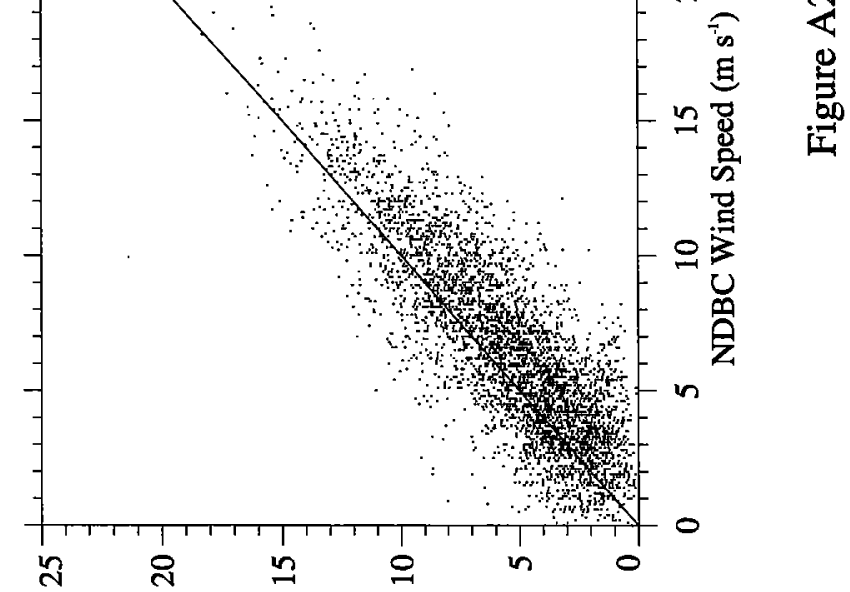

(r.s w) paads pu!M Iәpow 

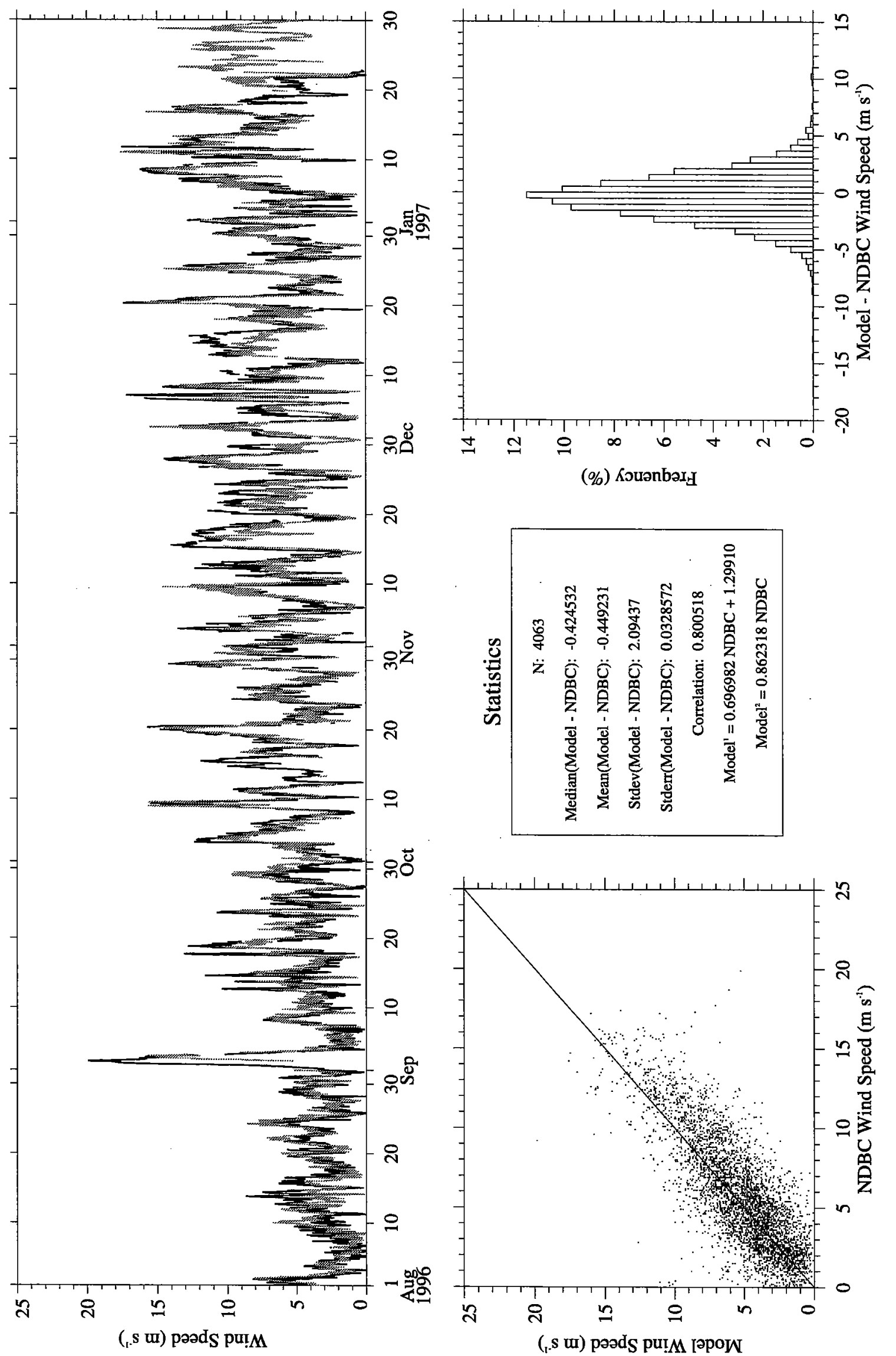

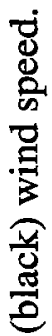
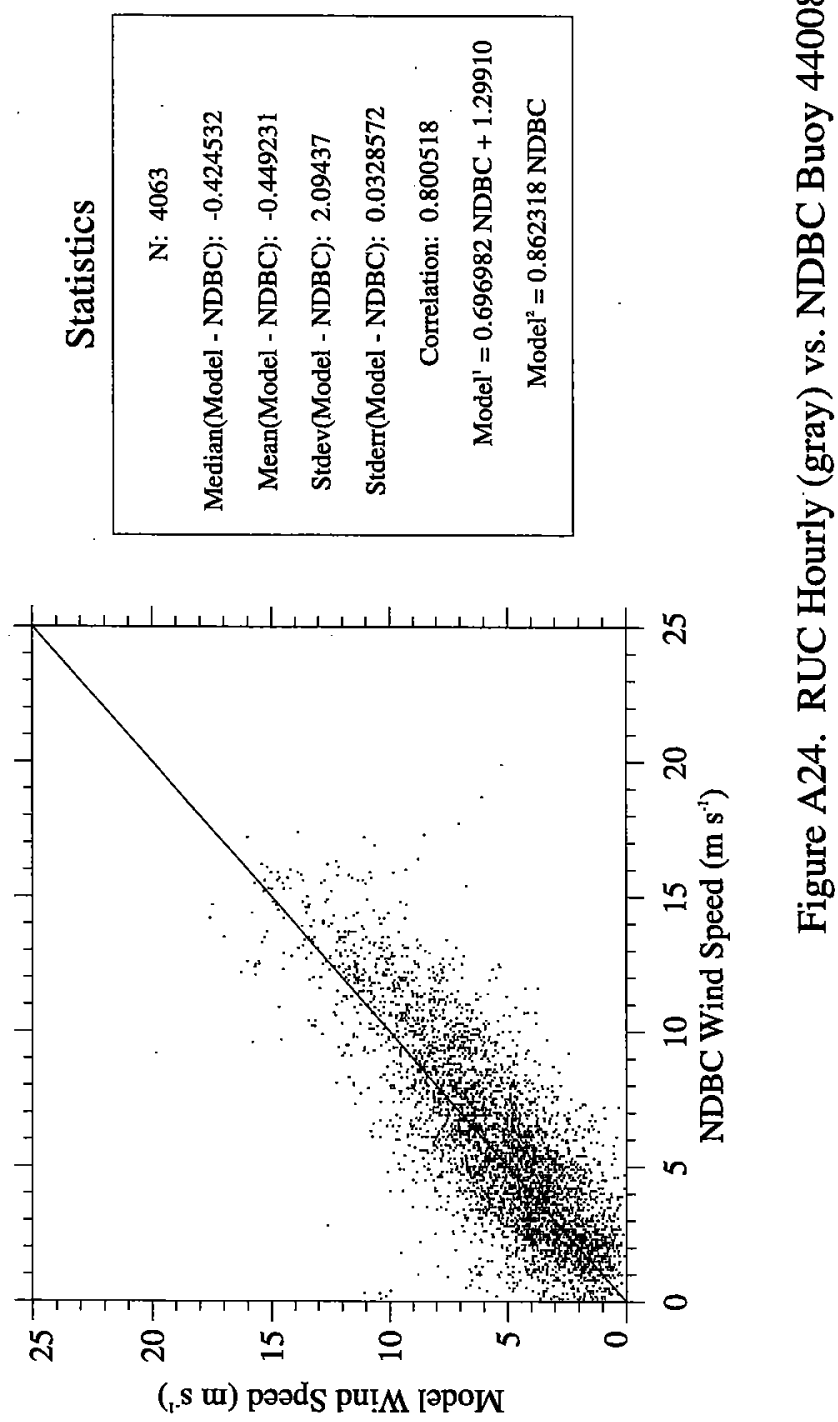

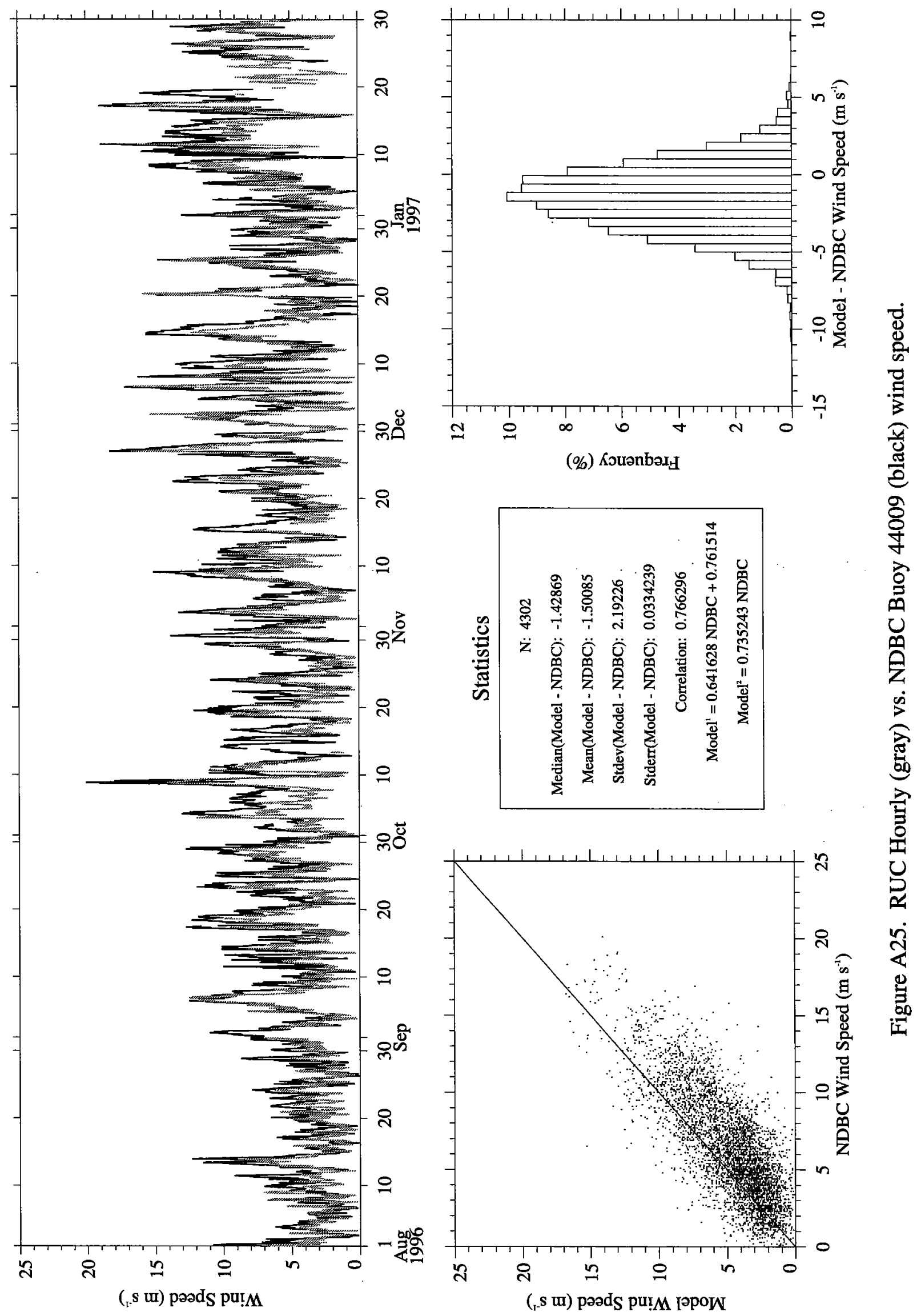


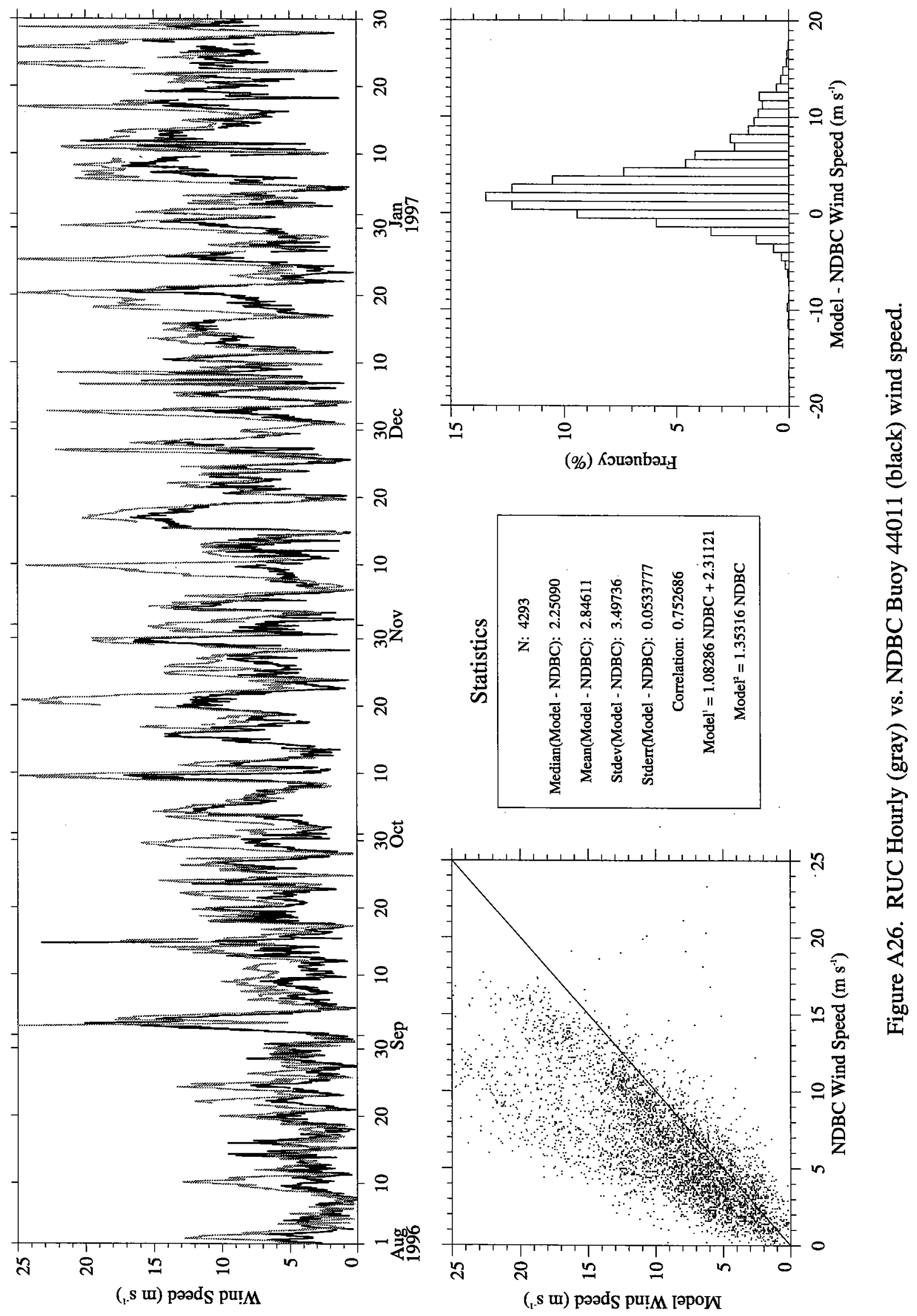



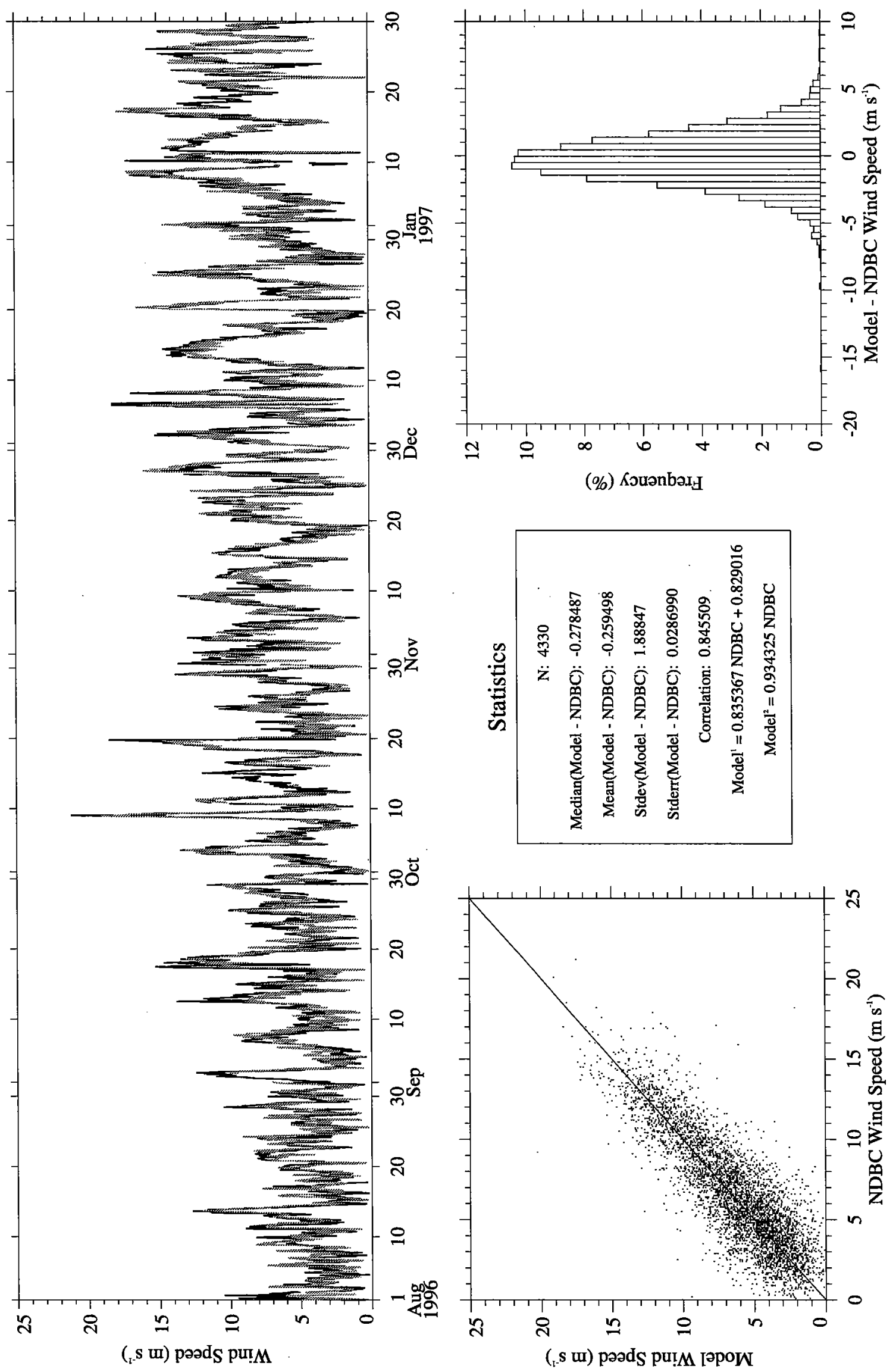

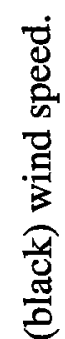

ชิำ
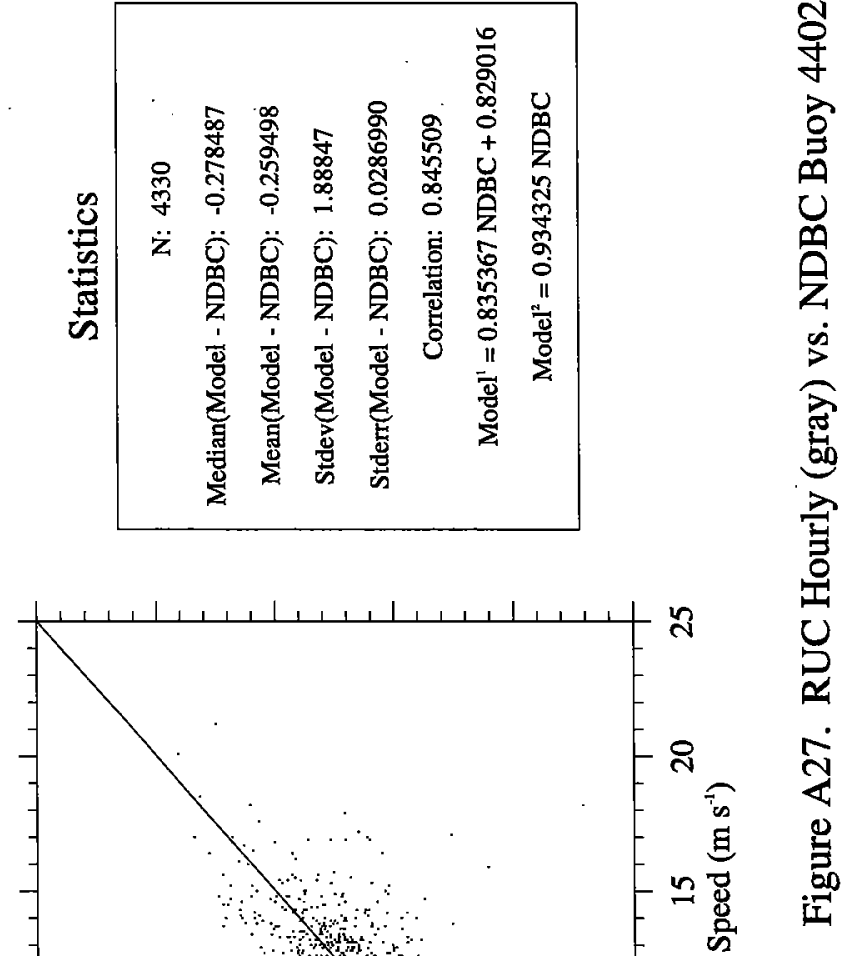

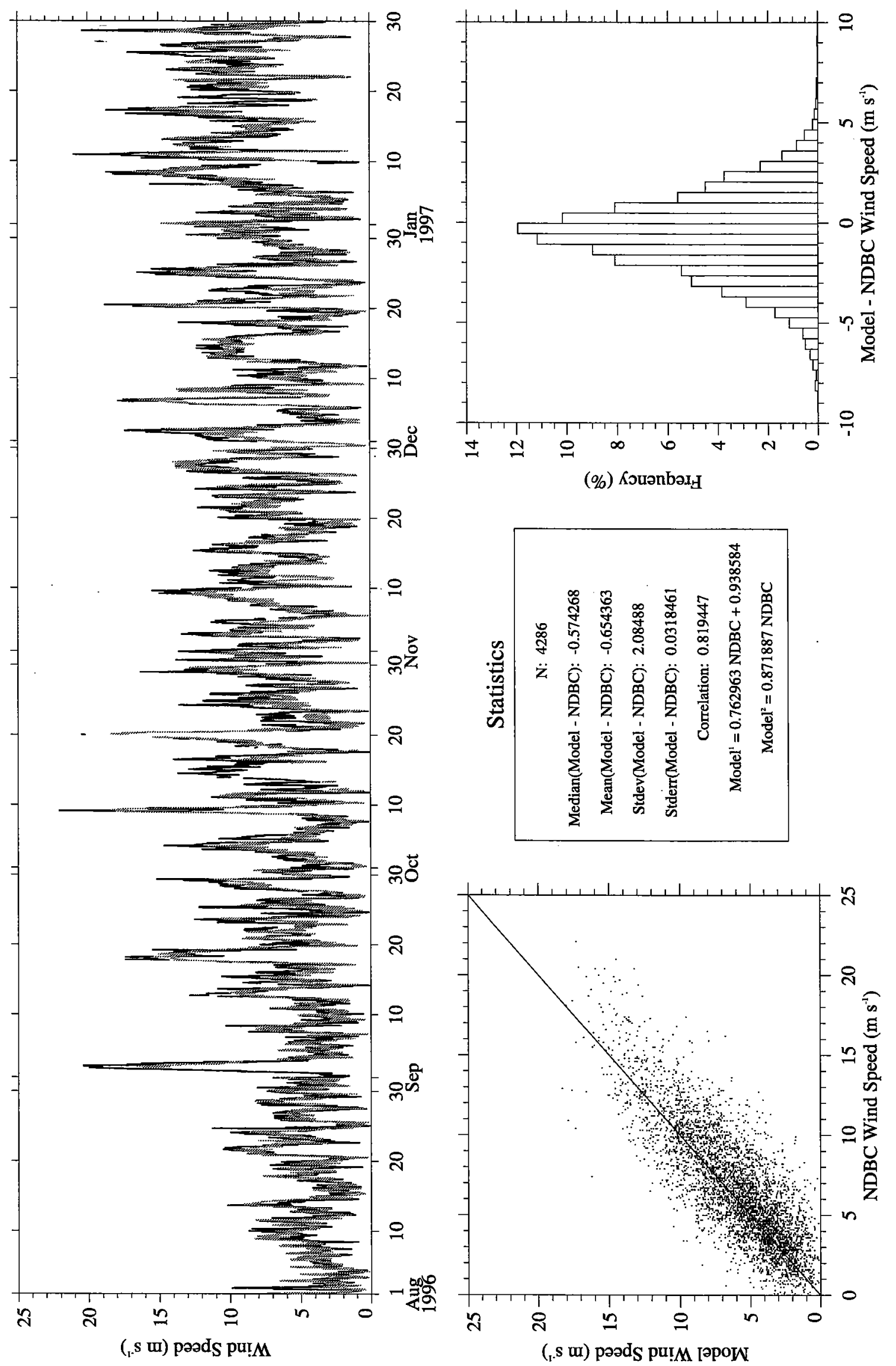

कृ
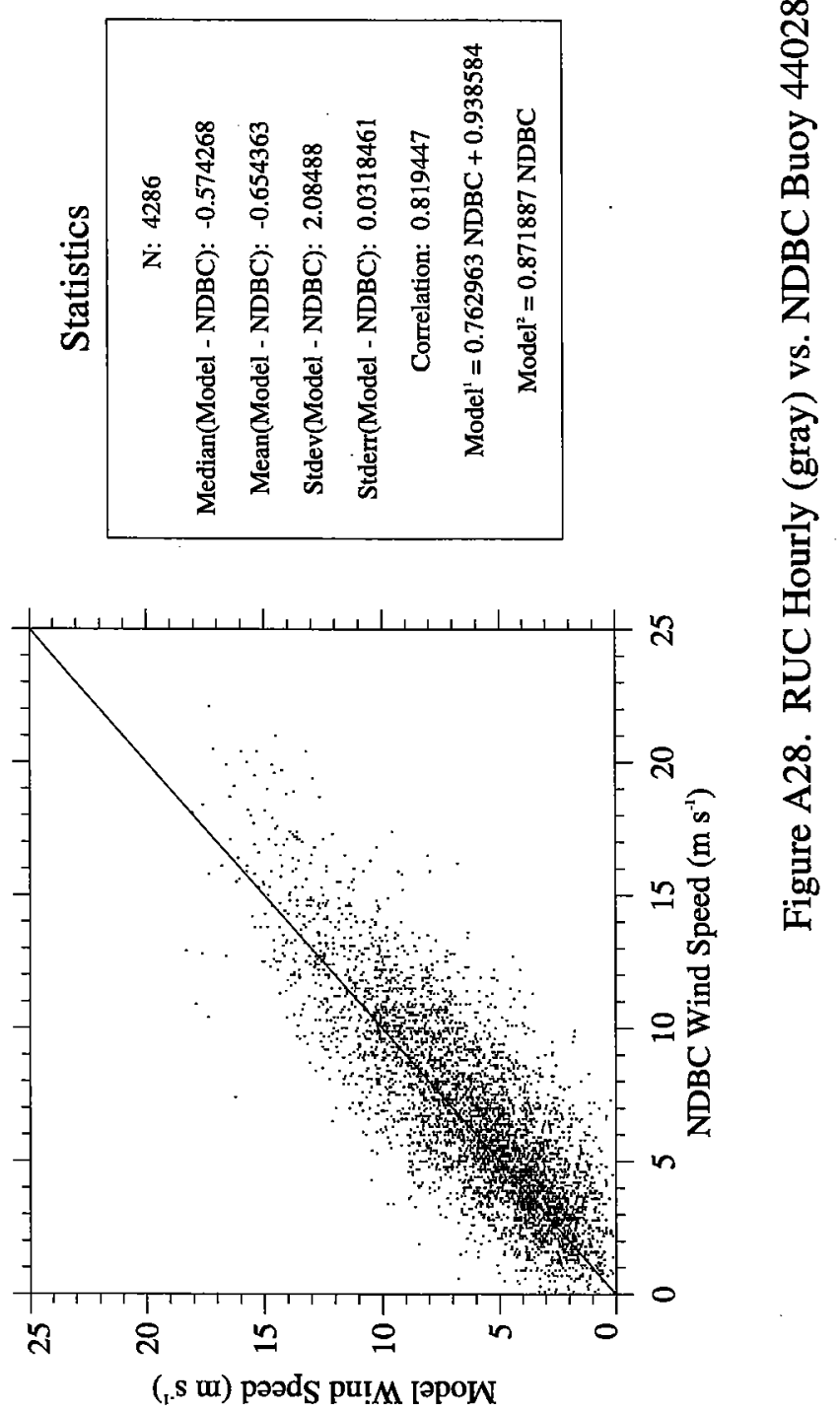


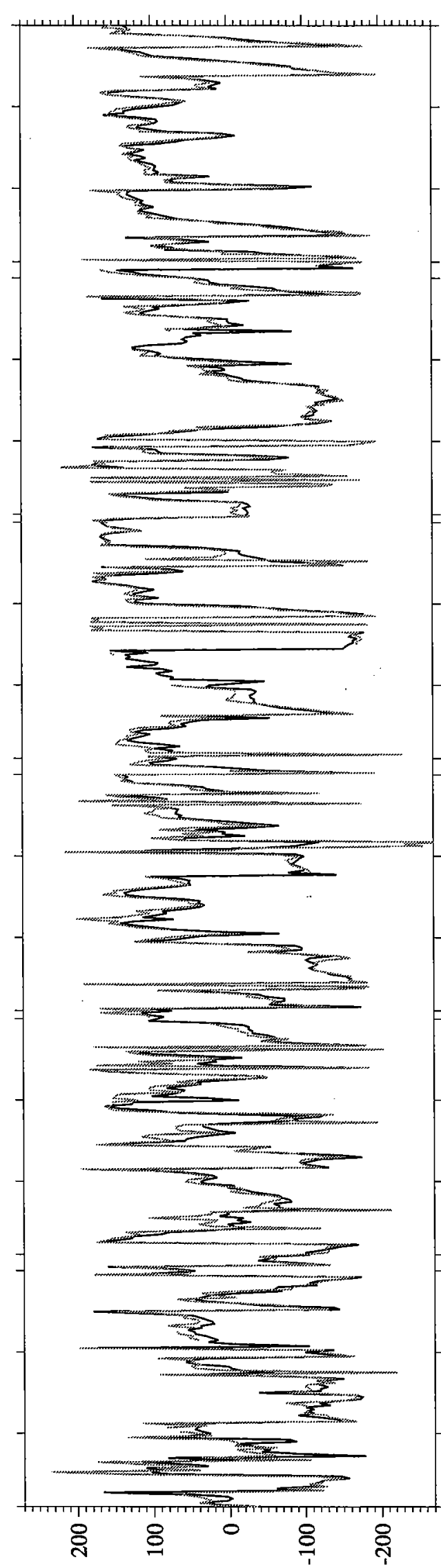

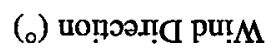

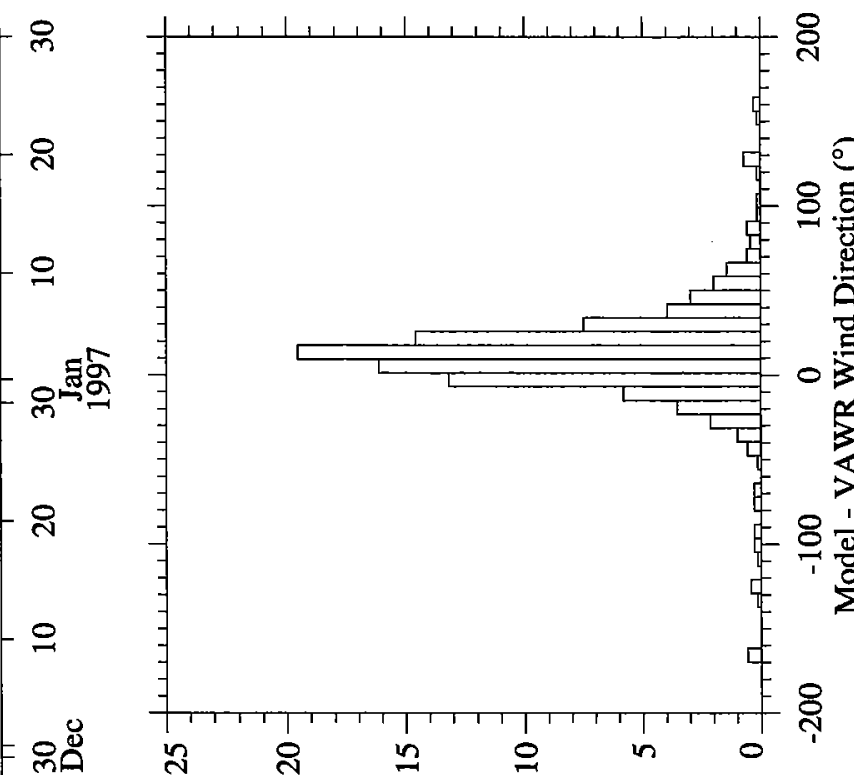

(\%) KouənbəIH

ิ

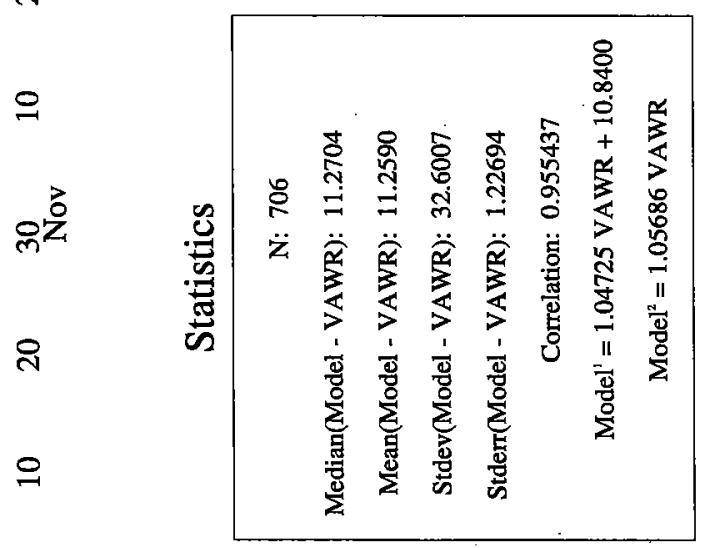

8ర
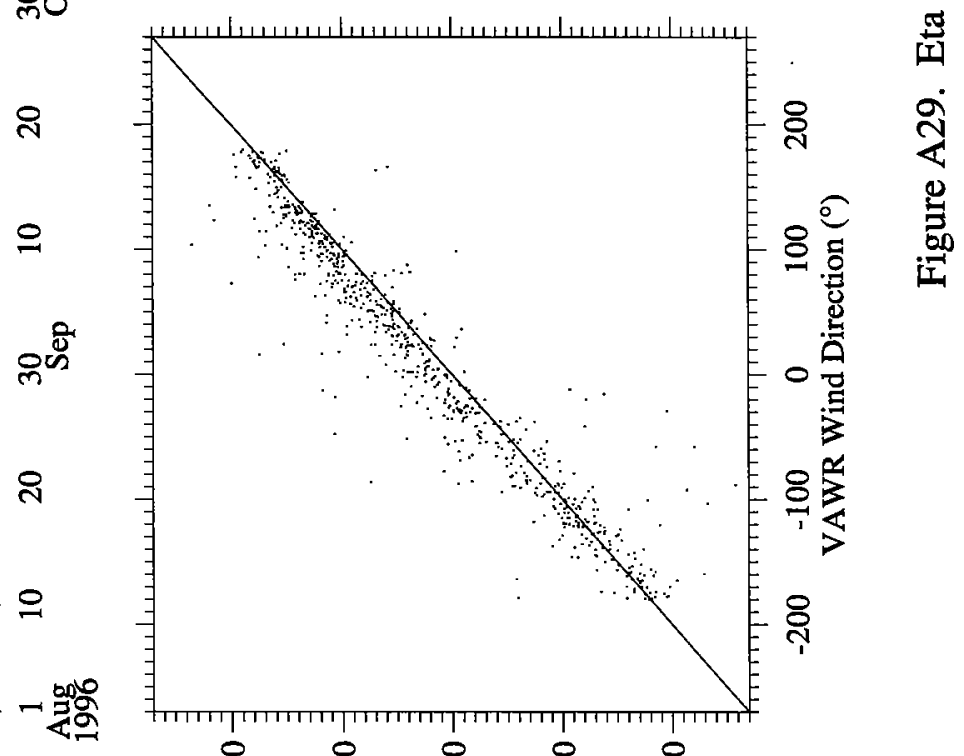

유 \& 8 \&

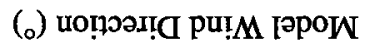




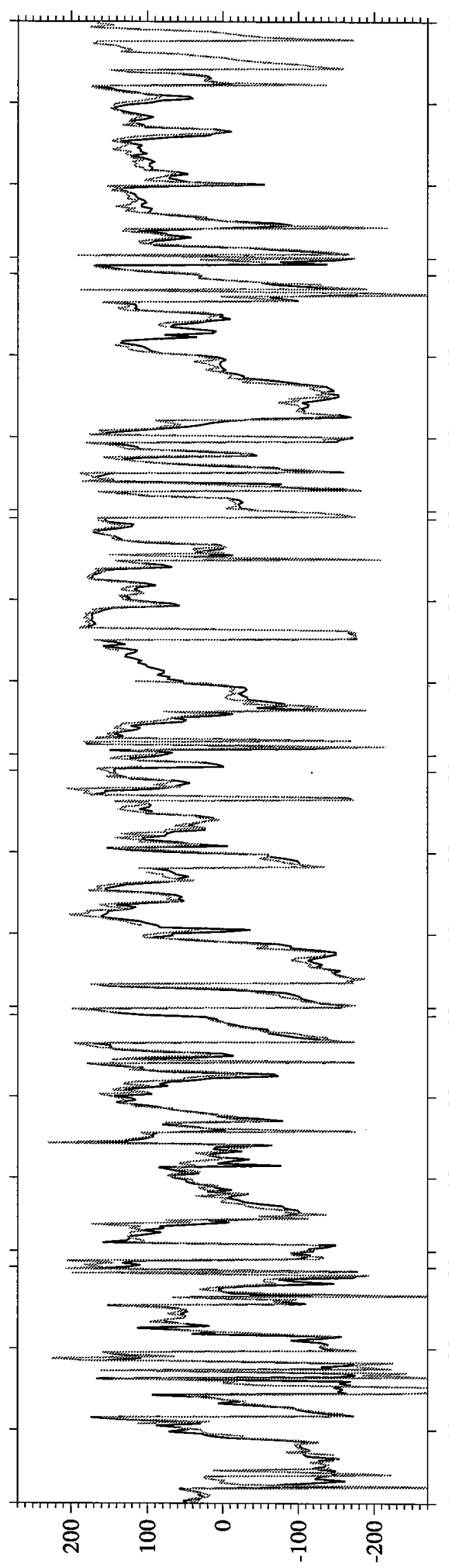

(.) นо!̣ววп! рu!M
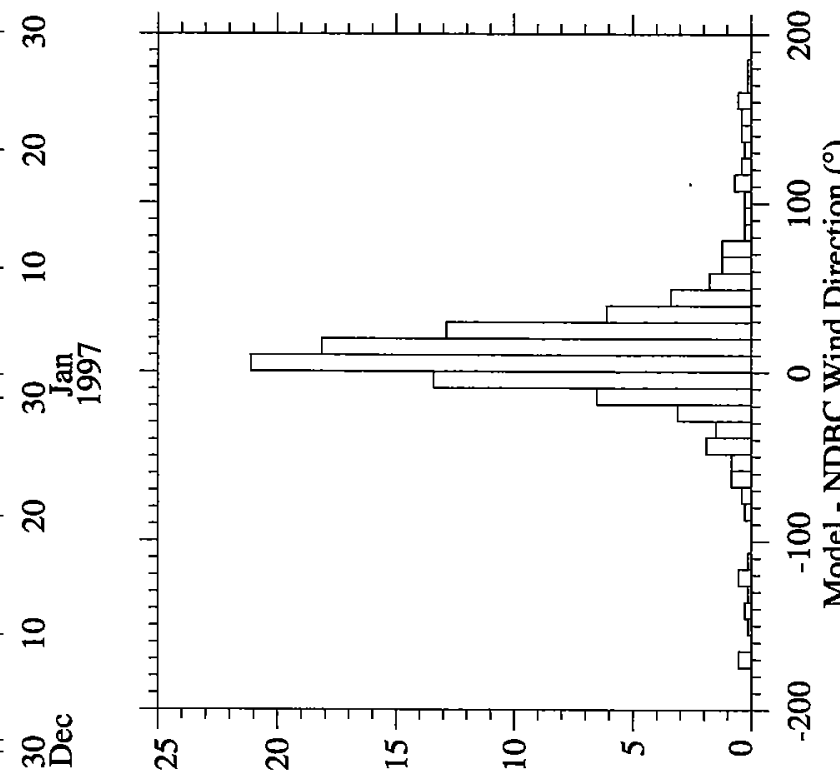

(\%) KouənbəIH

กิ

음

율

กิ

웅

ஜర్ర

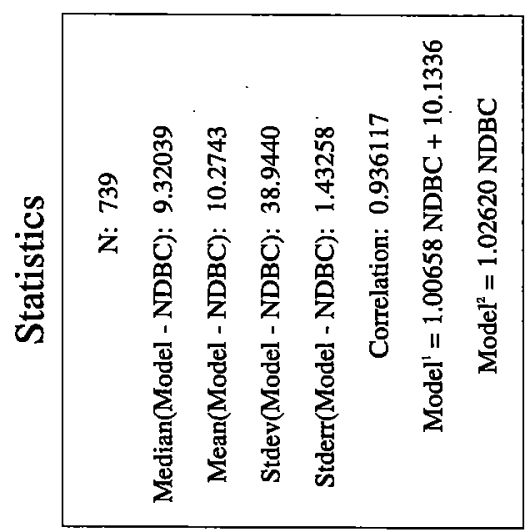

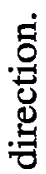

量

yㅜㅇ

胥

守

ลิำ

บ

角

$\dot{m}$

突

a

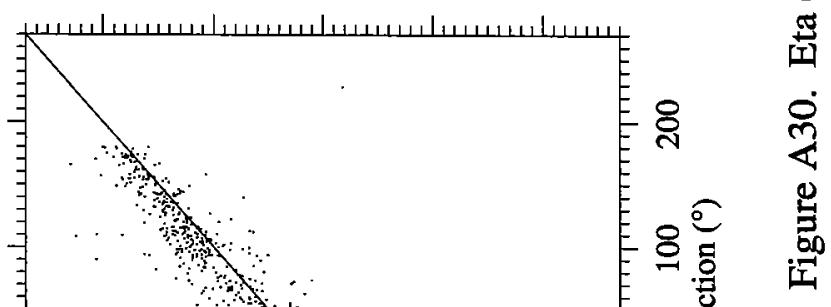

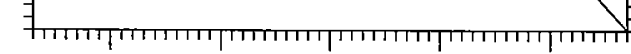

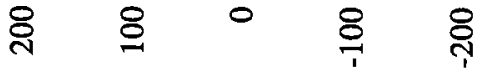

(о) uот̣рәп! рu!M Iәром 


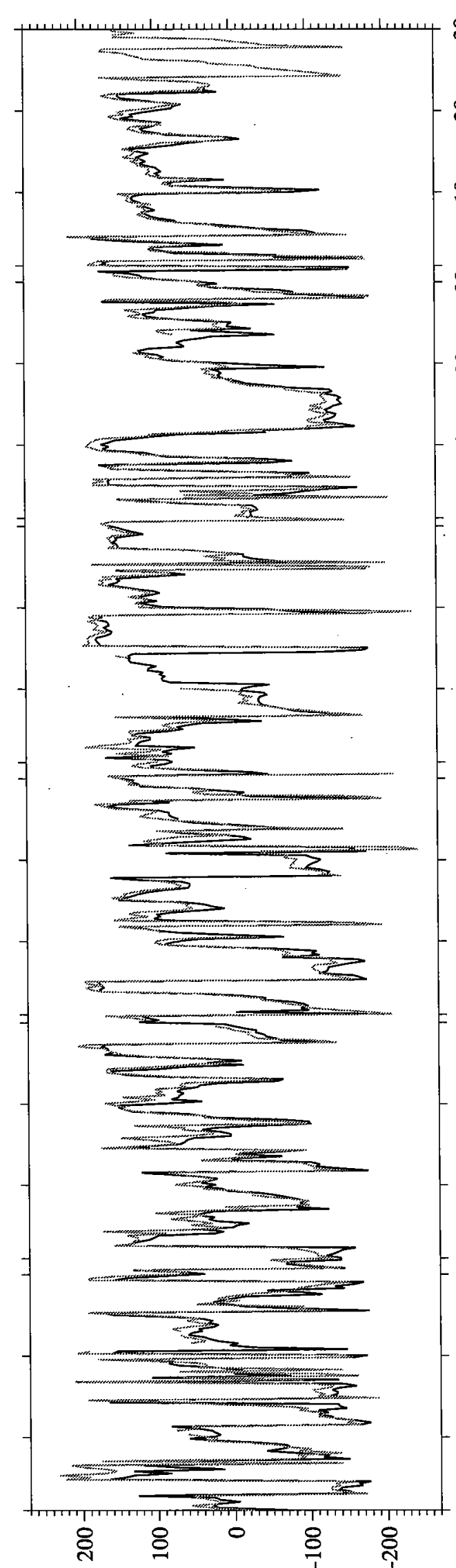

(o) uoṇoan! pu!M

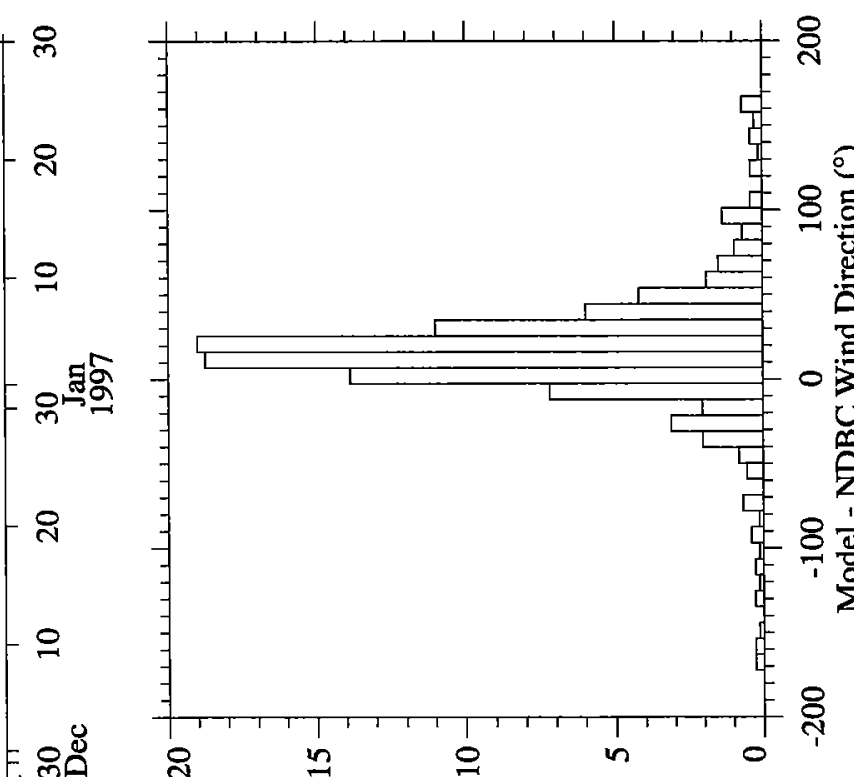

(\%) КоuэnbaدH

จิ

음

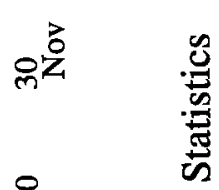

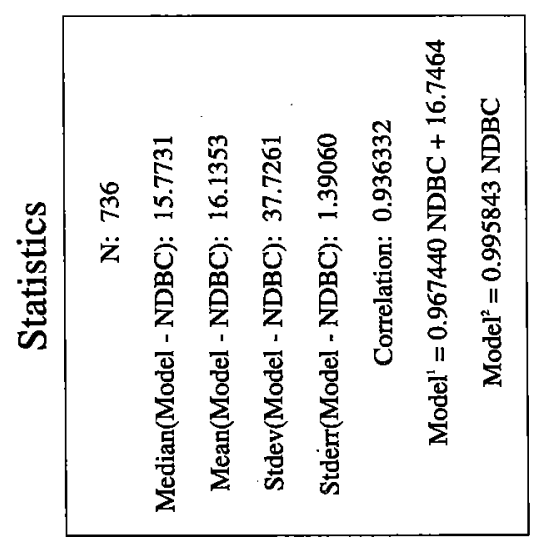

总

官

官

음

e



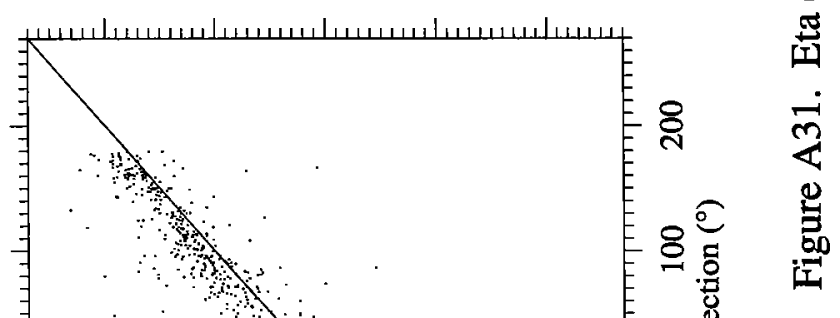

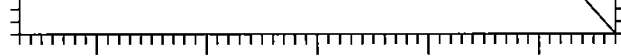

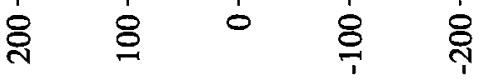

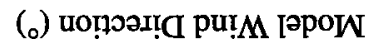




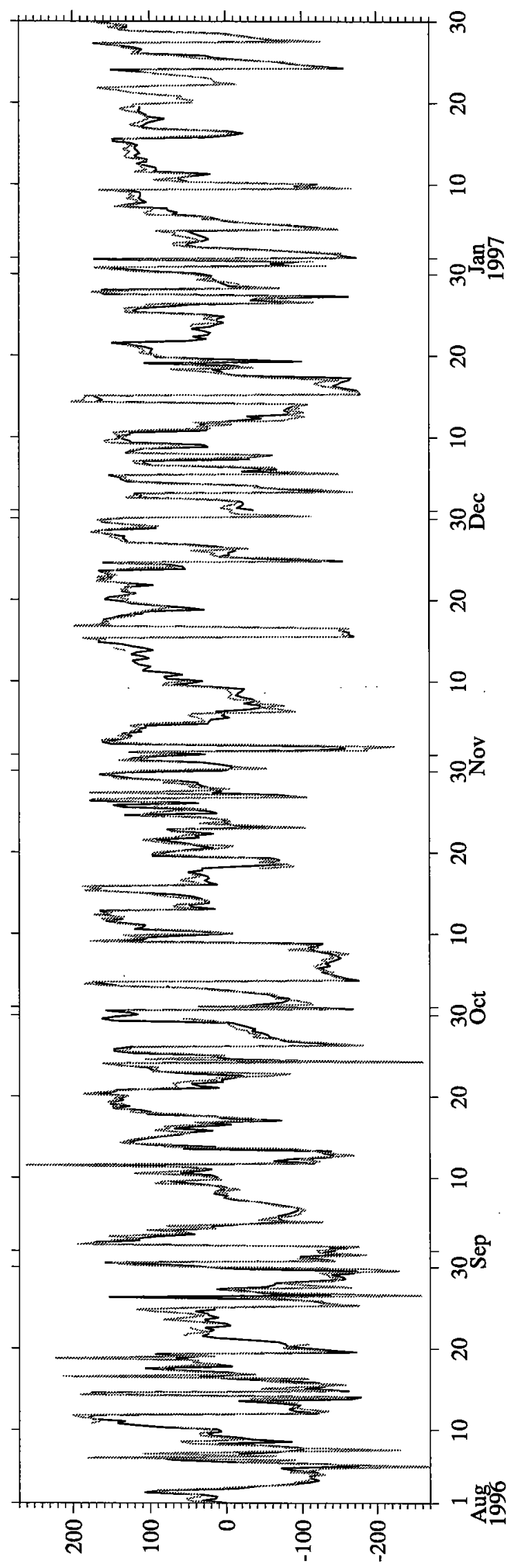

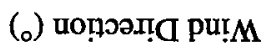

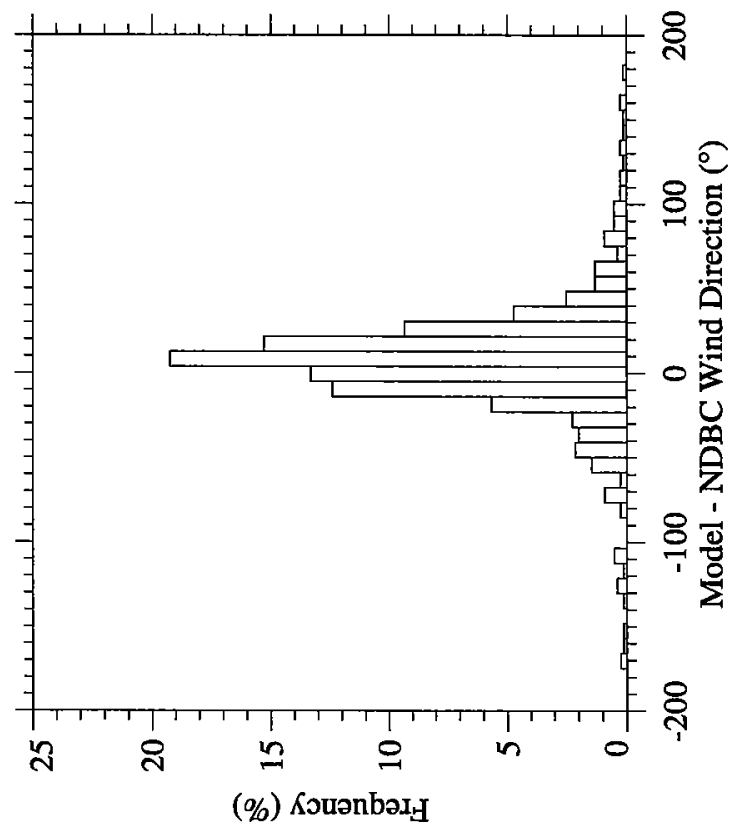

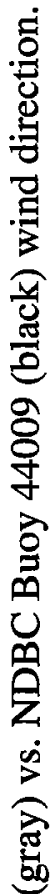

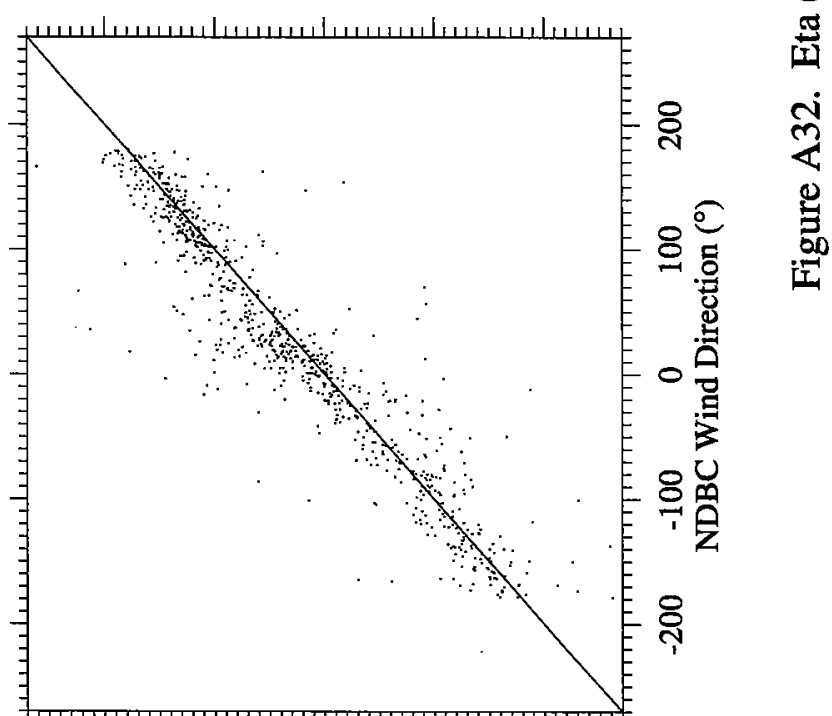

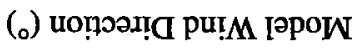




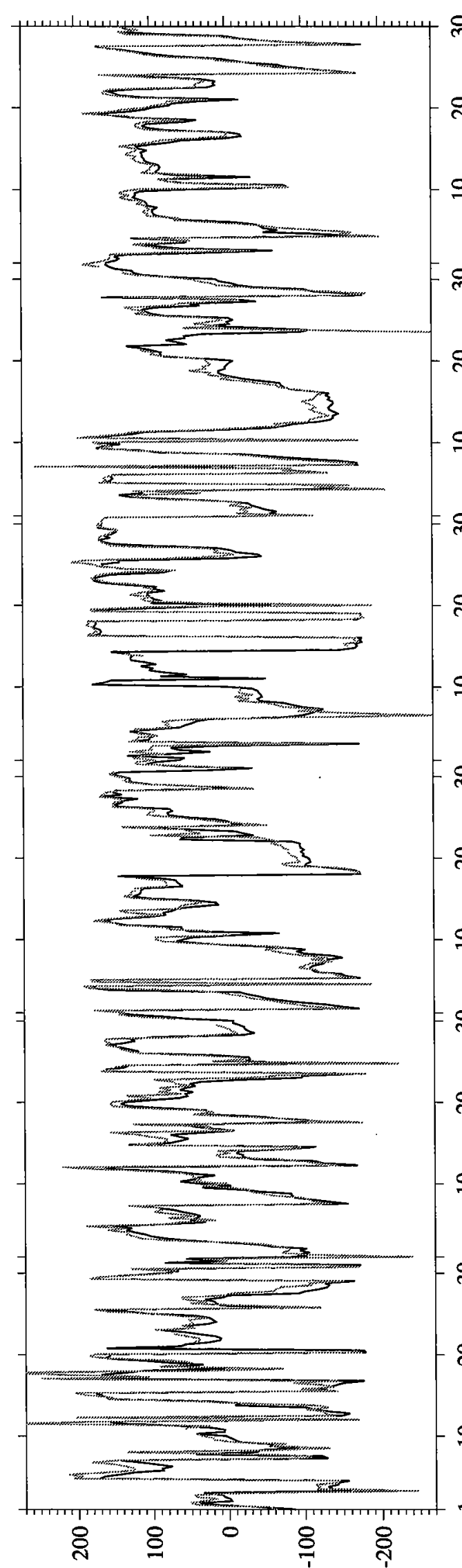

(о) иопюәпа рu!м

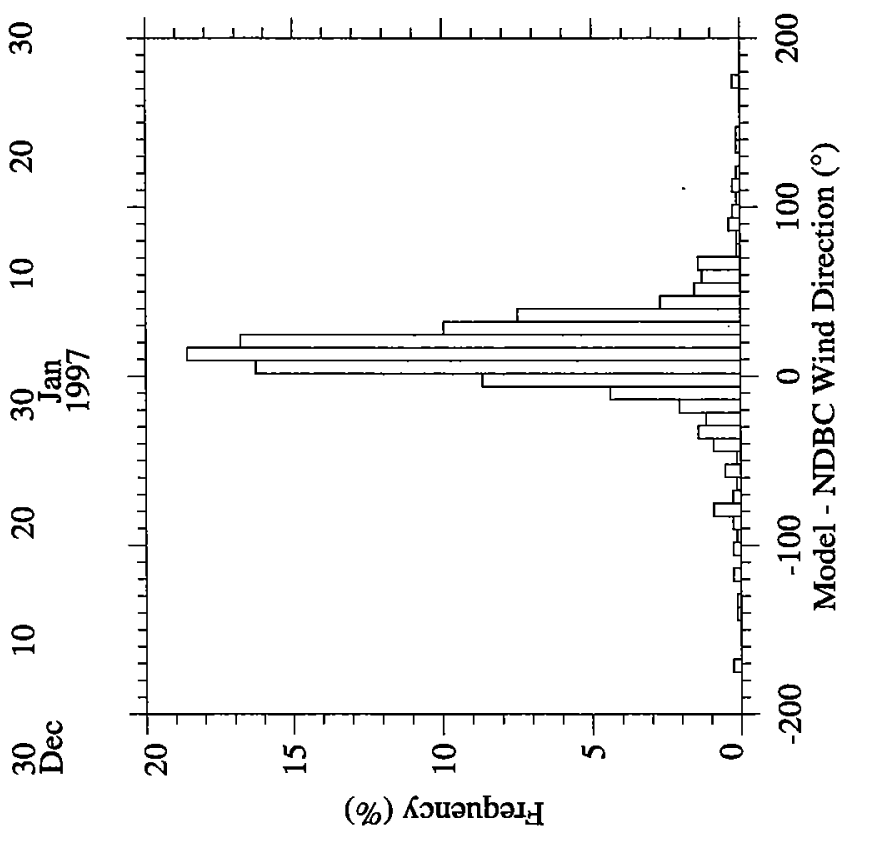

우

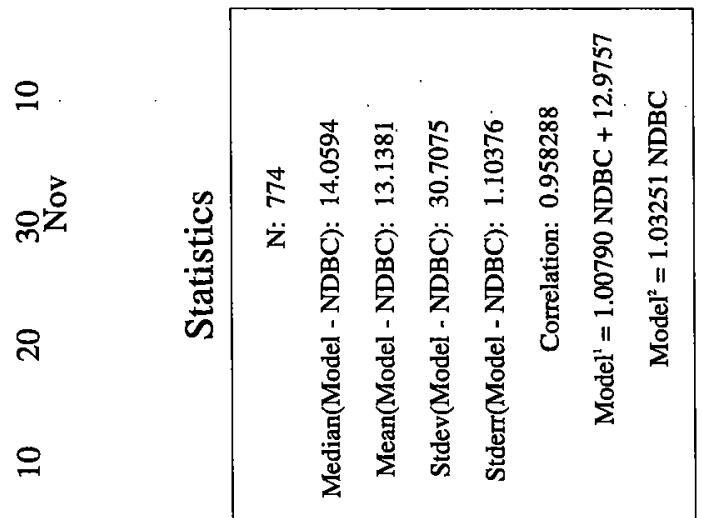

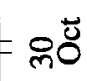
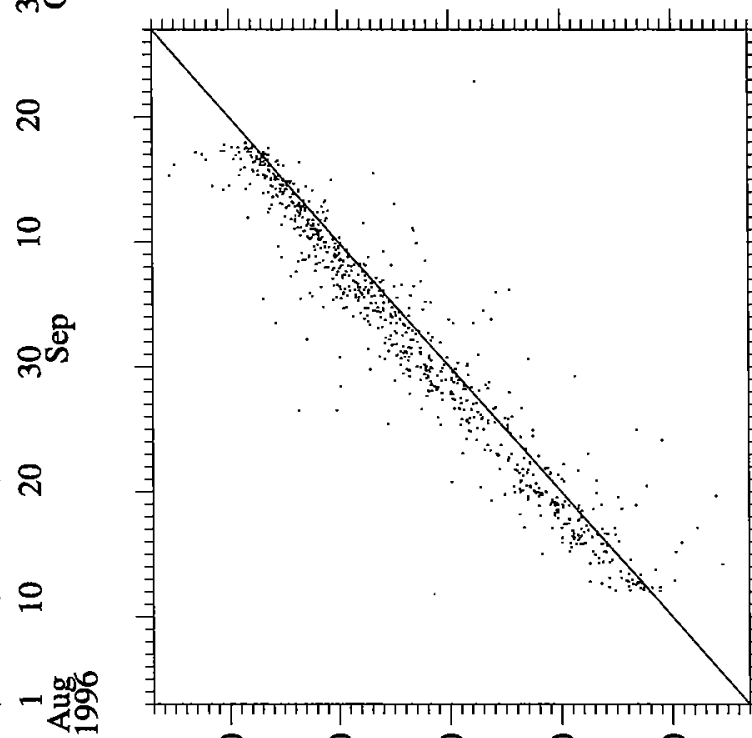

雳

ช ले

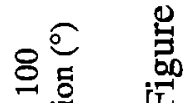

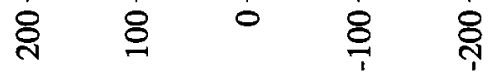

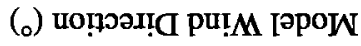




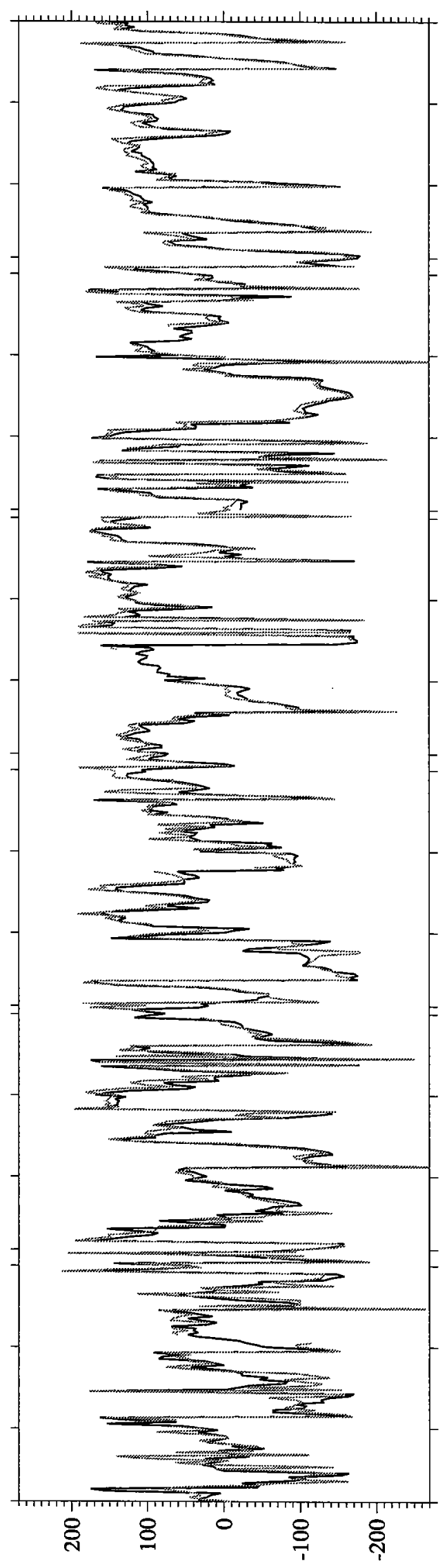

(。) uo!̣๗ə!̣ pu!M

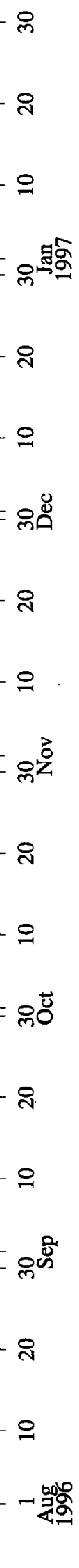

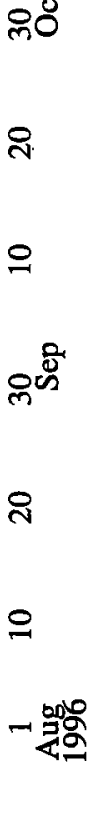

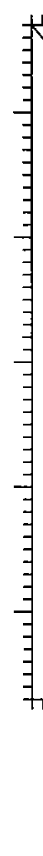

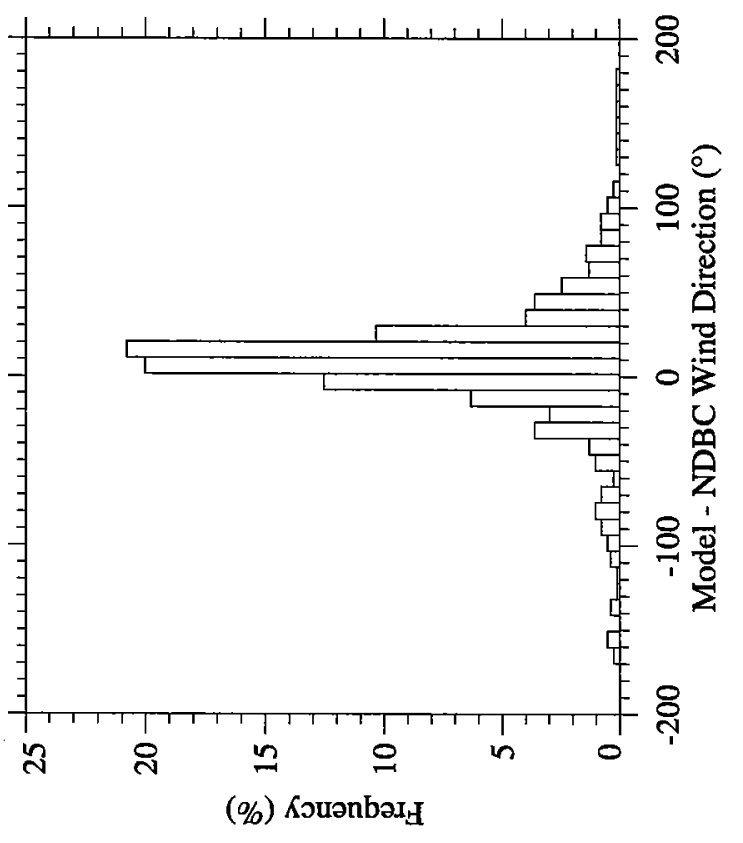

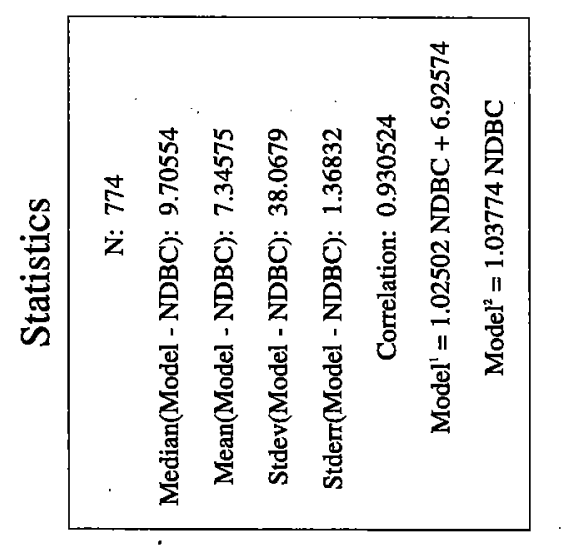

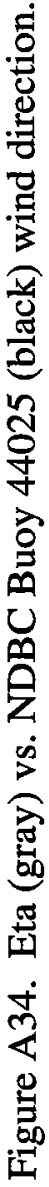




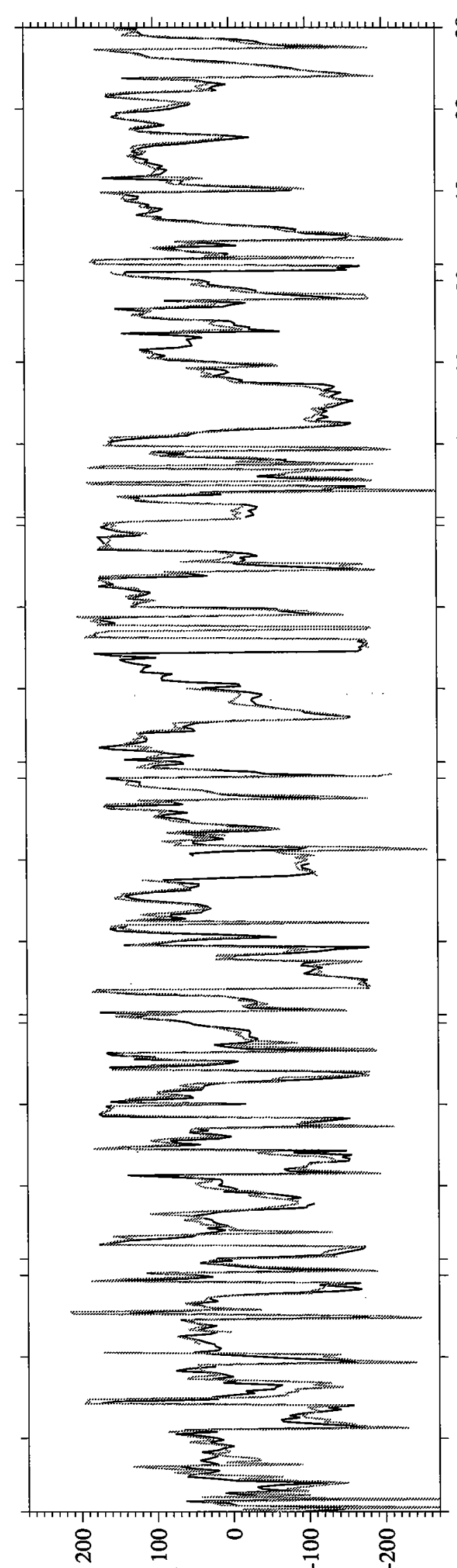

(o) uompoər! व pur:M

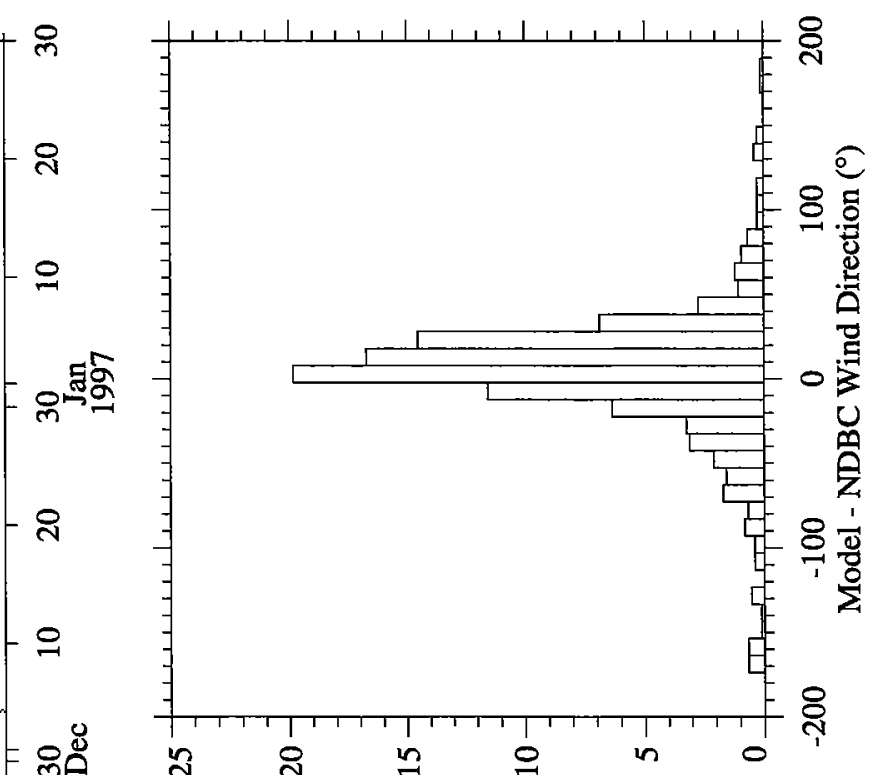

(\%) KouənbəI

สิ

응

这

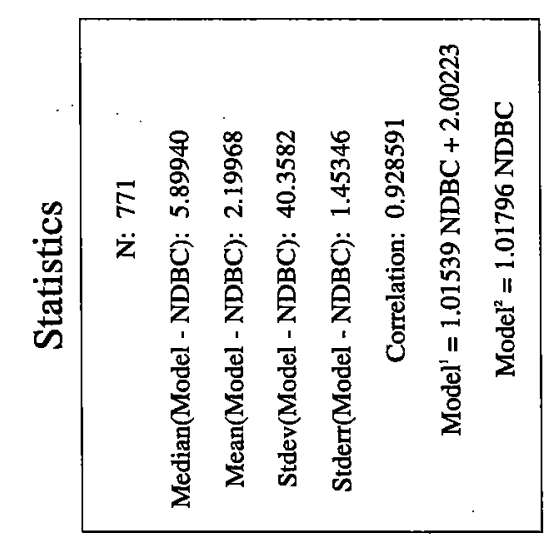

$=\infty \overline{0}$

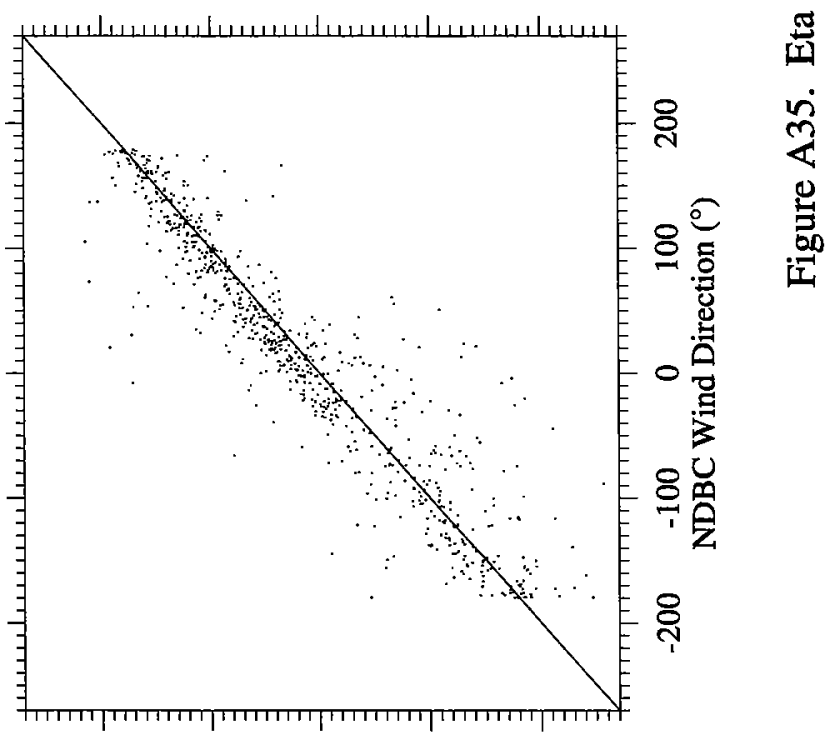

\& \& \&

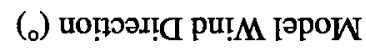




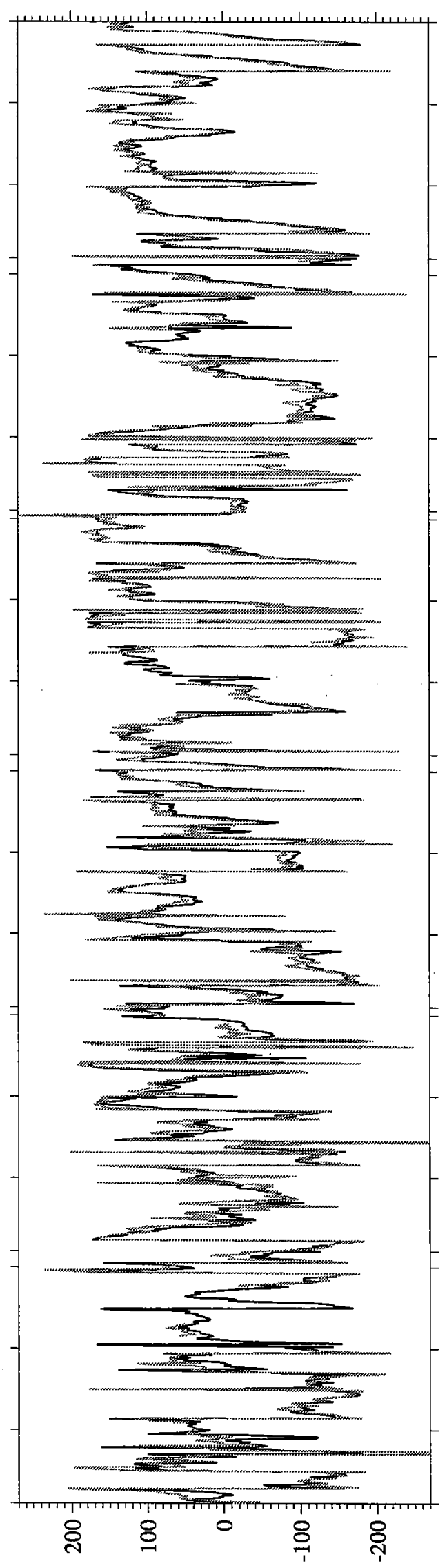

(。) uo!̣oa! व pu!M

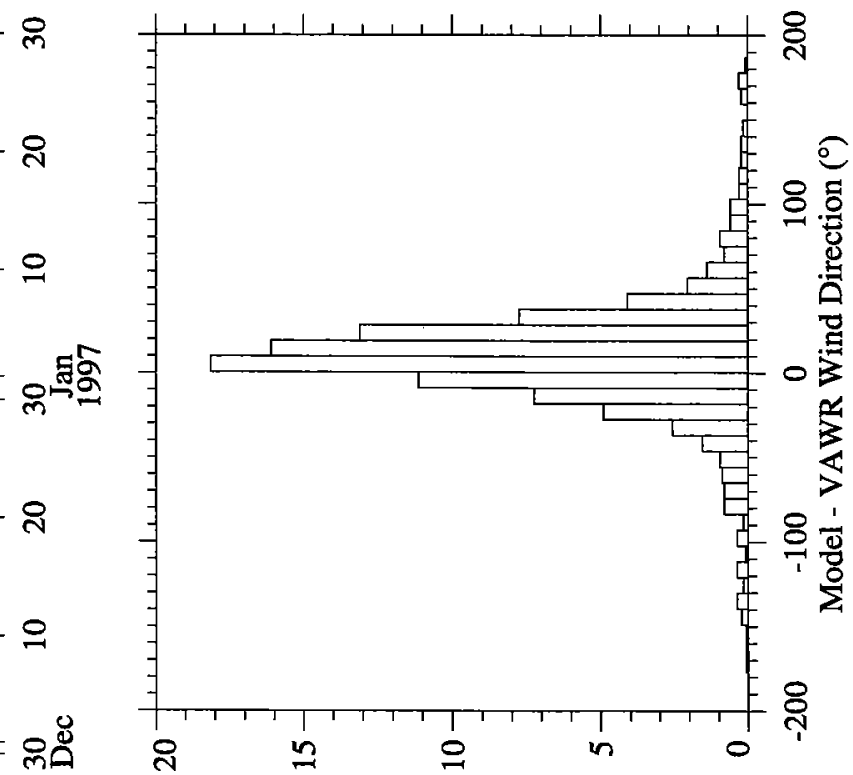

(\%) КэuənbəxH

8

오

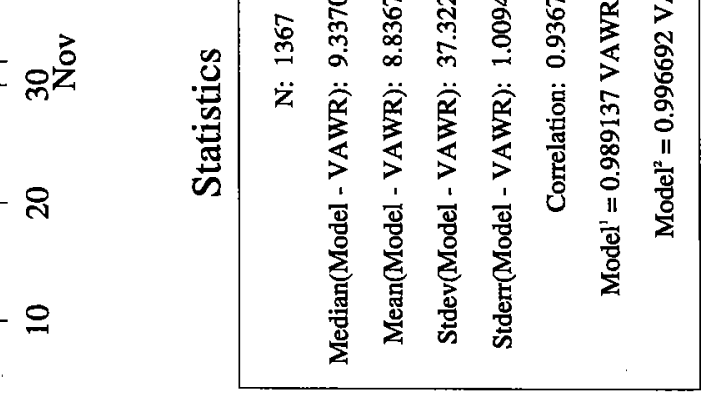

ஜัㅇ

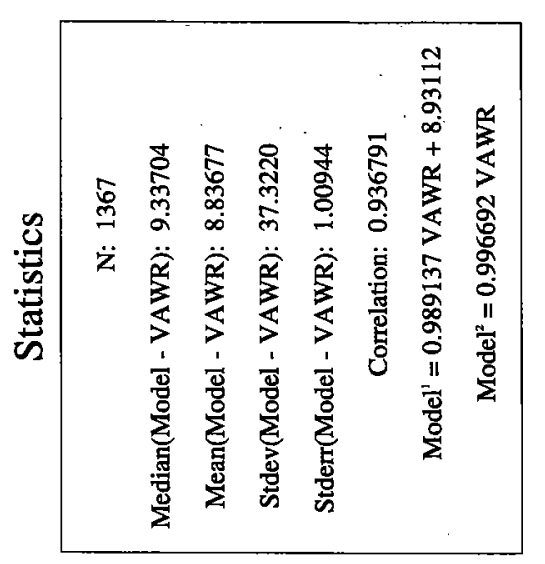

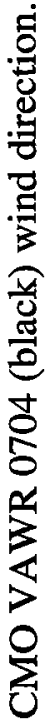

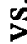

羦

a

?

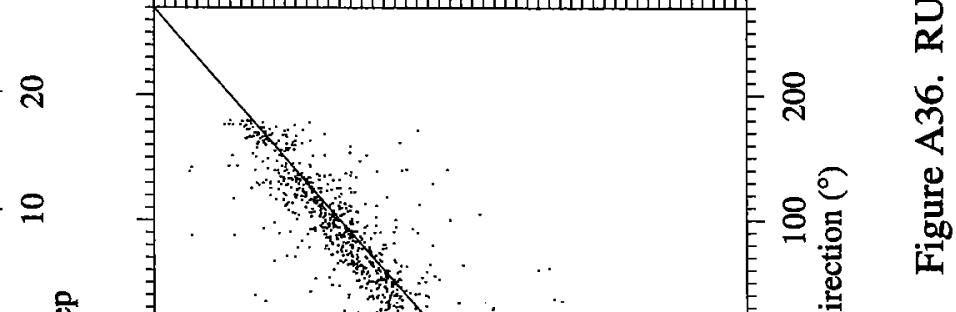

一管量

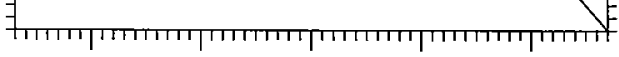

유 $80 \%$

(॰) uoṇoən! 


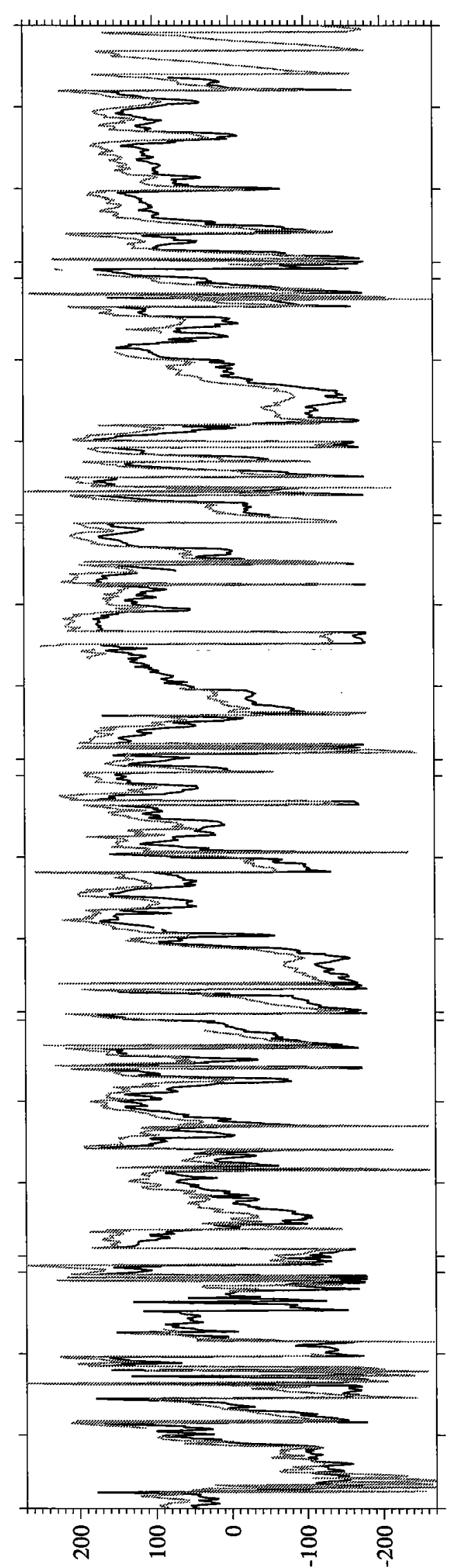

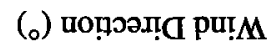

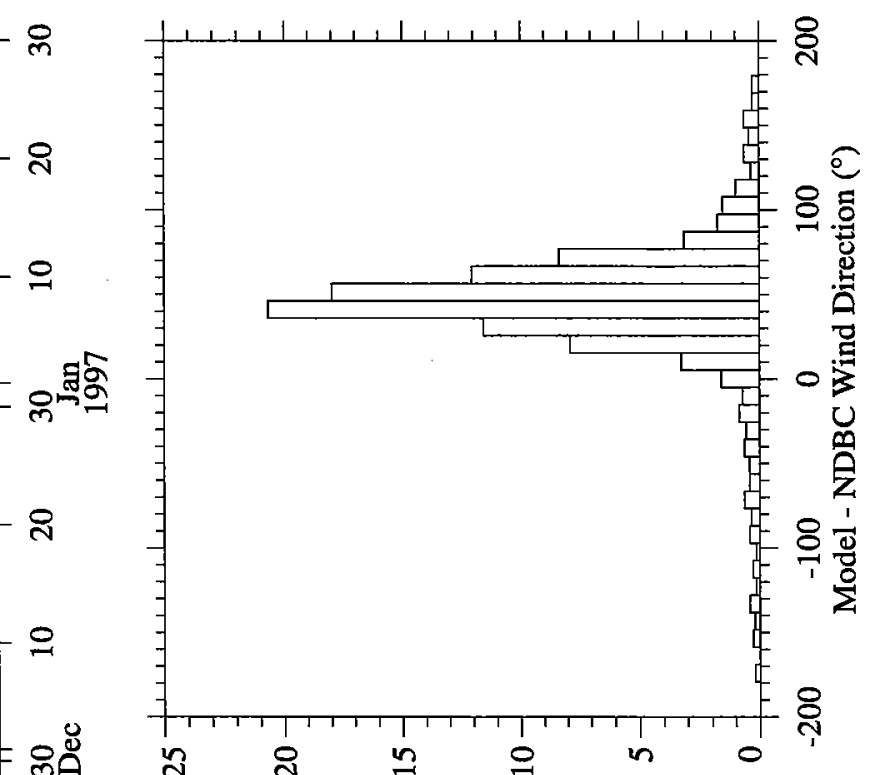

(\%) КэuənbəدH

요

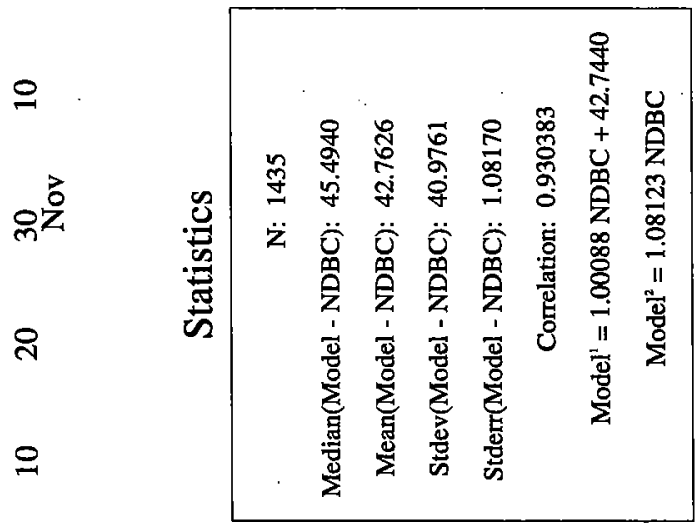

ஓర্

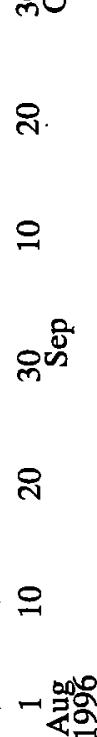

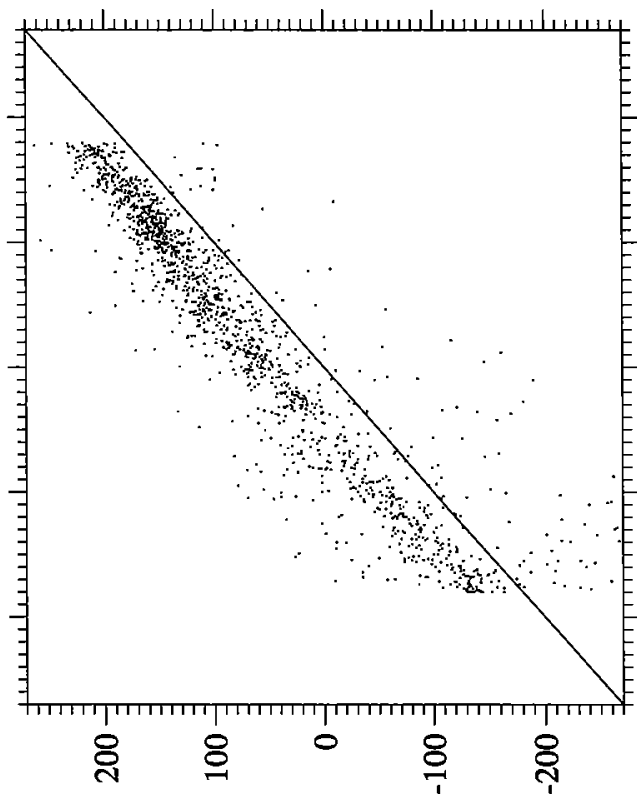

(॰) นопฺэпп рu!м гром 


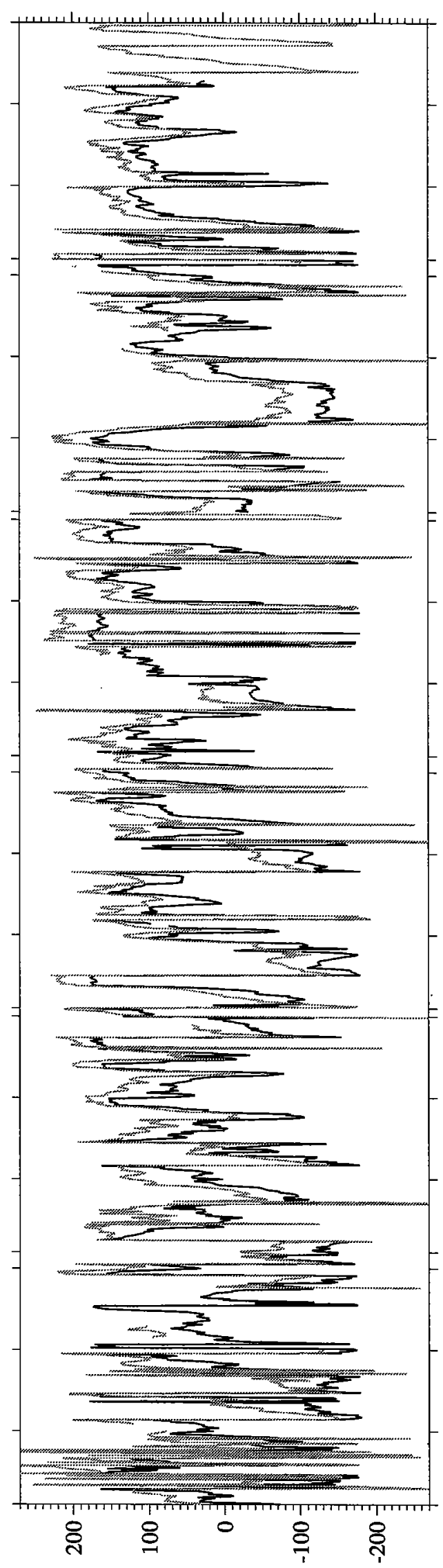

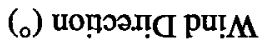

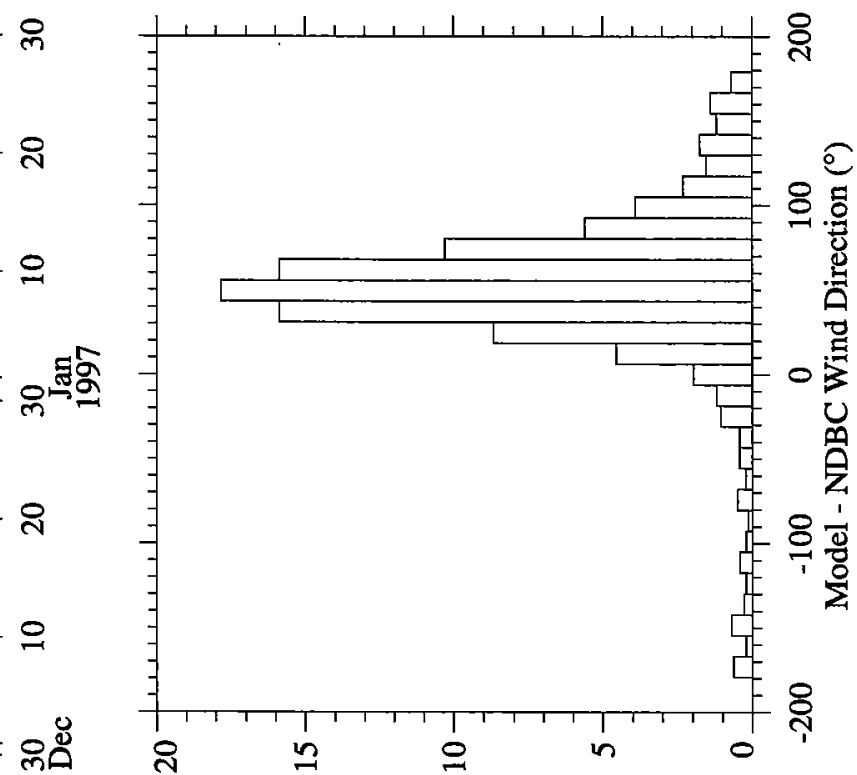

(\%) Кวuənbəx

กิ

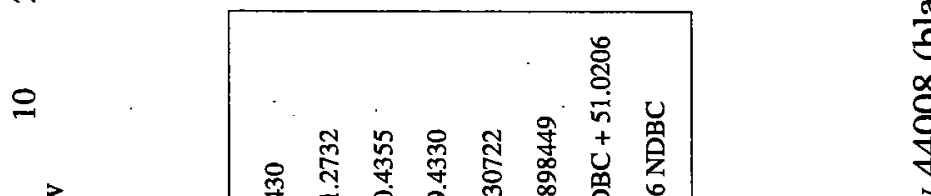

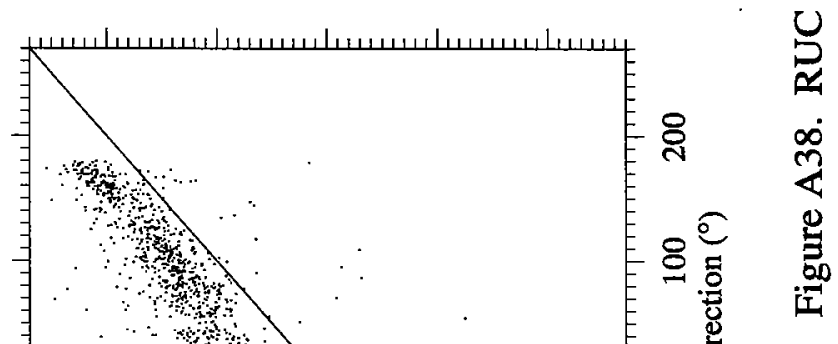

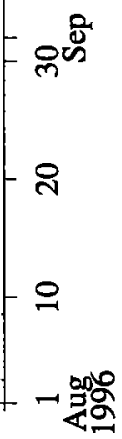

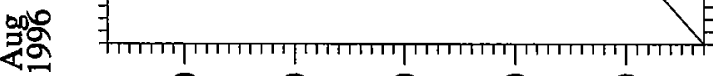

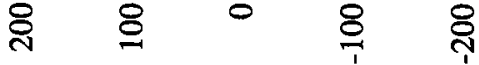

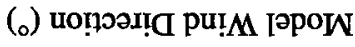




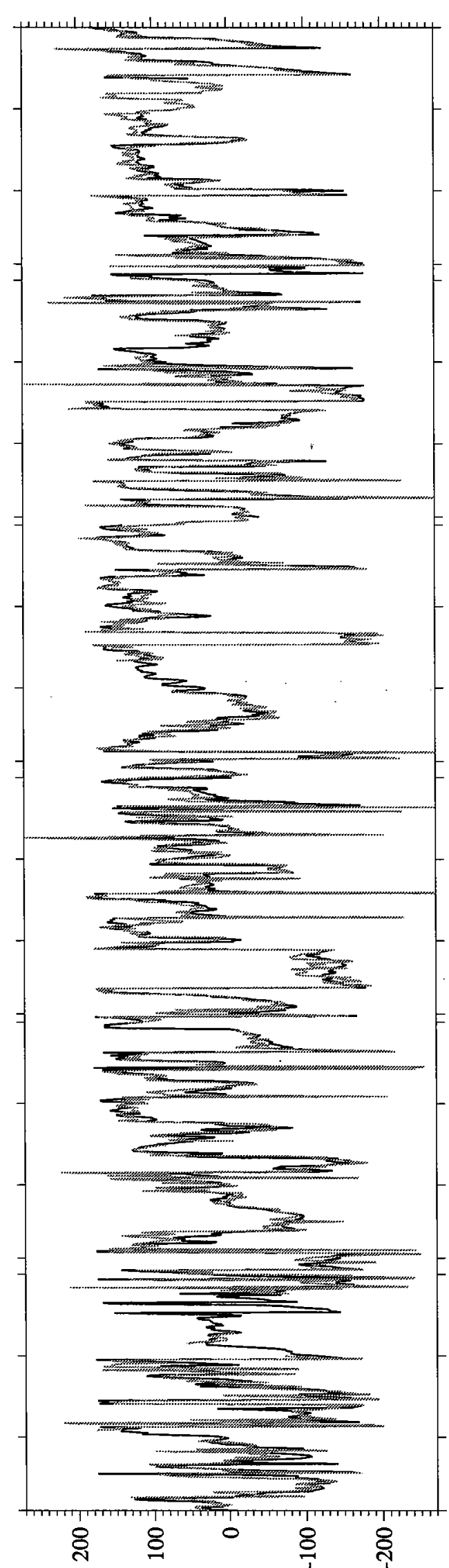

(。) uọ̣oər!̣ pu!M

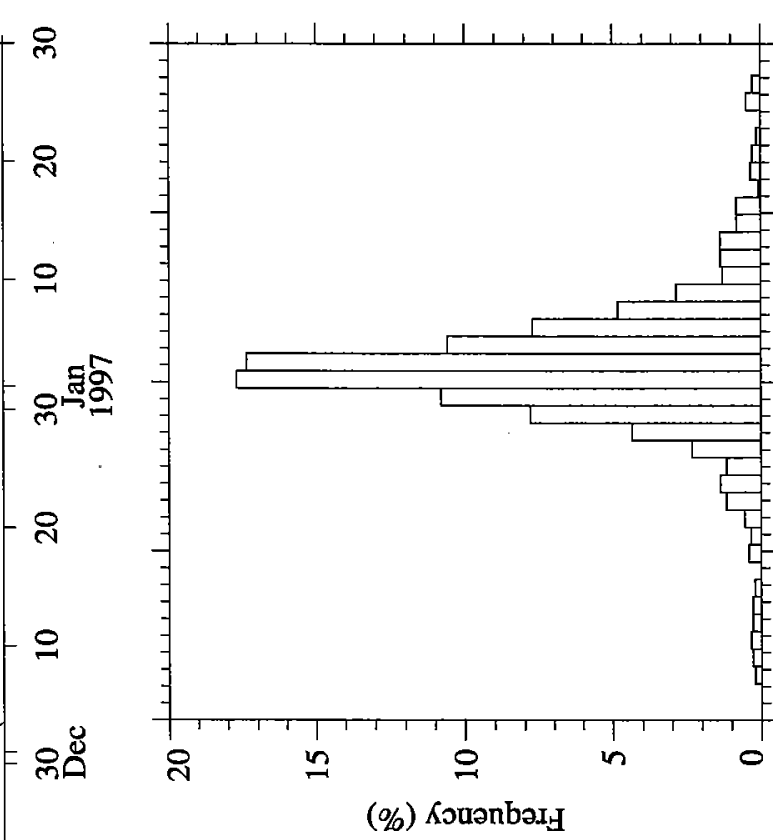

우

운

옳

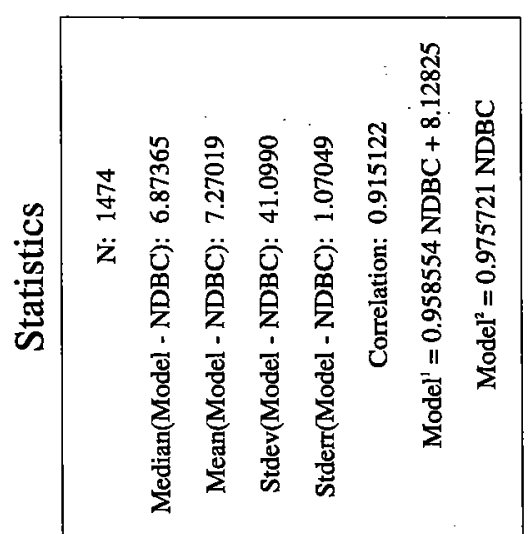

요

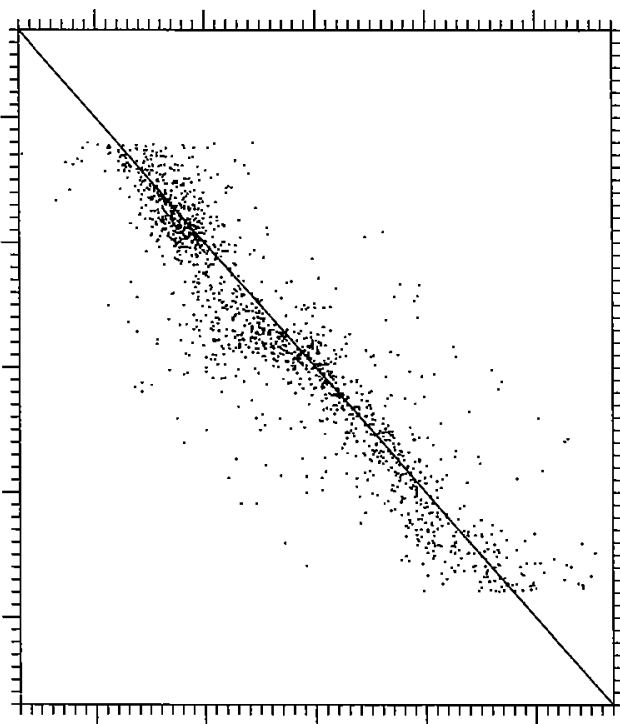

\& \& 8 \&

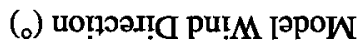




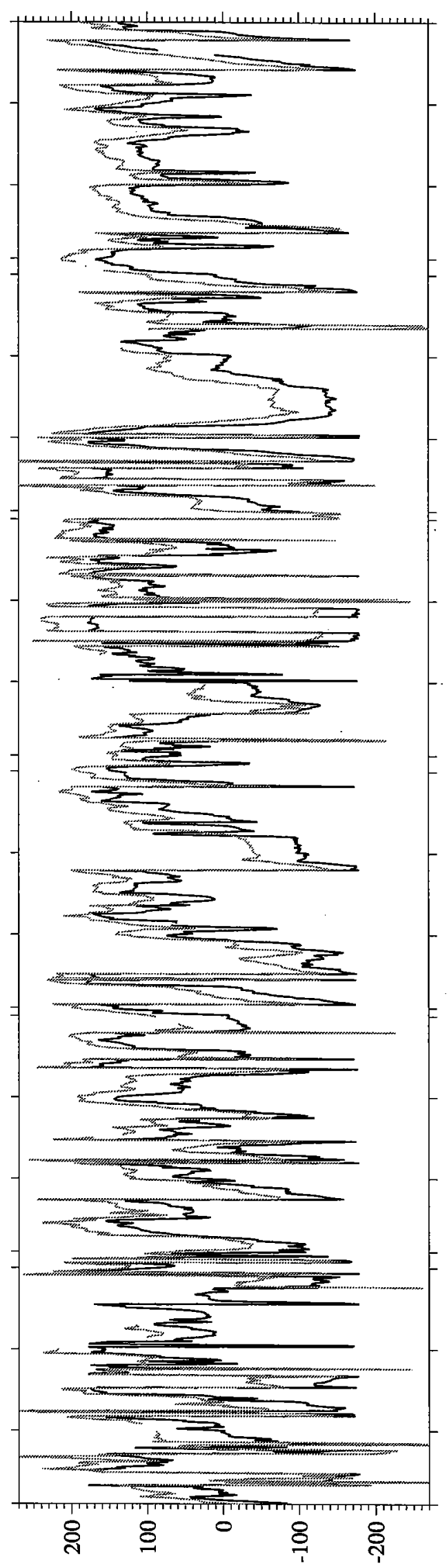

(.) иоп̣әәпа рu!м

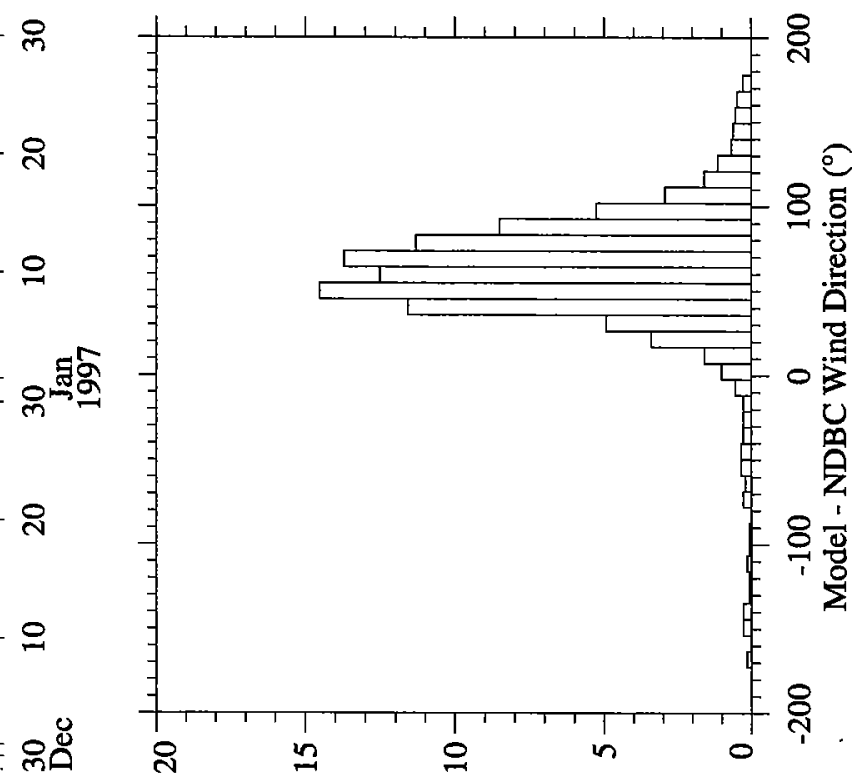

(\%) KouənbəxH

กิ

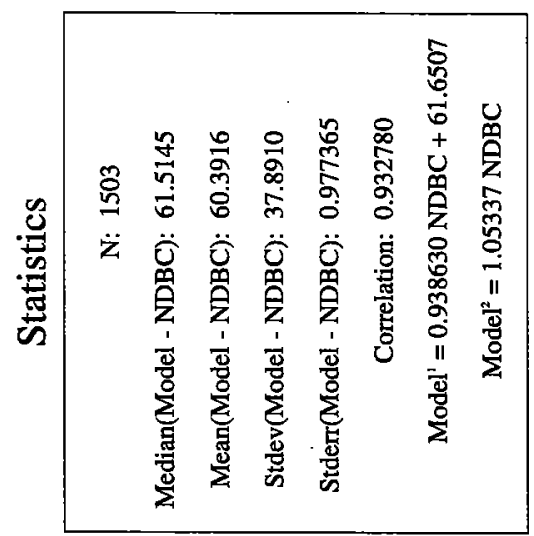

ळัँ

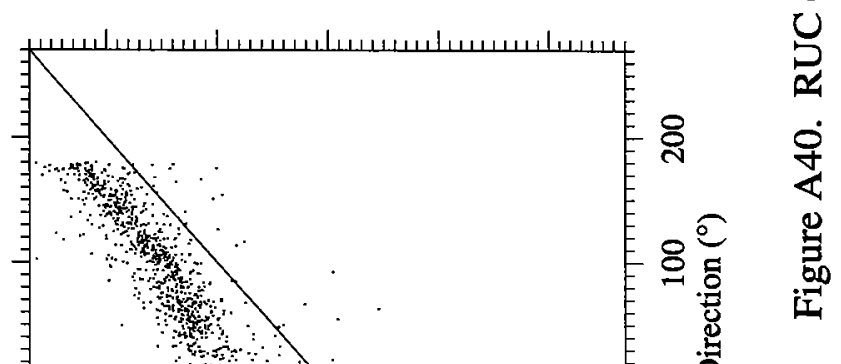

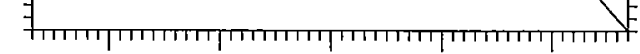

ஓ्ल \& 0 \&

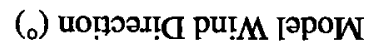




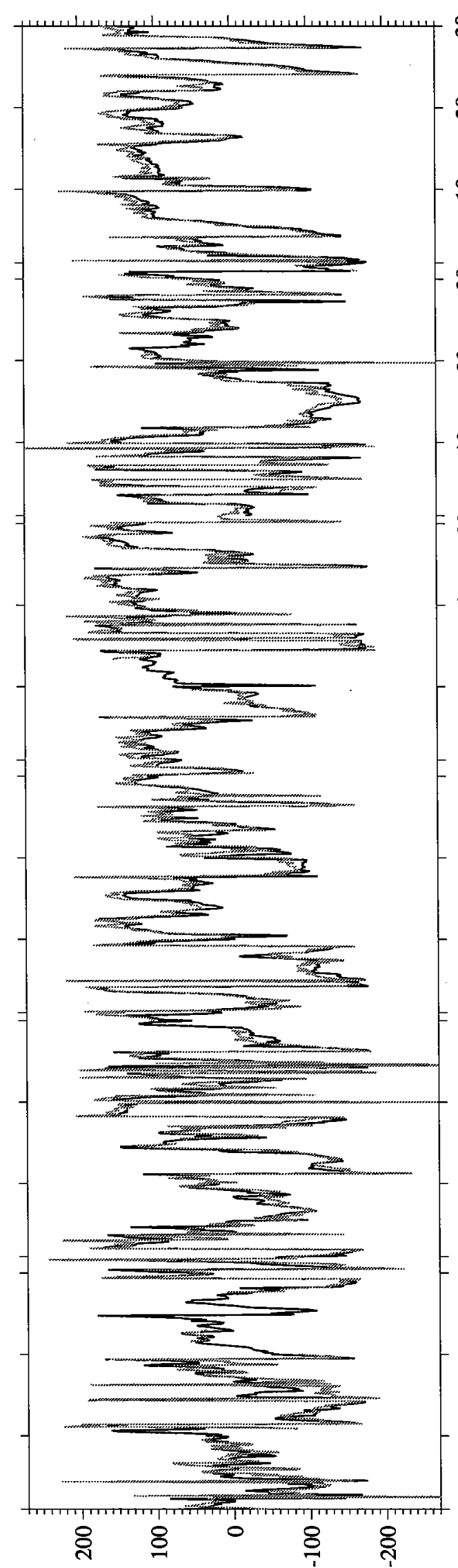

(o) uoṇoar!a pu!M

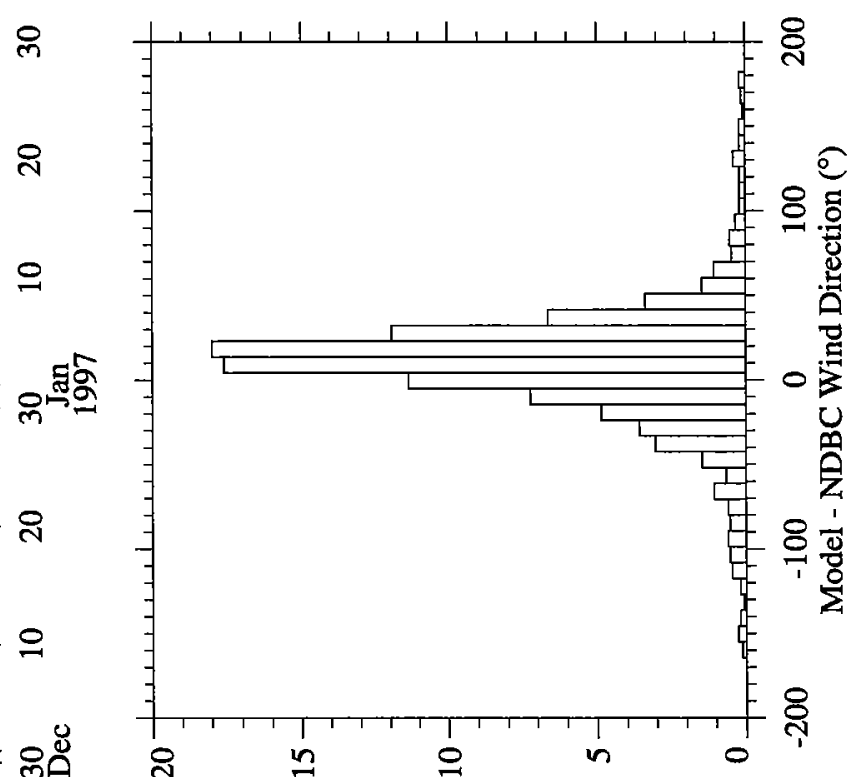

(\%) KouənbəxH

ㅇํ

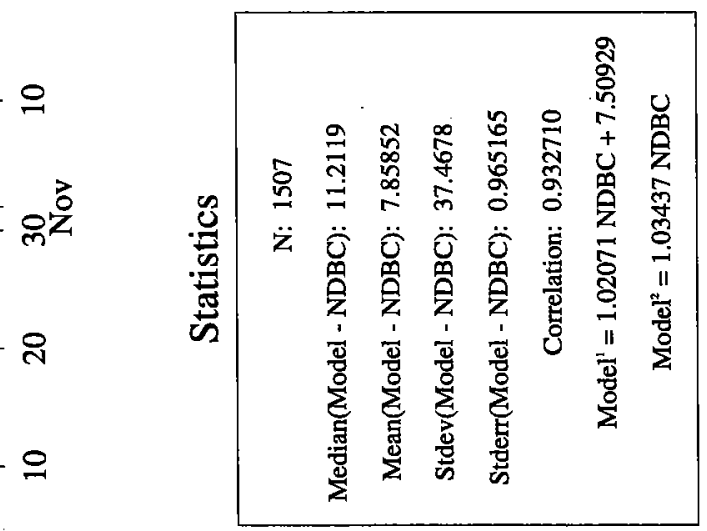

윰

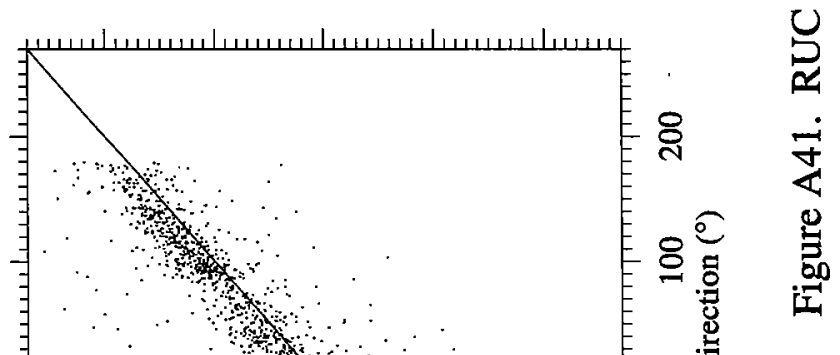

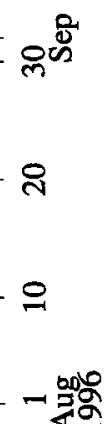

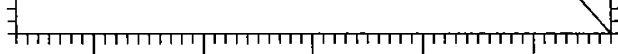

¿্ $80 \%$

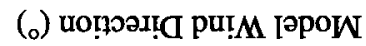




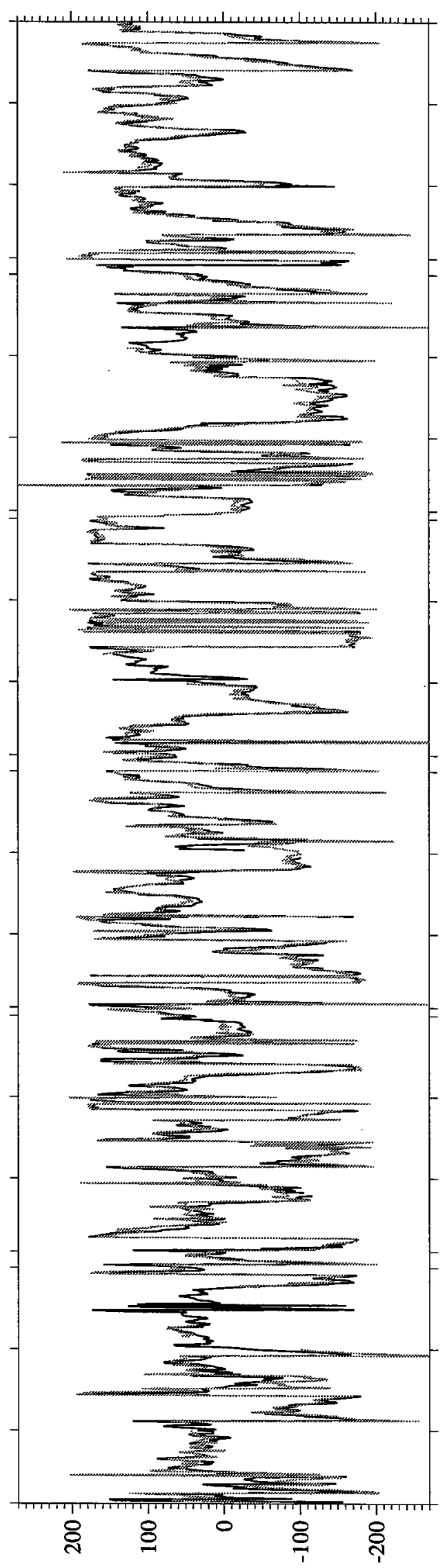

(。) uo!̣วan! pu!M

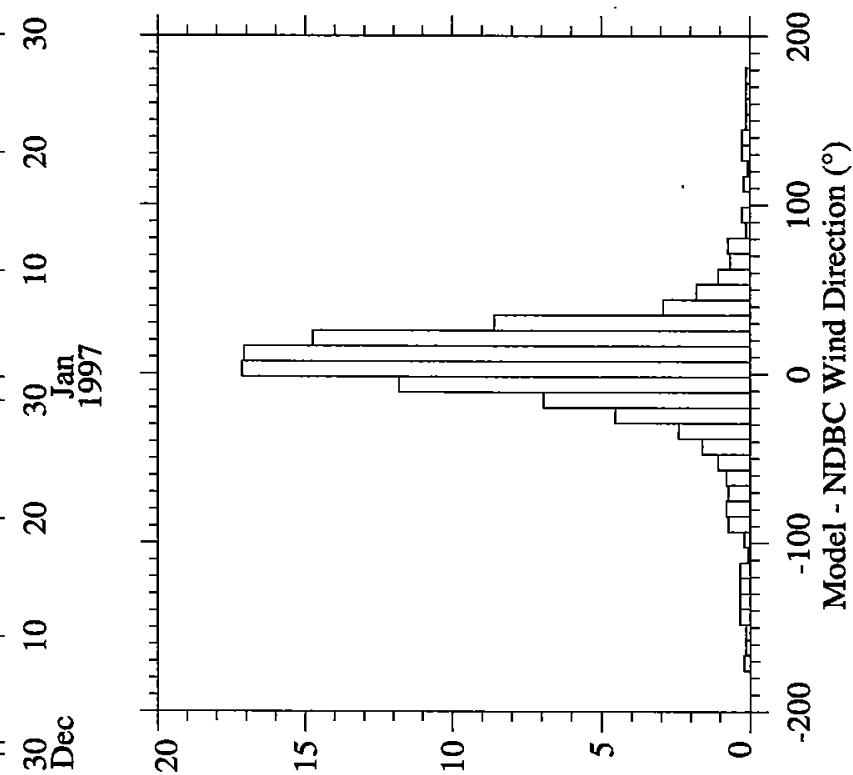

(\%) KouənbəIH

8

$-\circ$

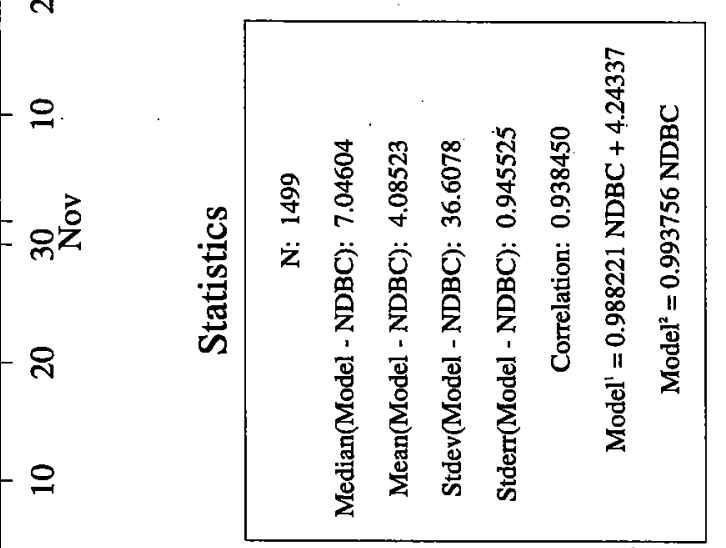

ஓ๐্

옹

y্즘

e

$\infty$

导

올

U

学

$\dot{p}$

ลิ

क्ज

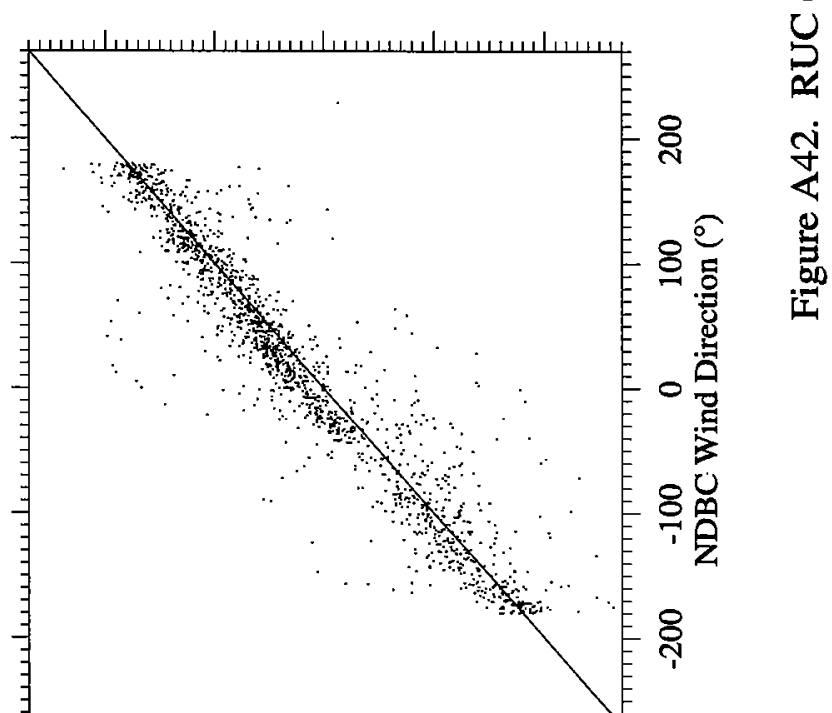




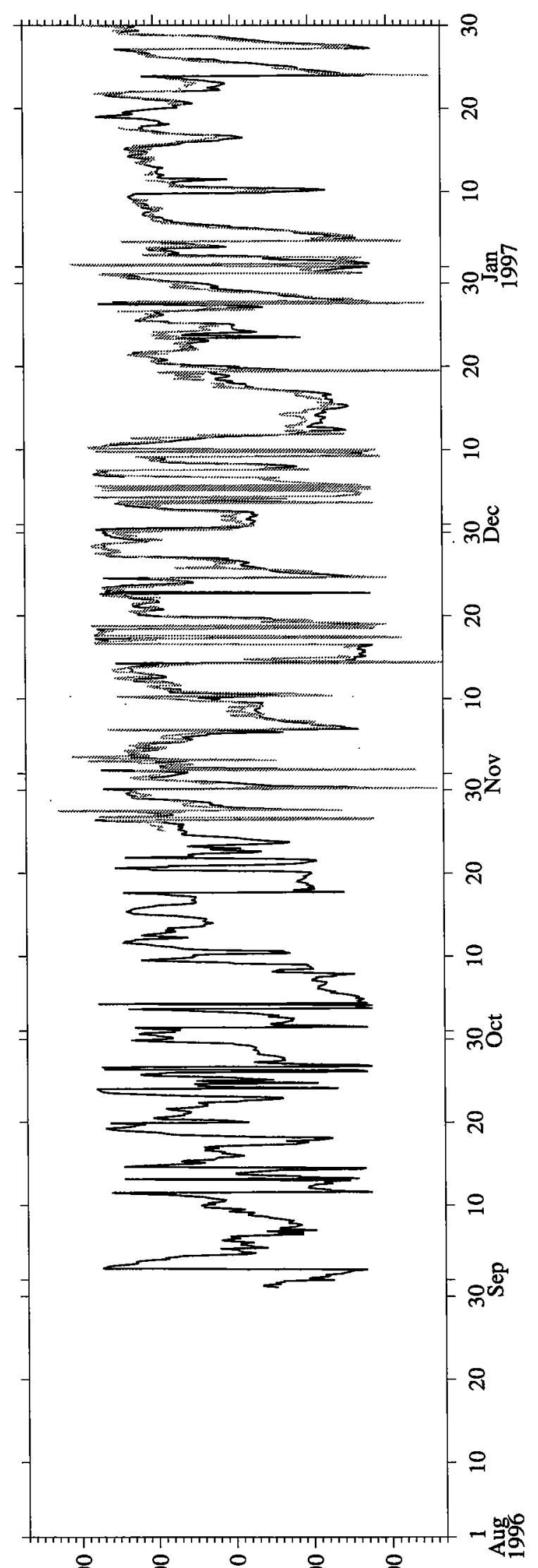

$8 \stackrel{4}{8} \stackrel{1}{9}$

(о) uọ̣วan! pu!M

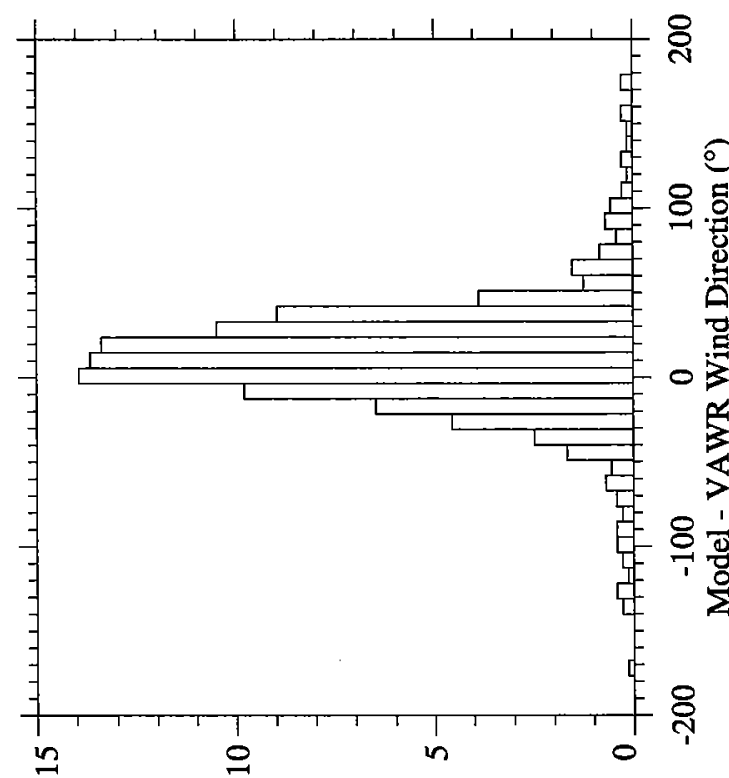

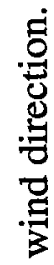

(\%) KouanbaI
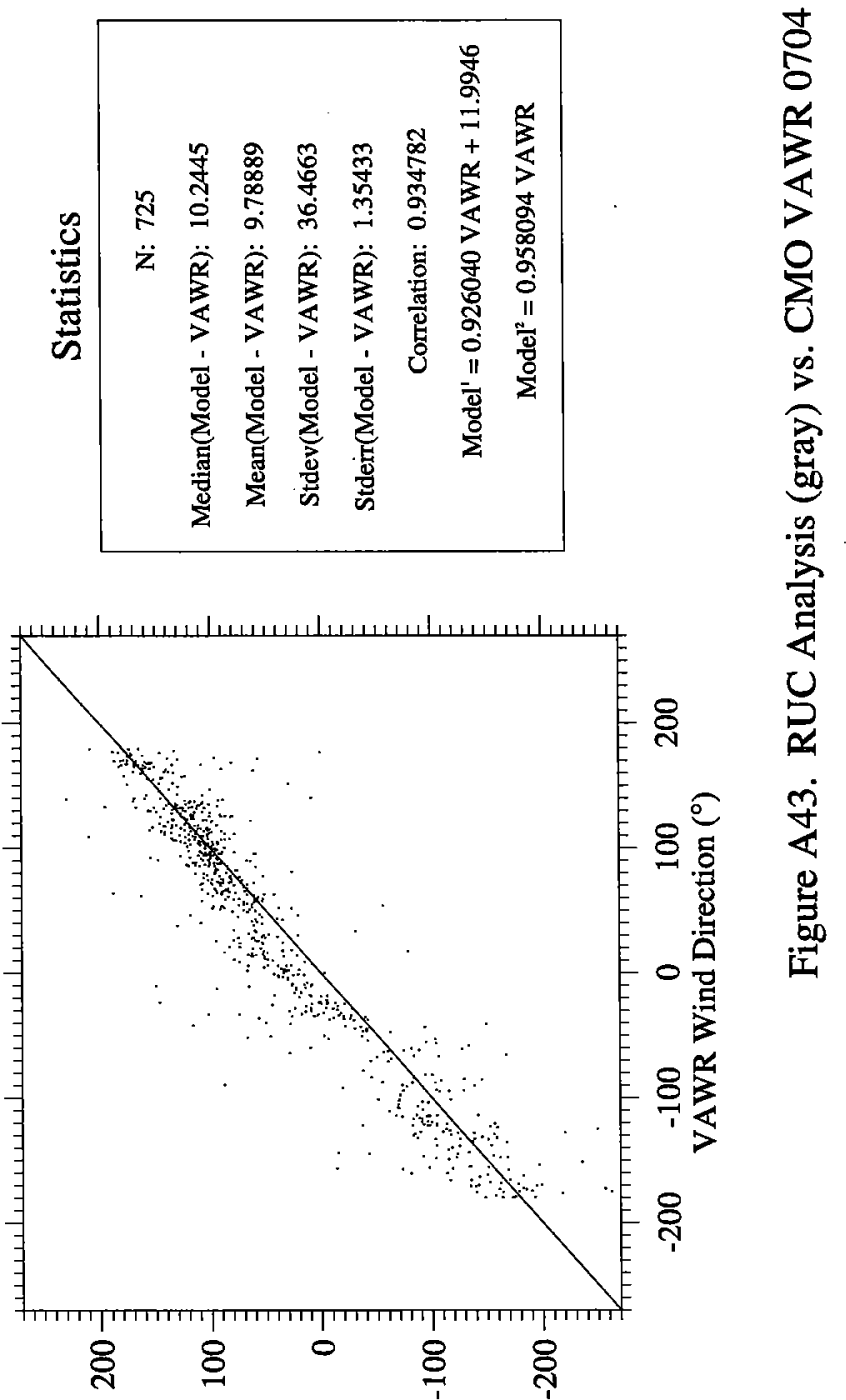

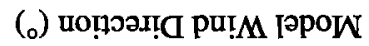




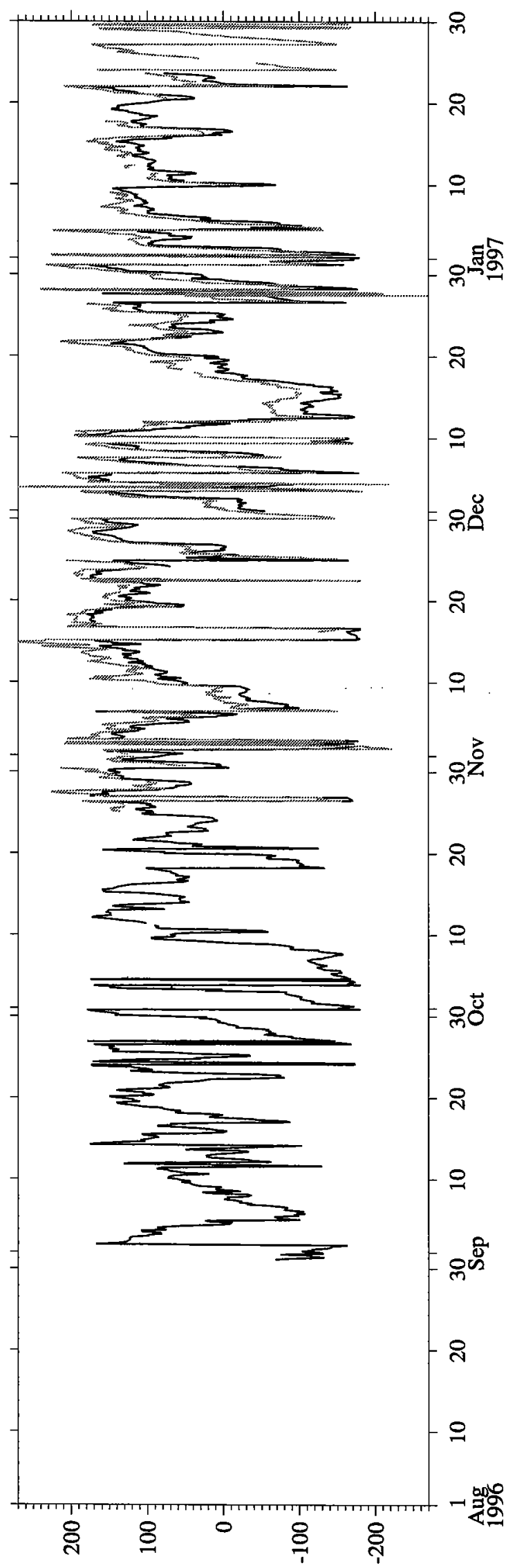

(o) uo!̣oər! व pu!M

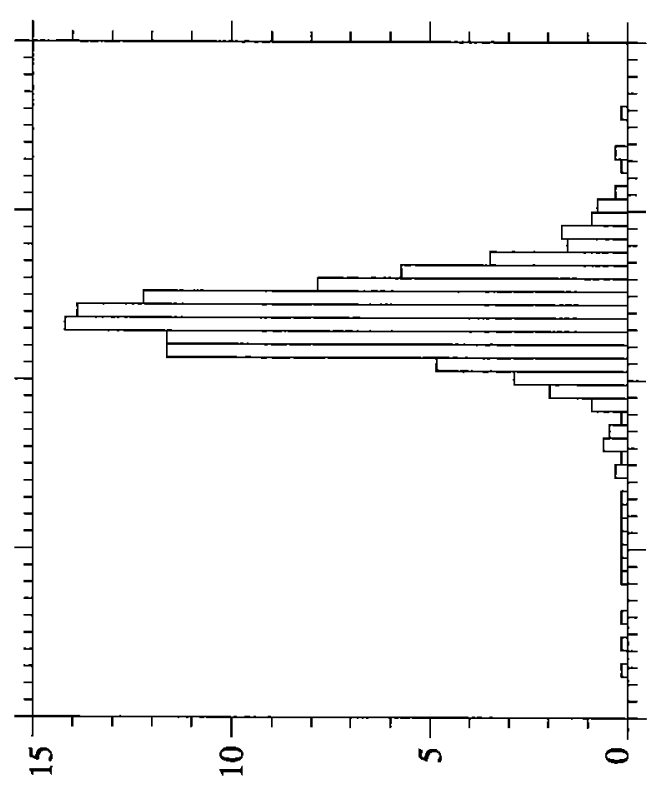

(\%) КэuənbəIH

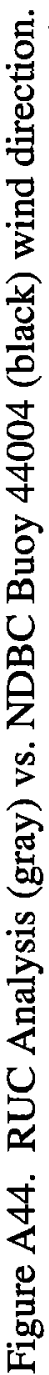

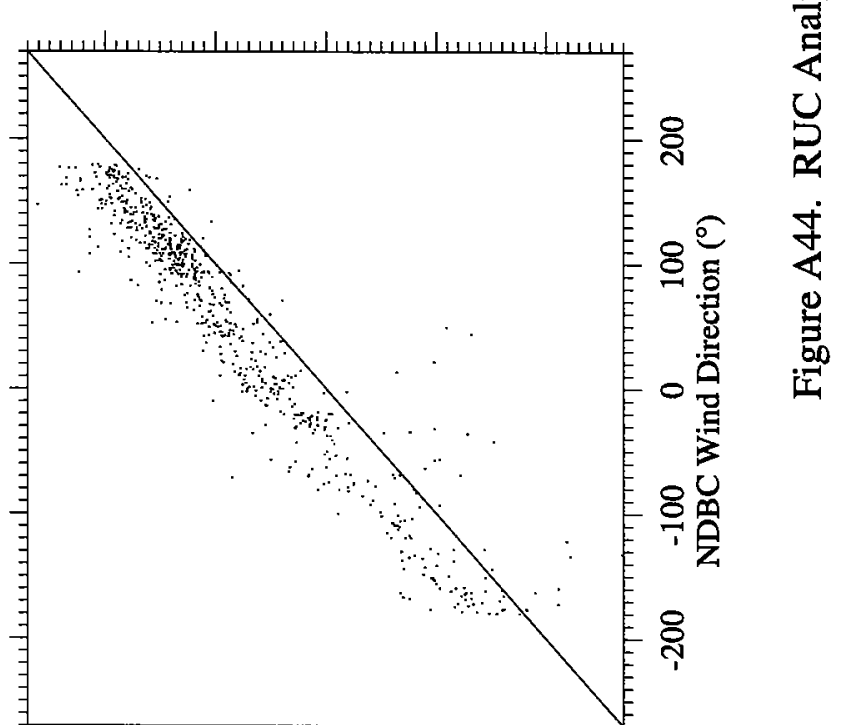

¿ 8008

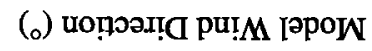




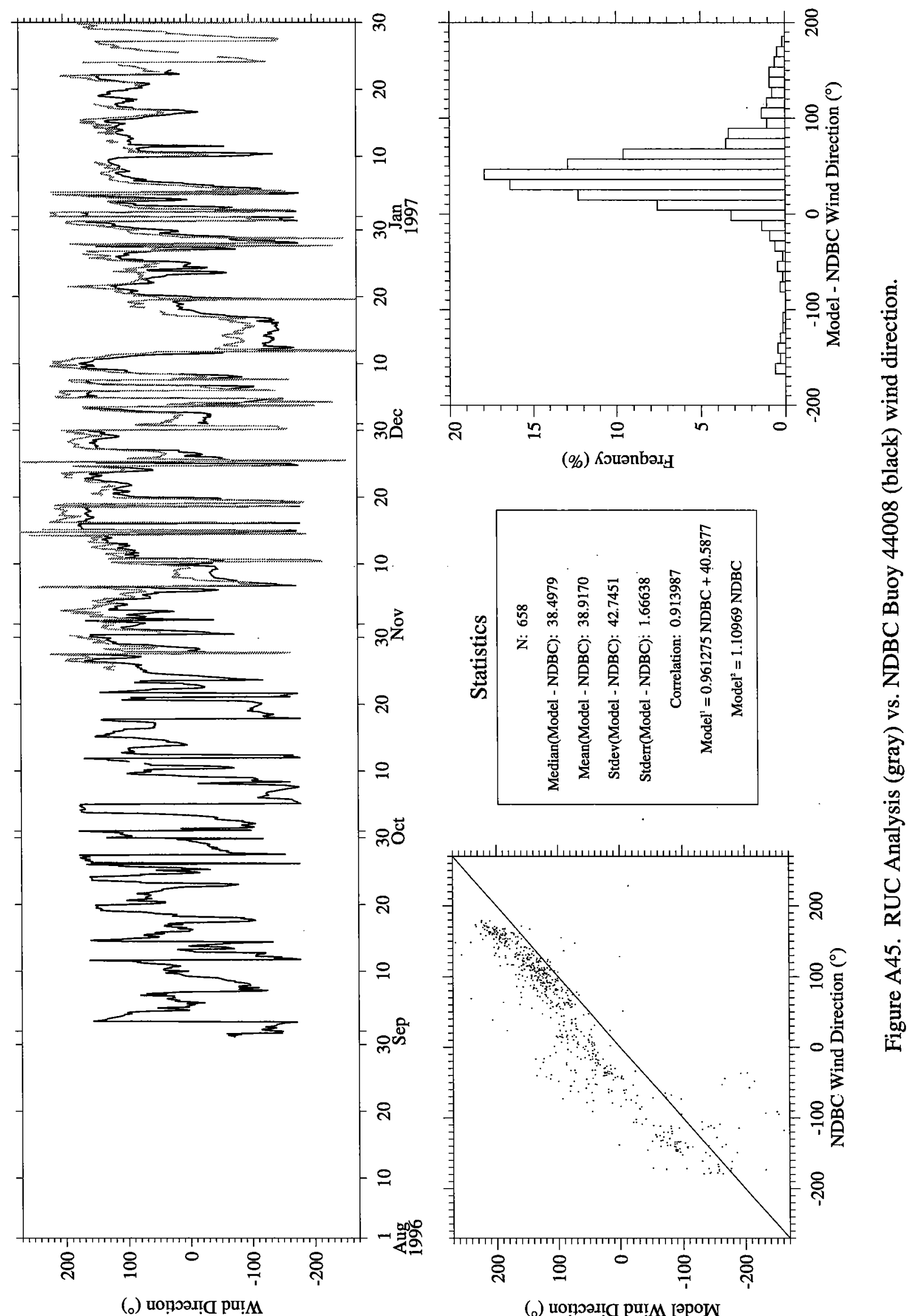




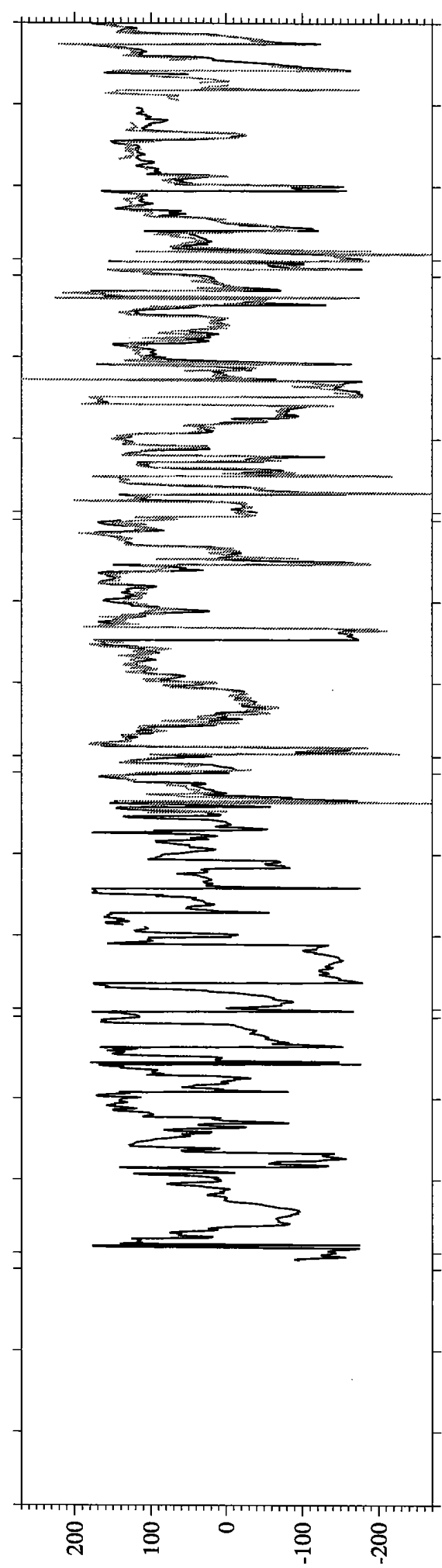

(。) uo!̣oว!! pu!M

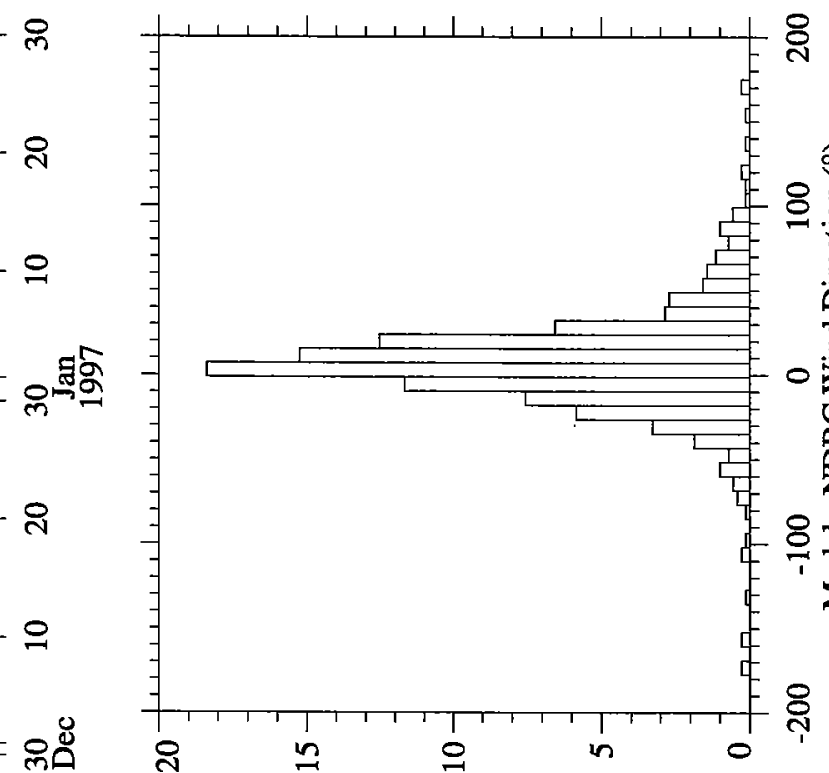

(\%) Кouənbər

8

음

$=\frac{3}{8}$

ㅇำ

온

유

ㅇำ

琭

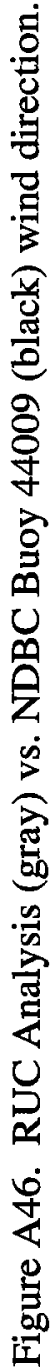




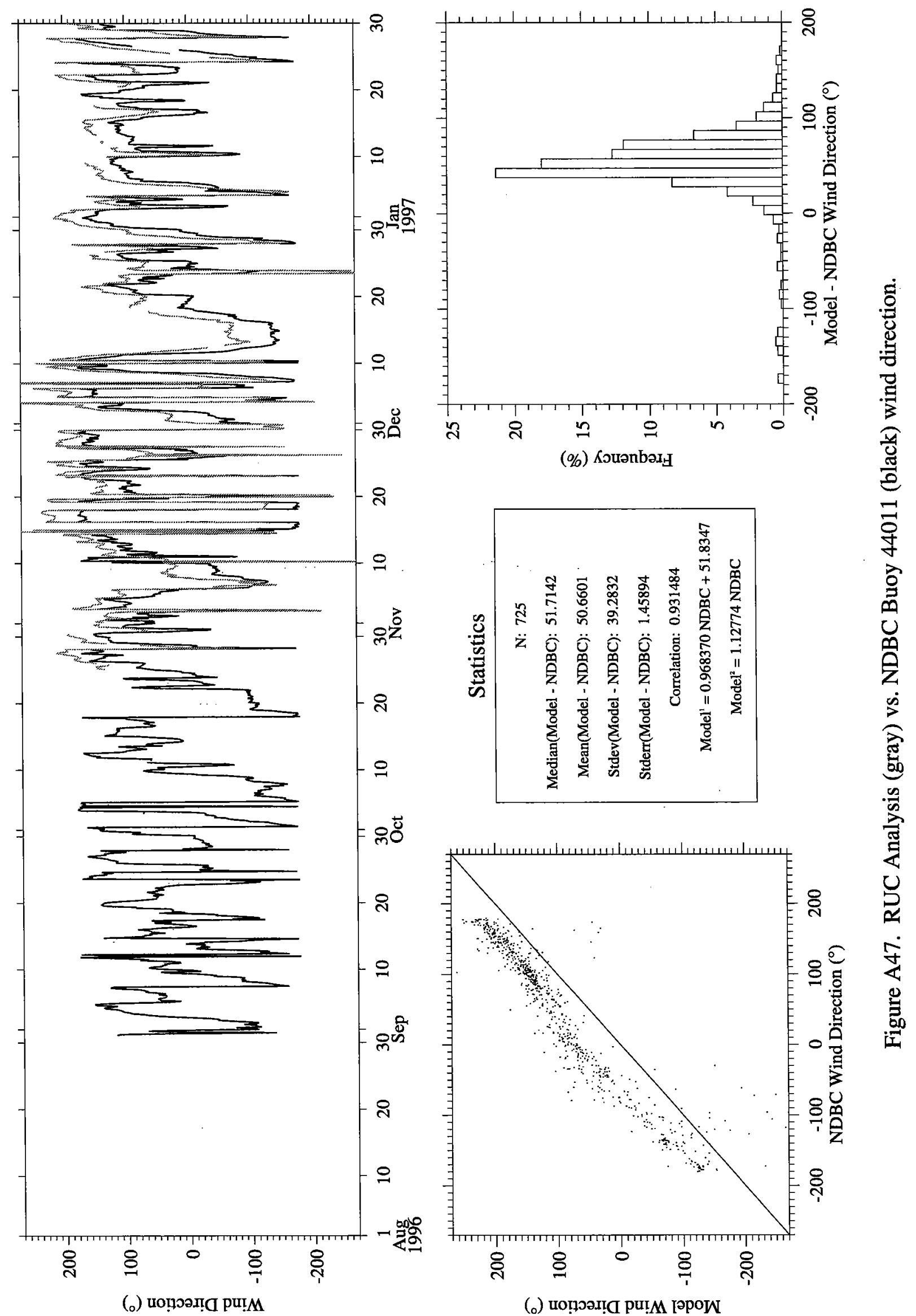




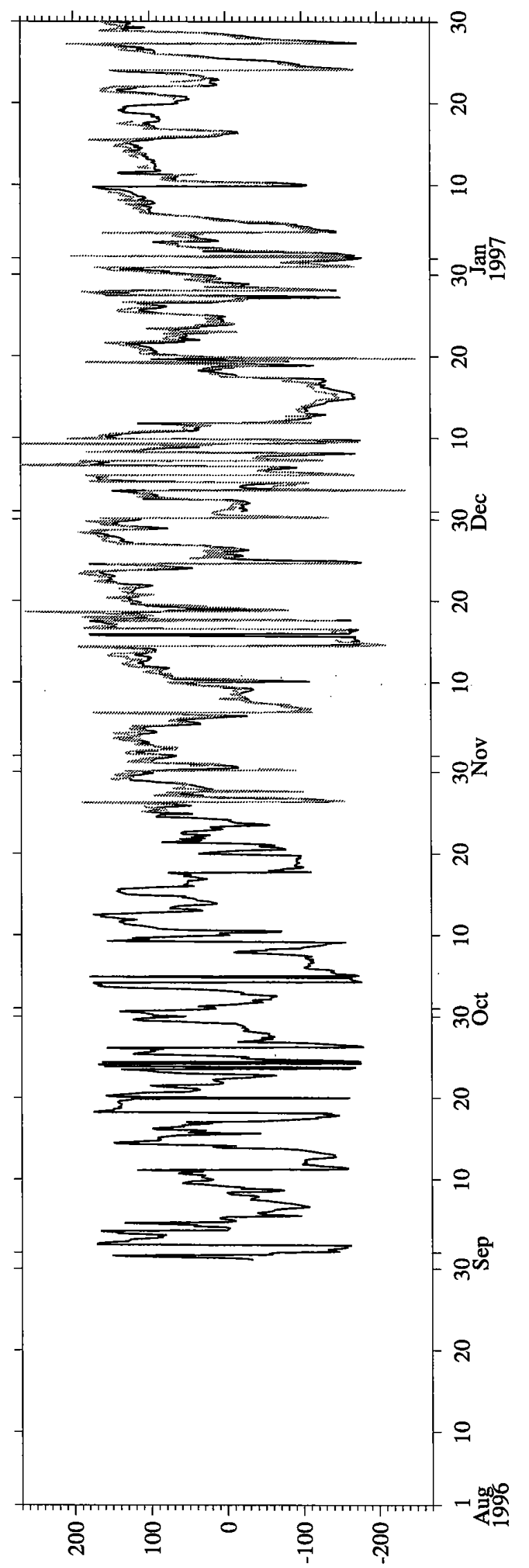

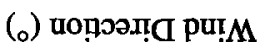
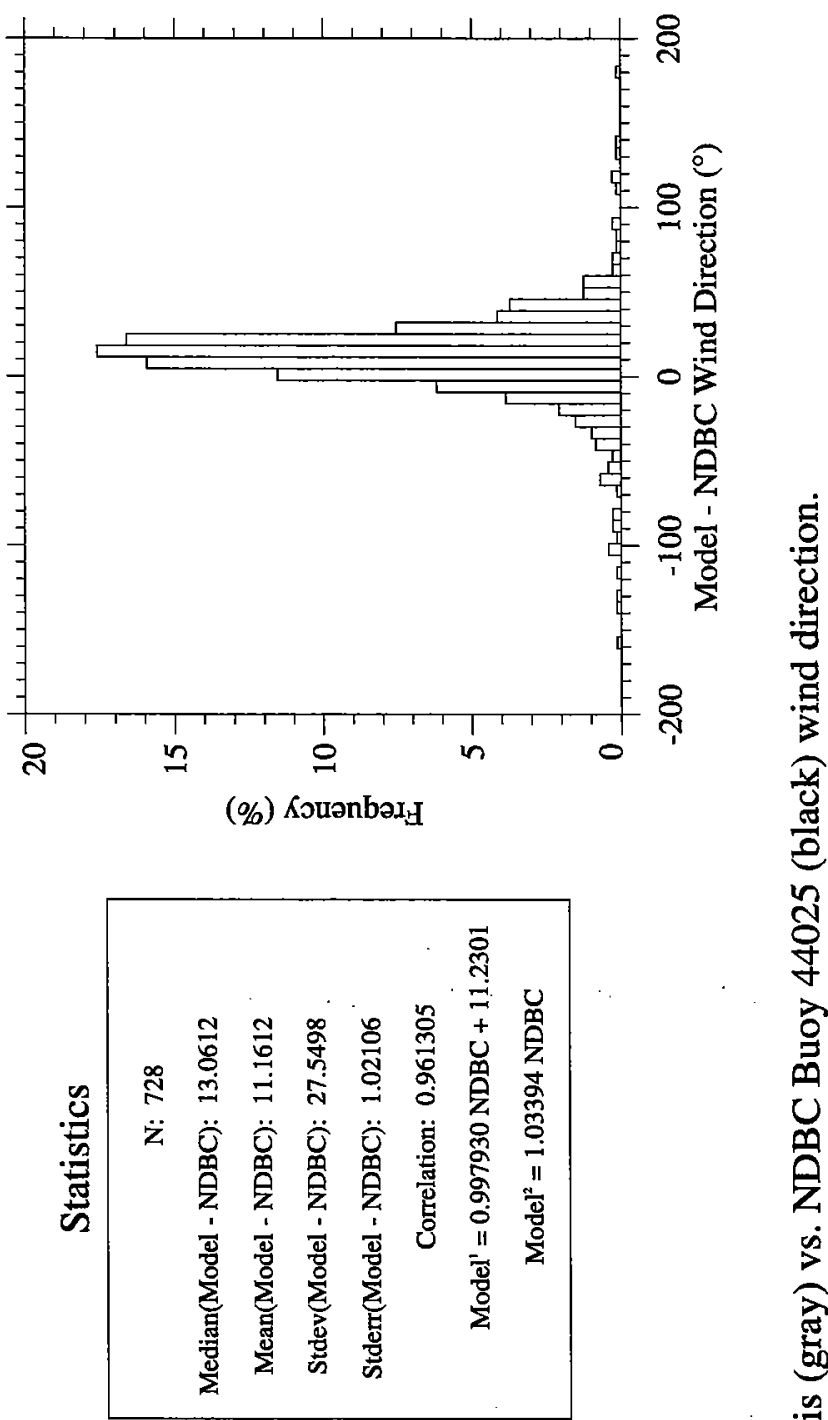

完

告 


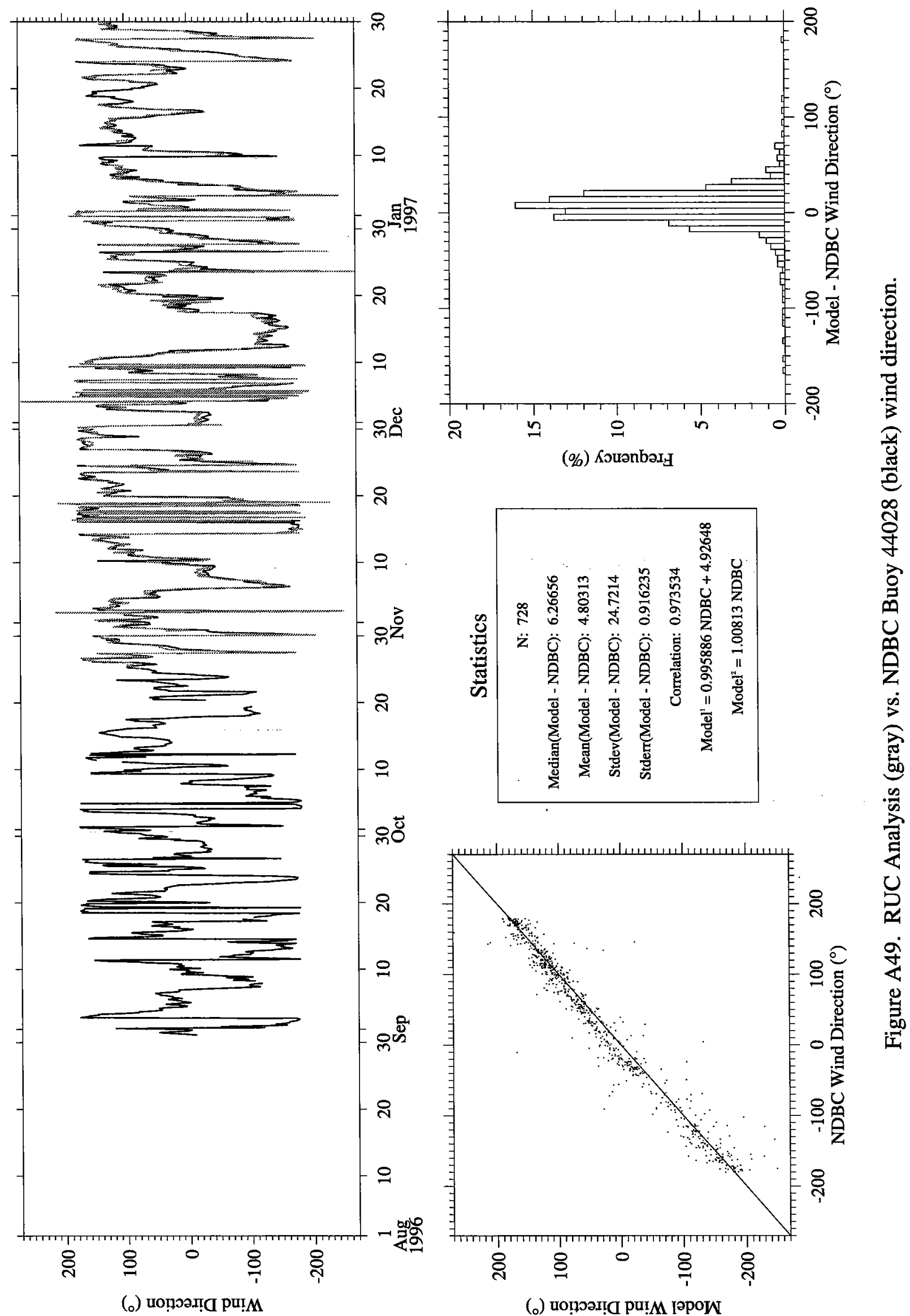




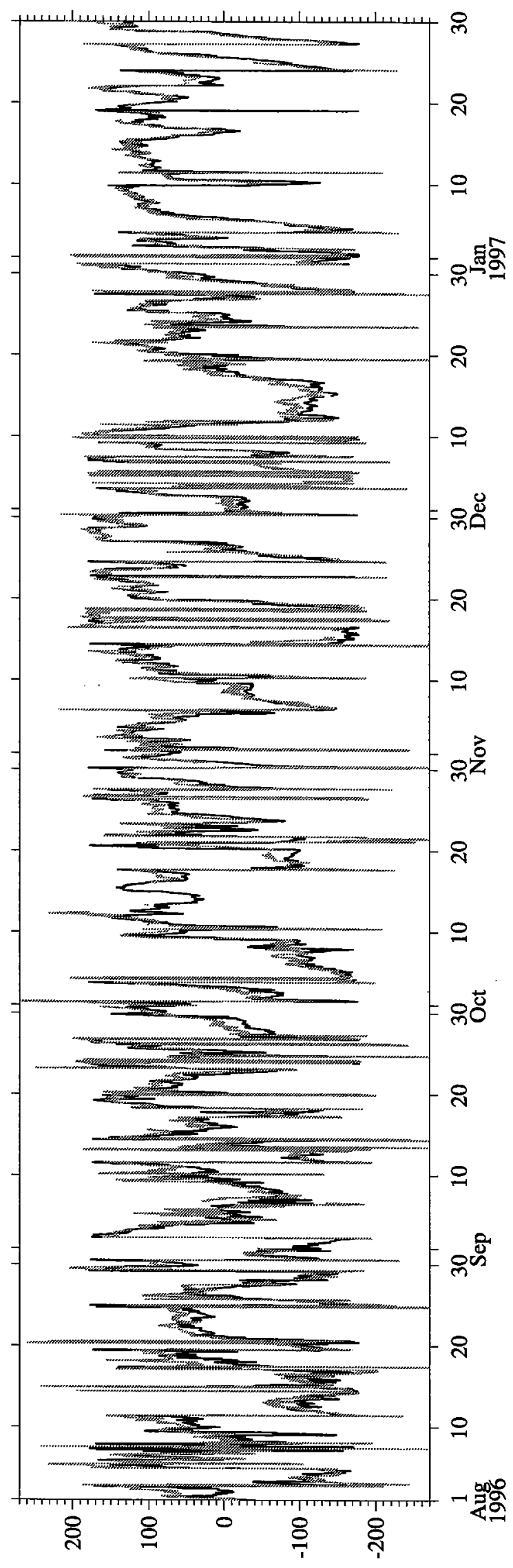

(॰) uop̣эวпם pu!M

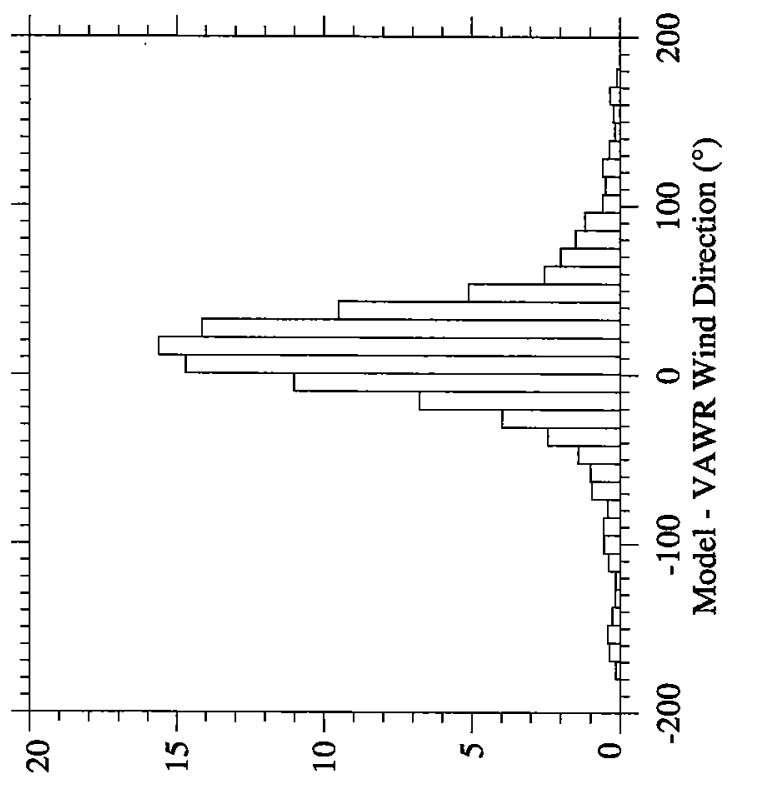

(\%) KouənbəI
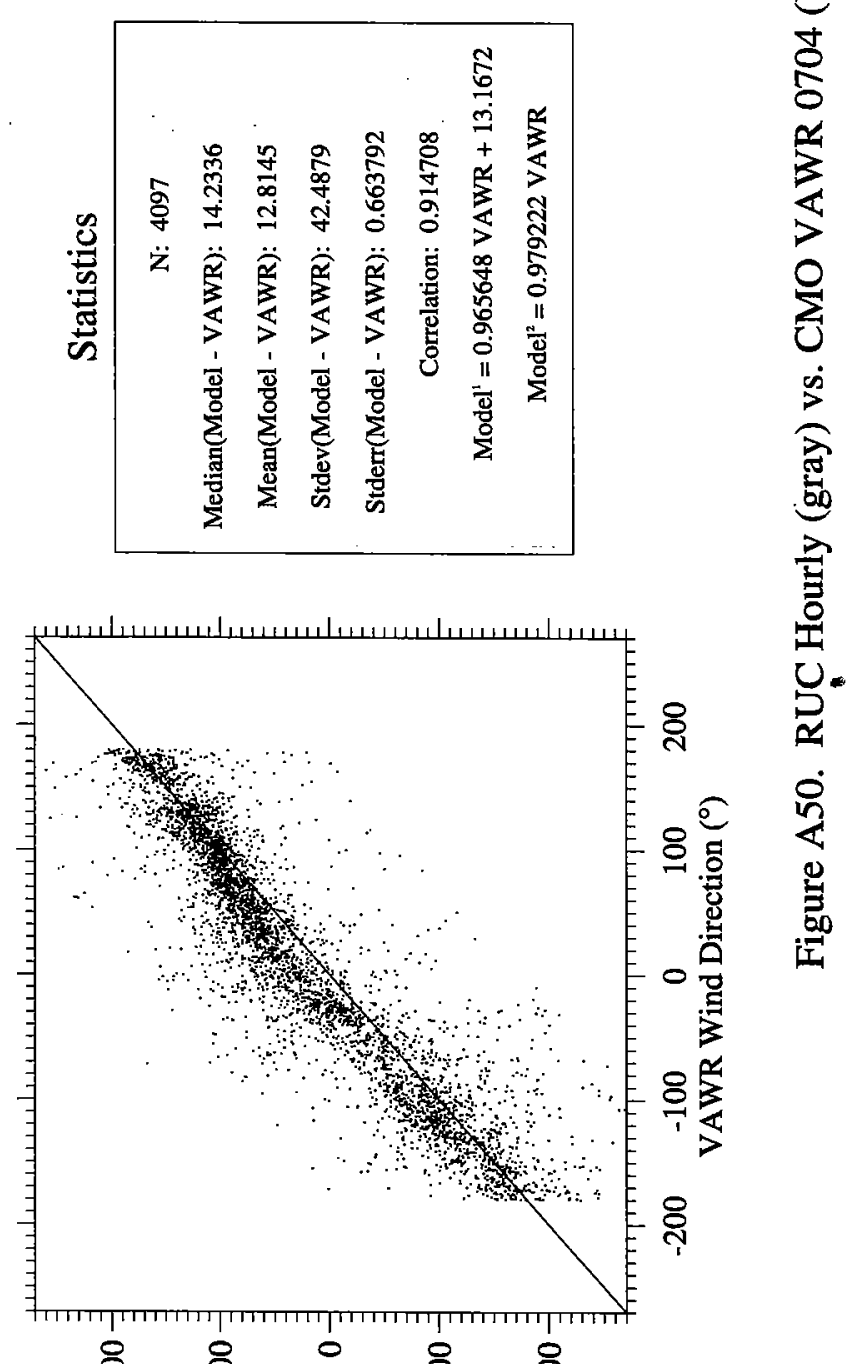

유 \& 0 ठ

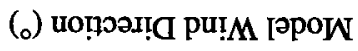




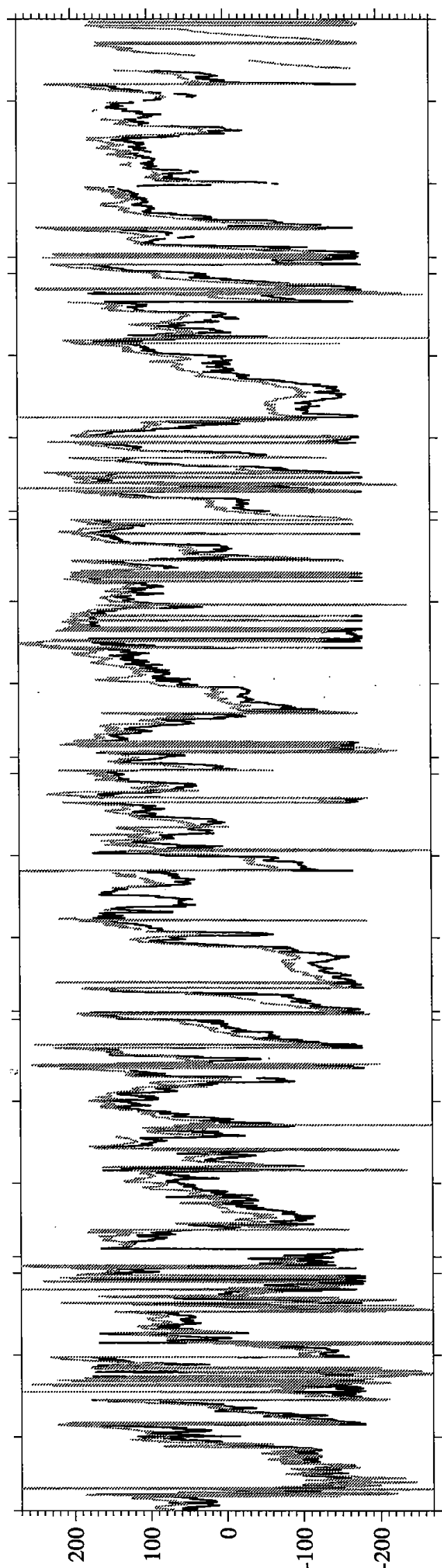

(.) иоп̣ог!ฺ рu!M

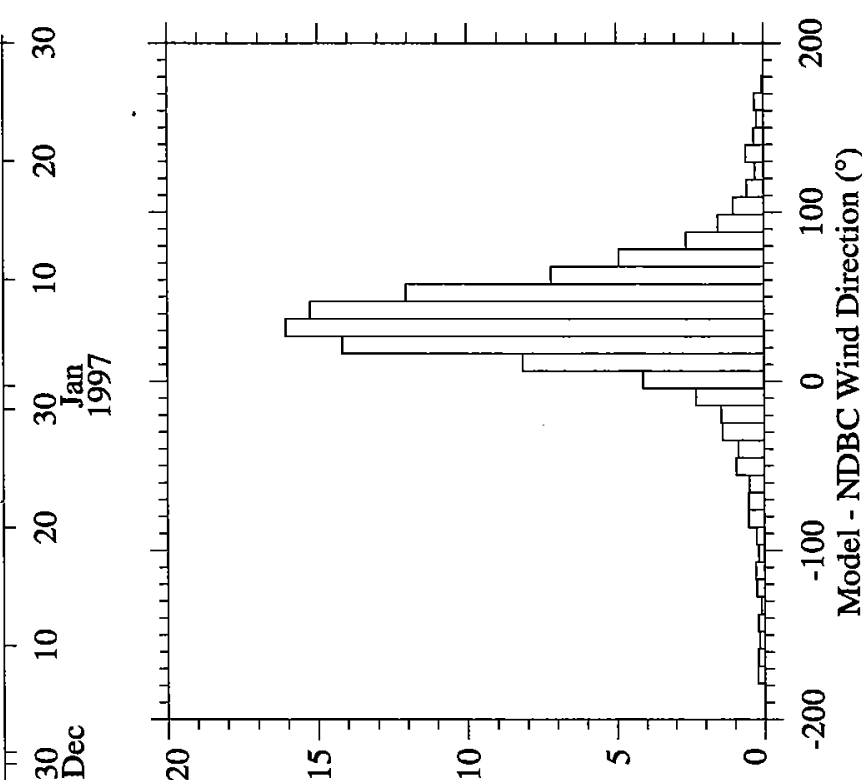

(\%) Kouənbəג

ำ

율

ำ

응

융
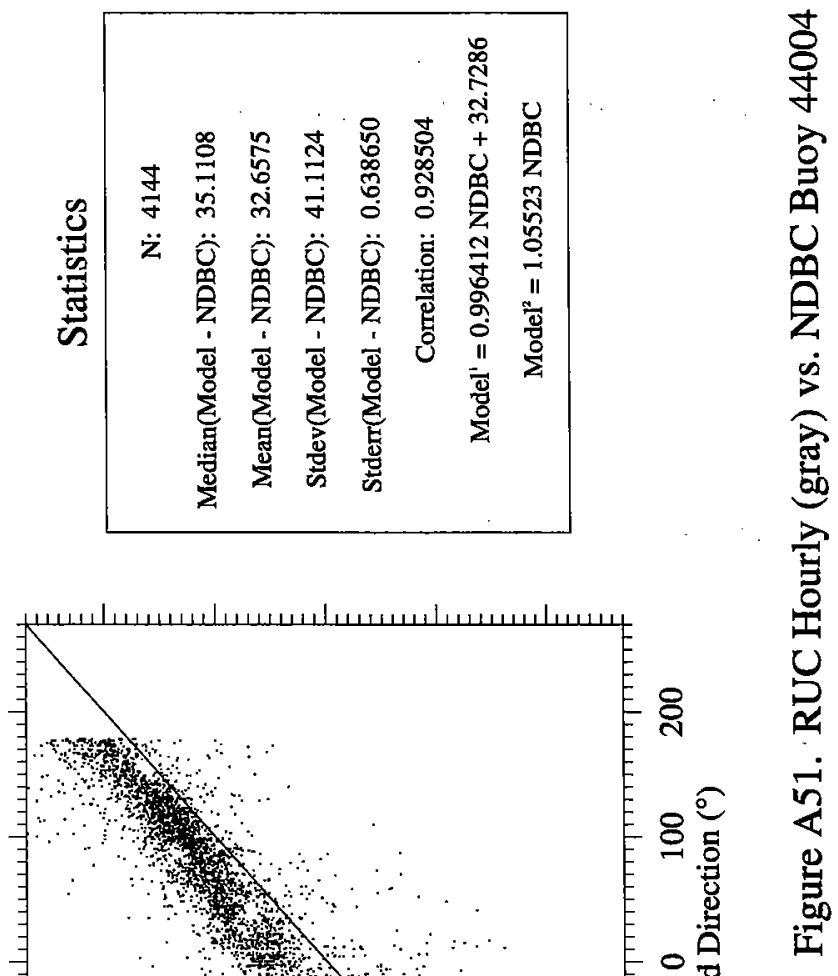

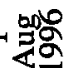

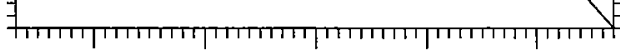

유 80 \&

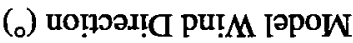

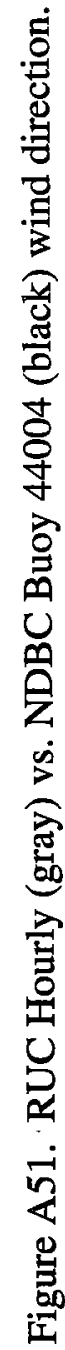




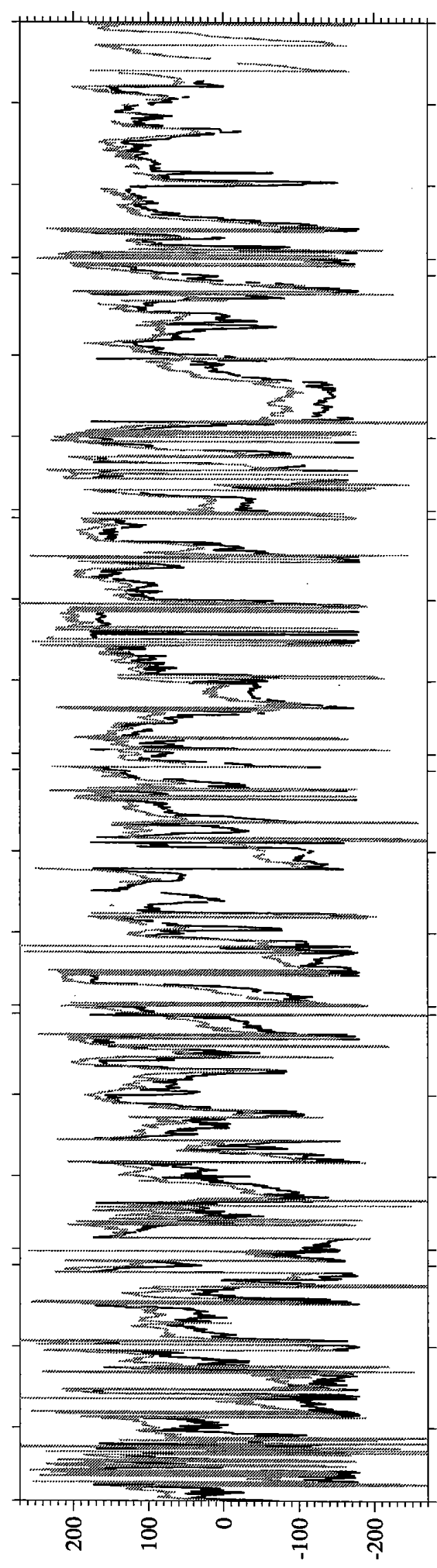

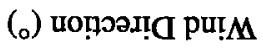

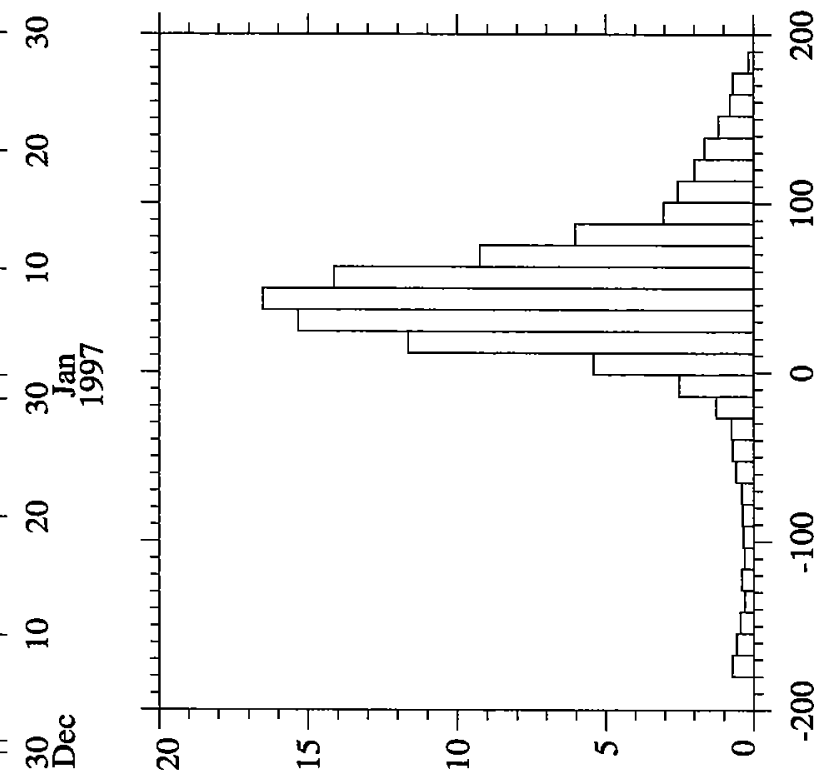

(\%) KouənbəدH

오

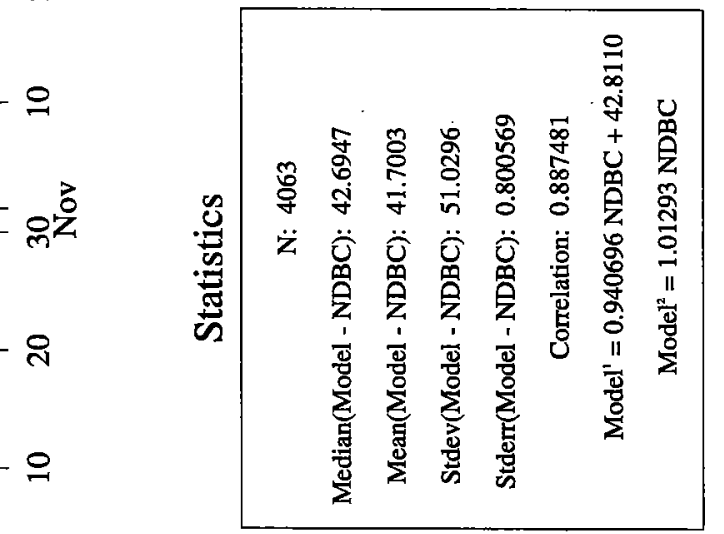

ஓัँ

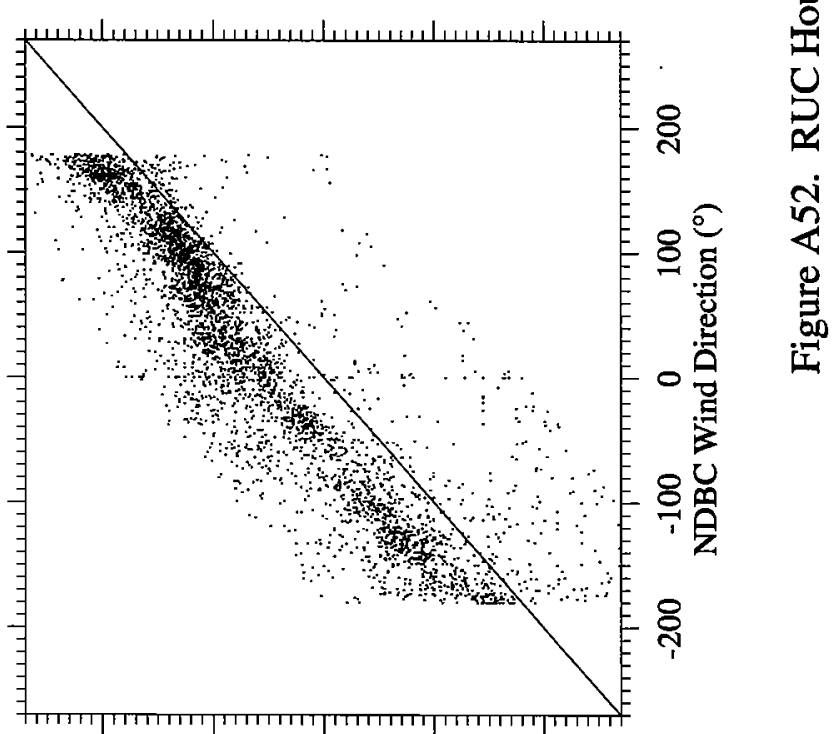

유 80 \&

(о) นопрәл!ब рu!M [әром

명

yㅜㄹ

$\infty$

导

官

兽

$\dot{s}$

突

오

으

율

요

으

- $\begin{array}{r}\mathrm{x} / 2 \\ -2\end{array}$

(n)




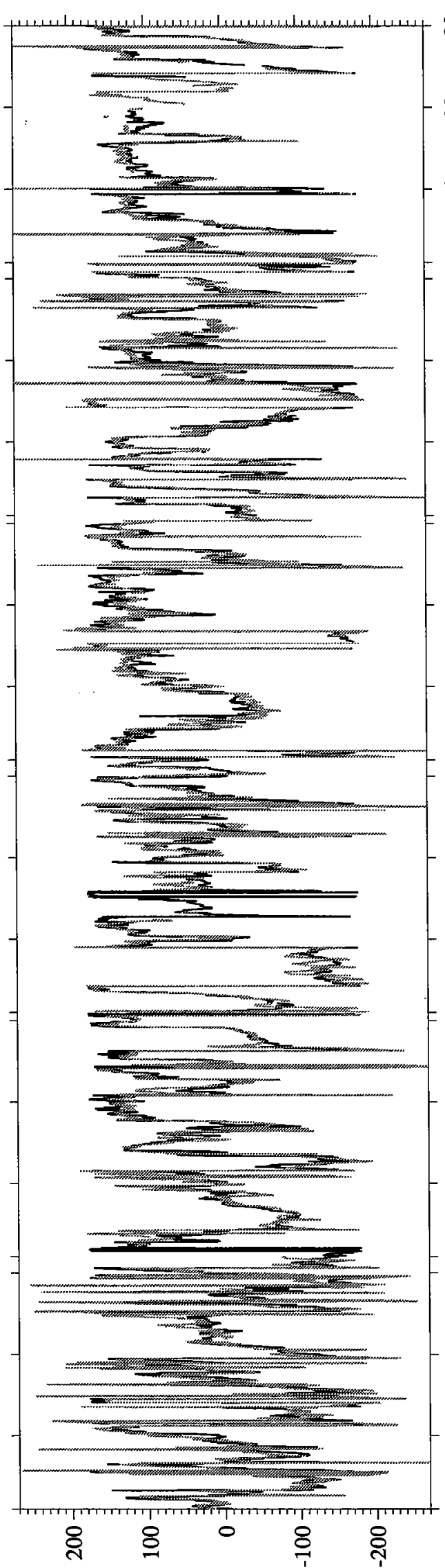

(๖) นоำวп! pน!M
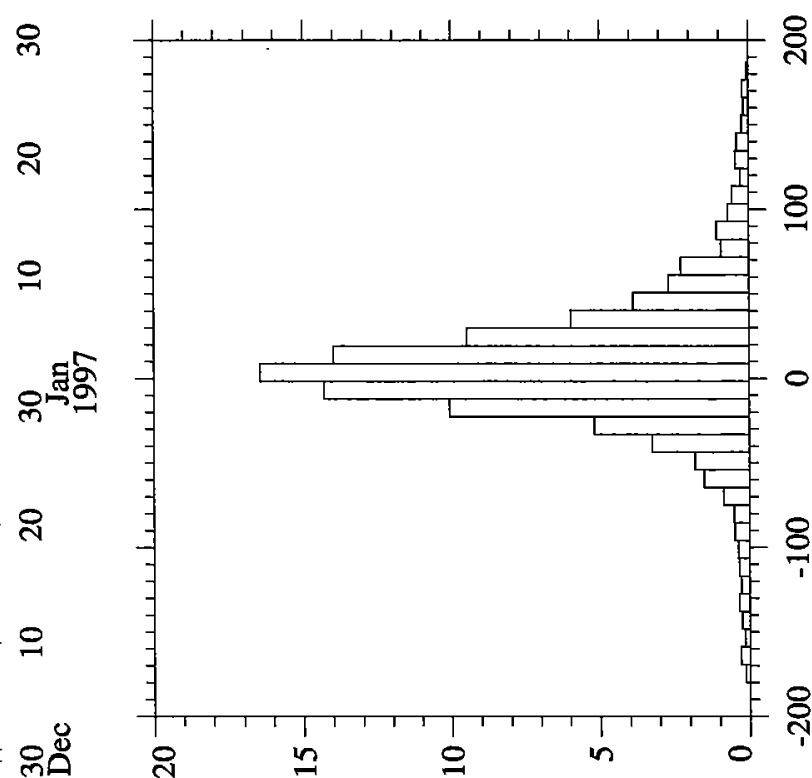

(\%) Кэuənbอม법

ㅇ

오

ㅎํ

ำ

음

융

苛

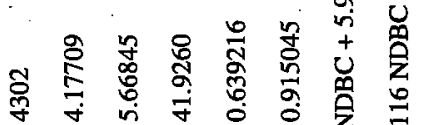
$\ddot{z}$
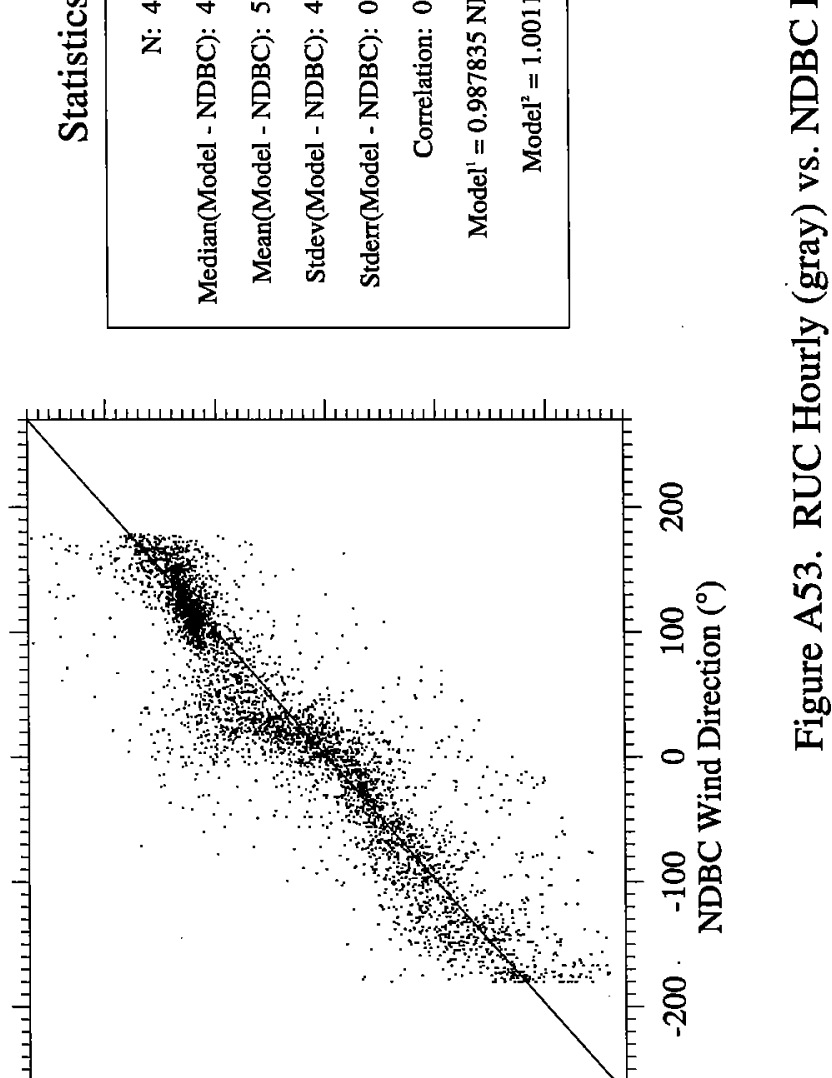

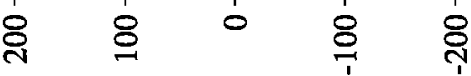

(。) иопฺрап! рu!M гәроW 


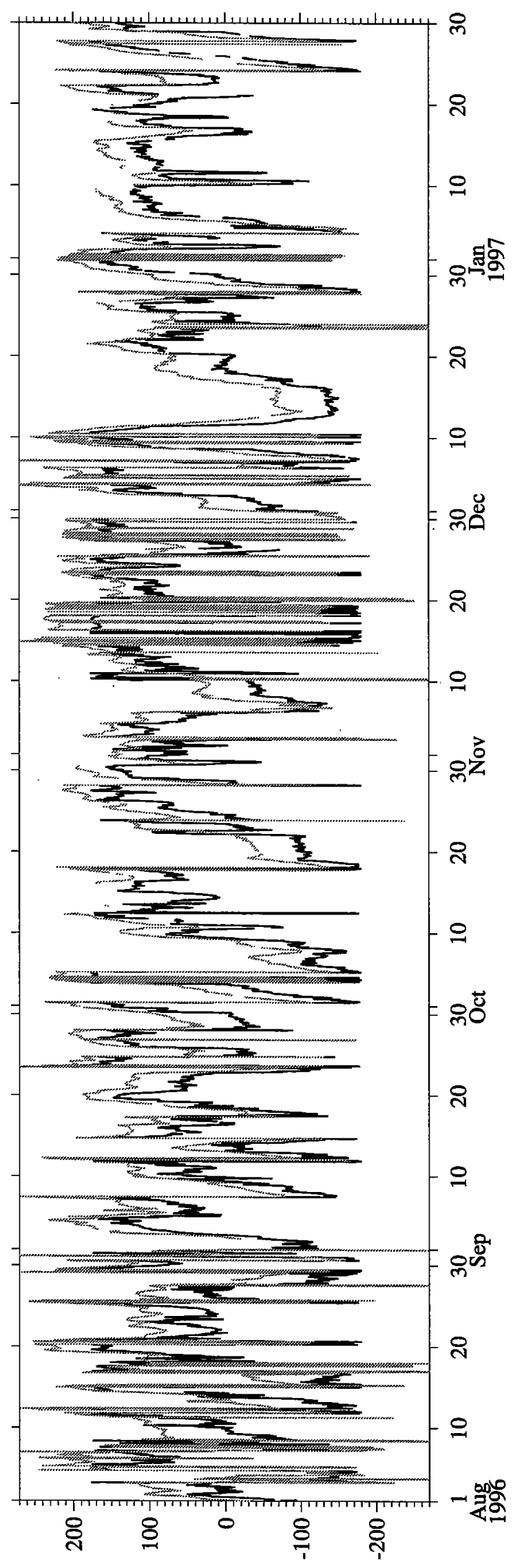

(о) uoп̣әапа рu!M

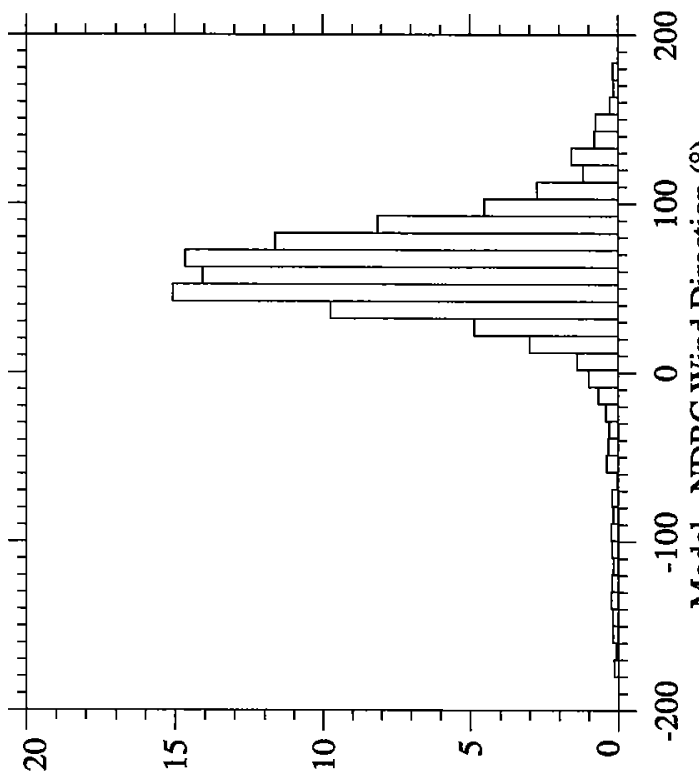

(\%) КวuənbəI

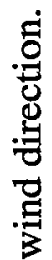

월
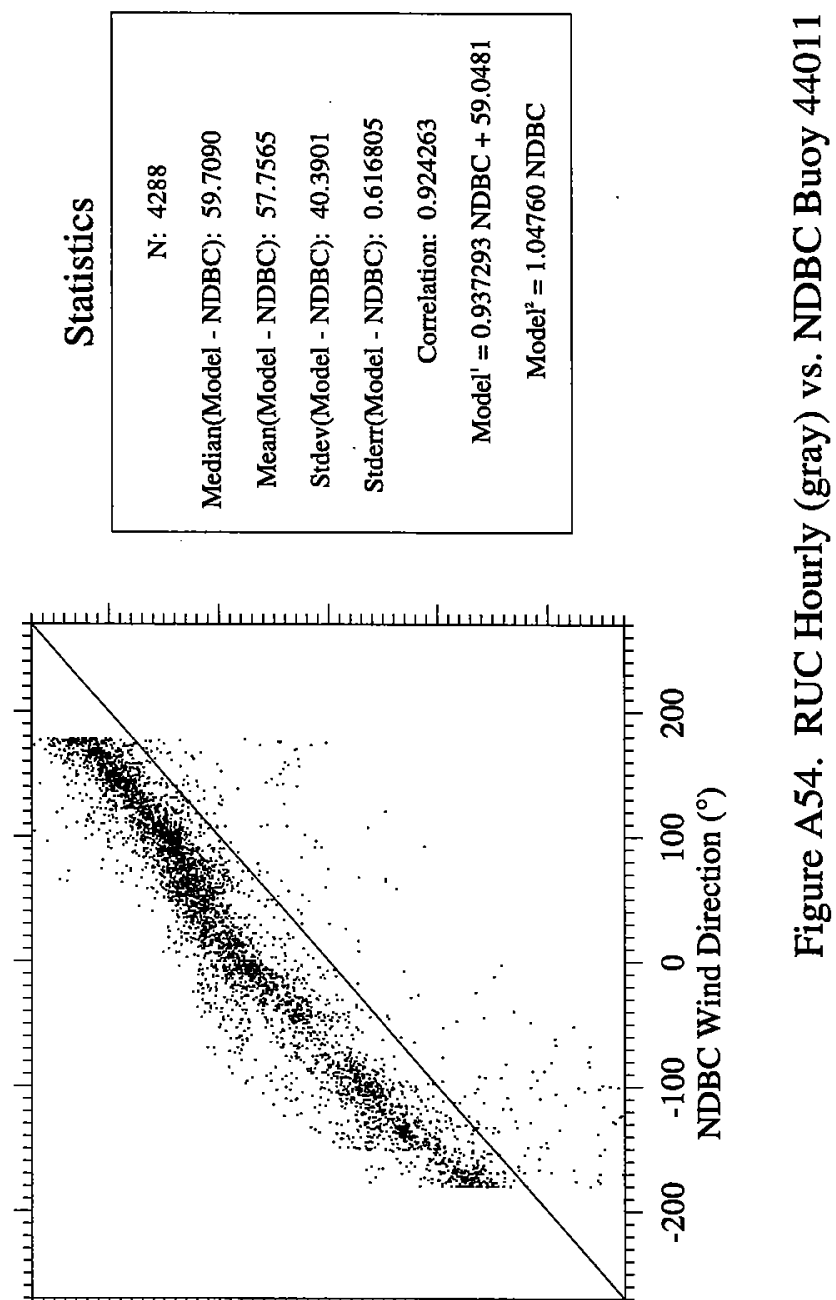

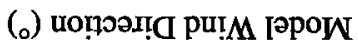




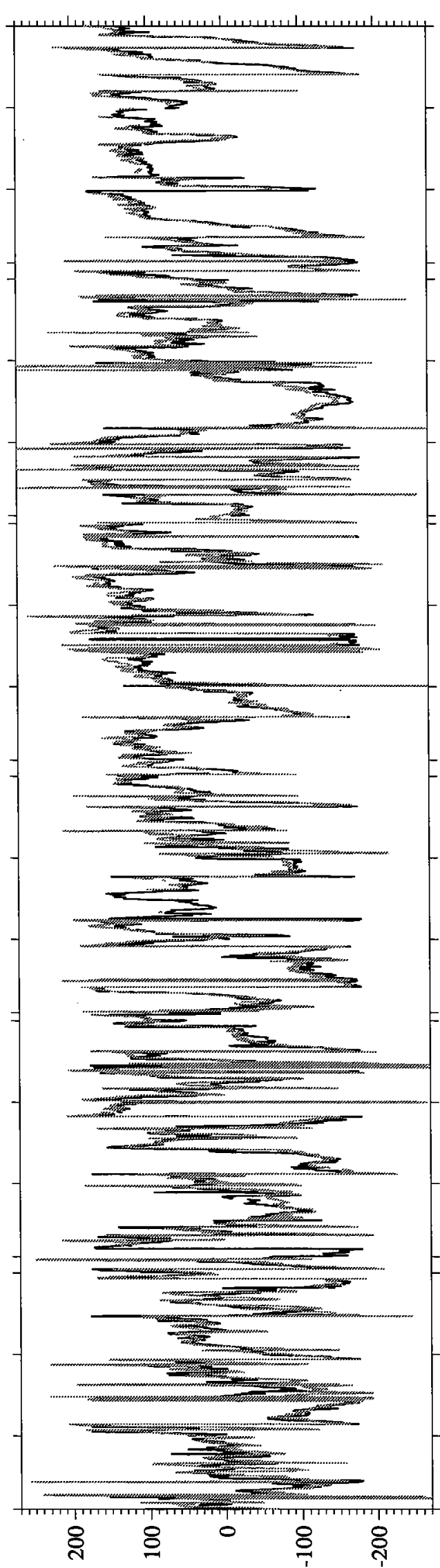

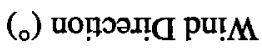

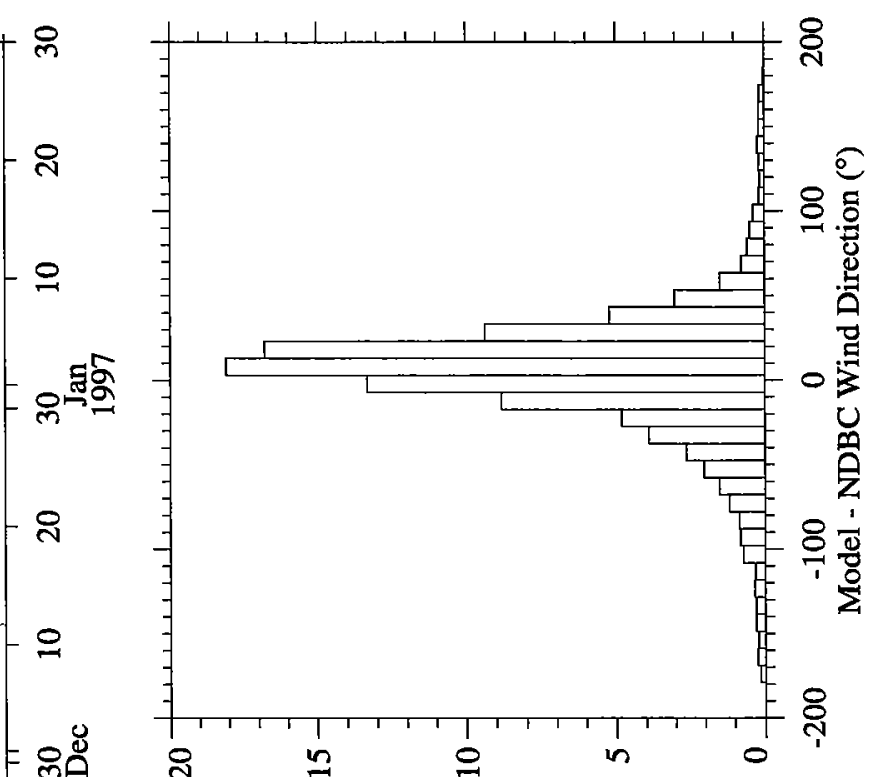

(\%) Kouənbər⿶

จ

운

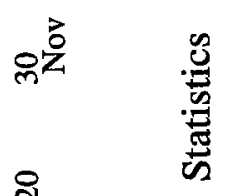

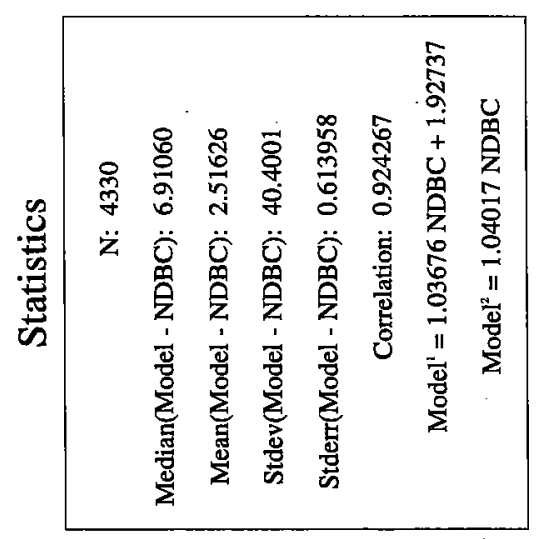

คెั

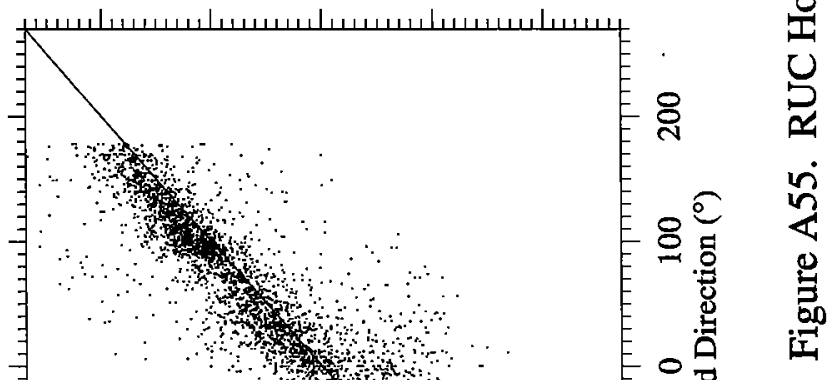




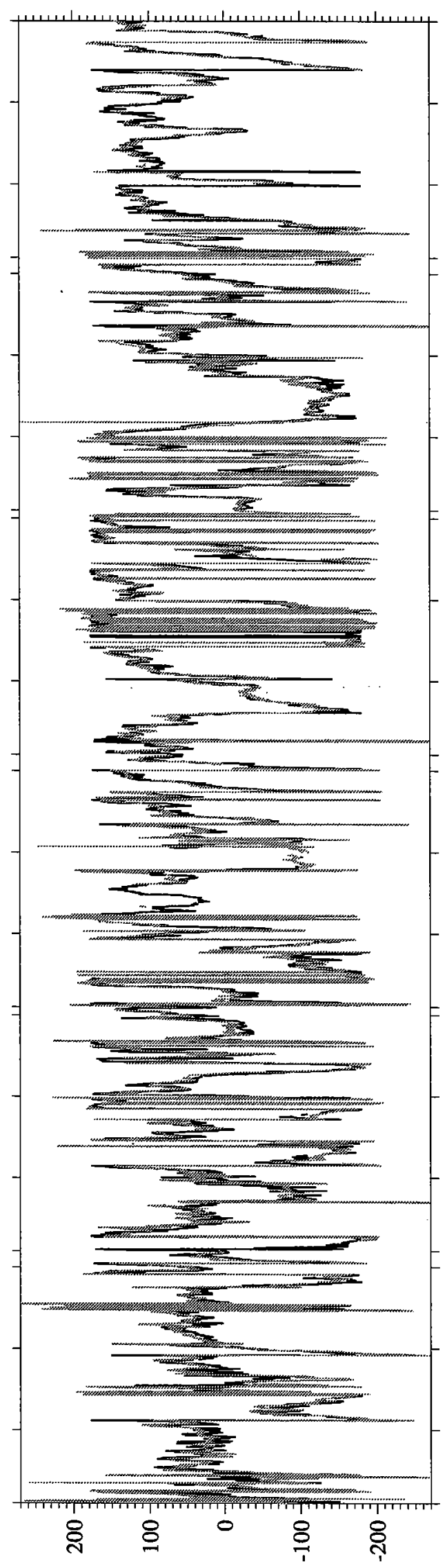

(॰) uoṭэәп! рuा:M

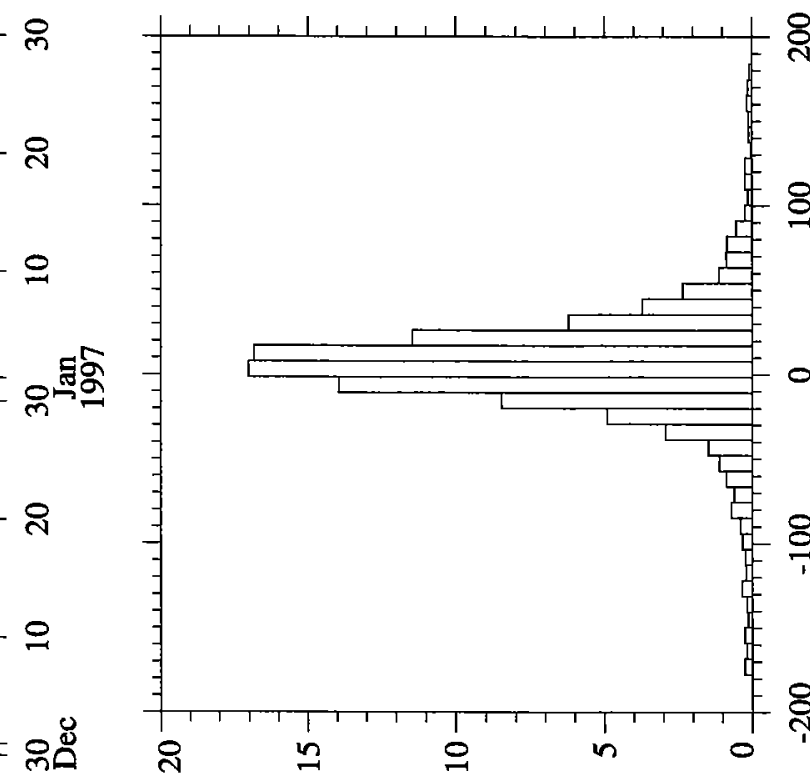

(\%) Kouənbəx.

요

으

ᄋㄹ

กิ

음

రిల్ర

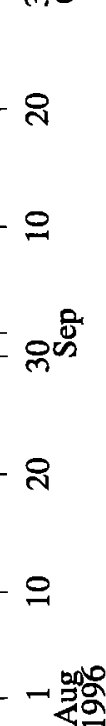

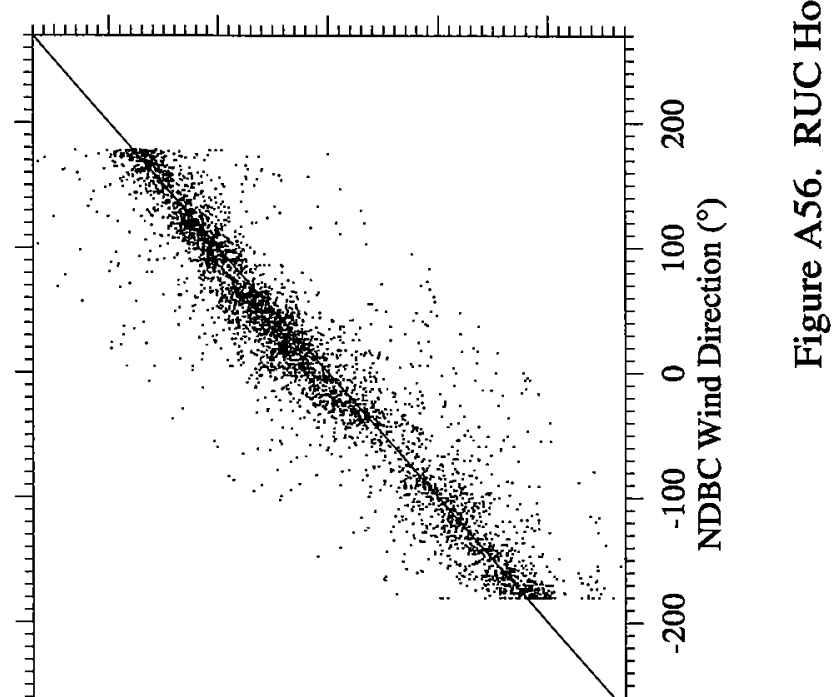



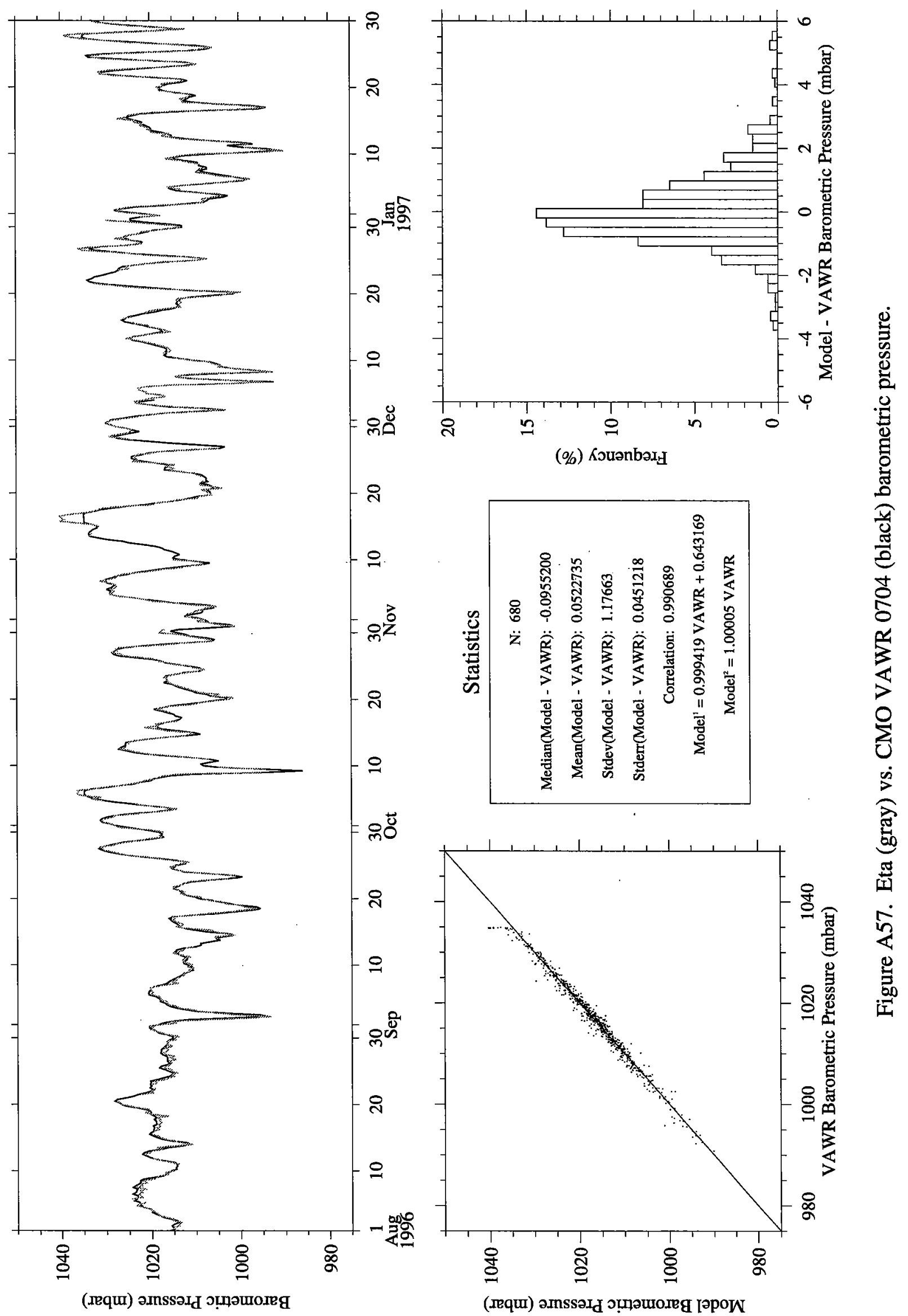


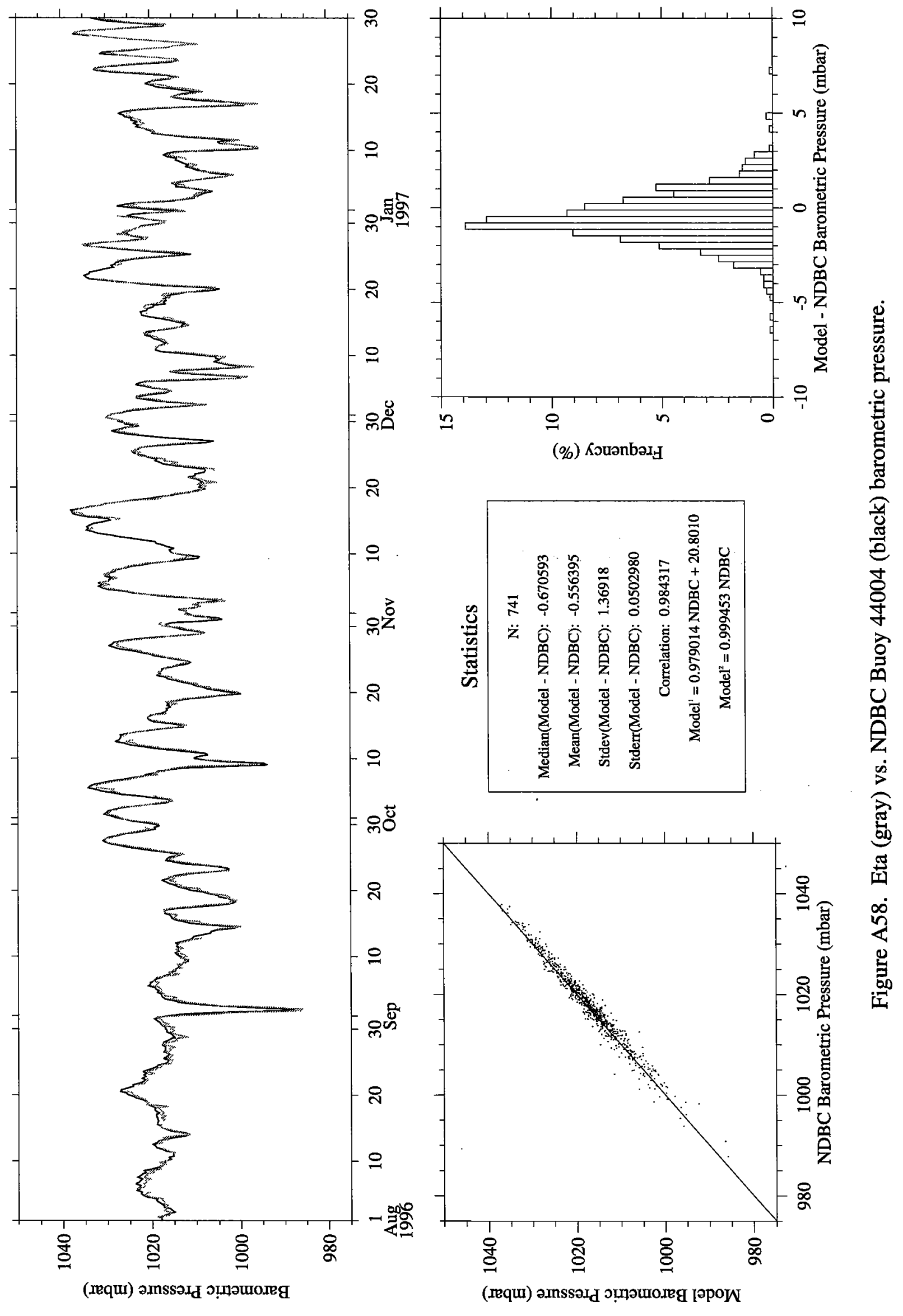



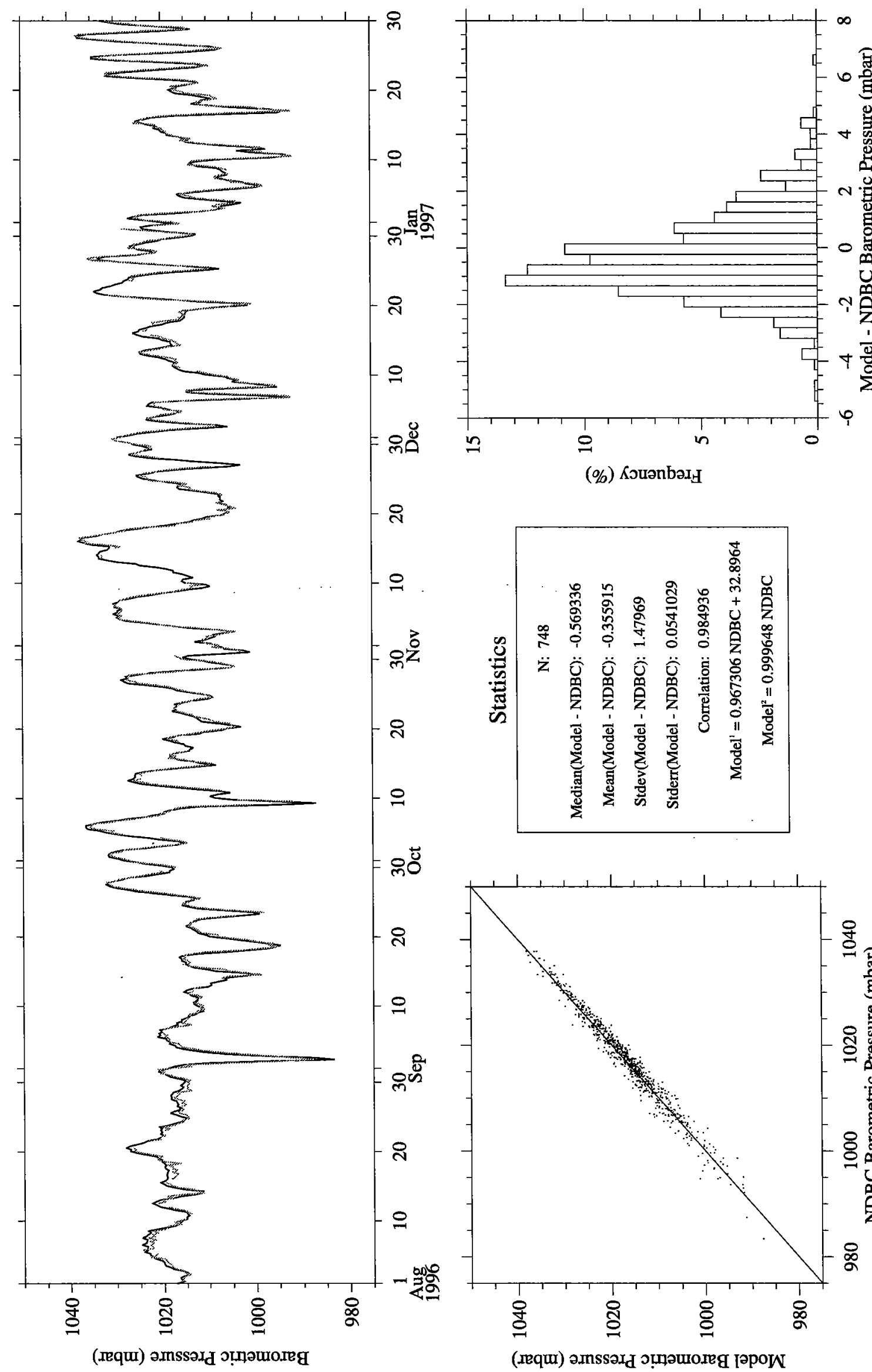

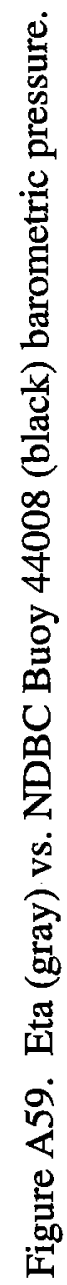



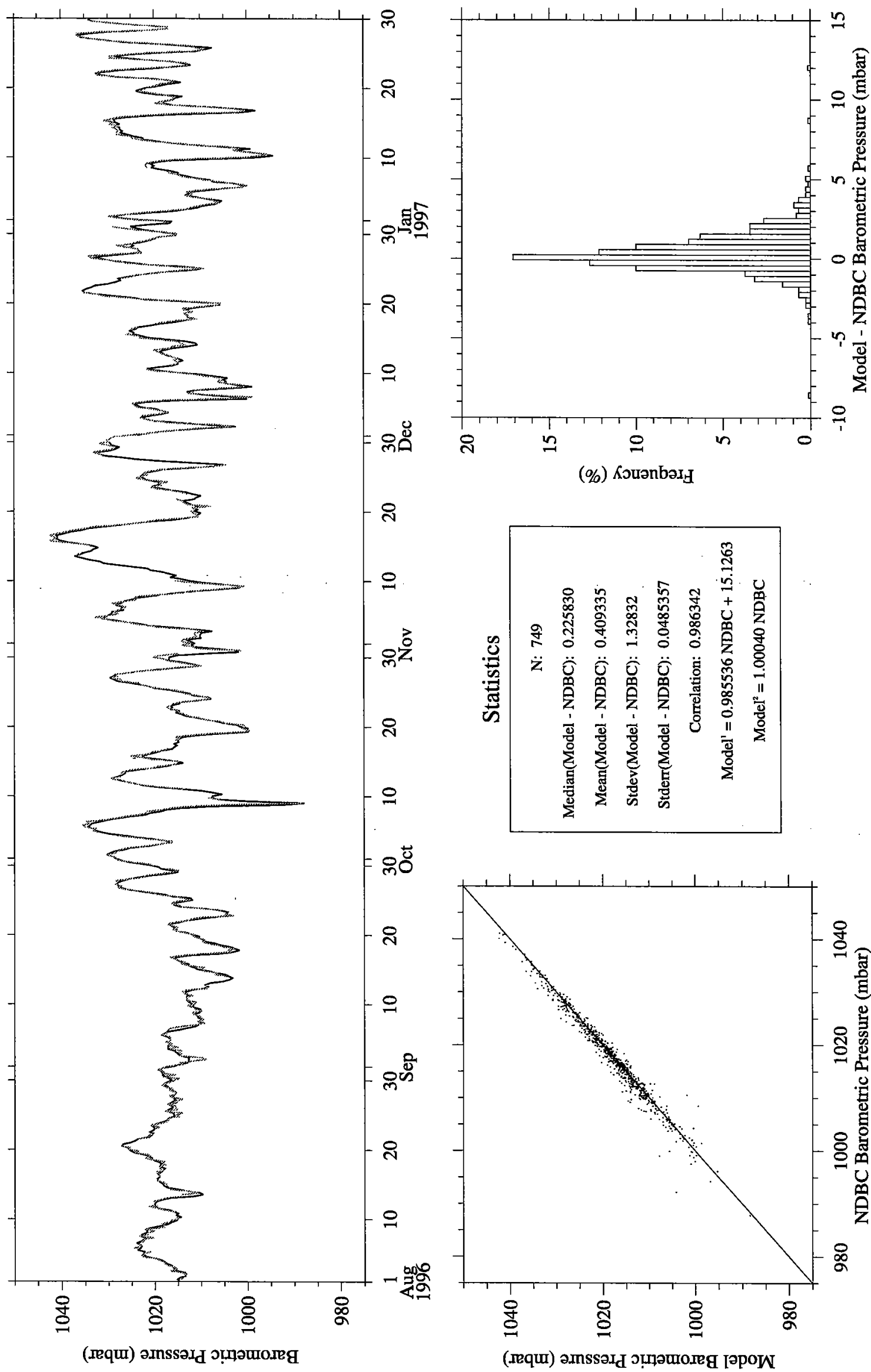

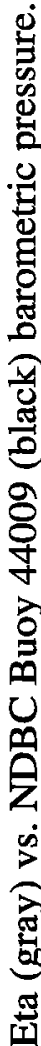
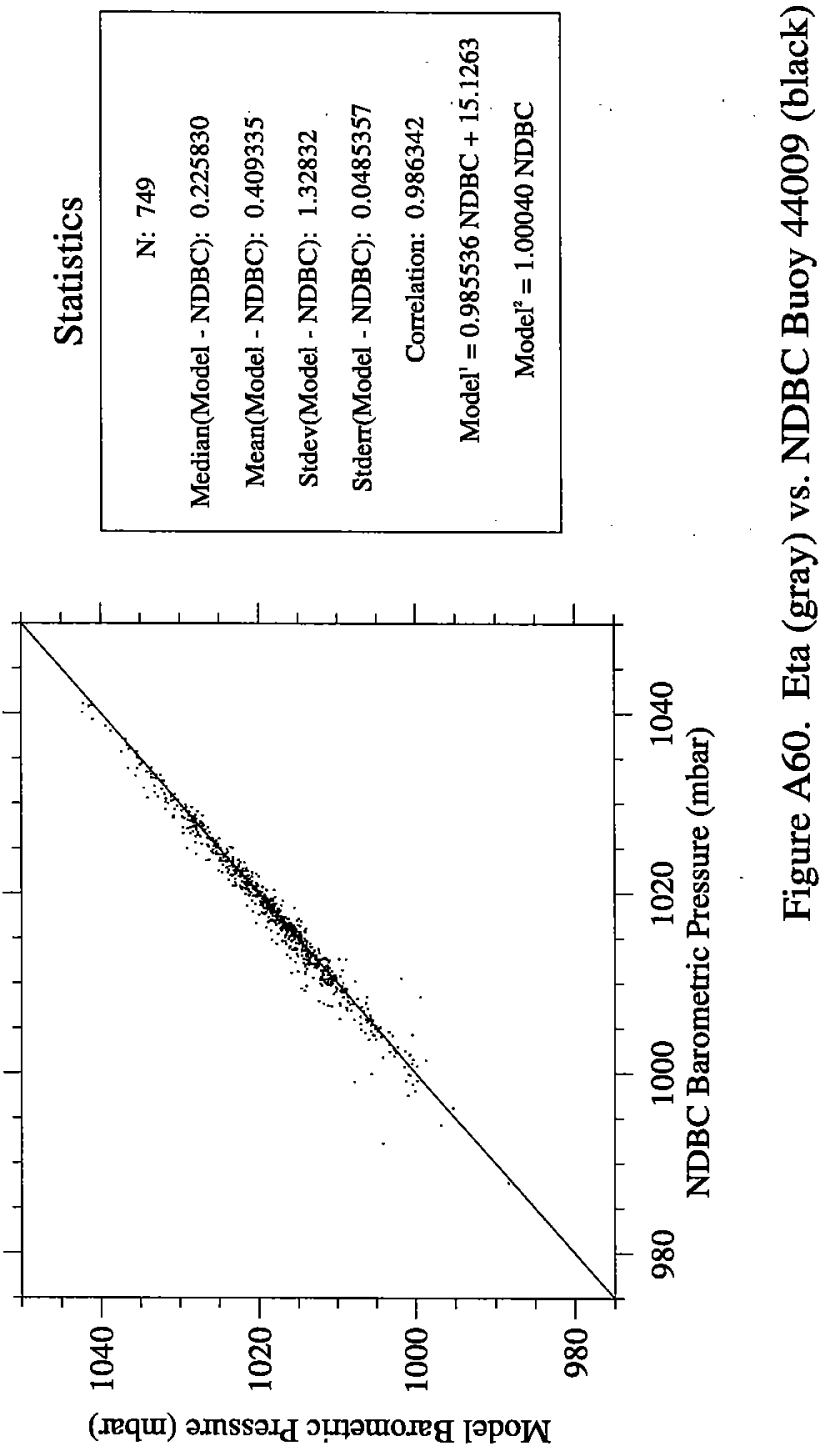


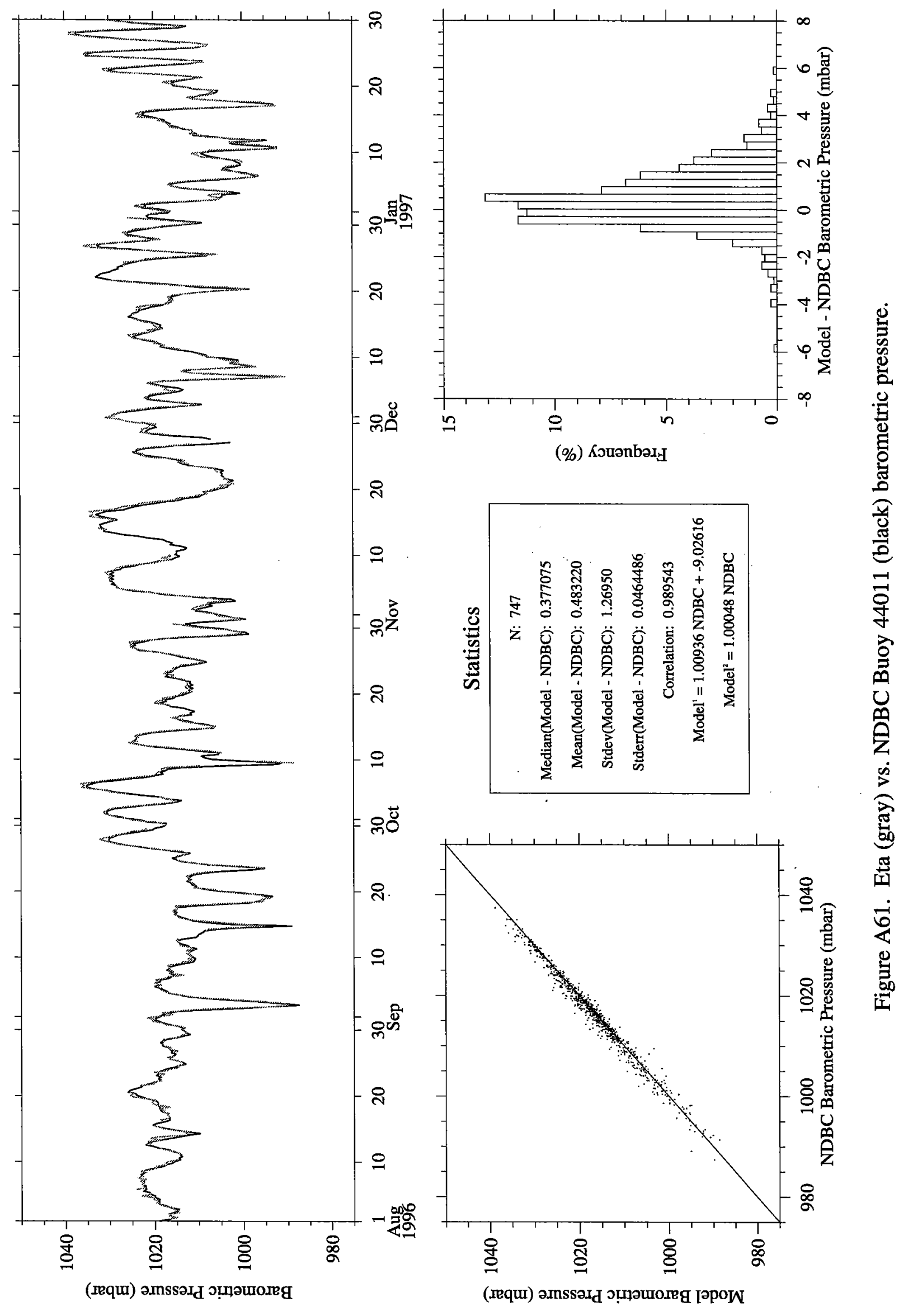




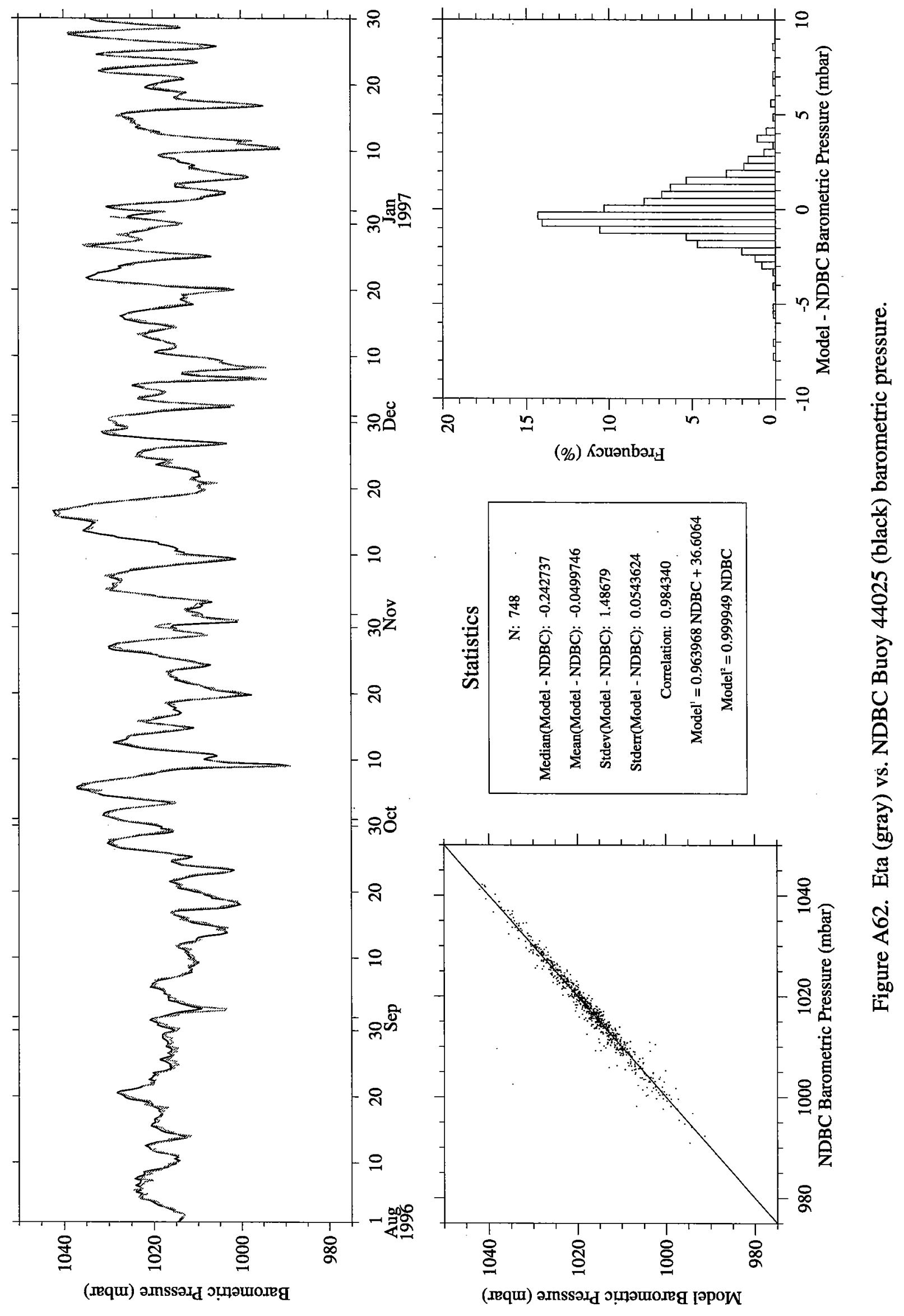



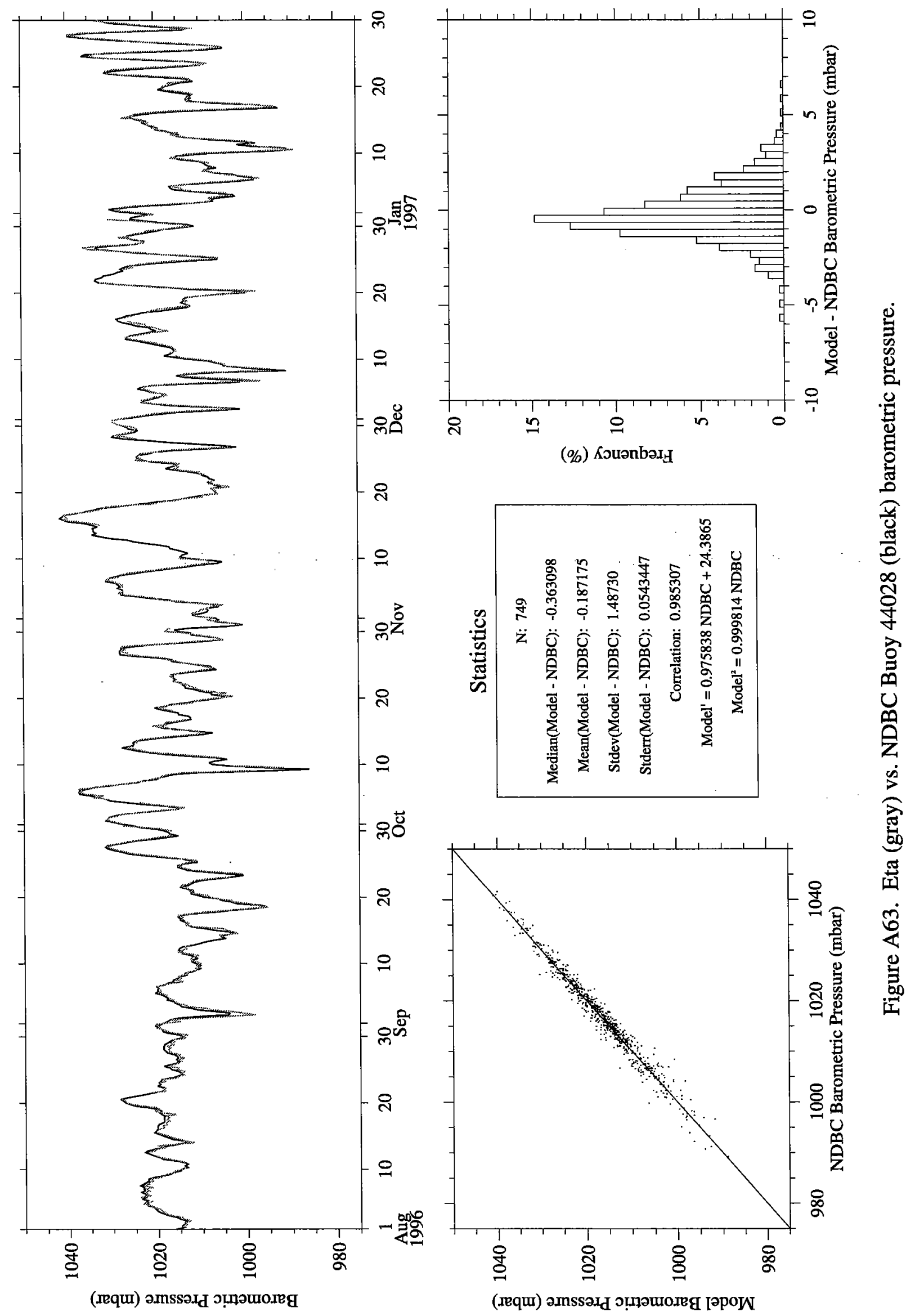


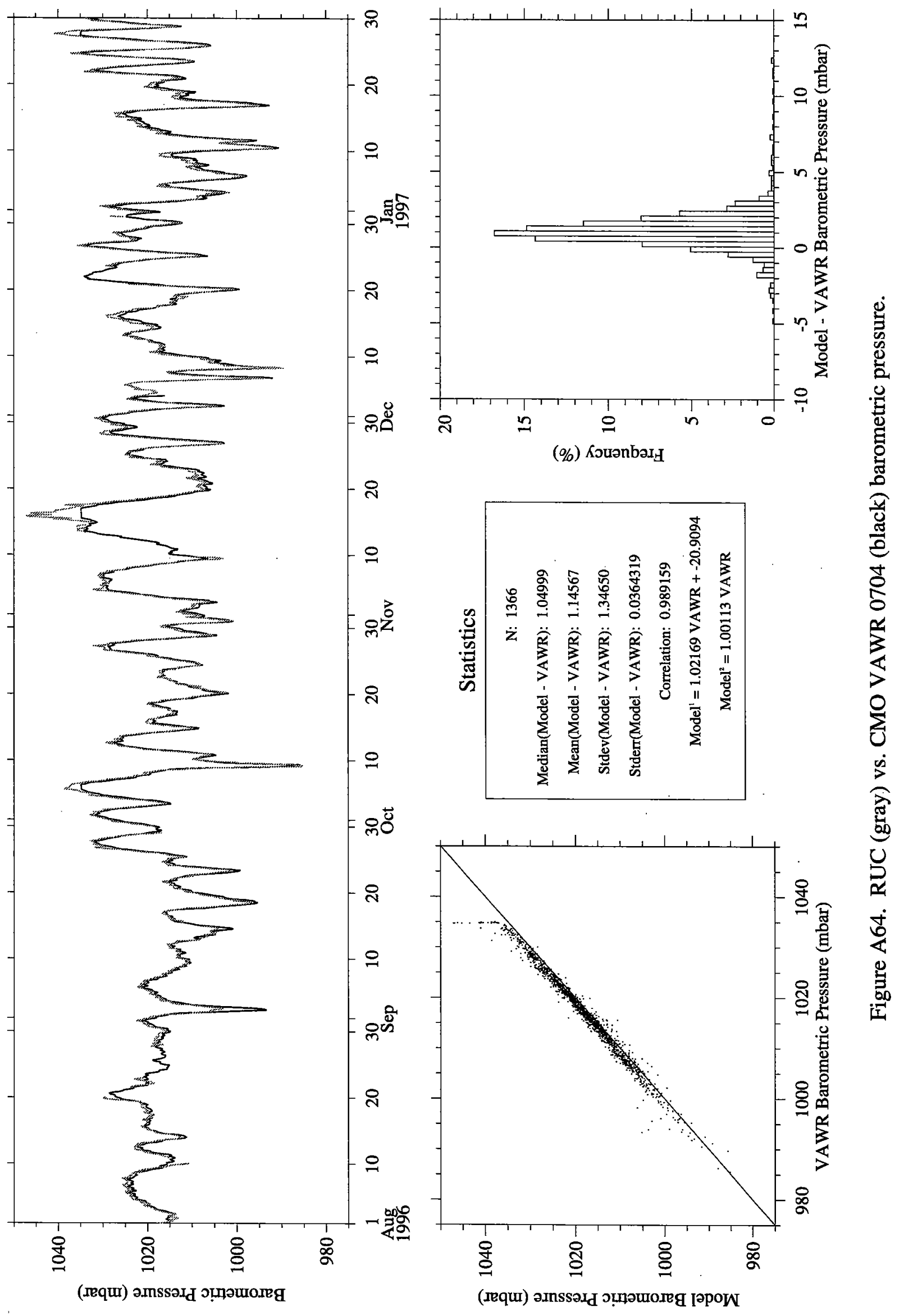



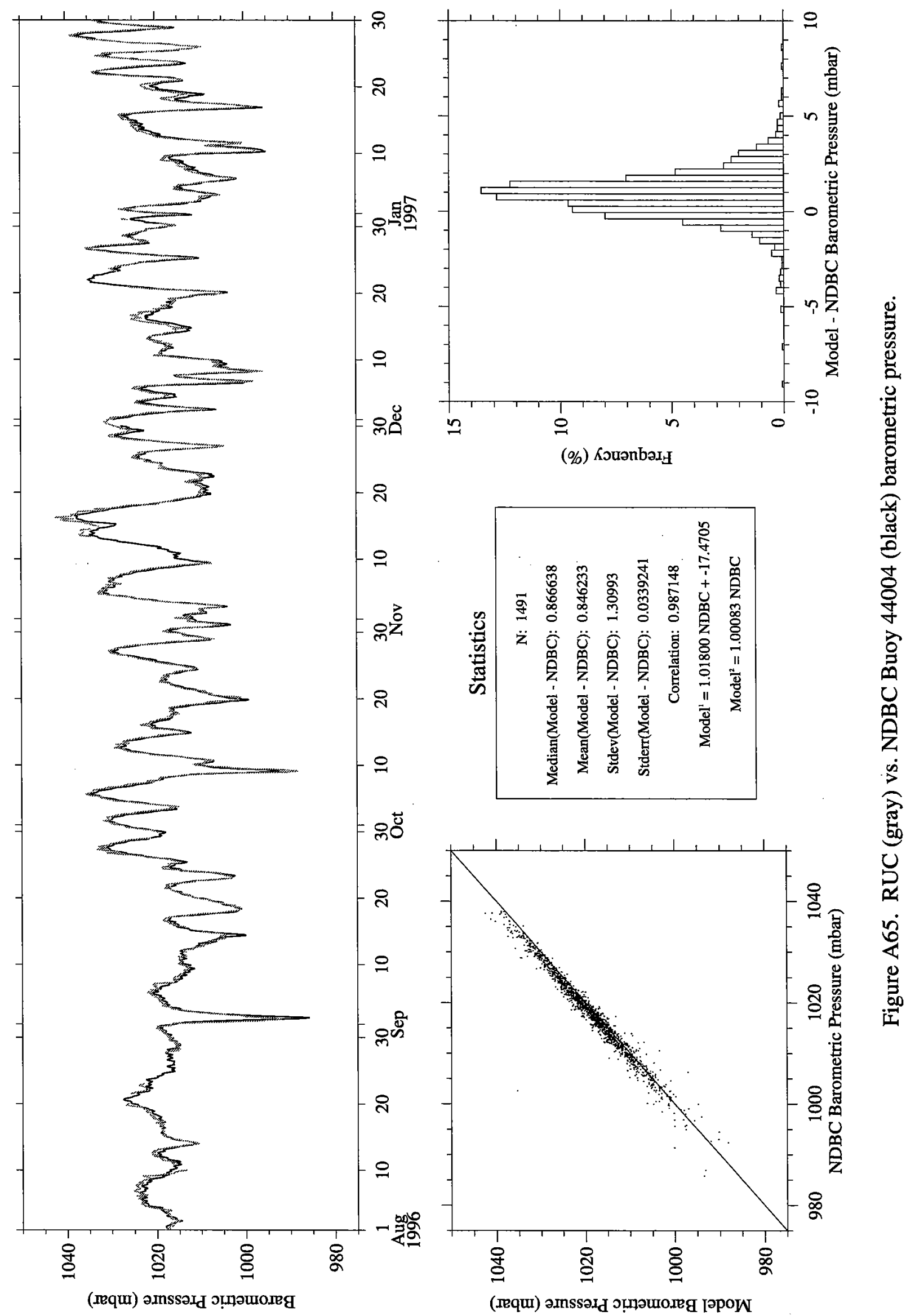


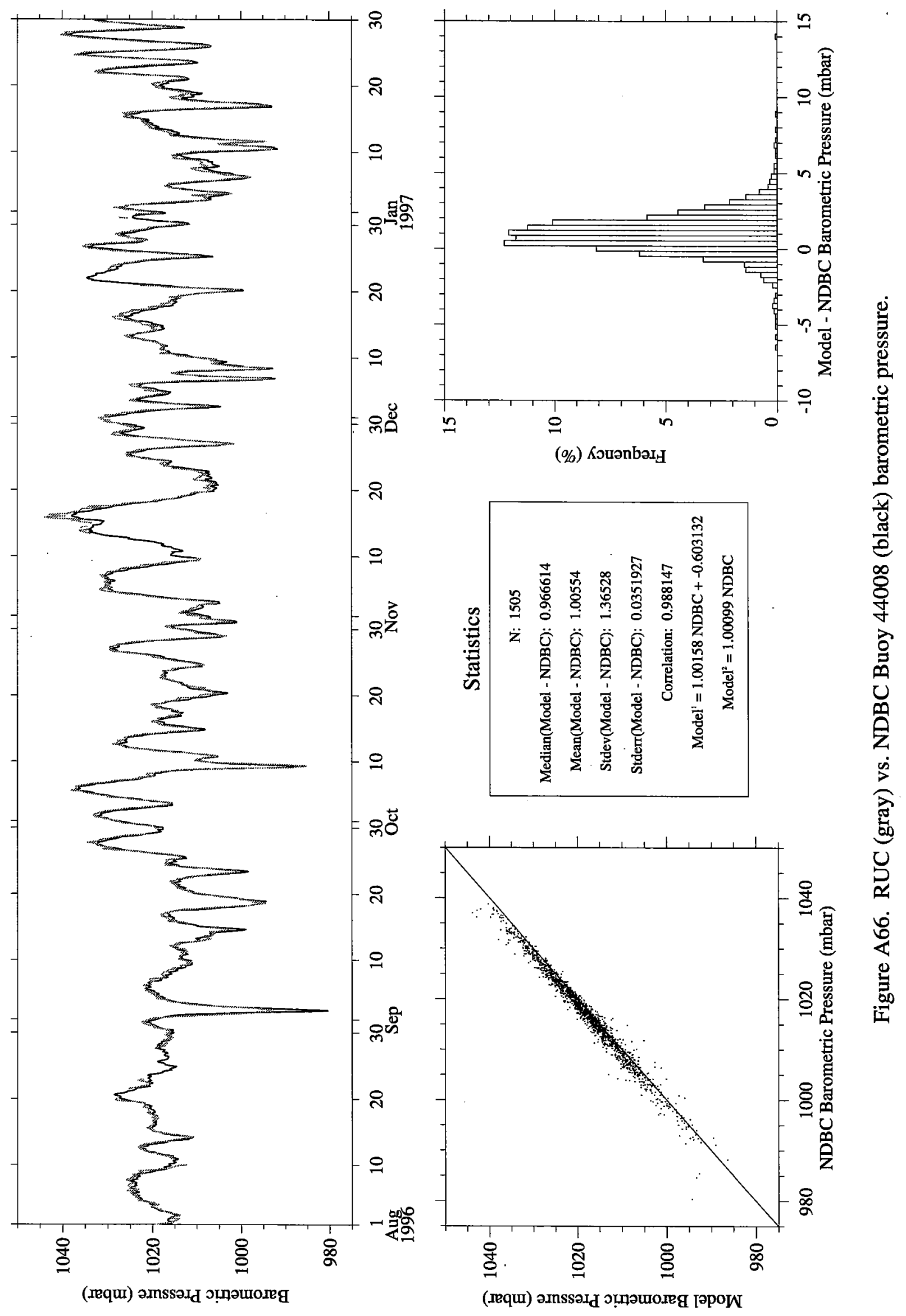



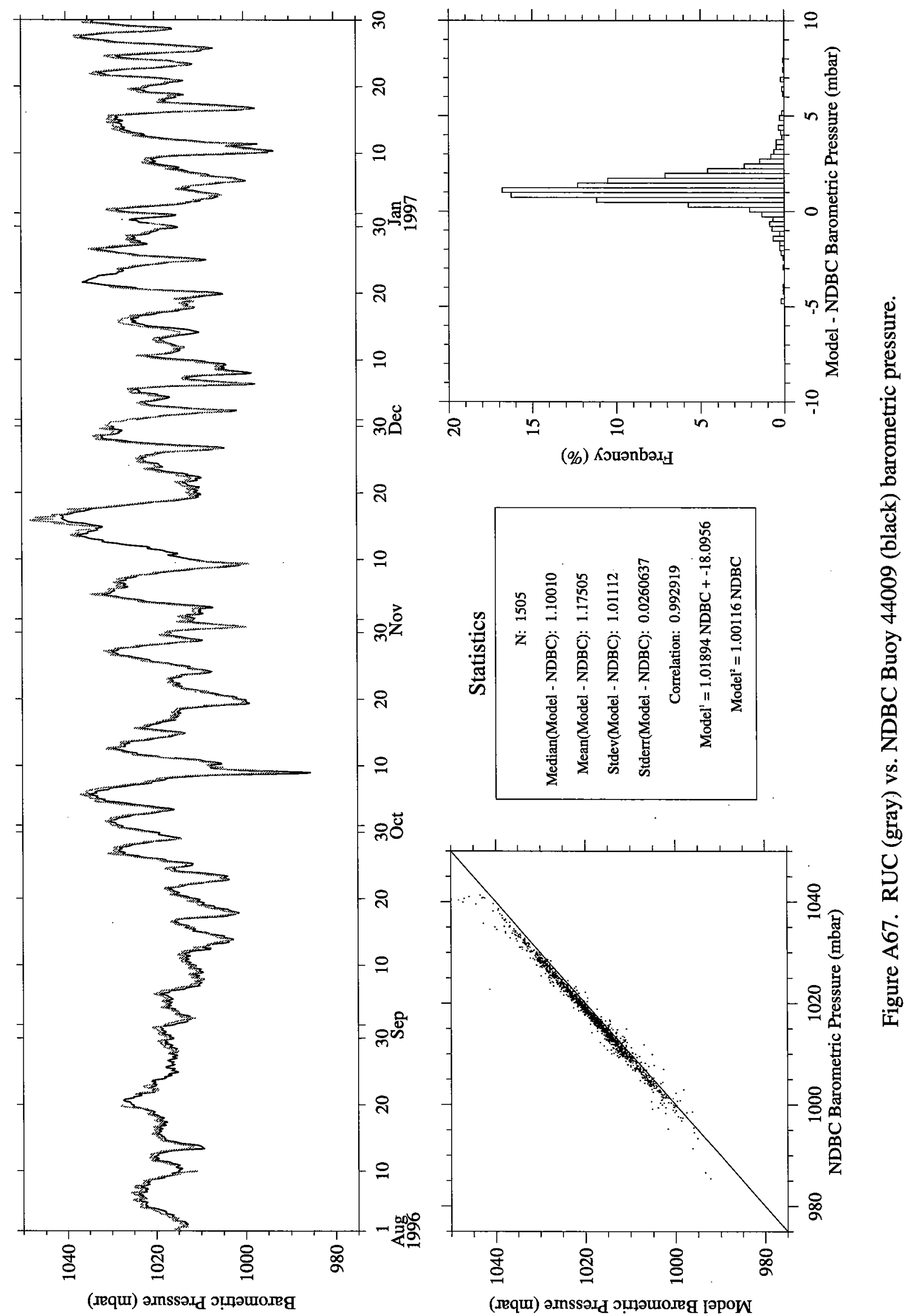

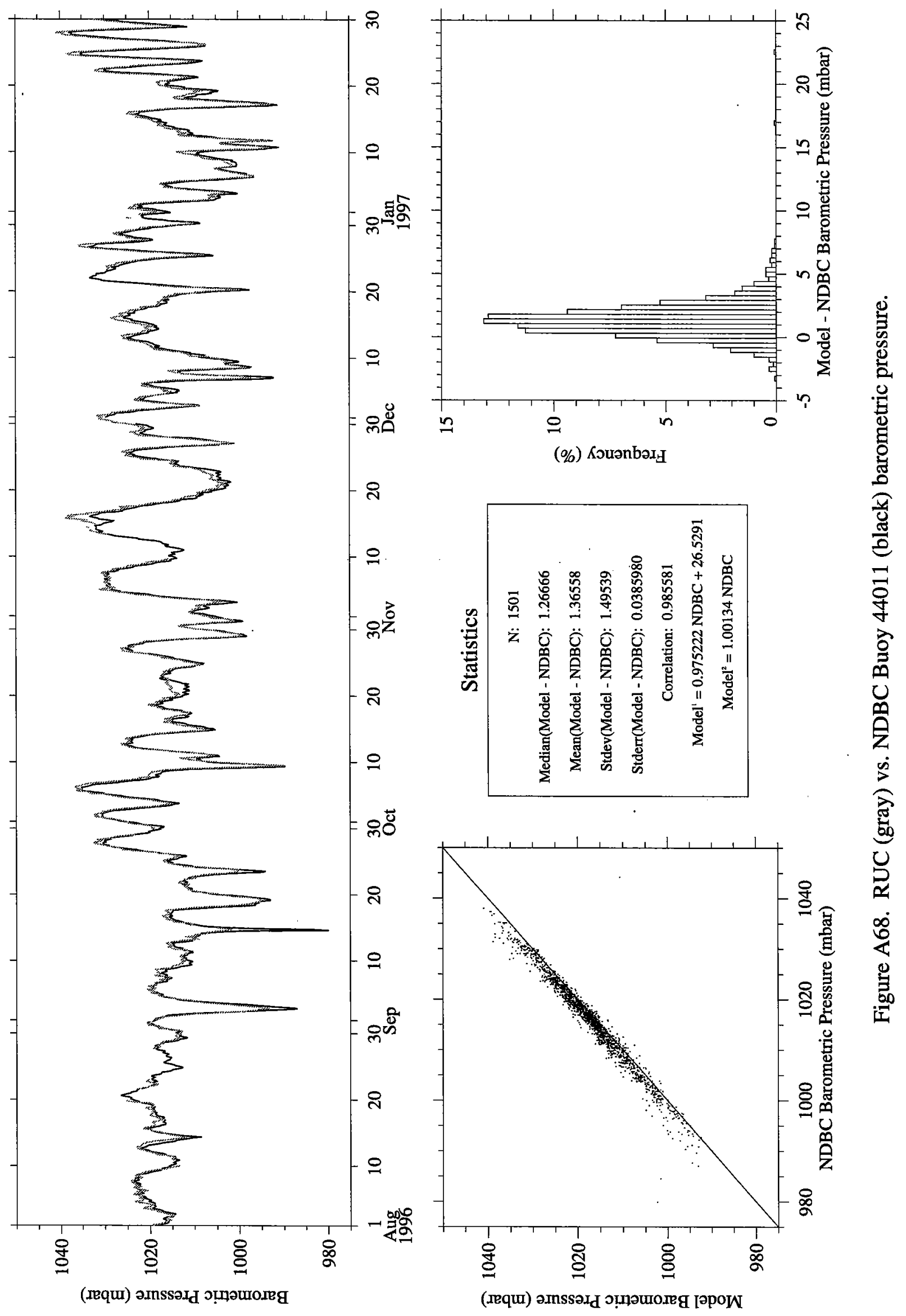

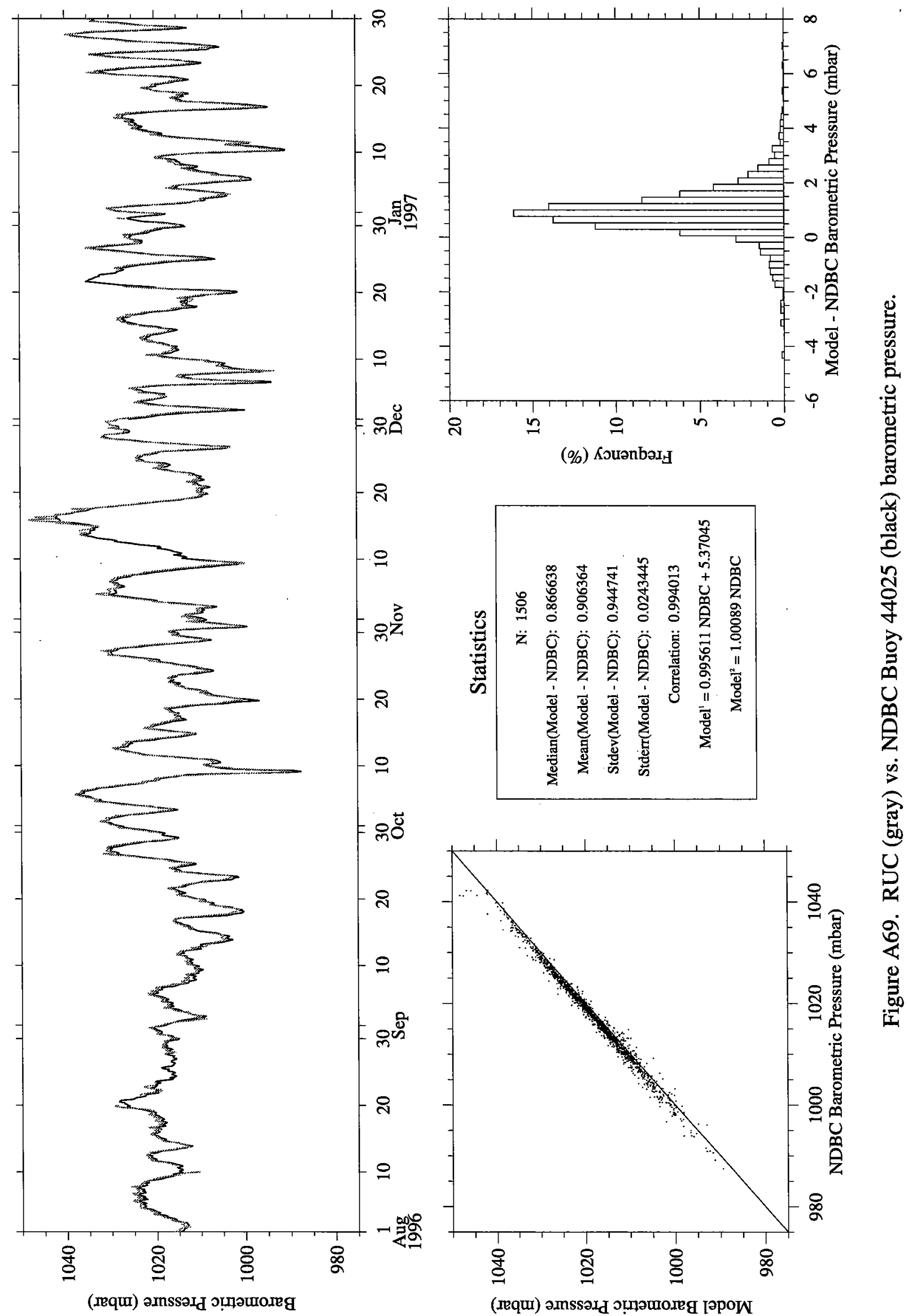


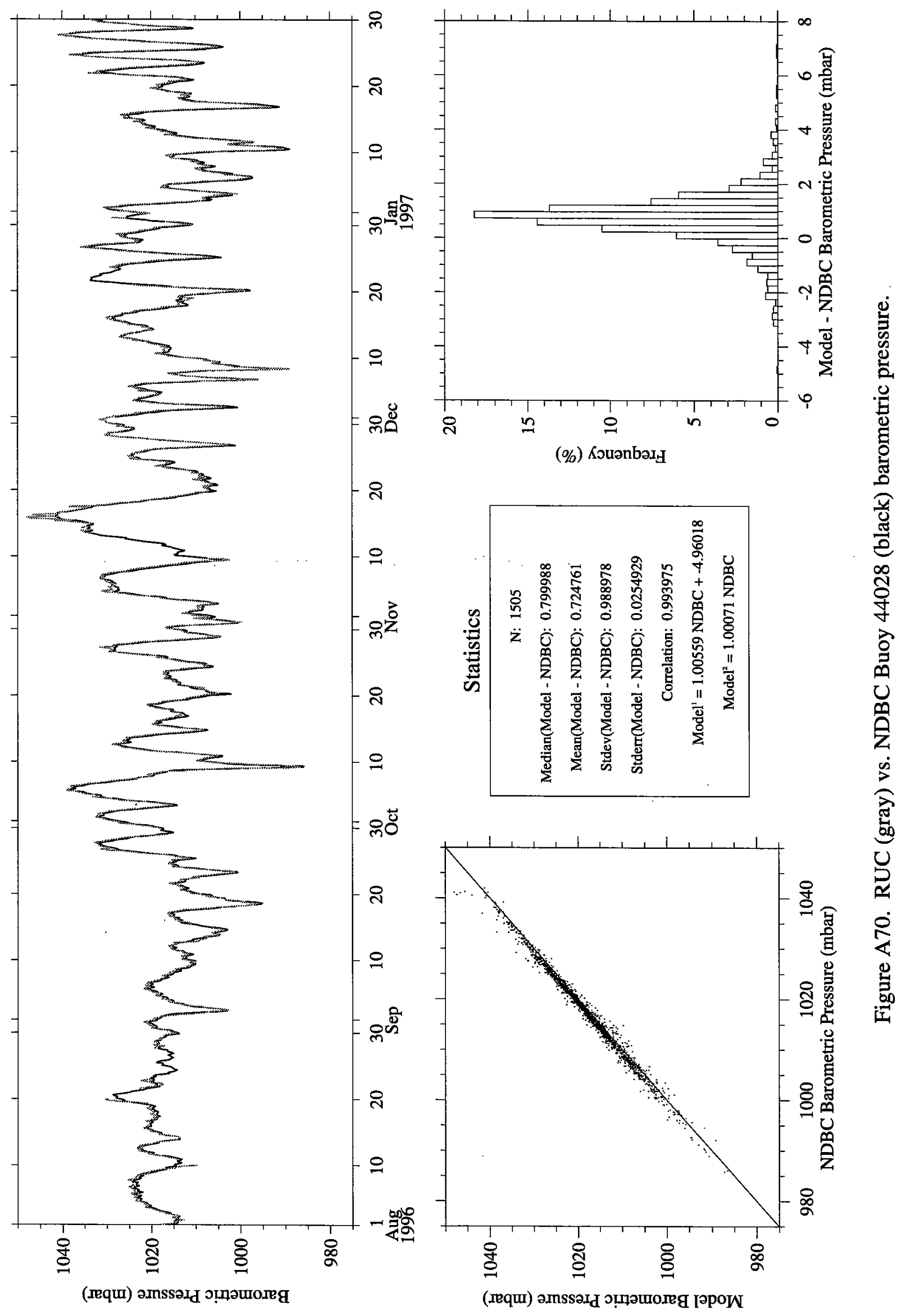




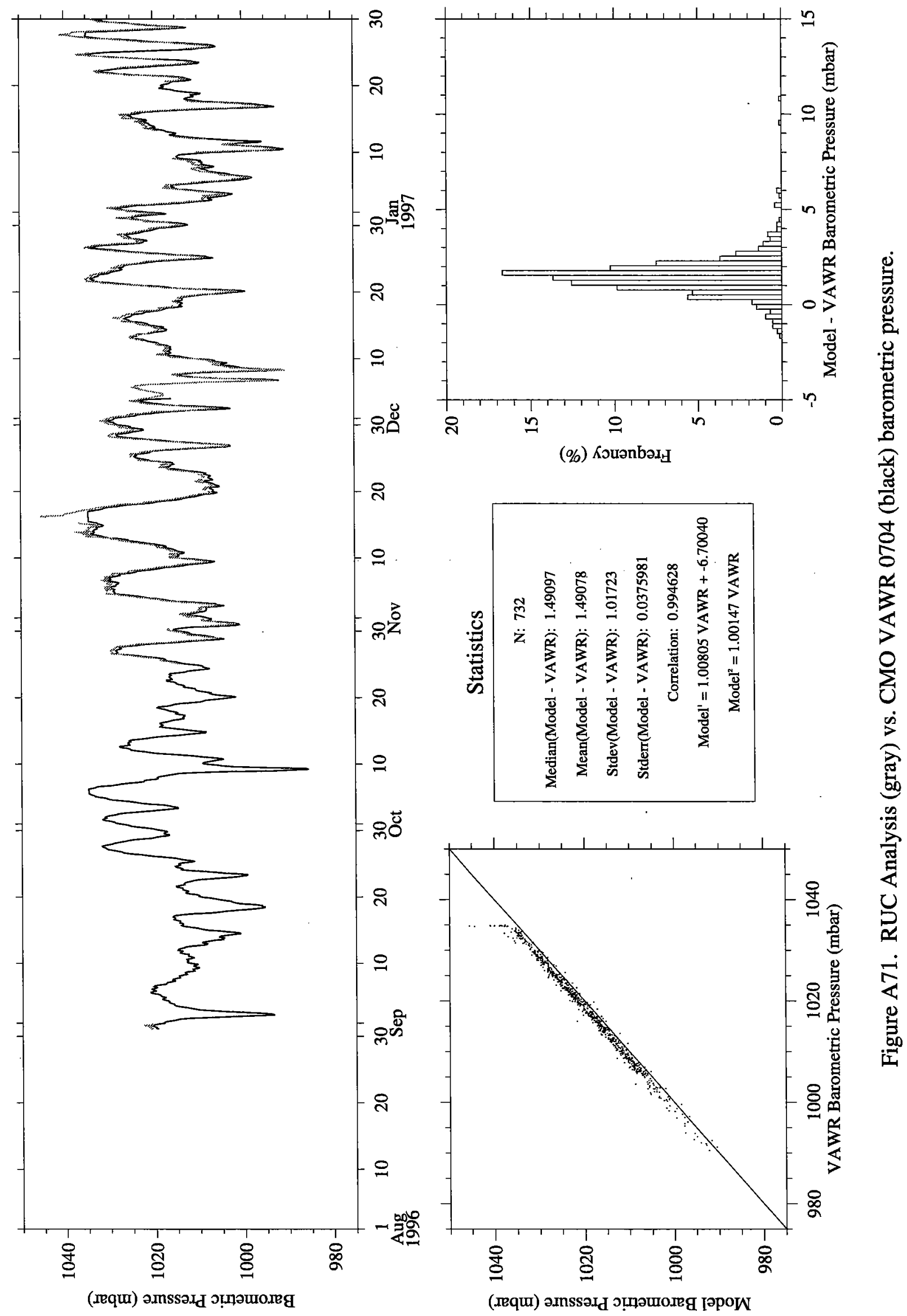




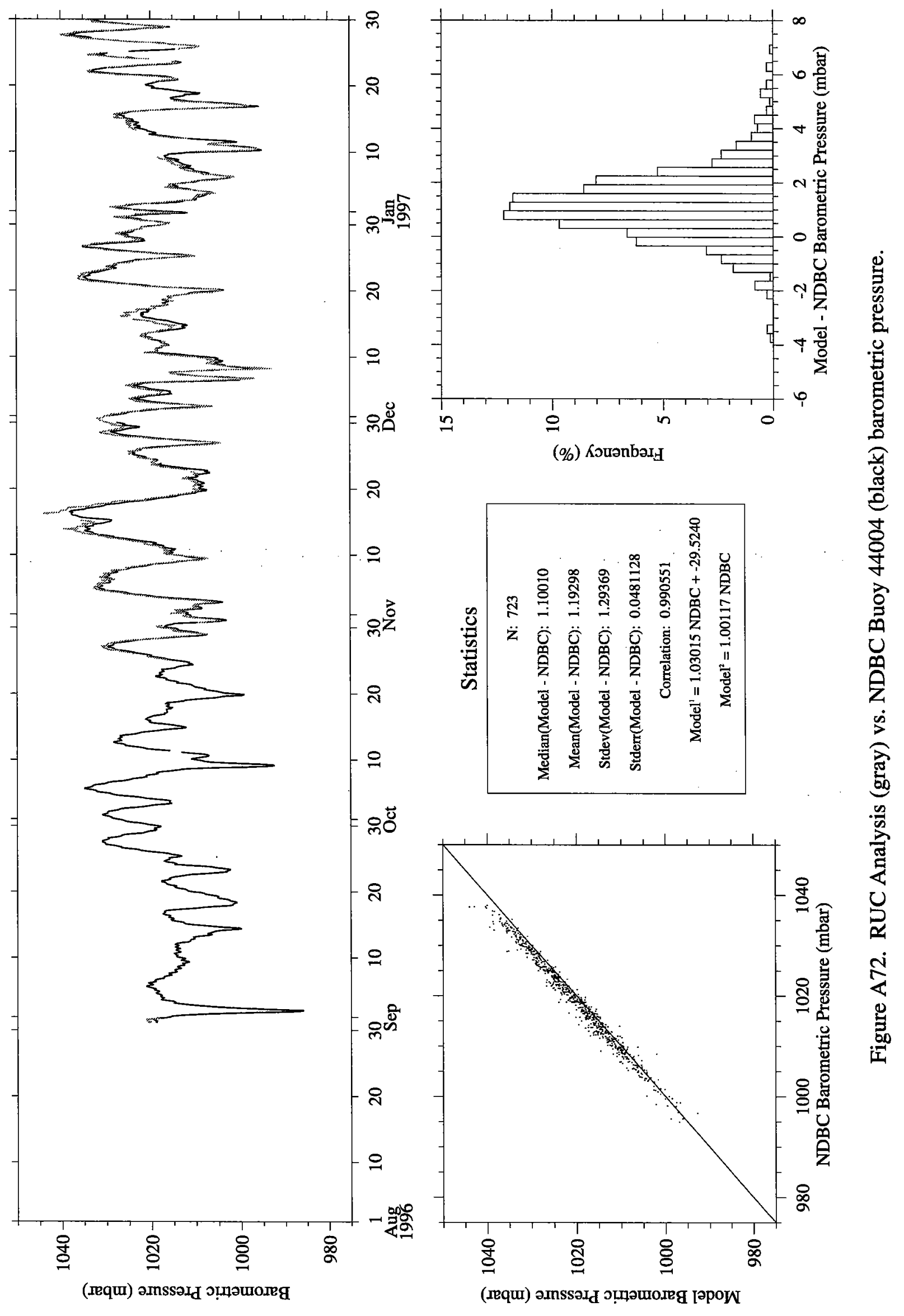



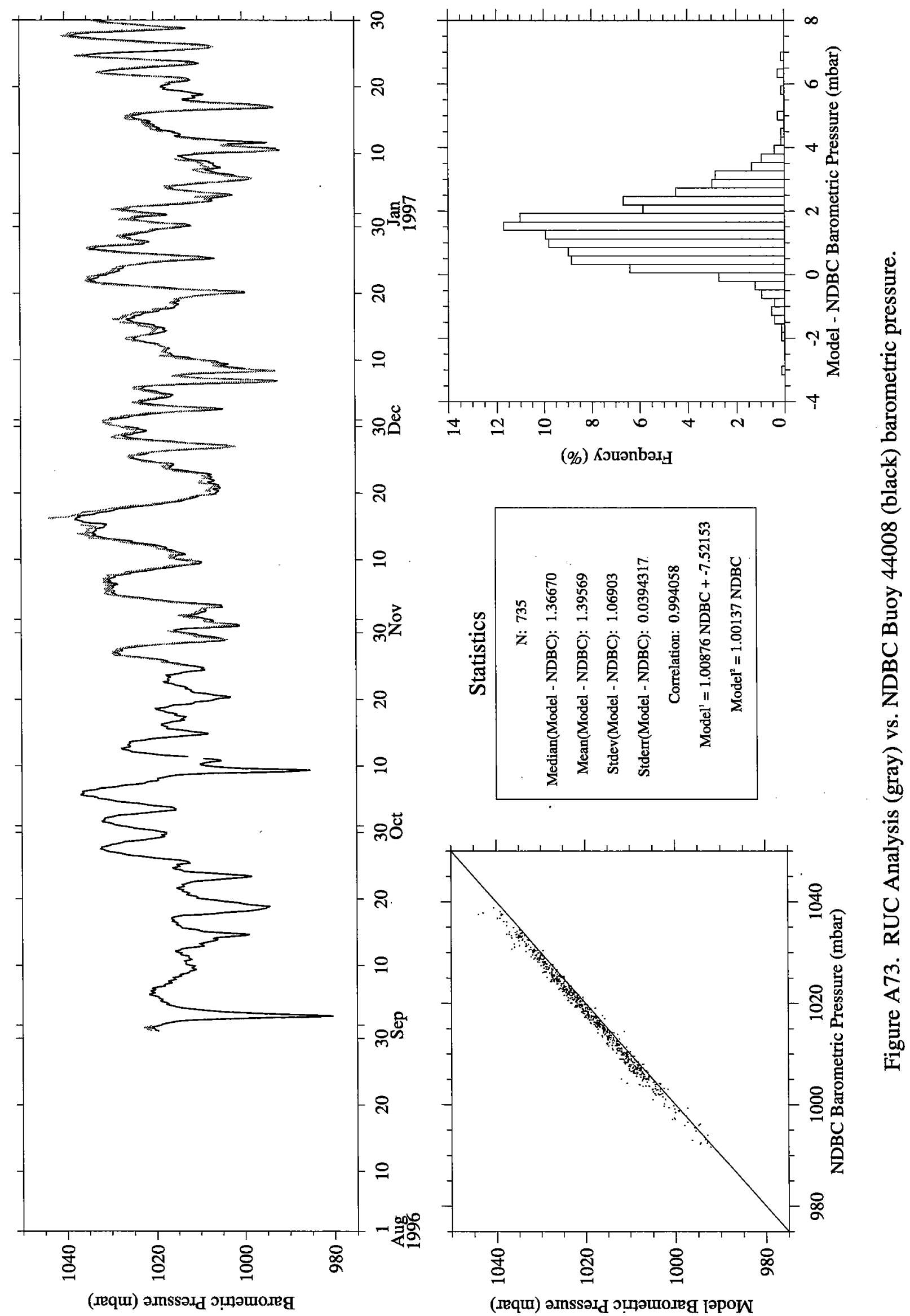


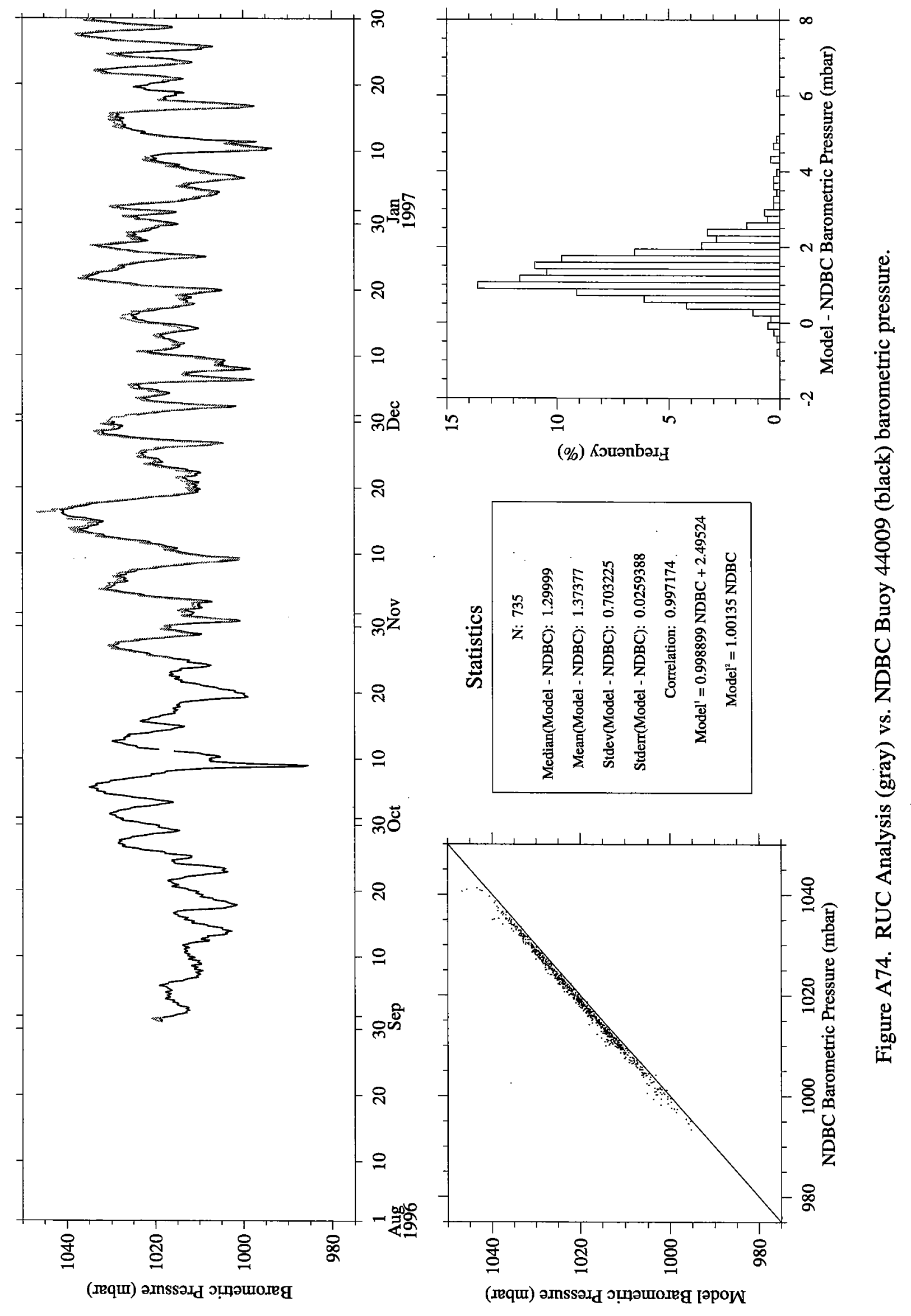




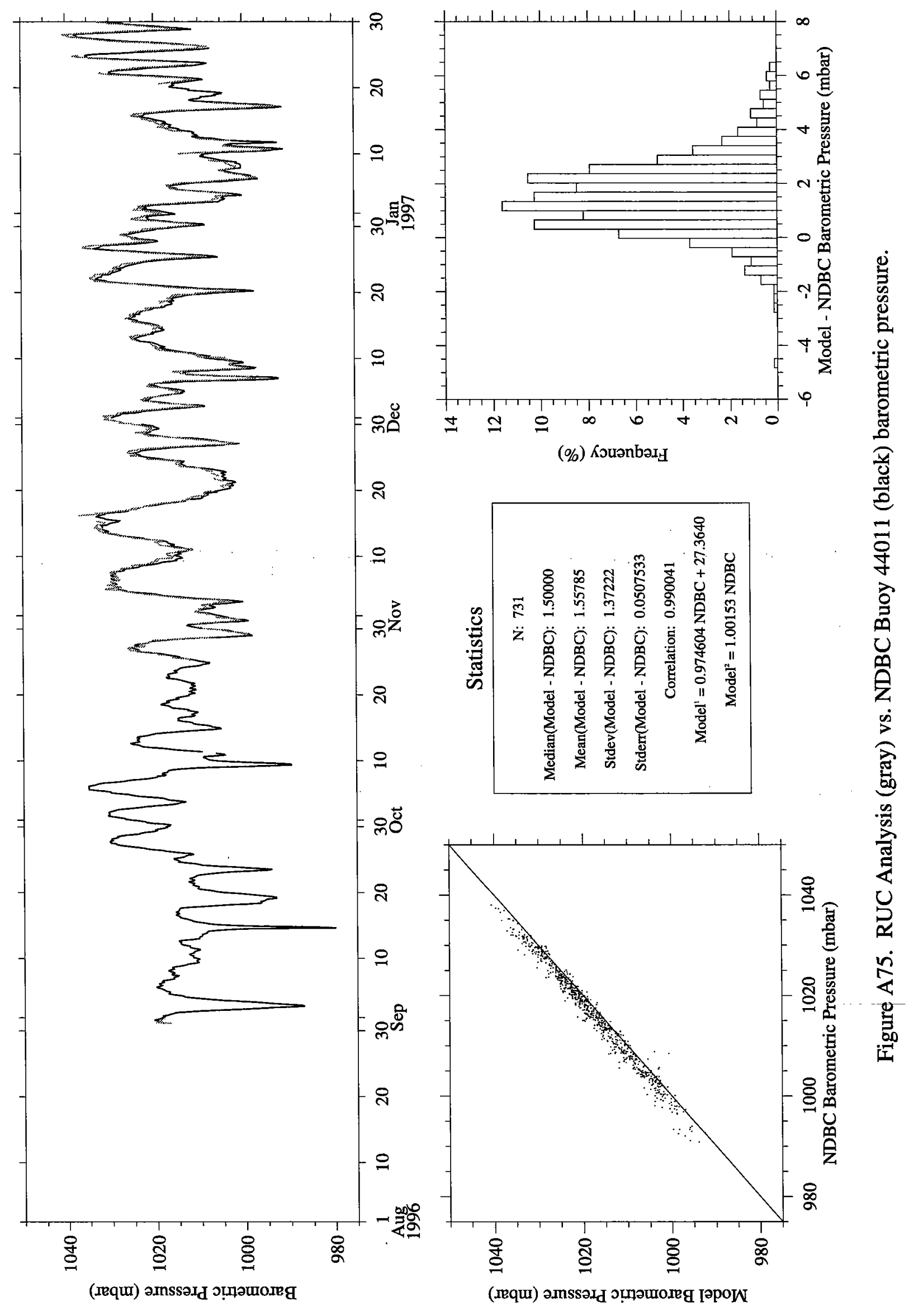




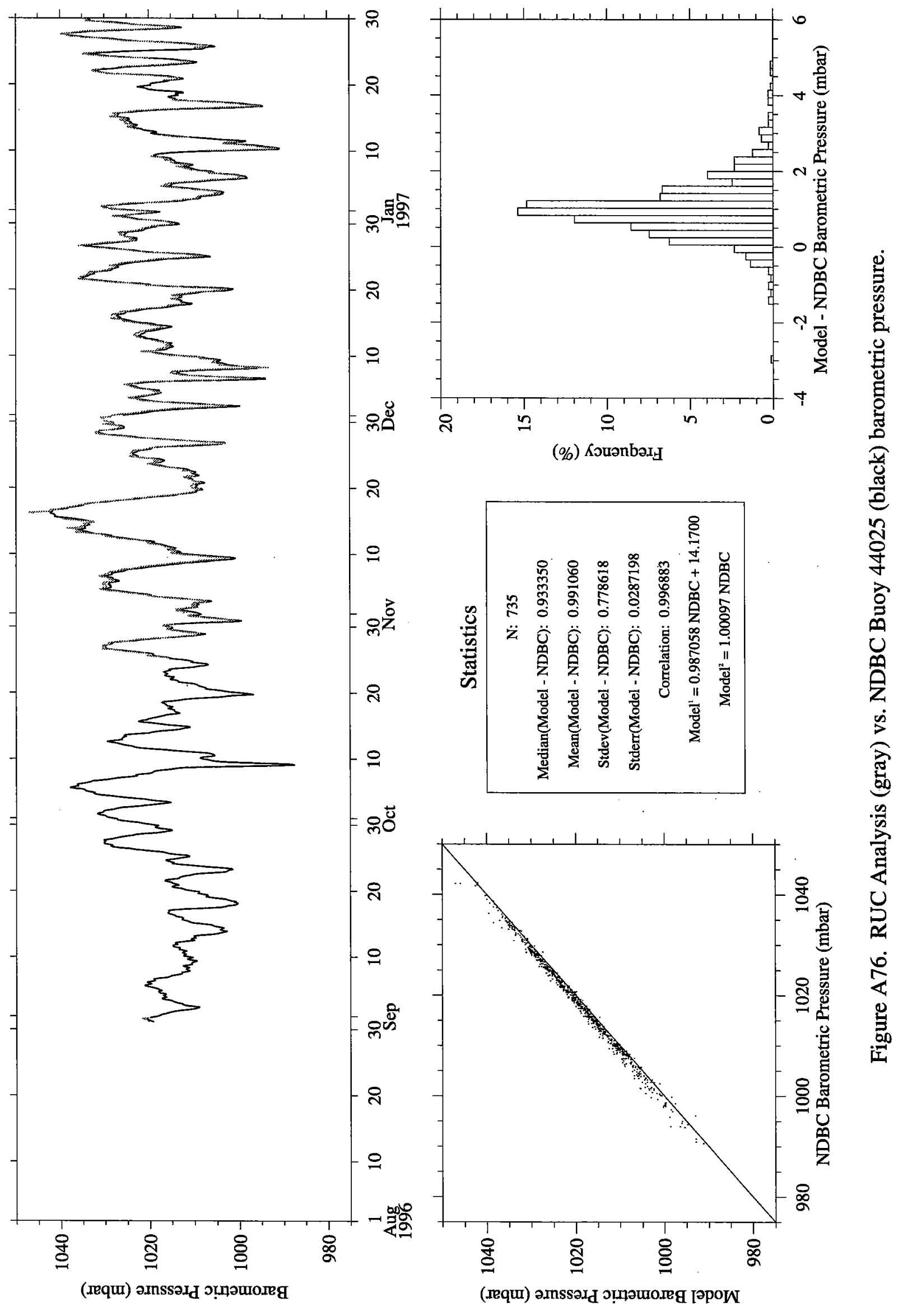



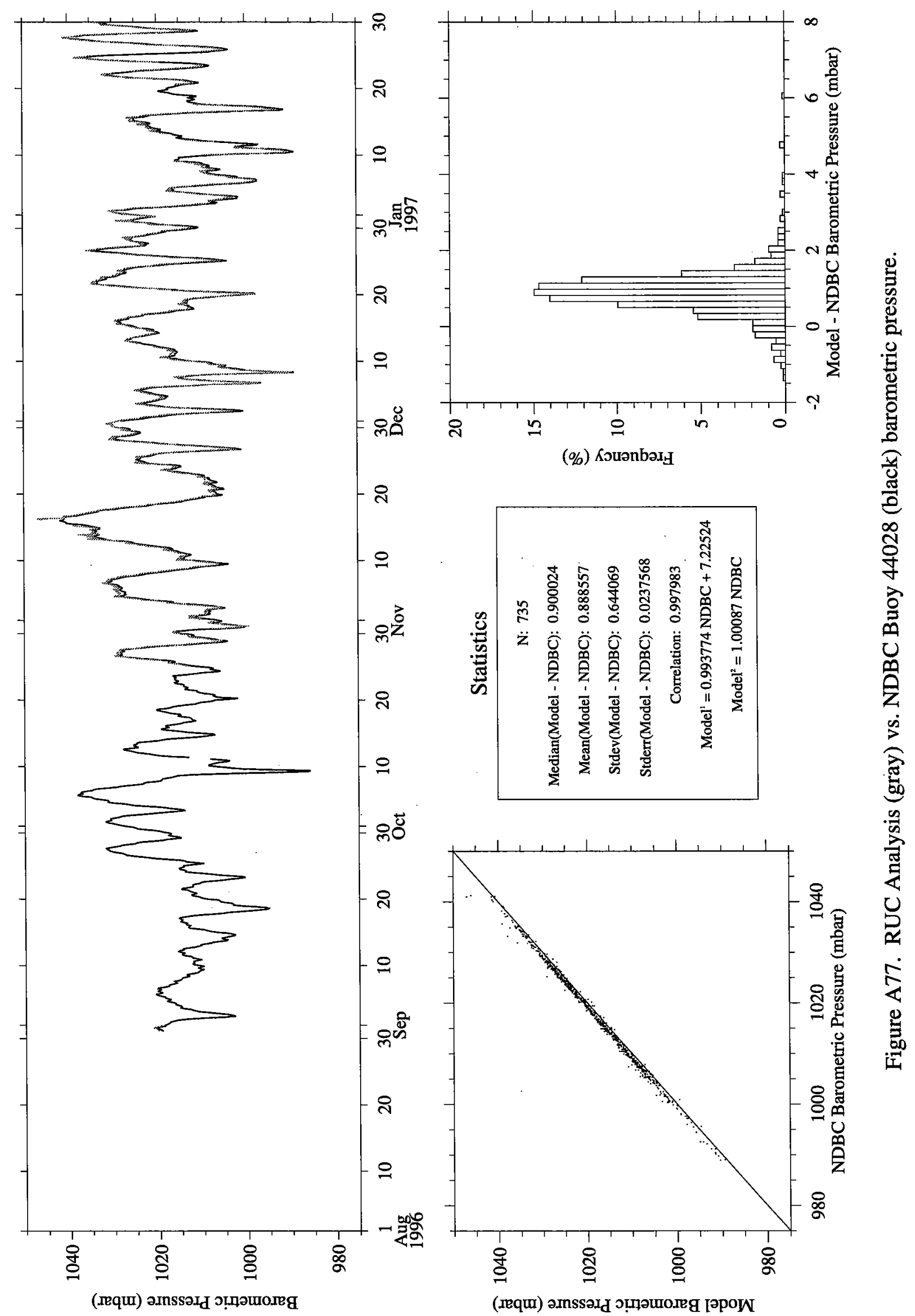


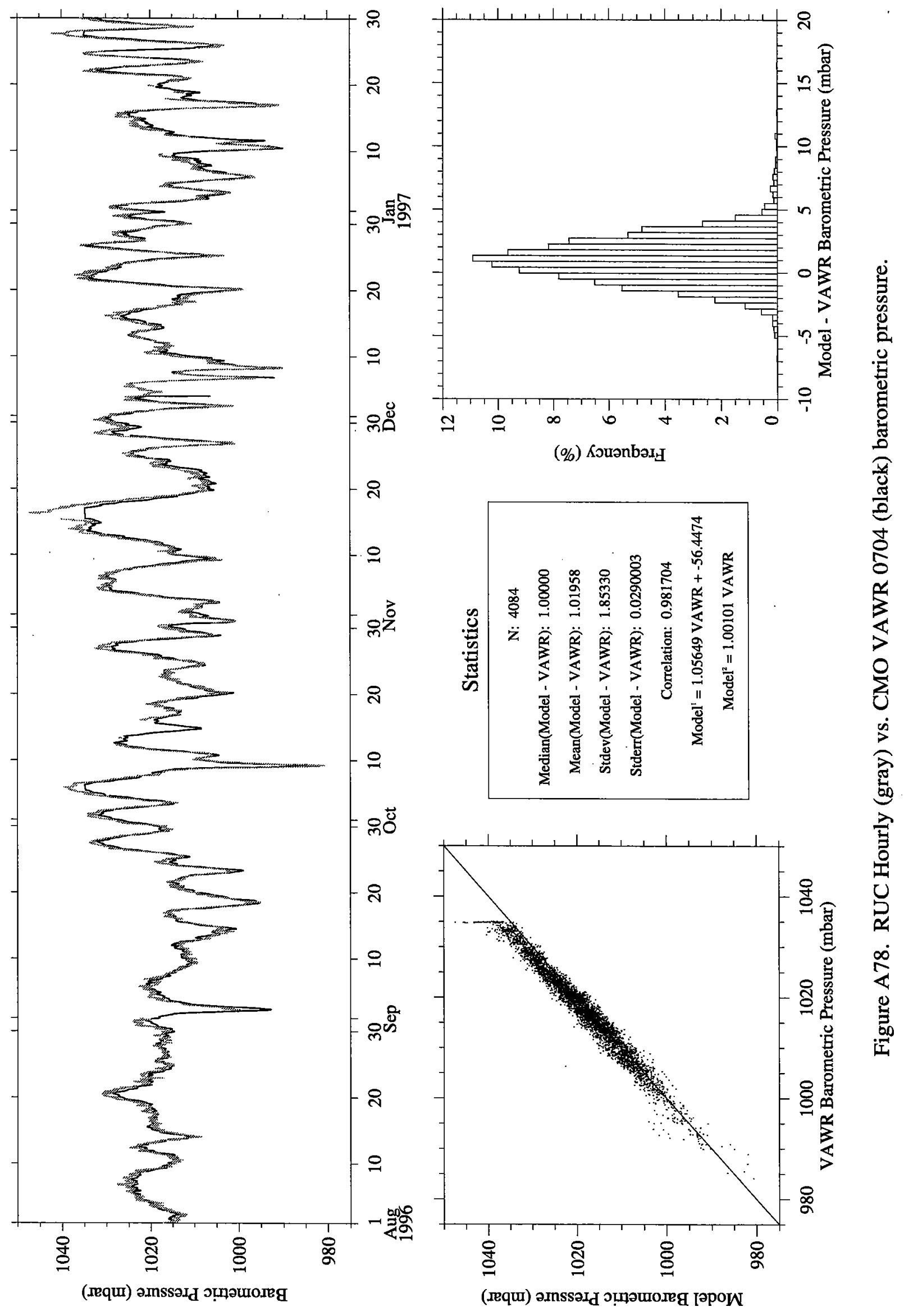



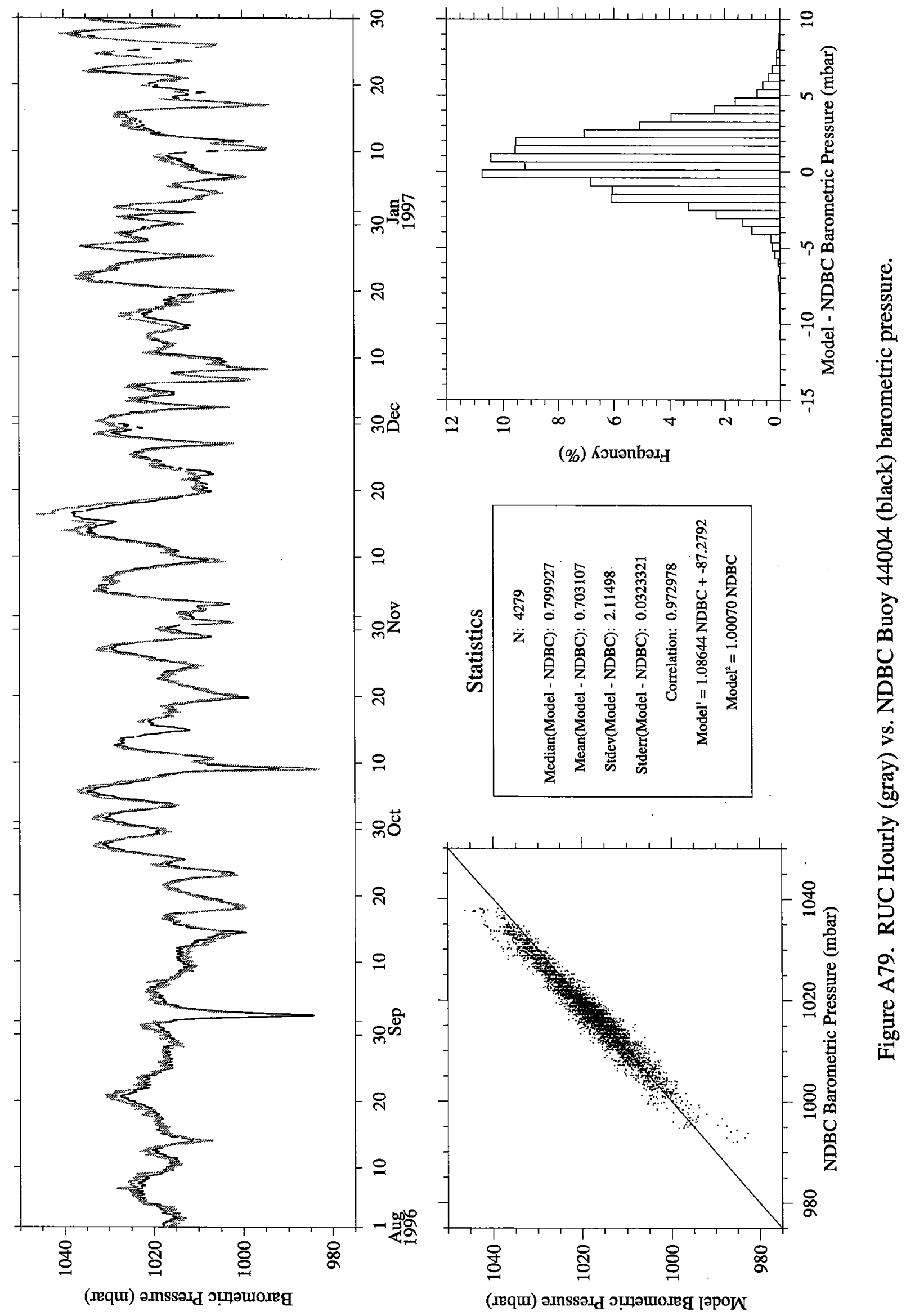

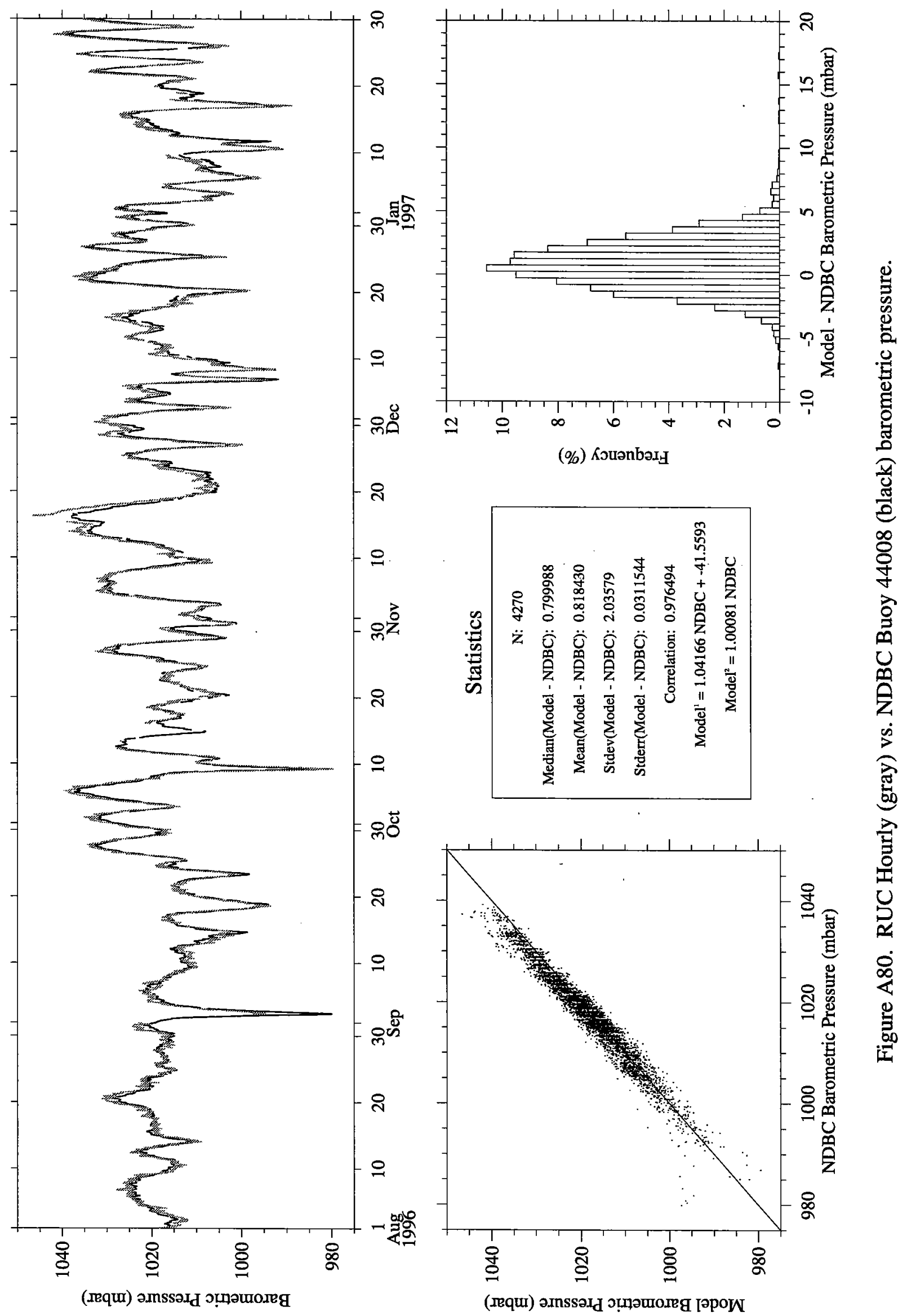

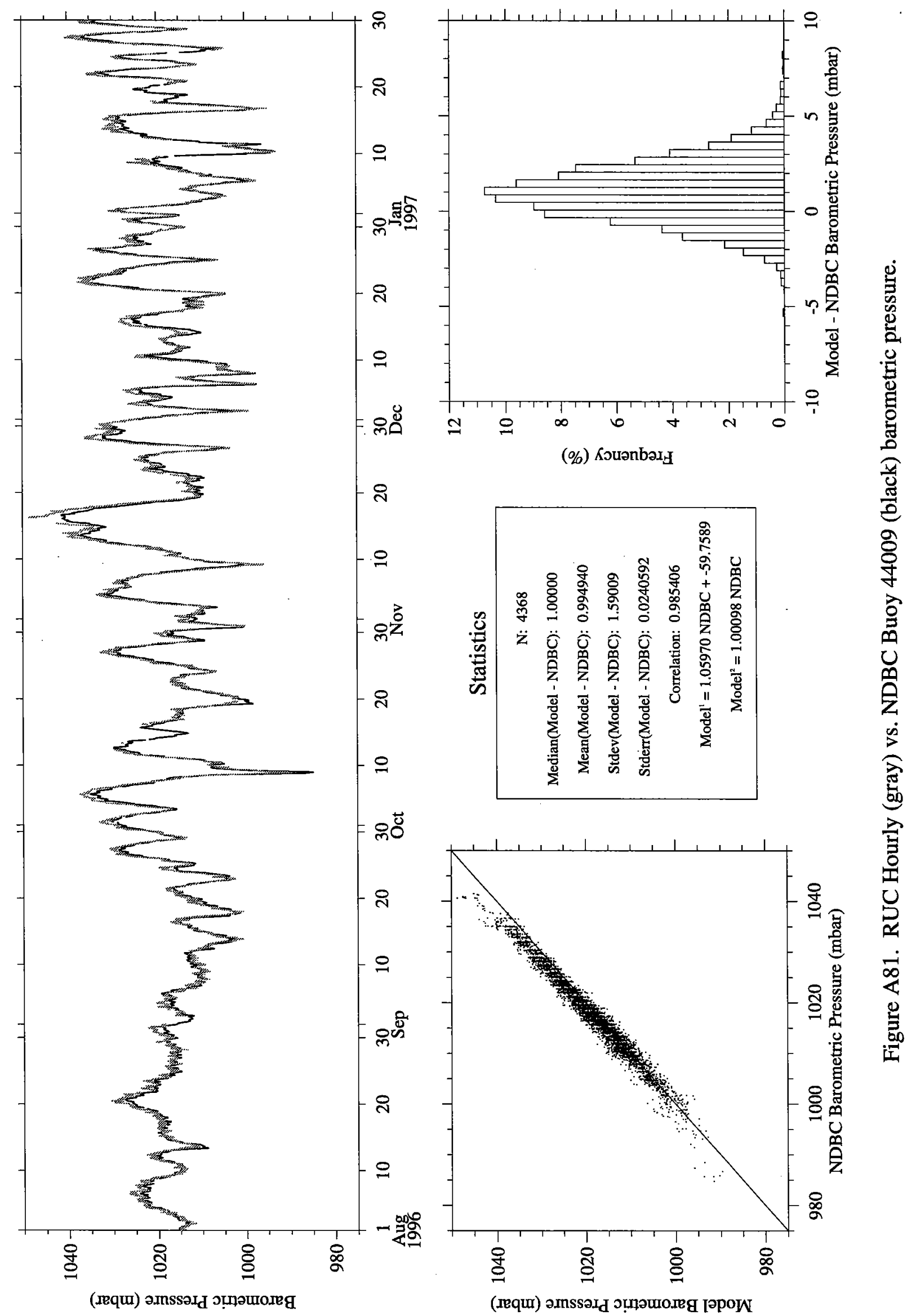


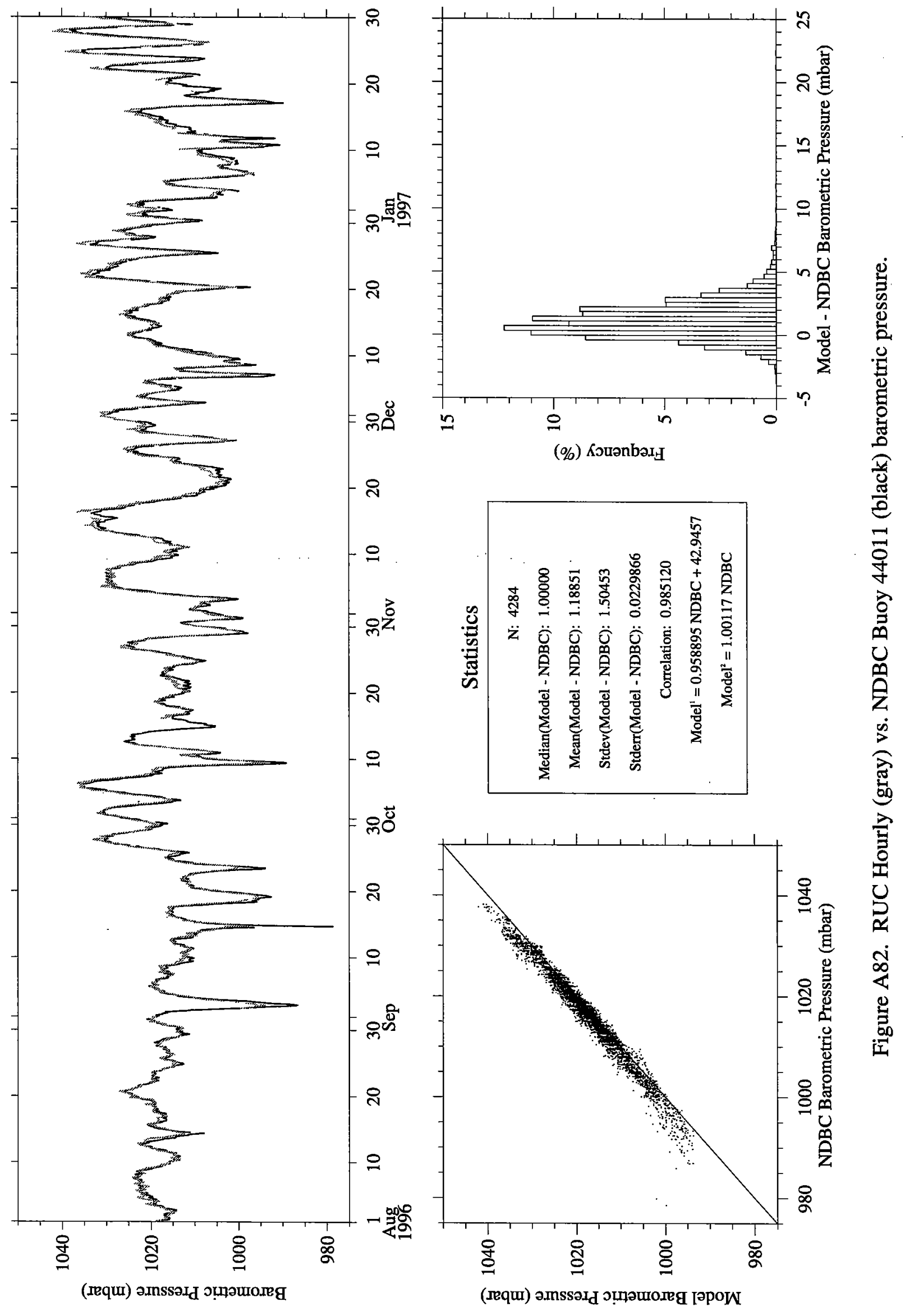



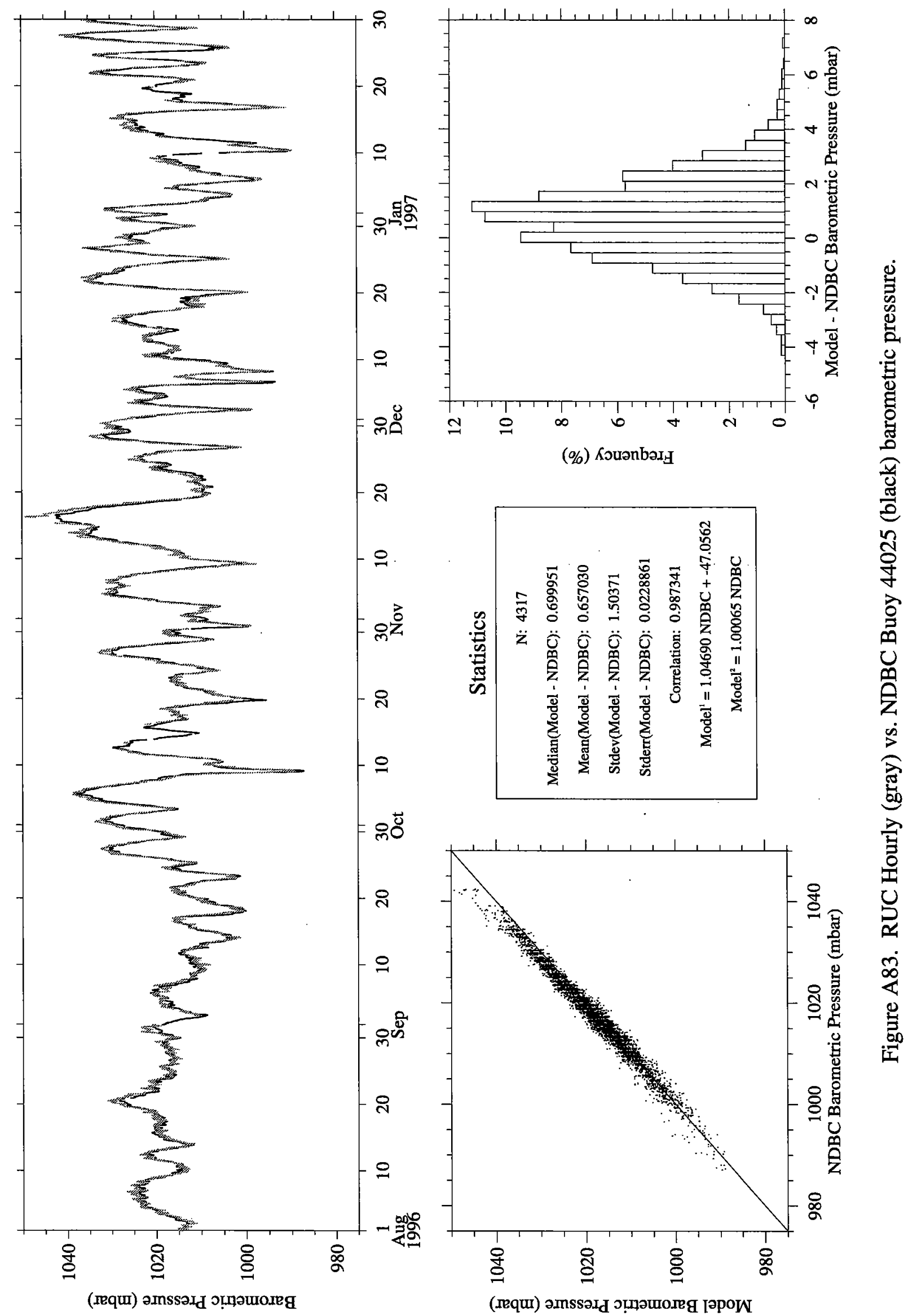

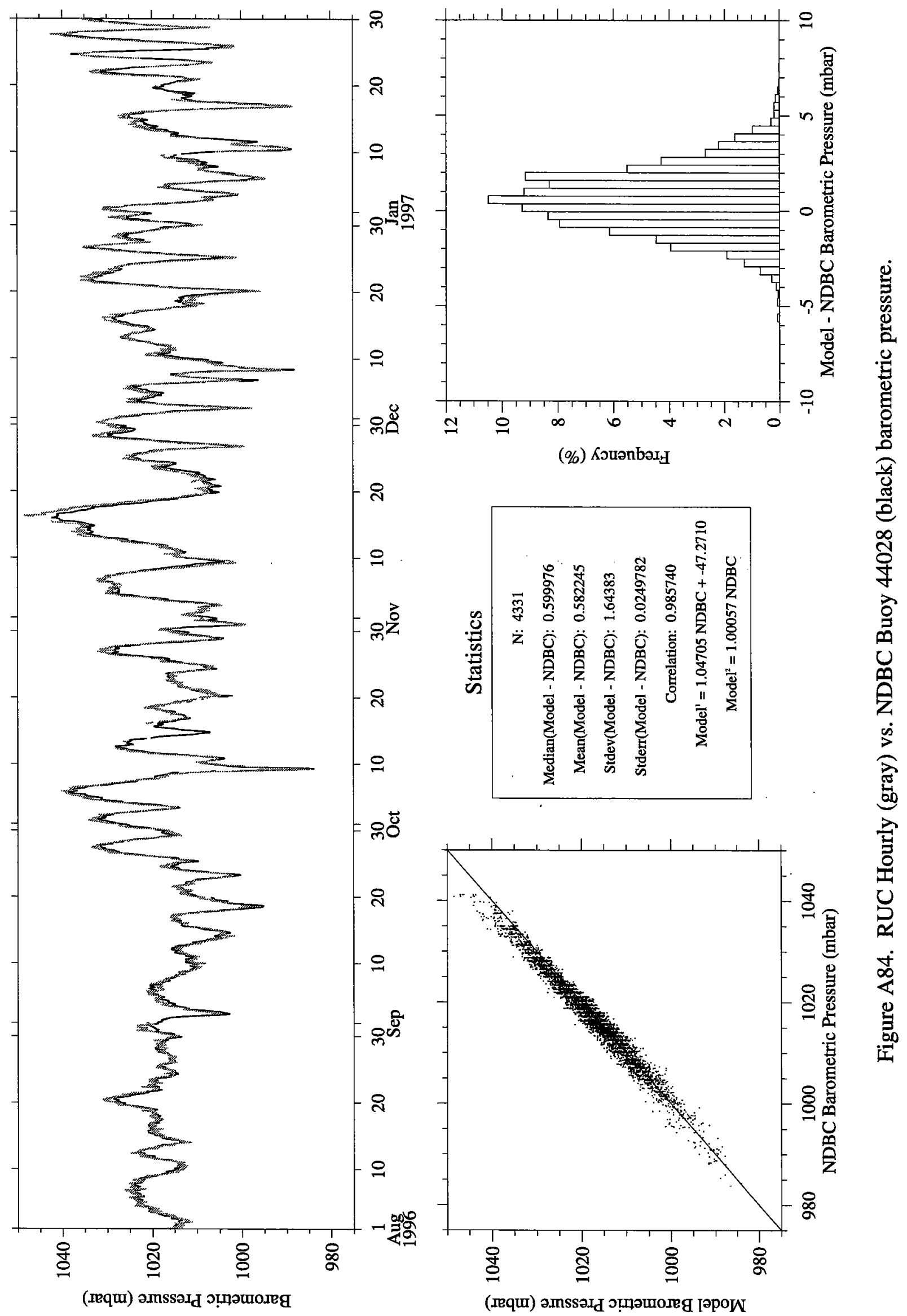


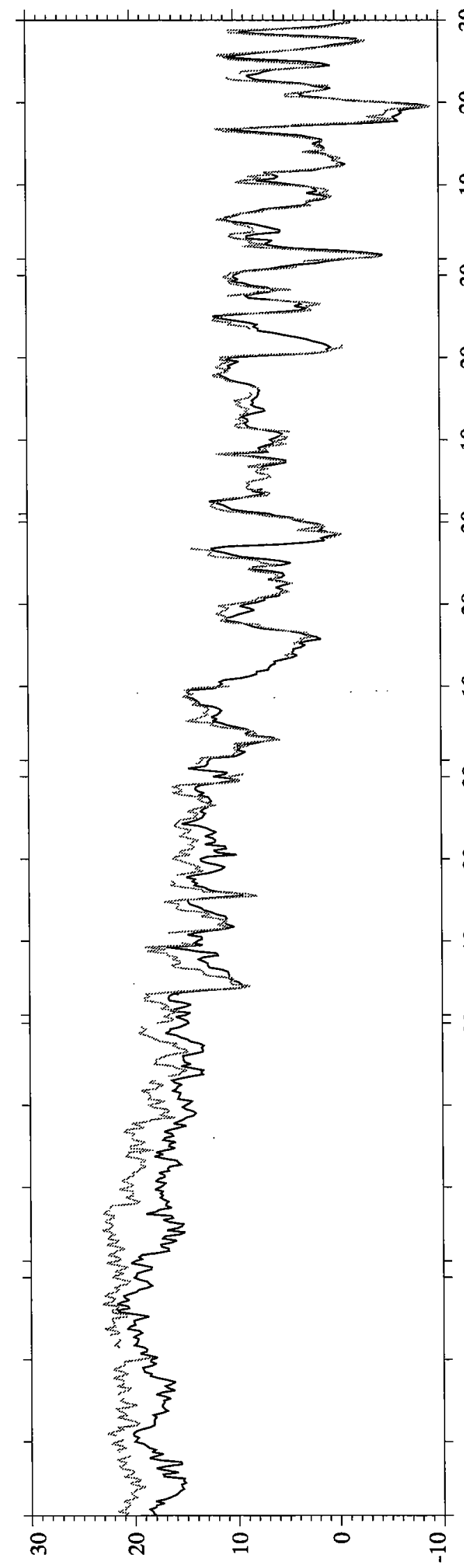

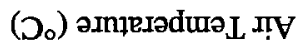

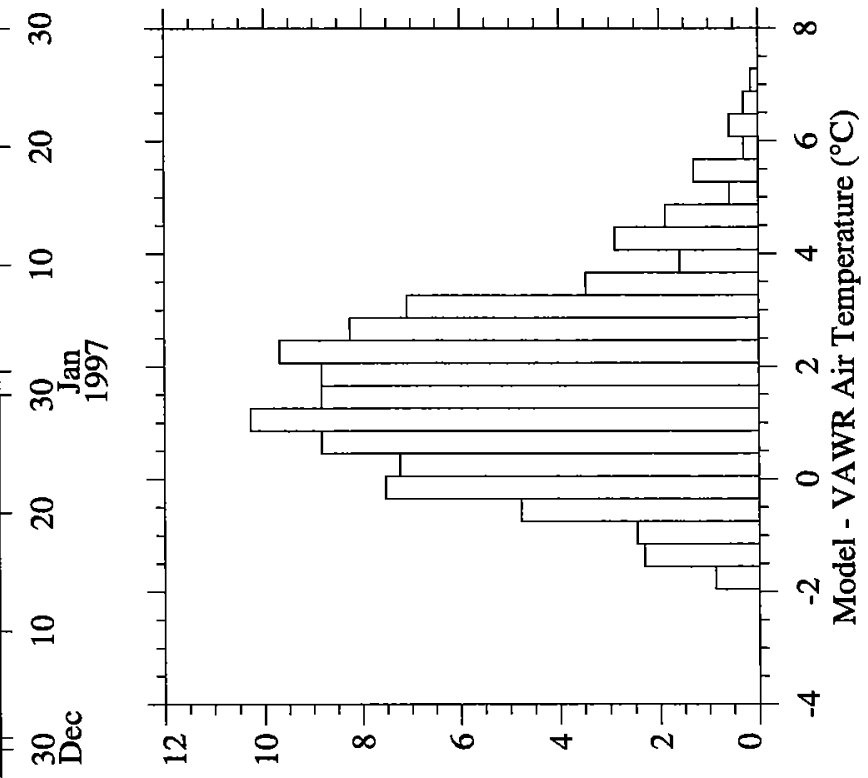

(\%) Кәuәnbəد

$-4$

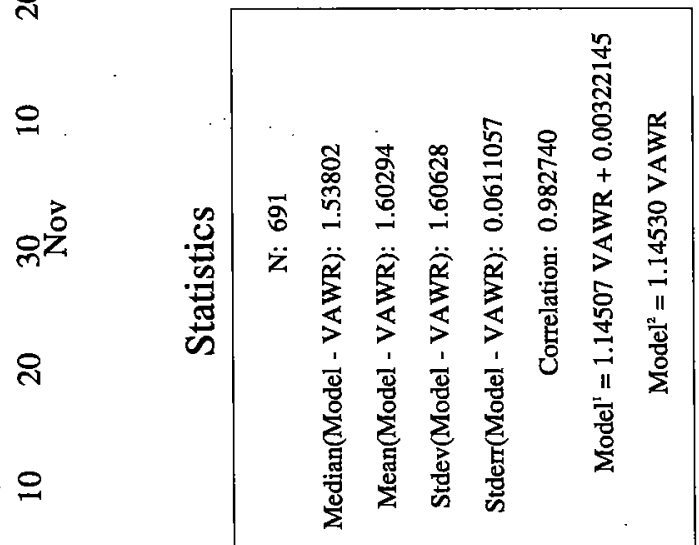

ळ.ั

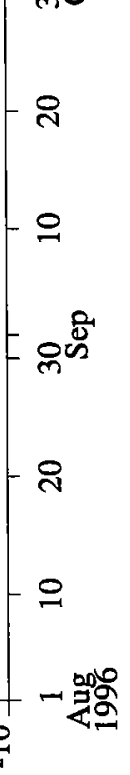

ำㅇำ

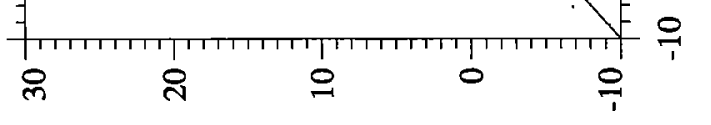

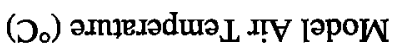



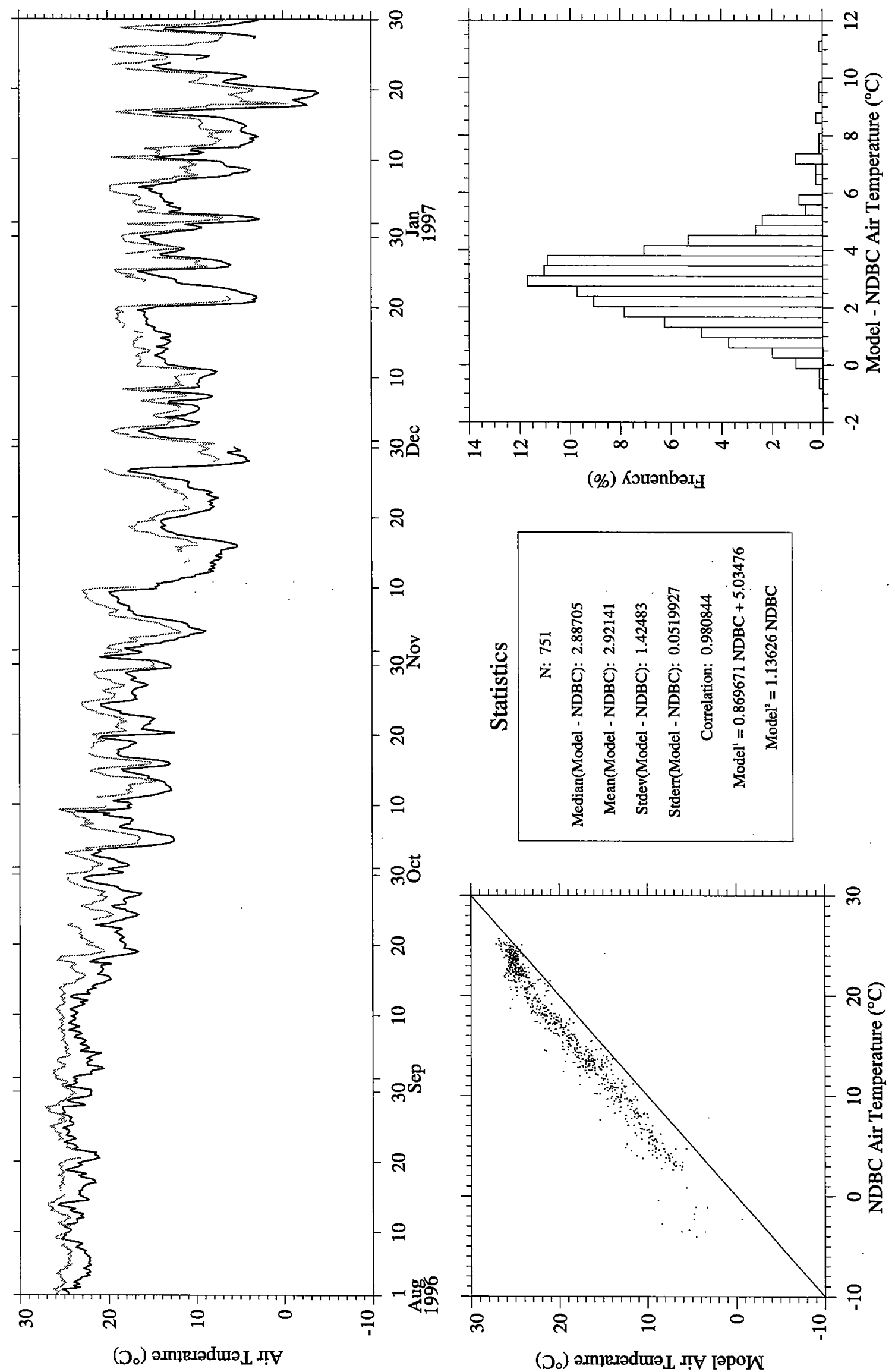

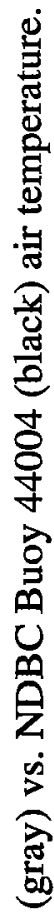
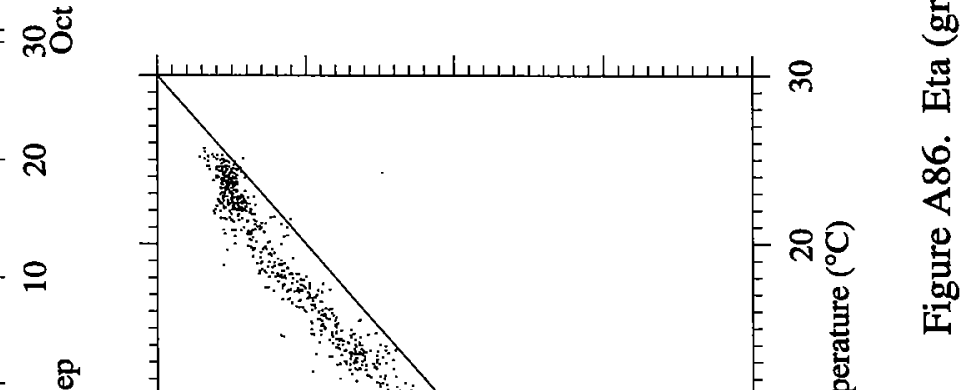


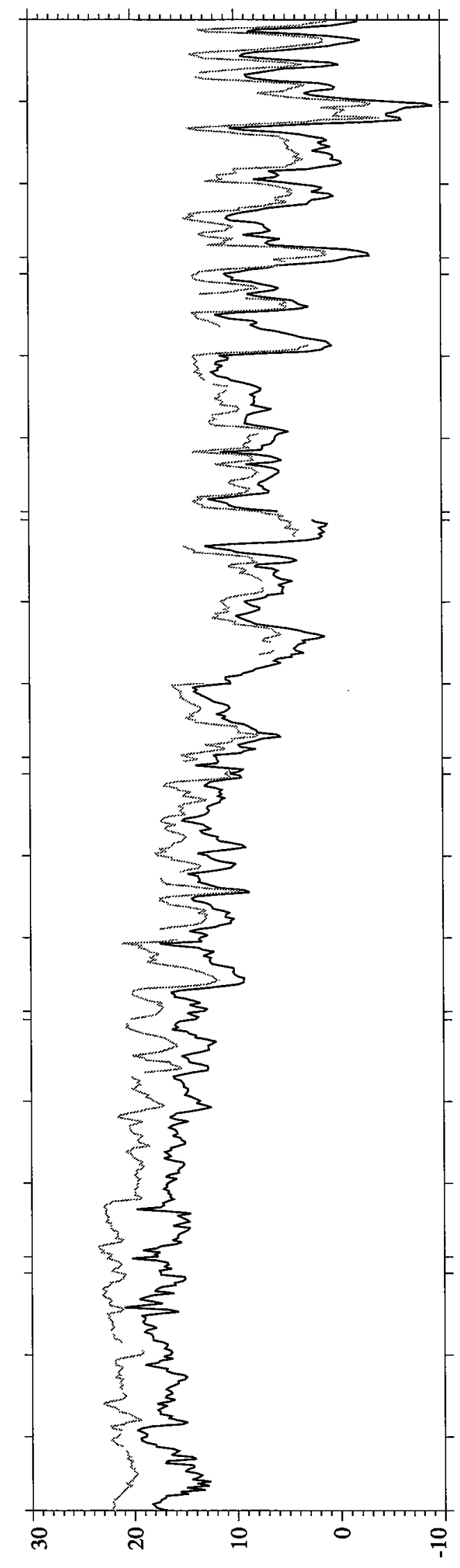

(Do) əmperadura L I!V

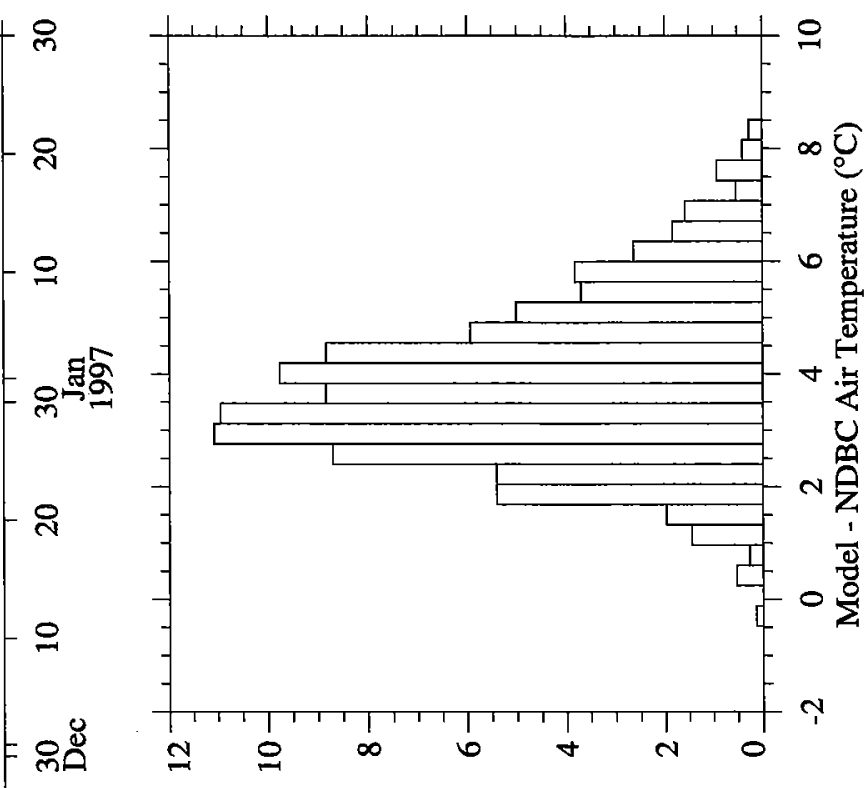

(\%) Kouənbəx

ำ

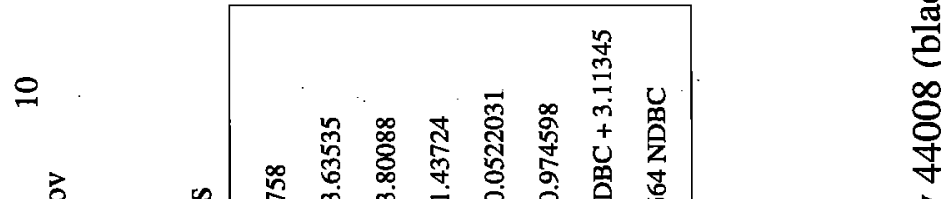

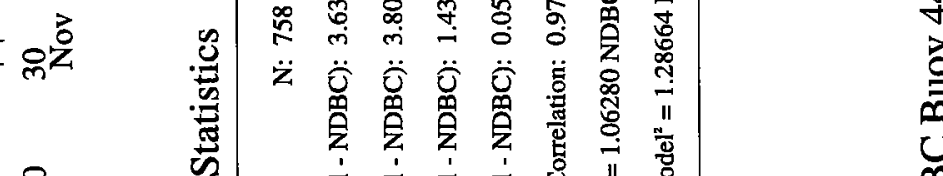

กิ

으

요

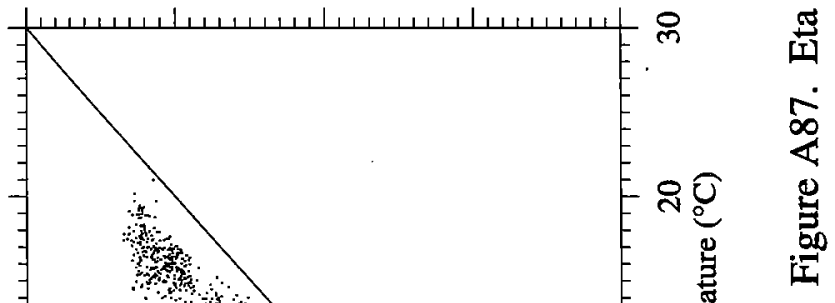

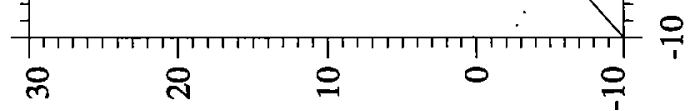

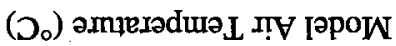




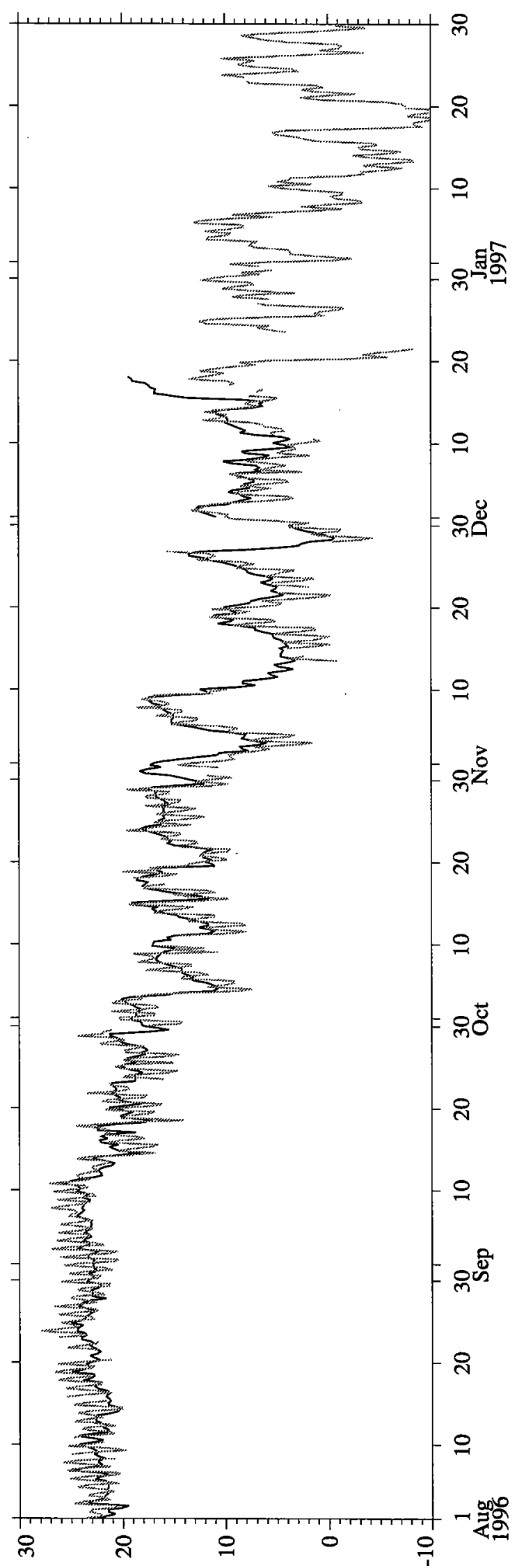

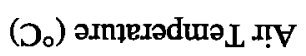

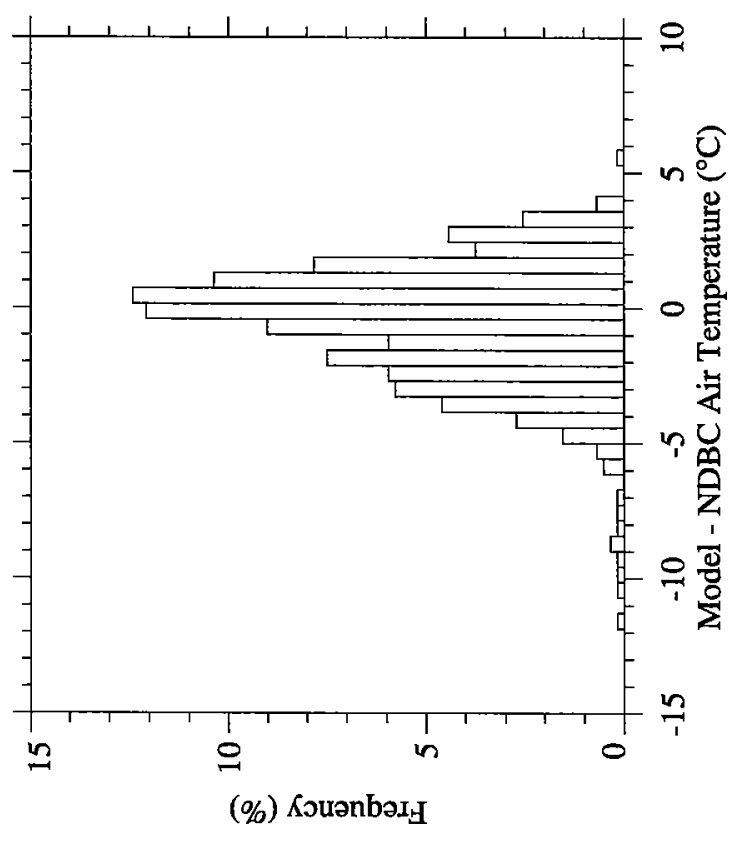

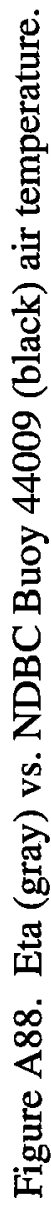




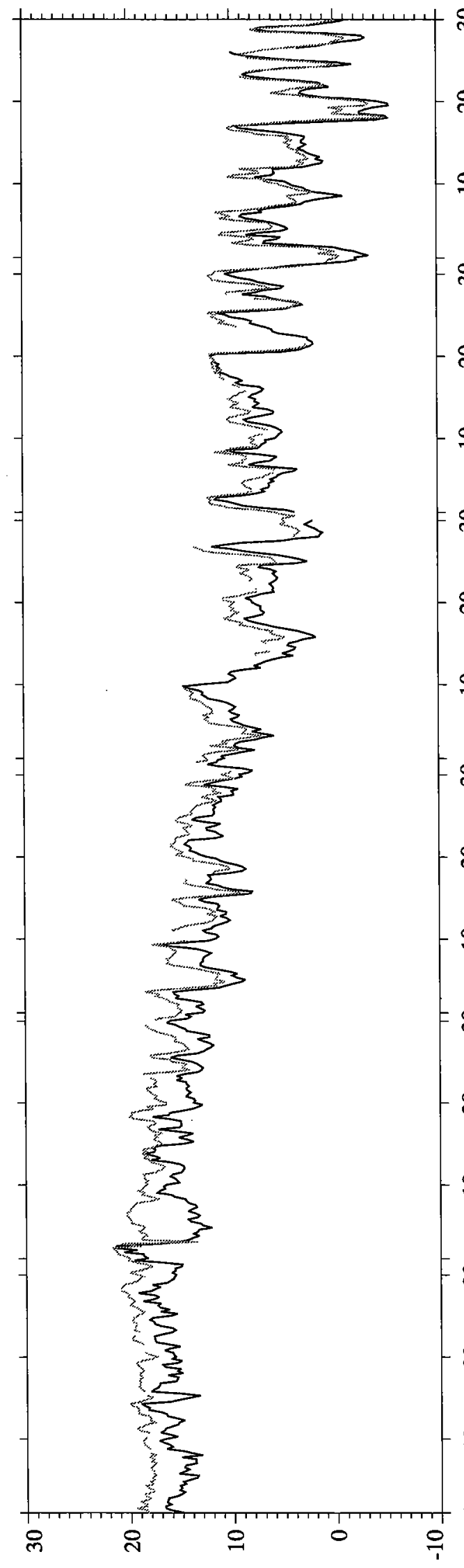

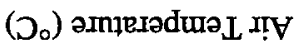

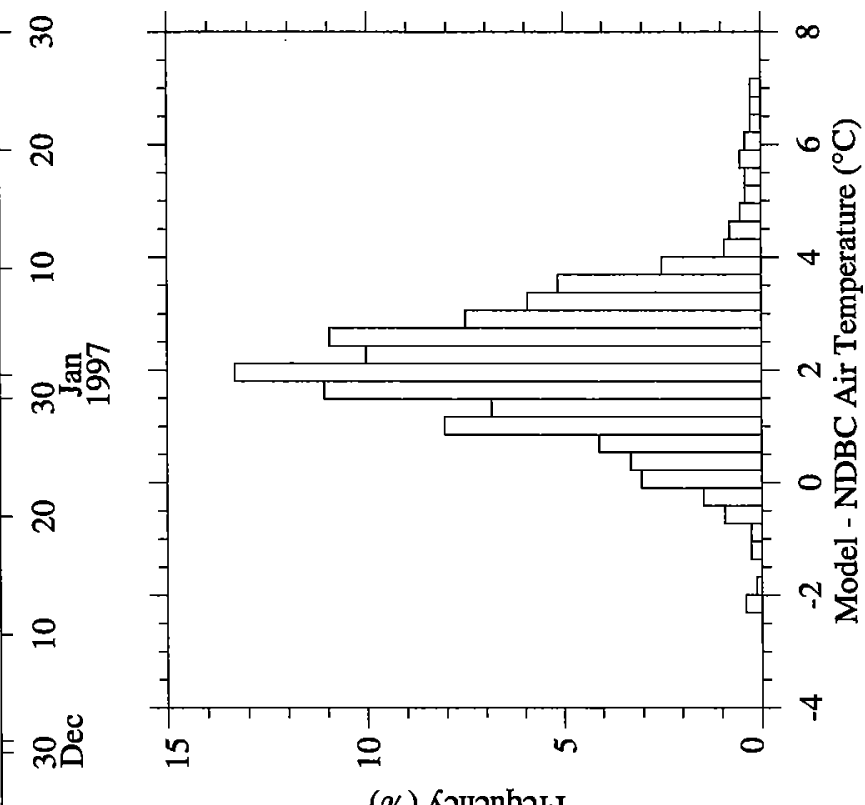

(\%) Kouənbəג

ㅇ

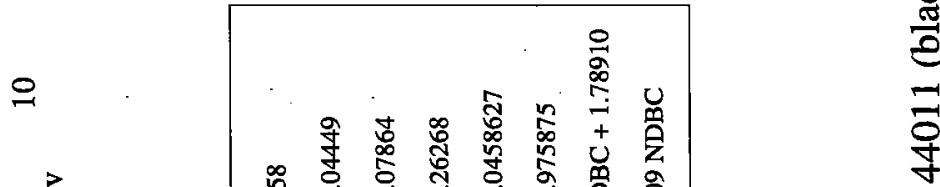

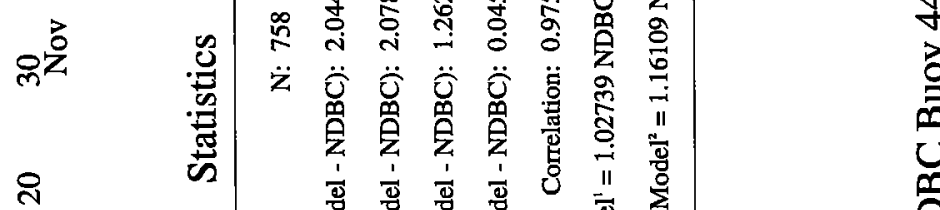

우

ஓ๐̆

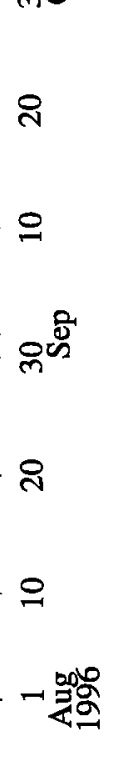

ㅁoㅇ

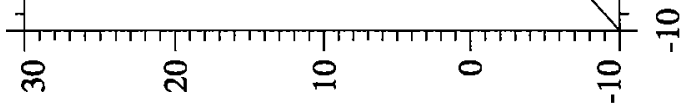

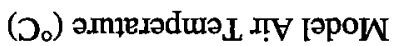



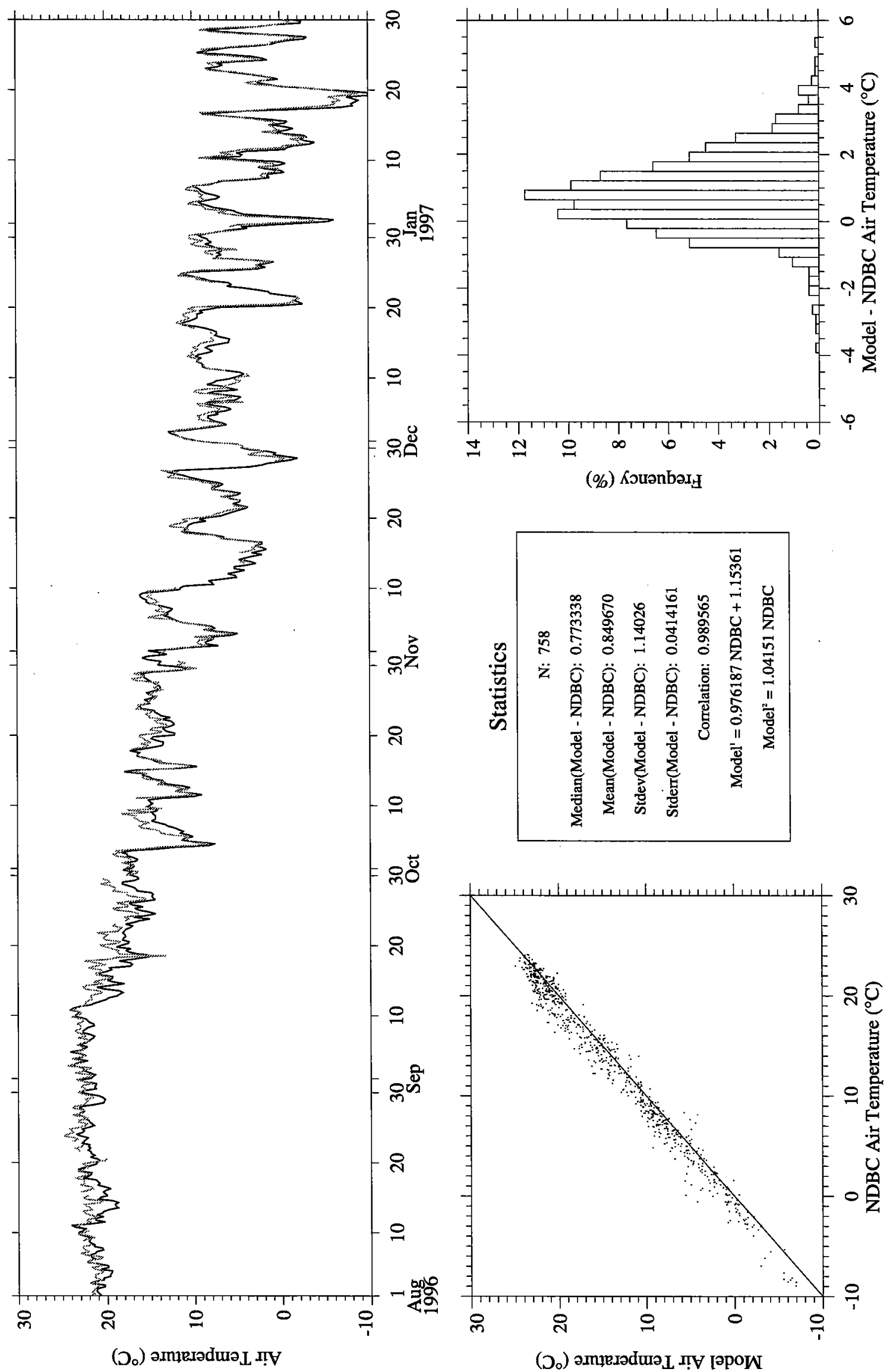

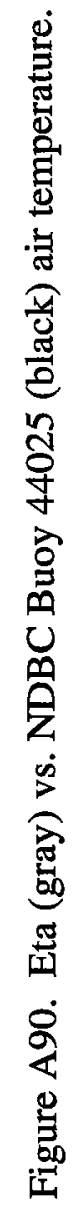




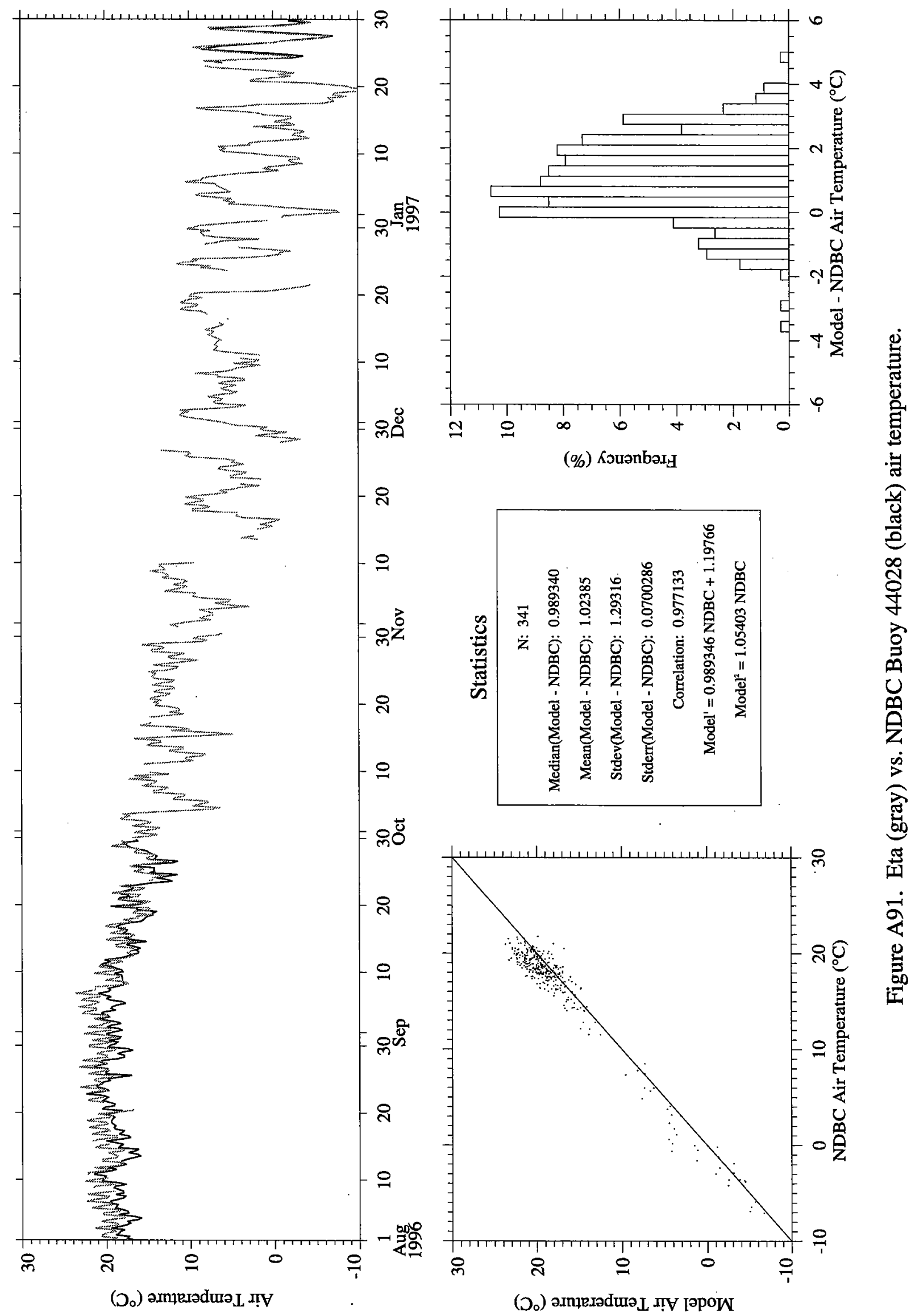




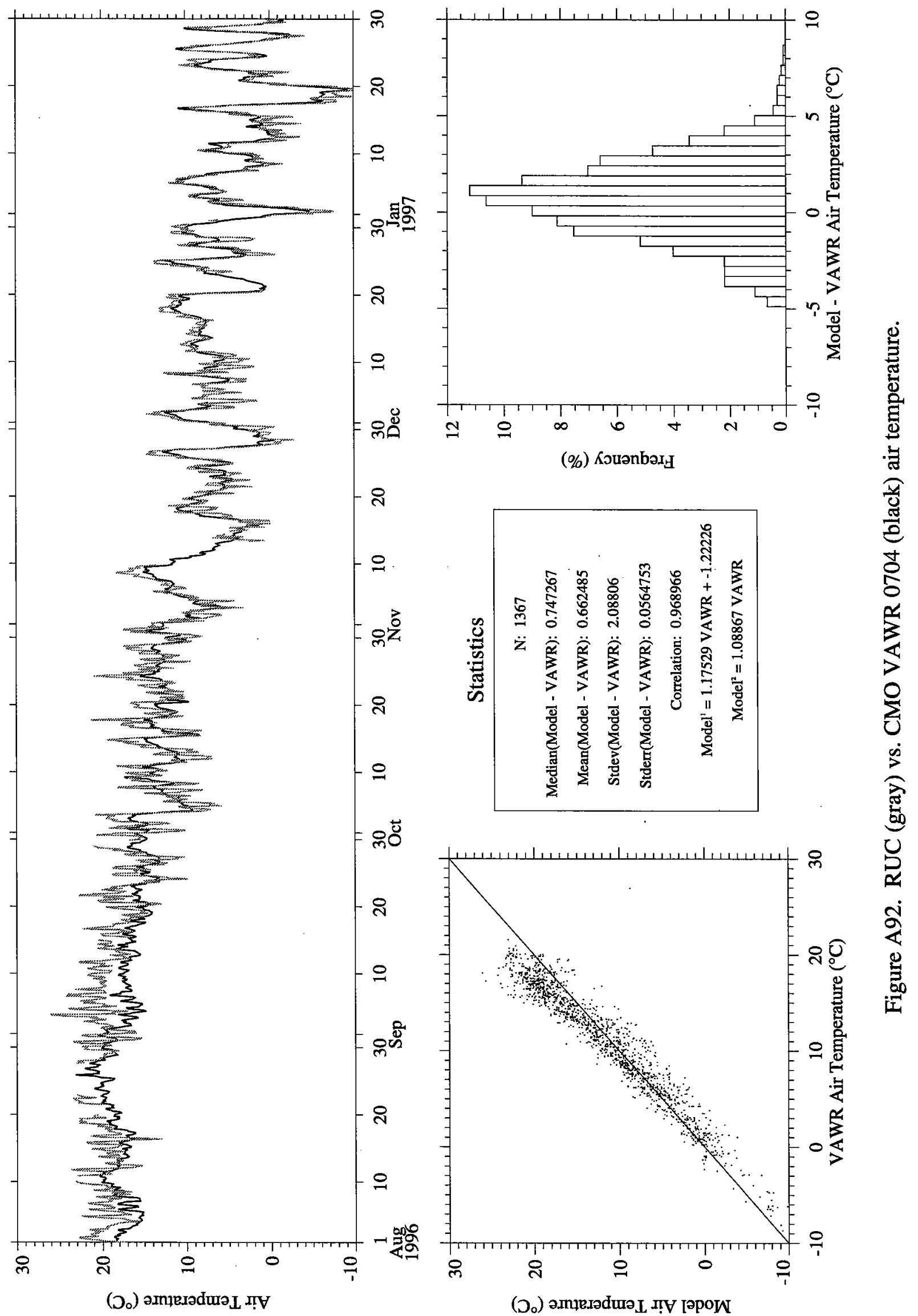




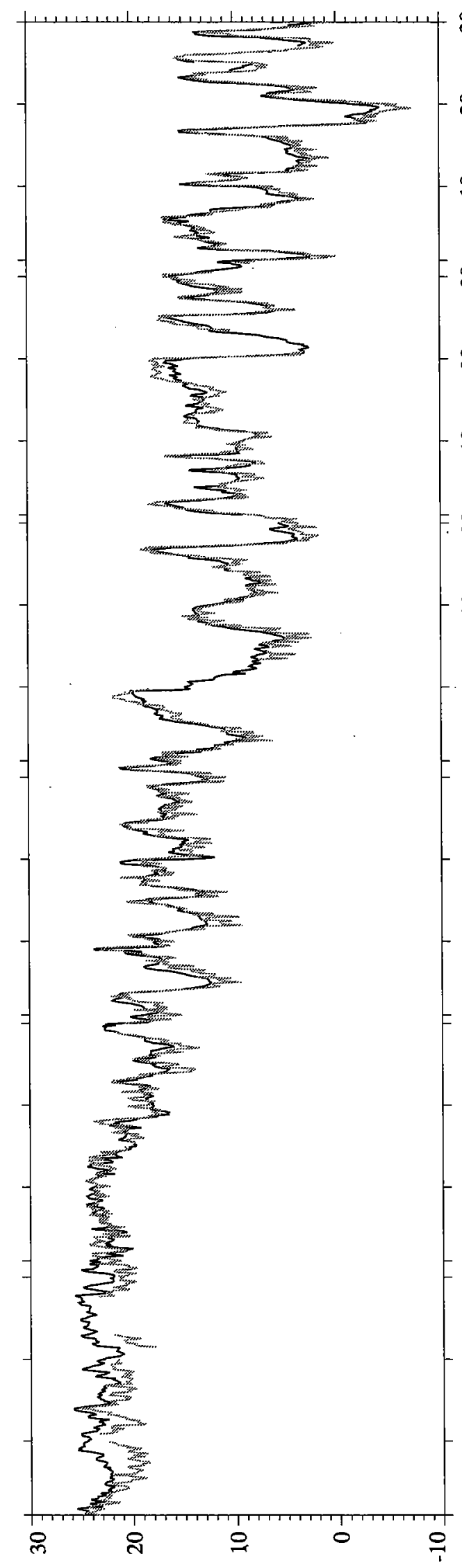

(つ) әmцегәdшә L I!

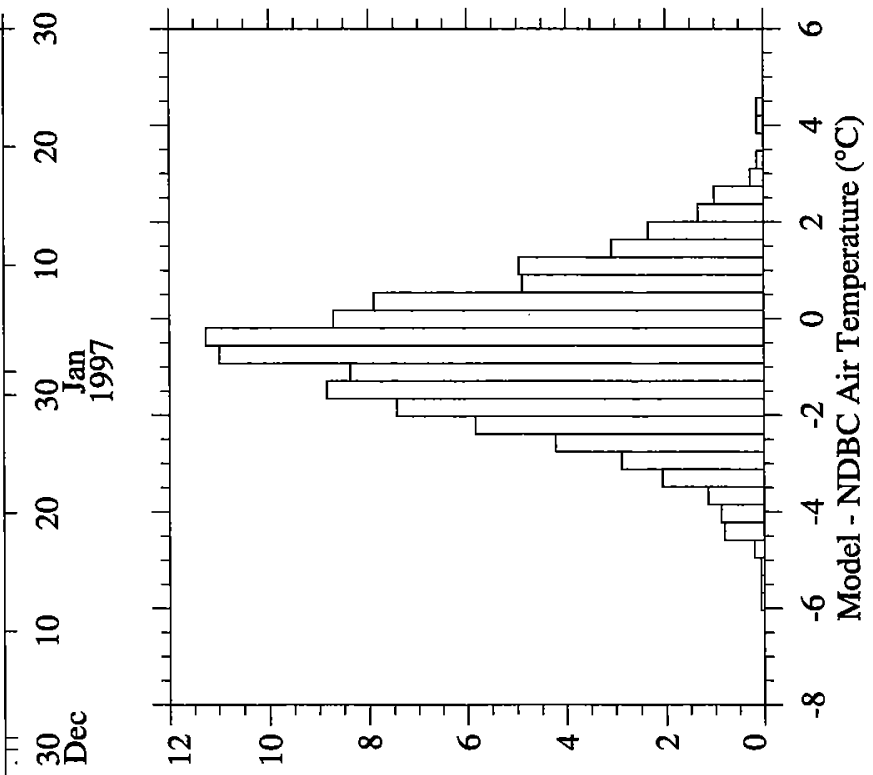

(\%) КวuənbəدH

กิ

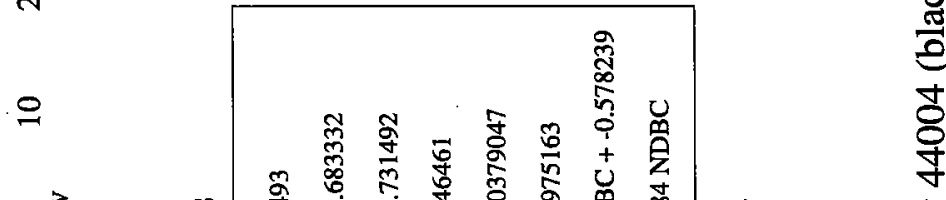

e

苞

$\rightarrow$ i

$\ddot{z} \ddot{0} \ddot{0} \ddot{0} \ddot{0}$ 命

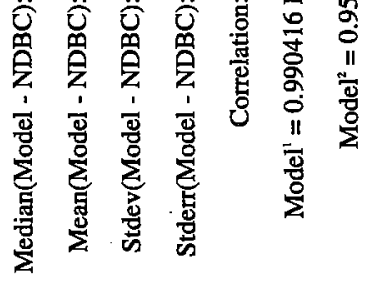

웅

लेष

ชิ

오

요

우

으

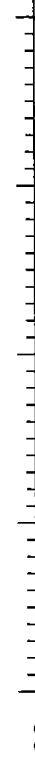

年

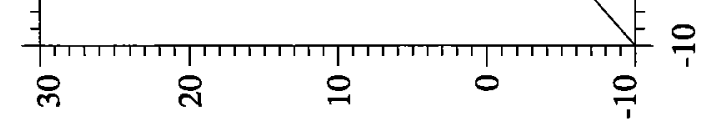

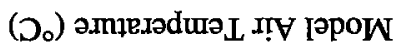

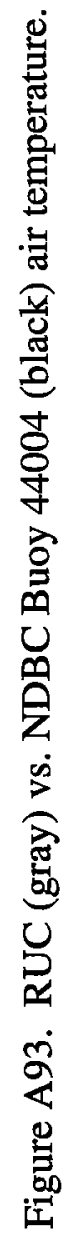




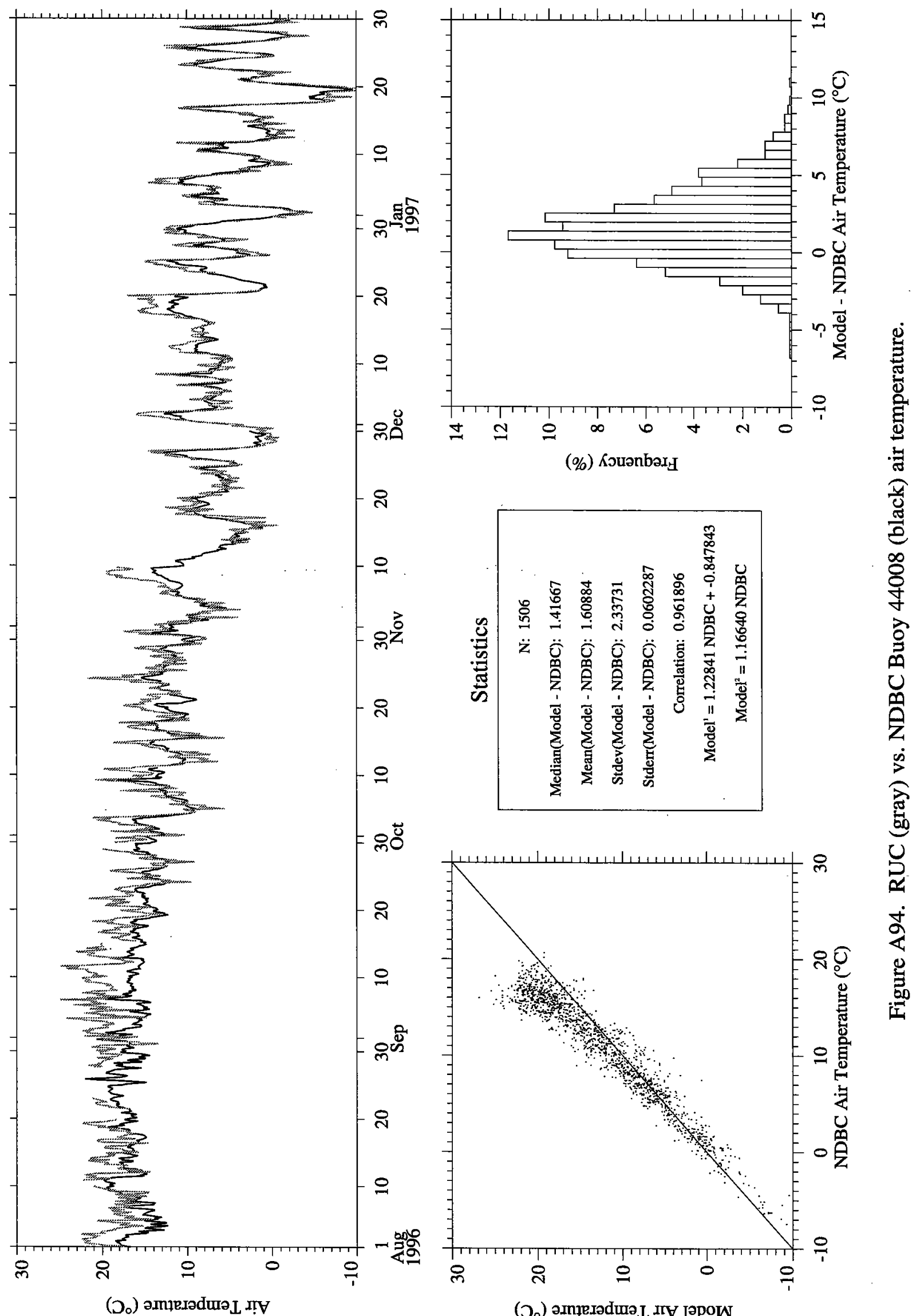




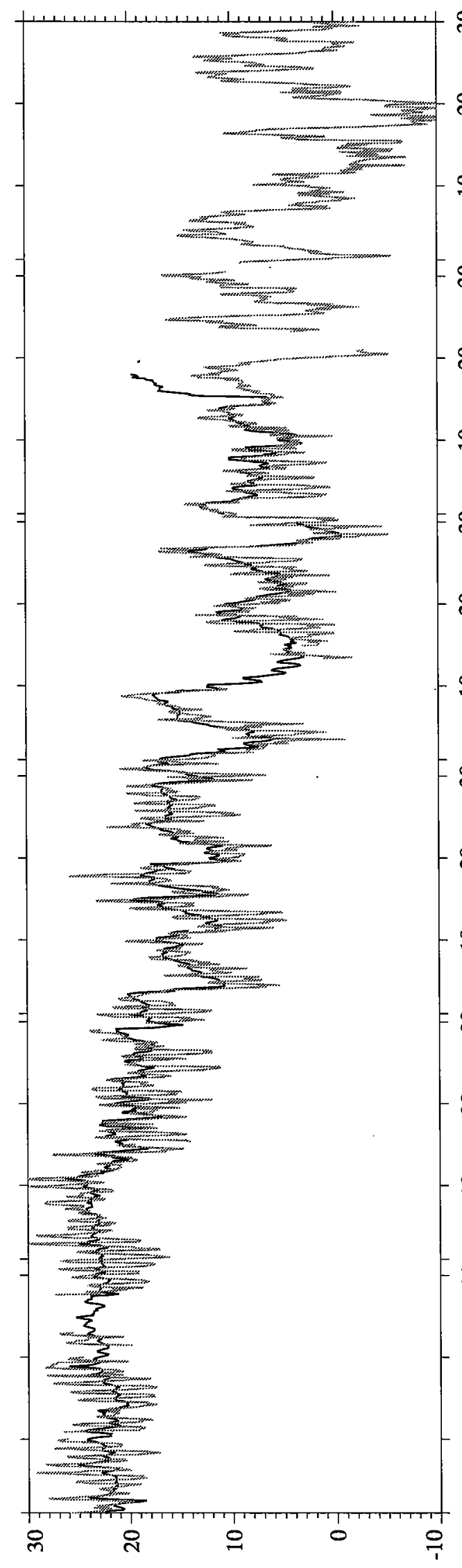

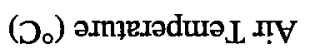

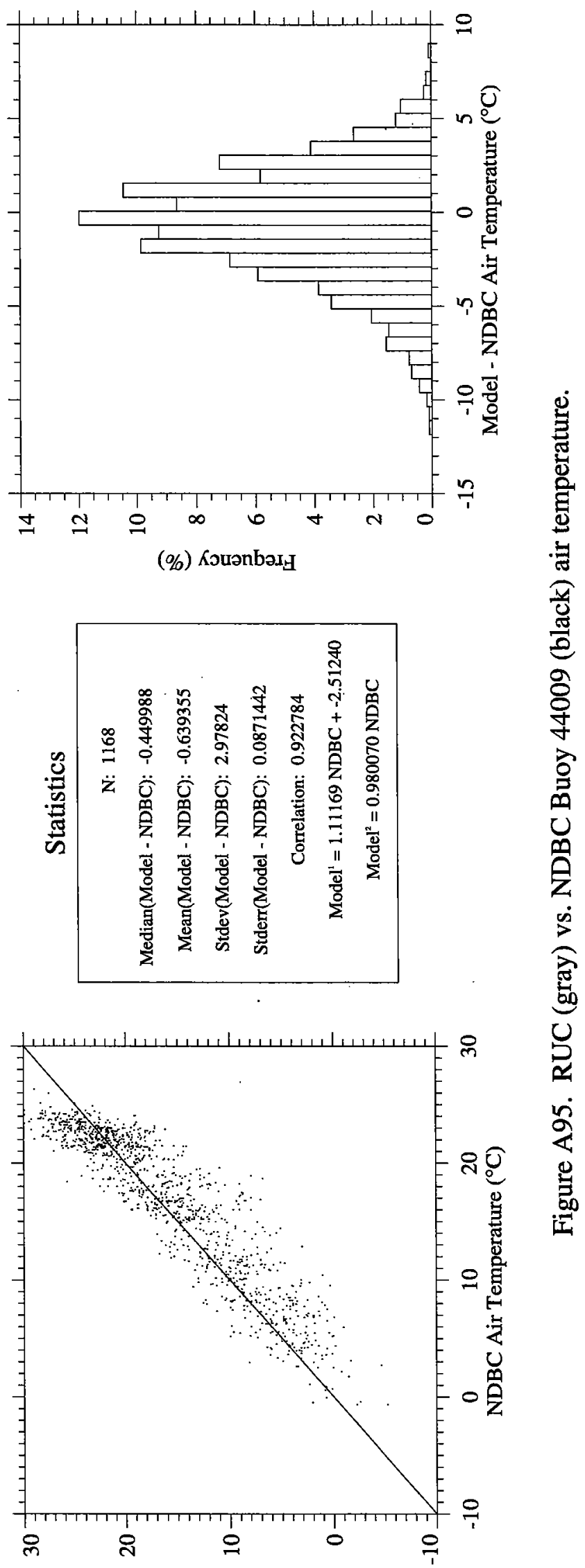

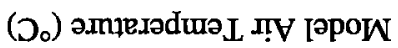




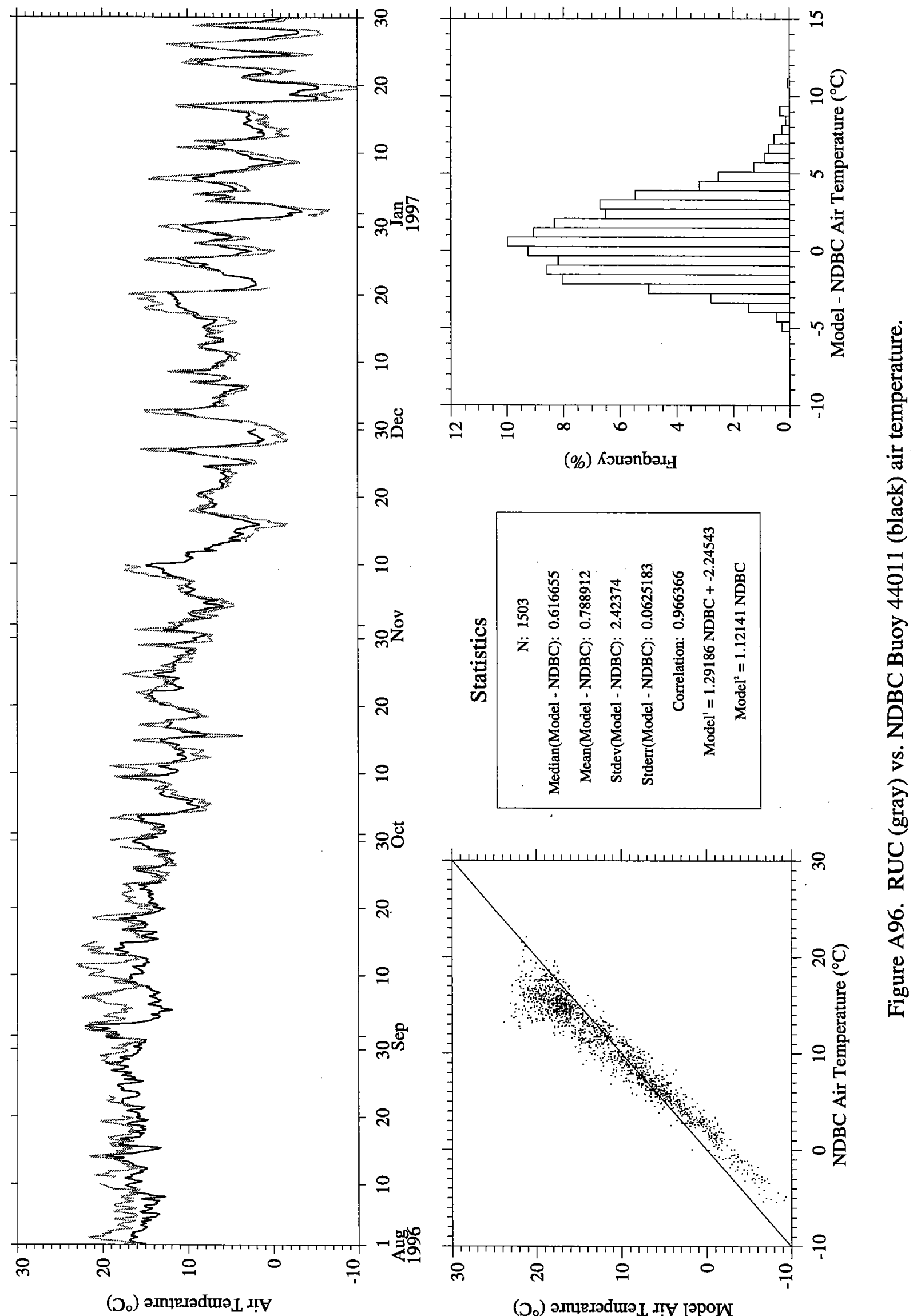




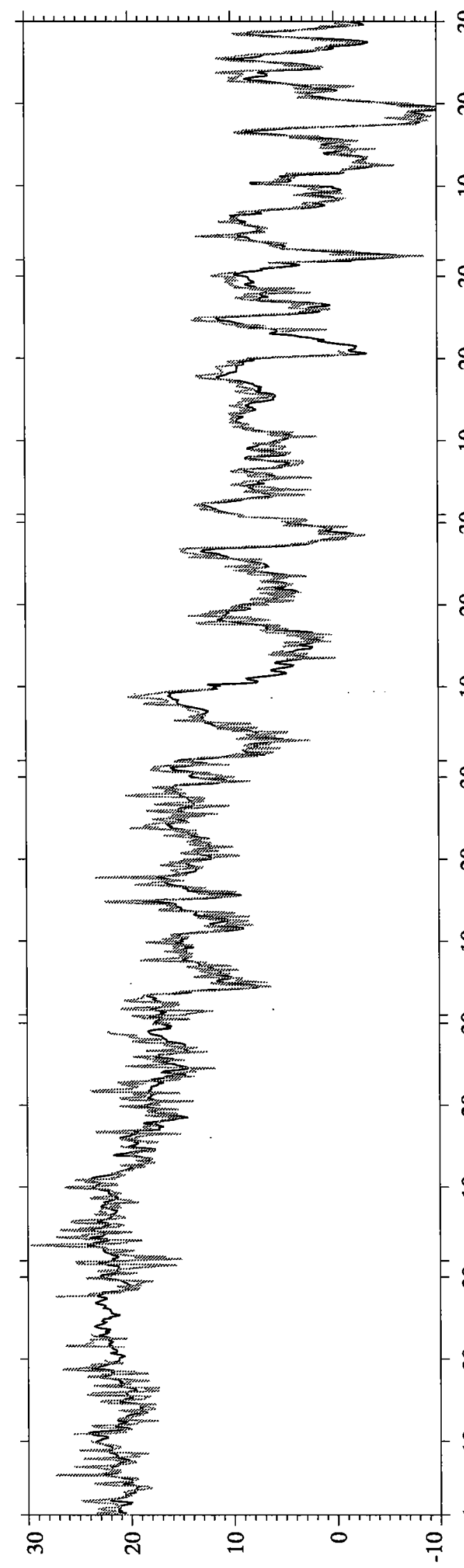

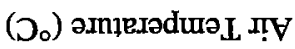

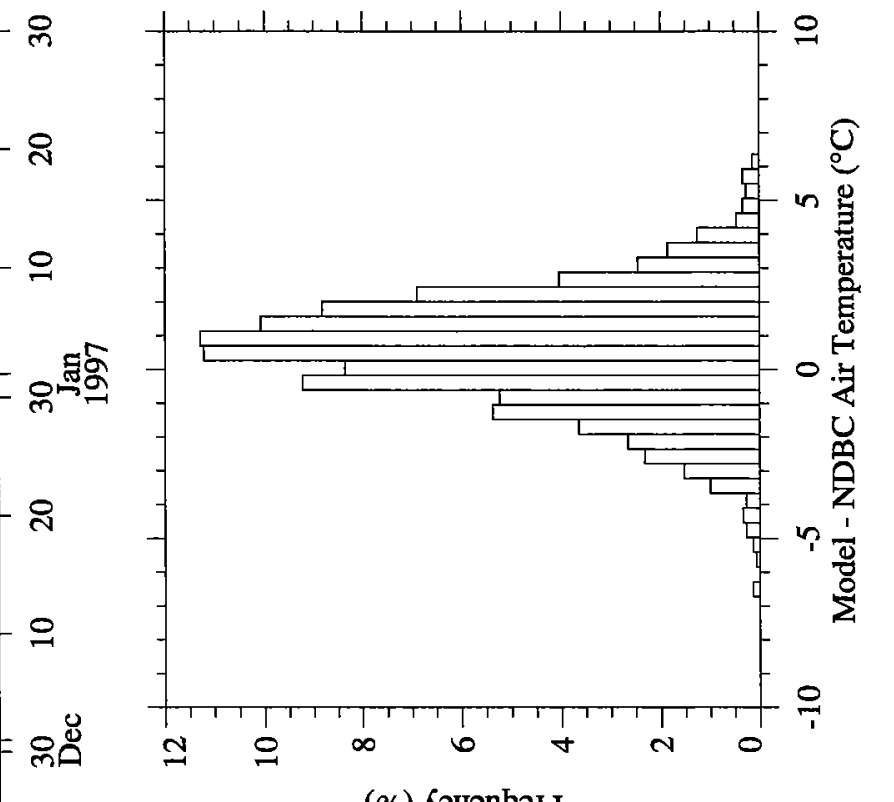

(\%) Kouənbə⿸尸

ำ

우

율

요

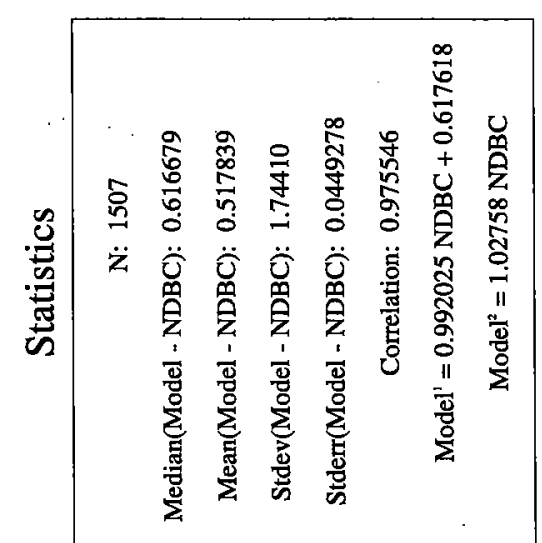

유

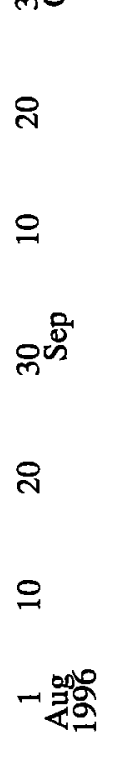

요

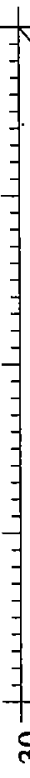

$=$
$=$
$=$
$=$
$=$
$=$
$=$
$=$
$=$
$=$
$=$

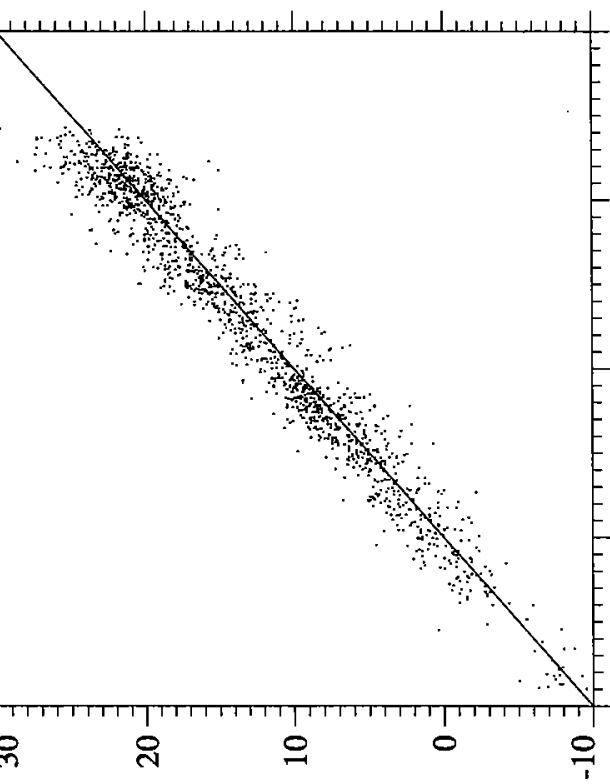

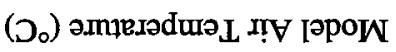



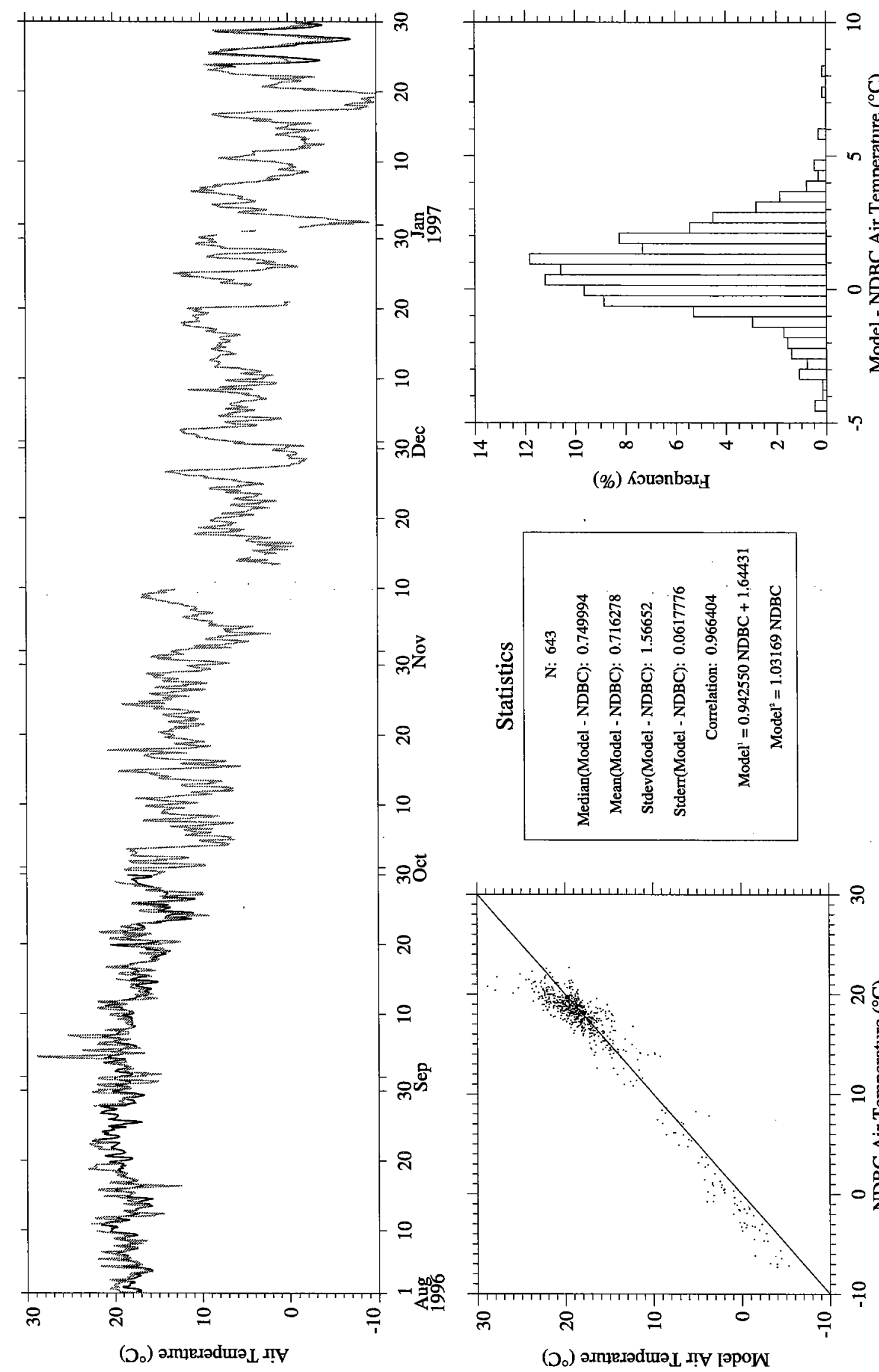

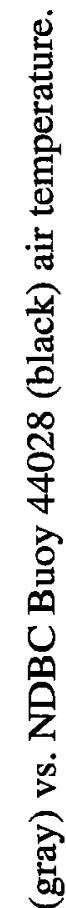

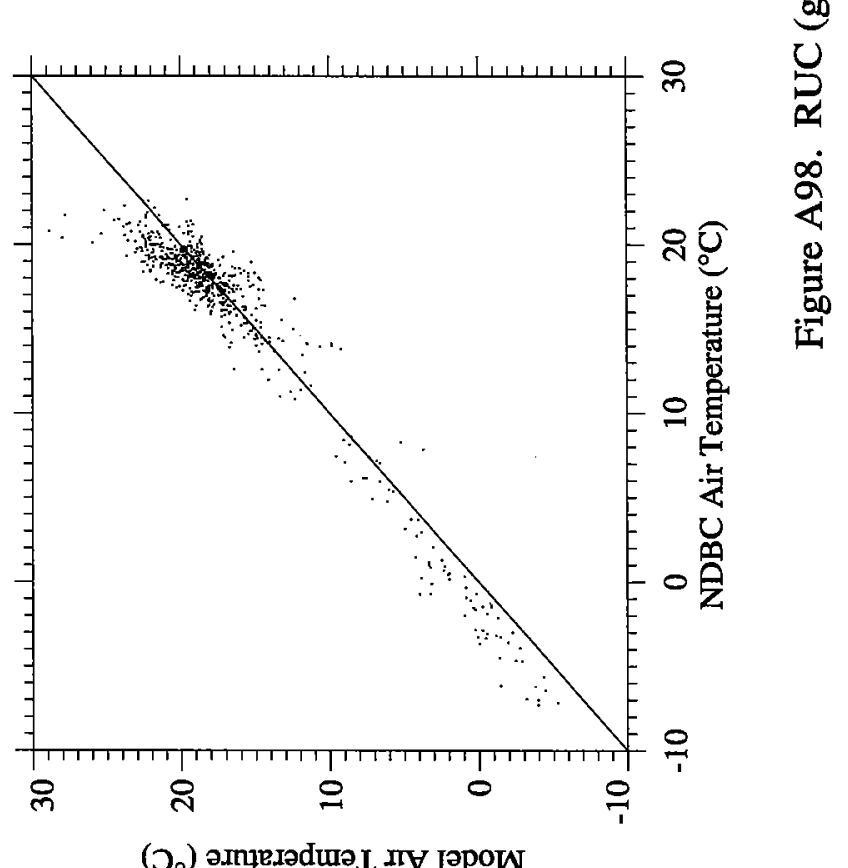




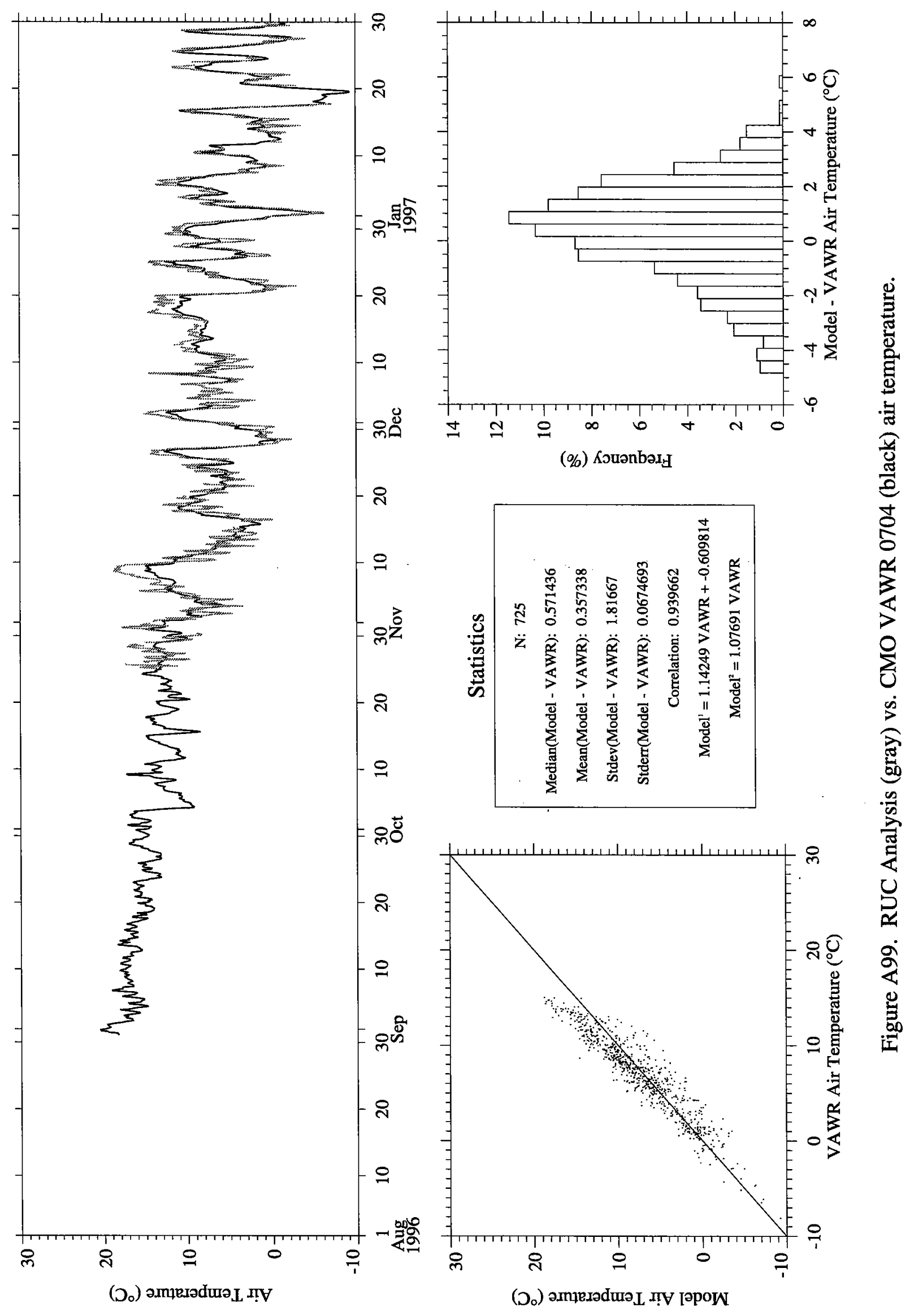




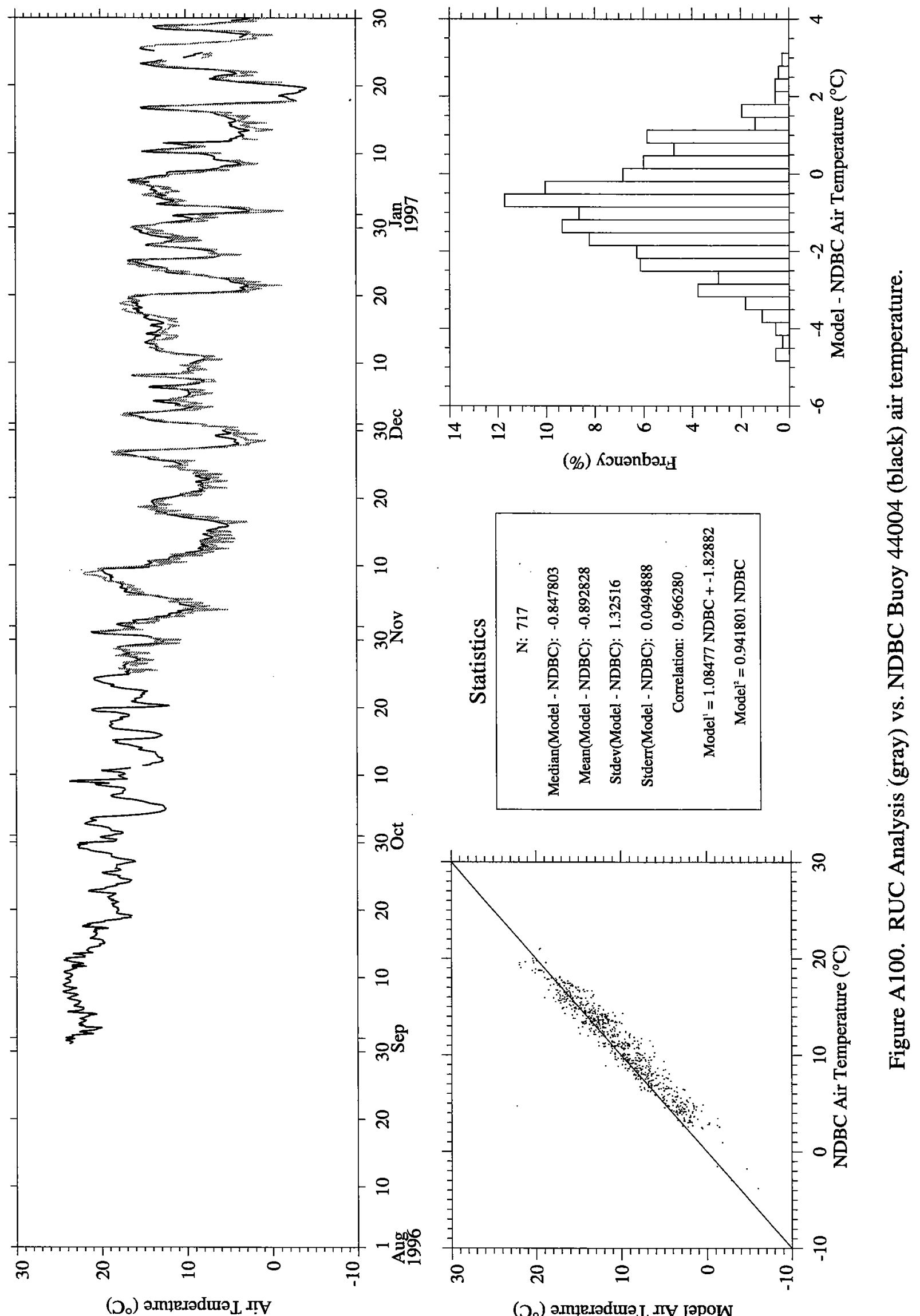




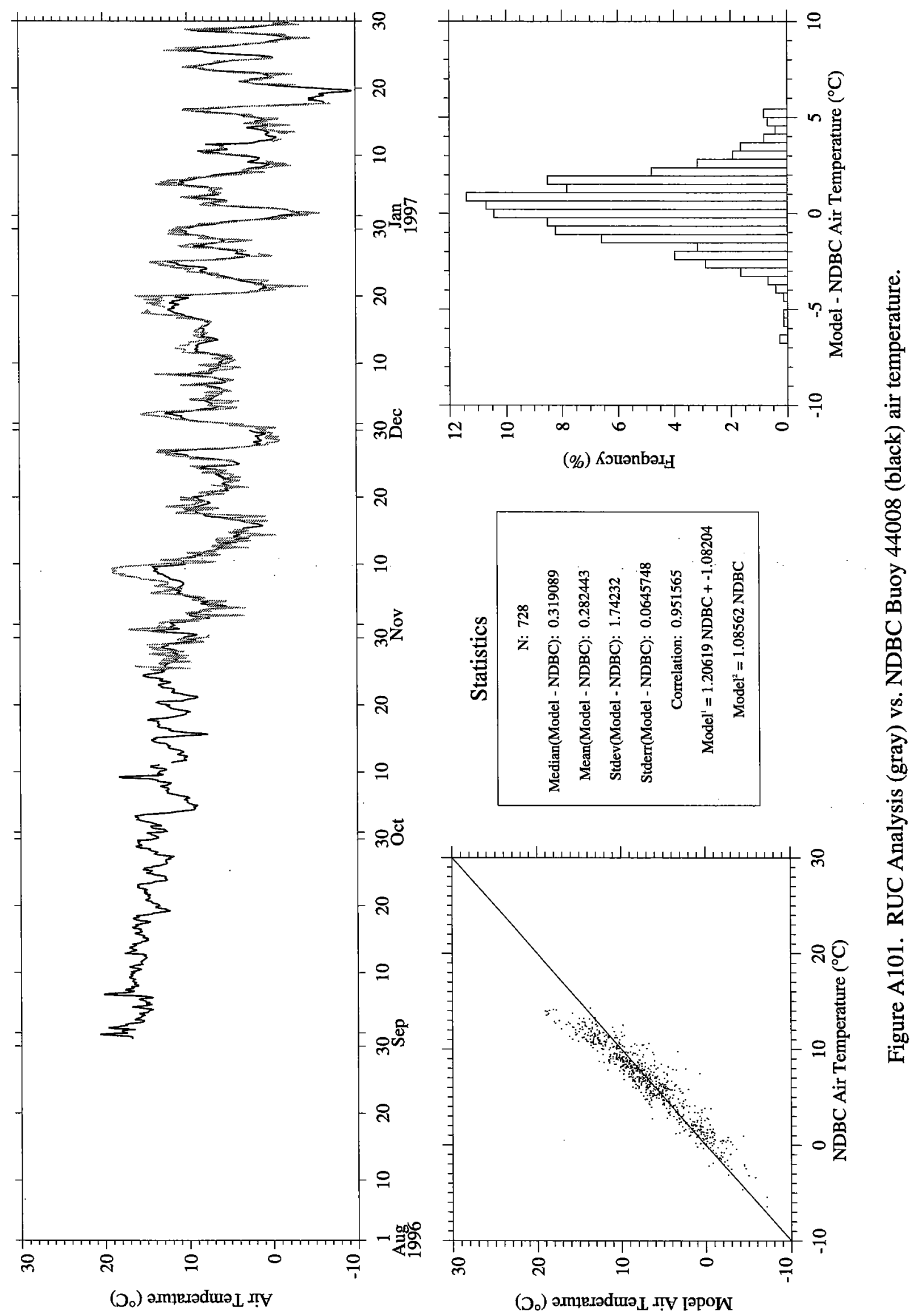




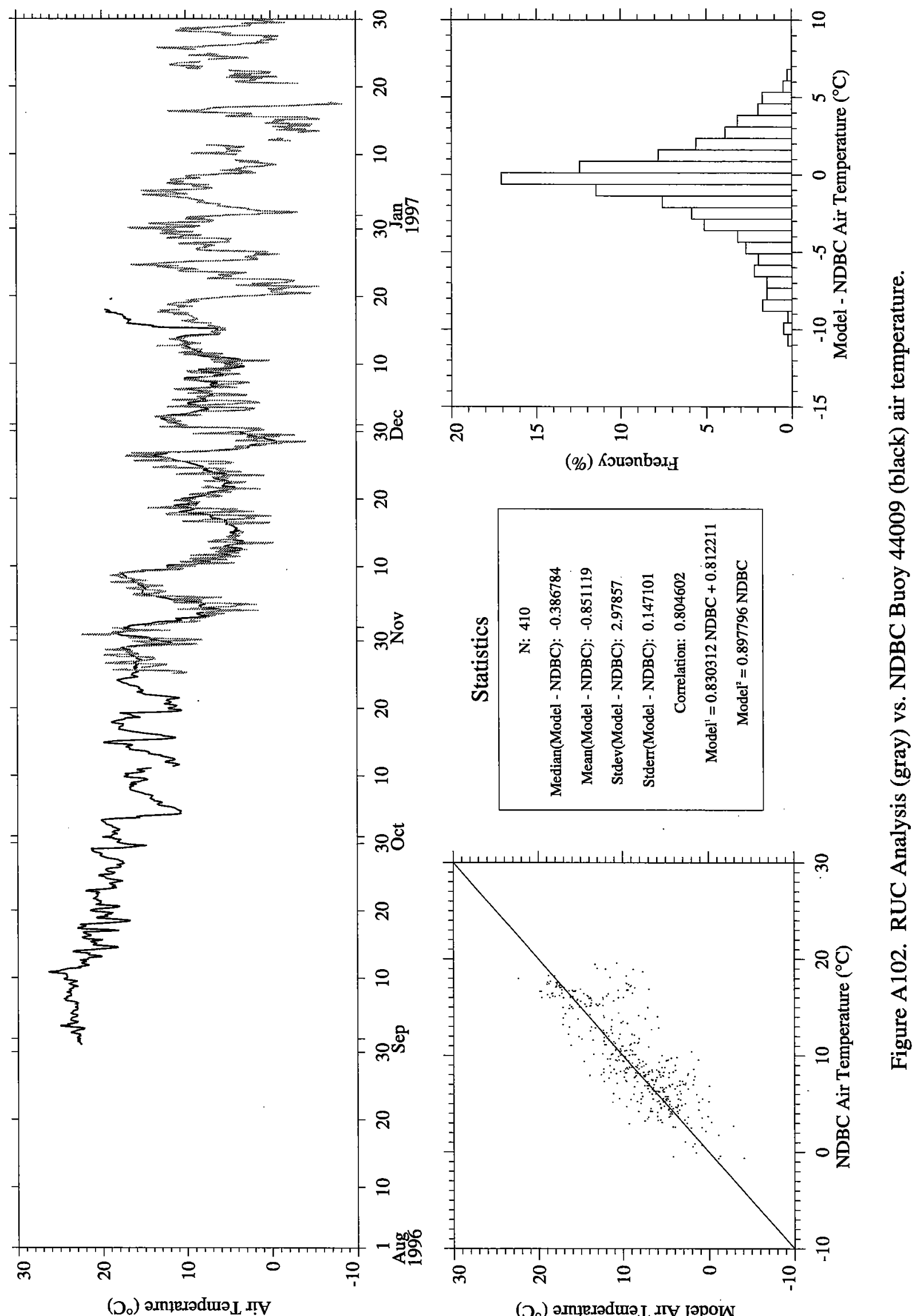




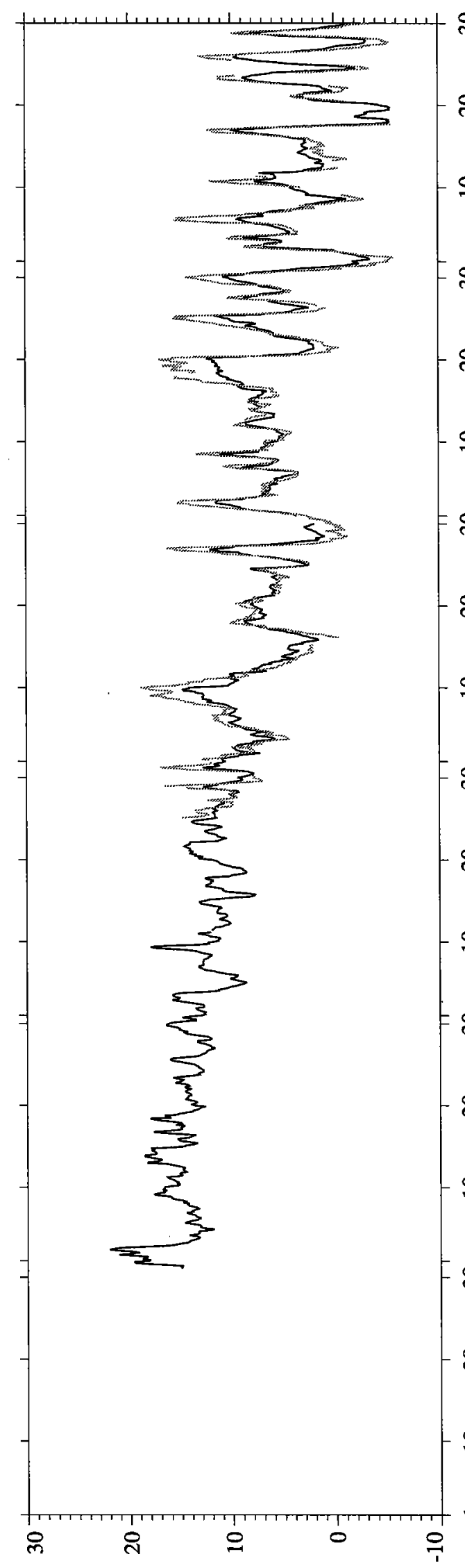

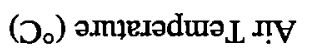

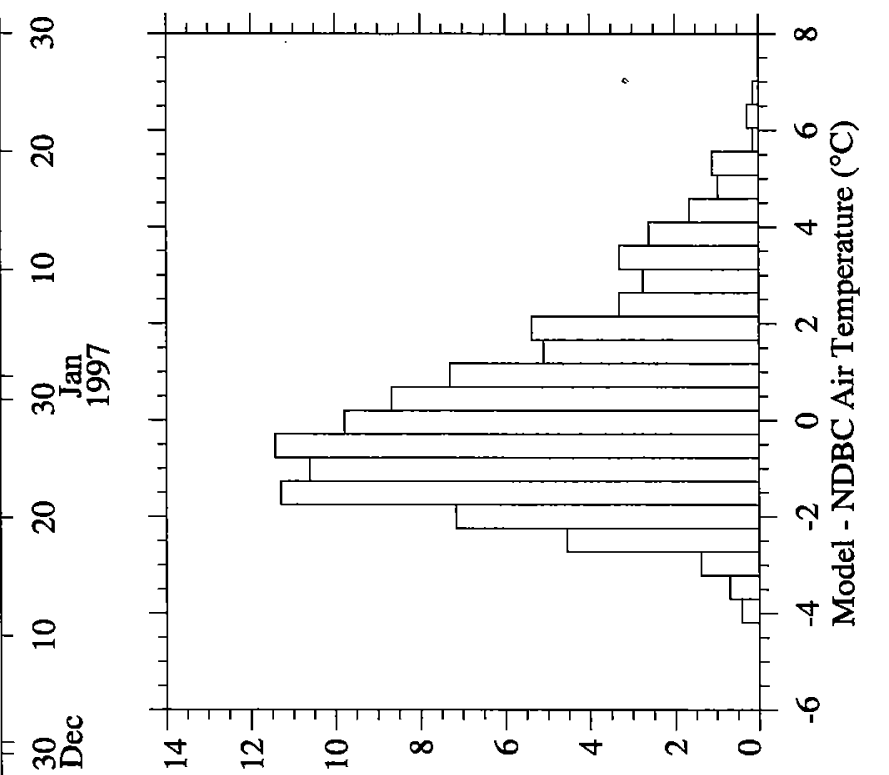

(\%) Кวuənbวג

สิ

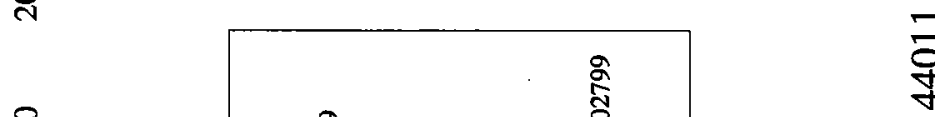

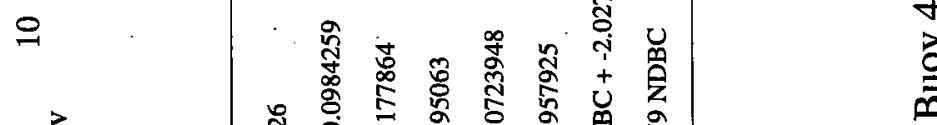

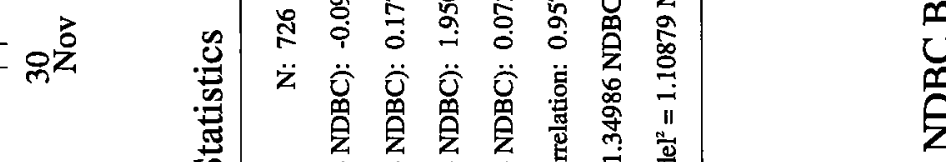

오

옹

윰
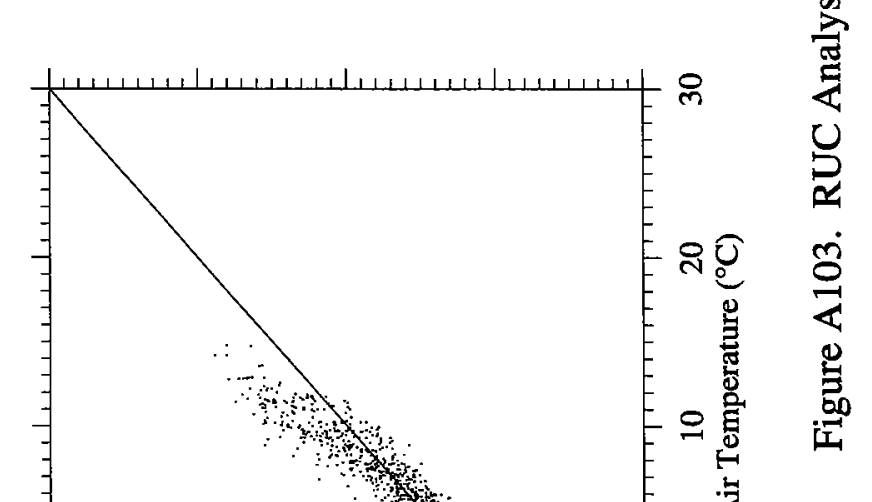


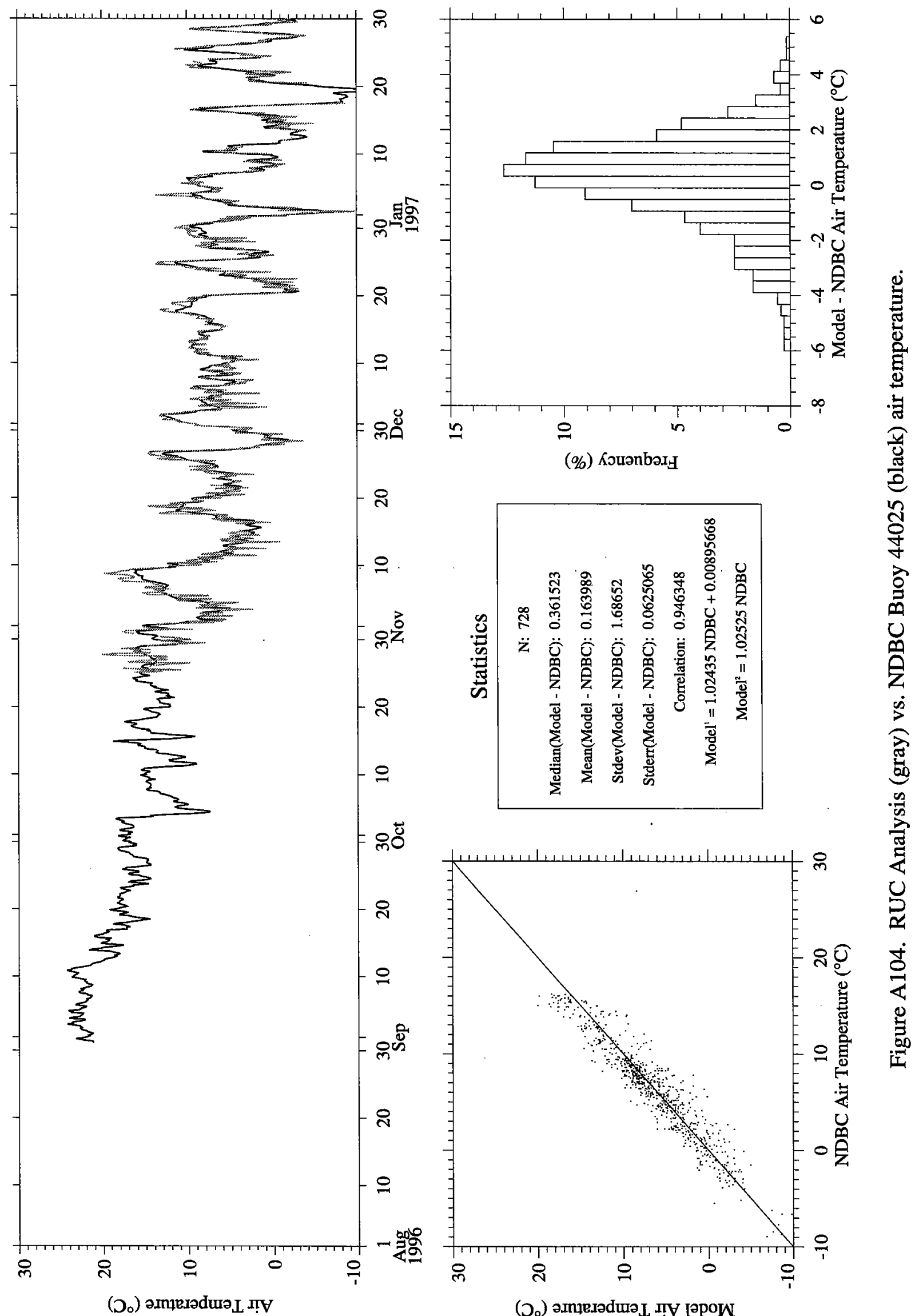




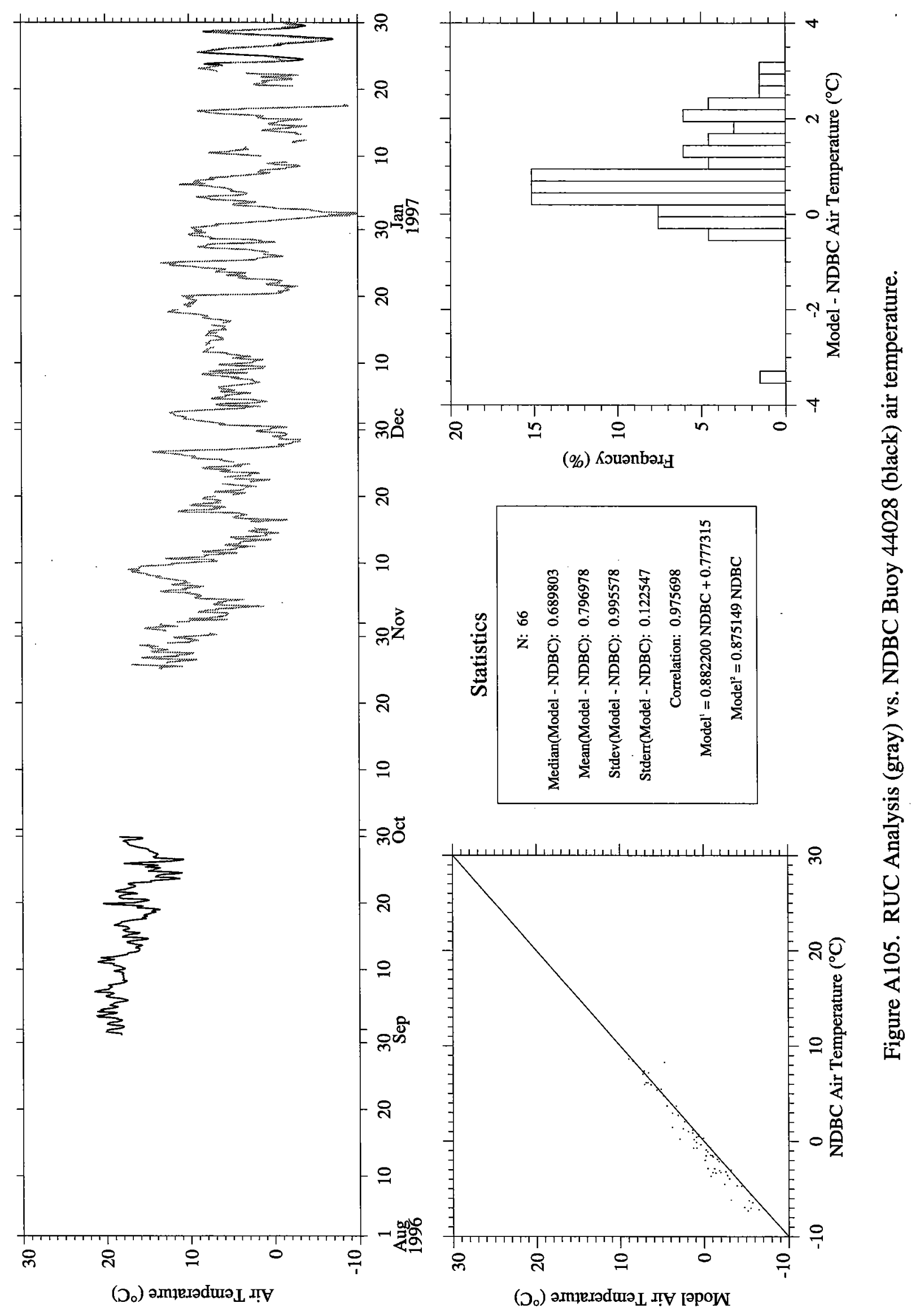




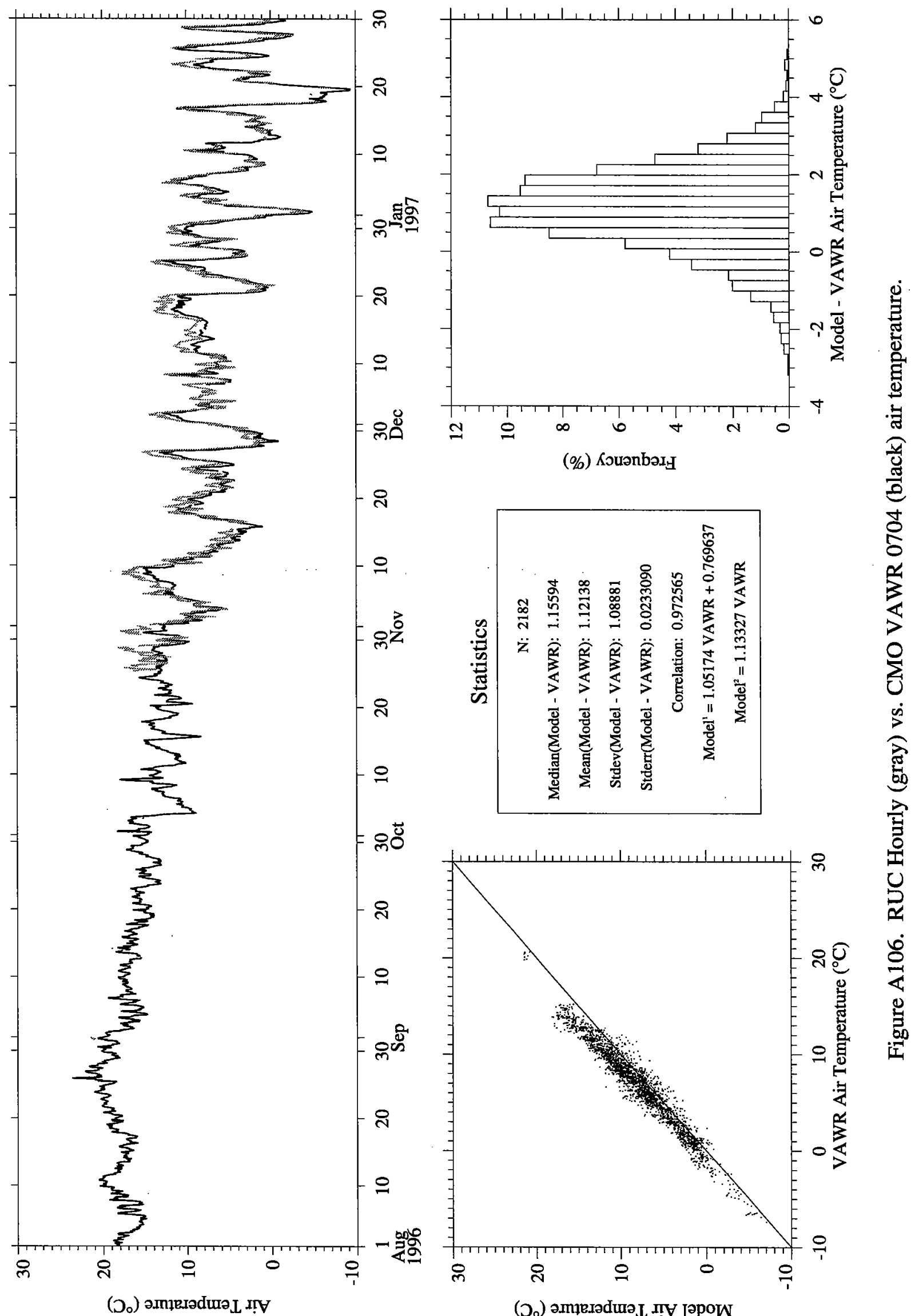




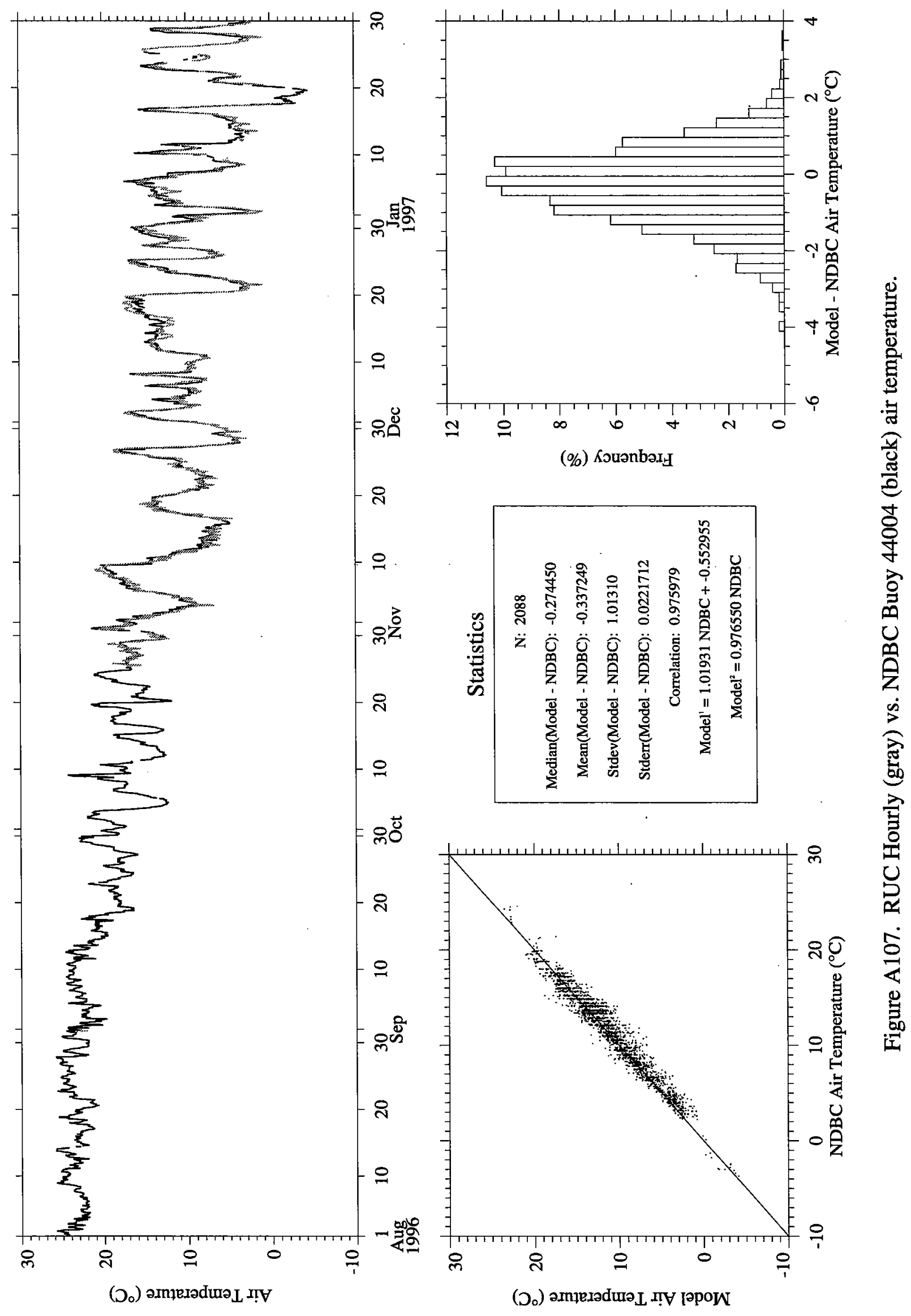




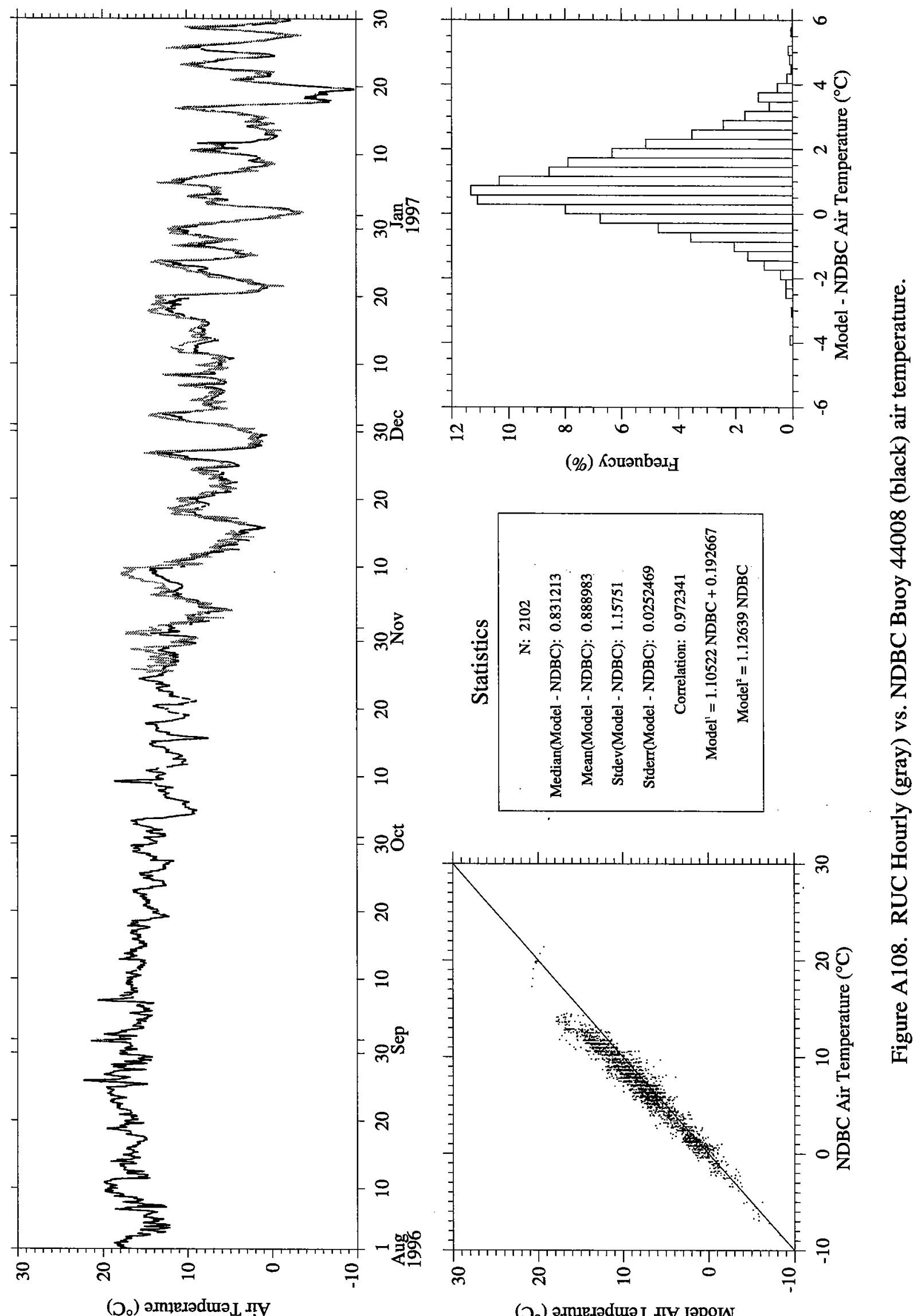




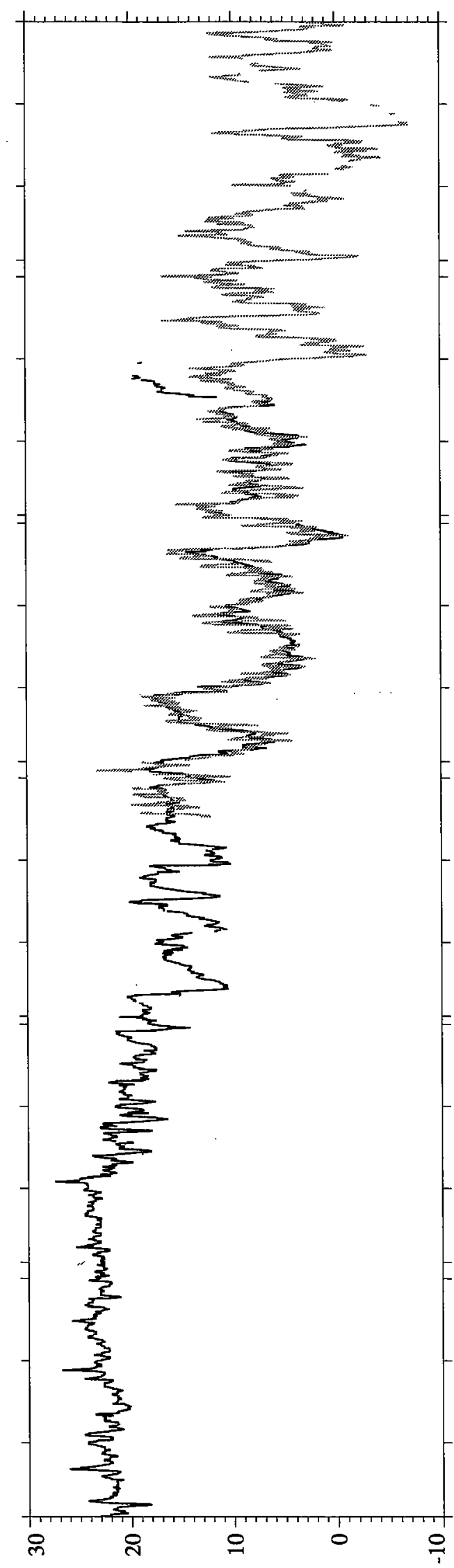

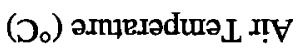

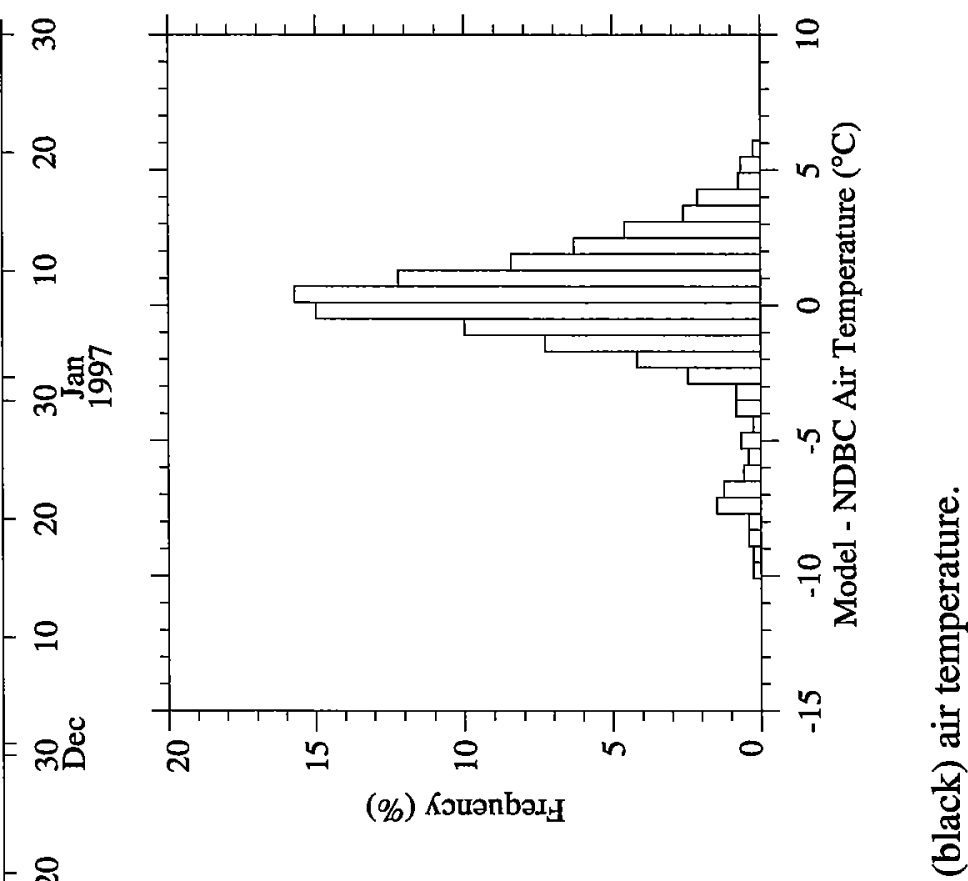

- 10

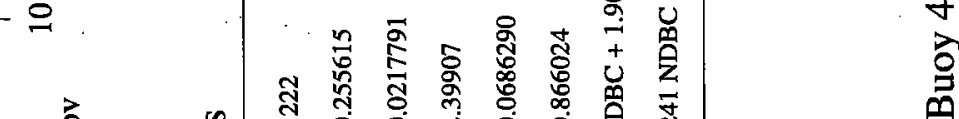

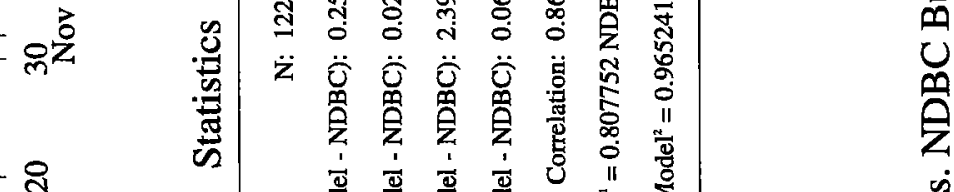

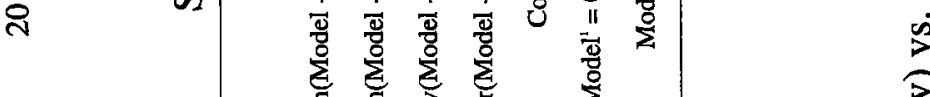

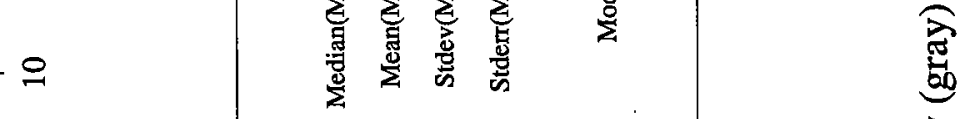
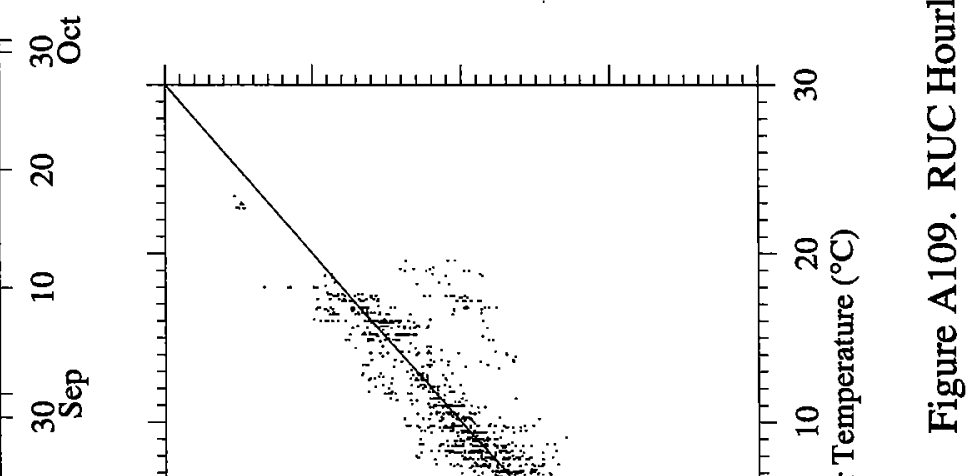

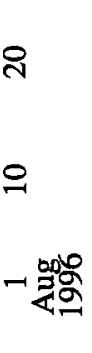

迹量

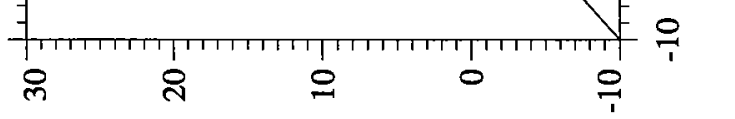

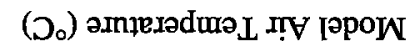




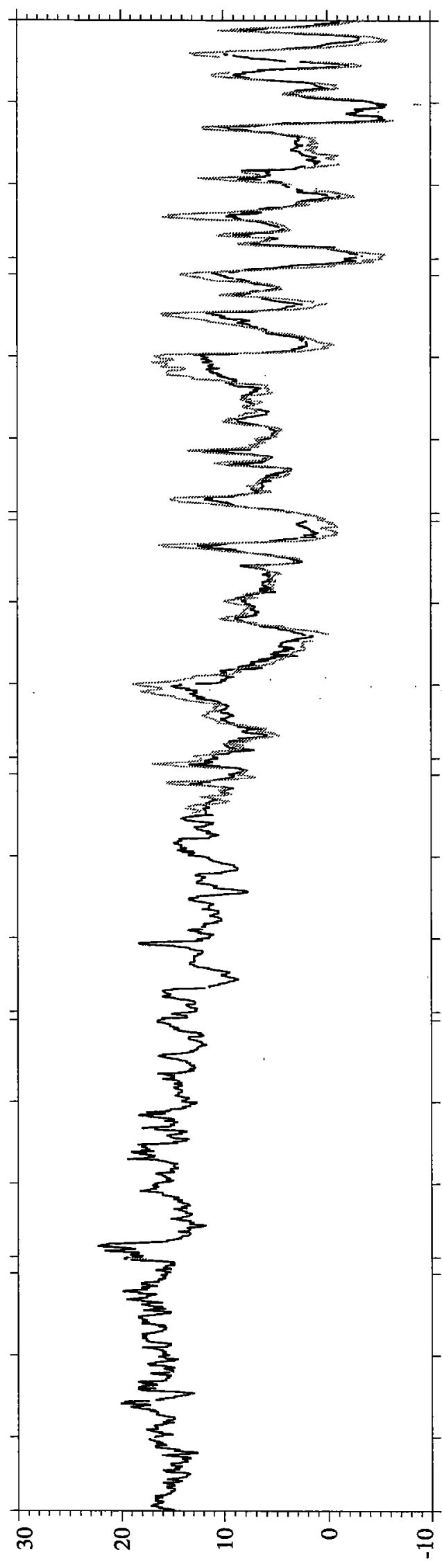

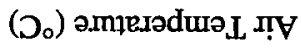

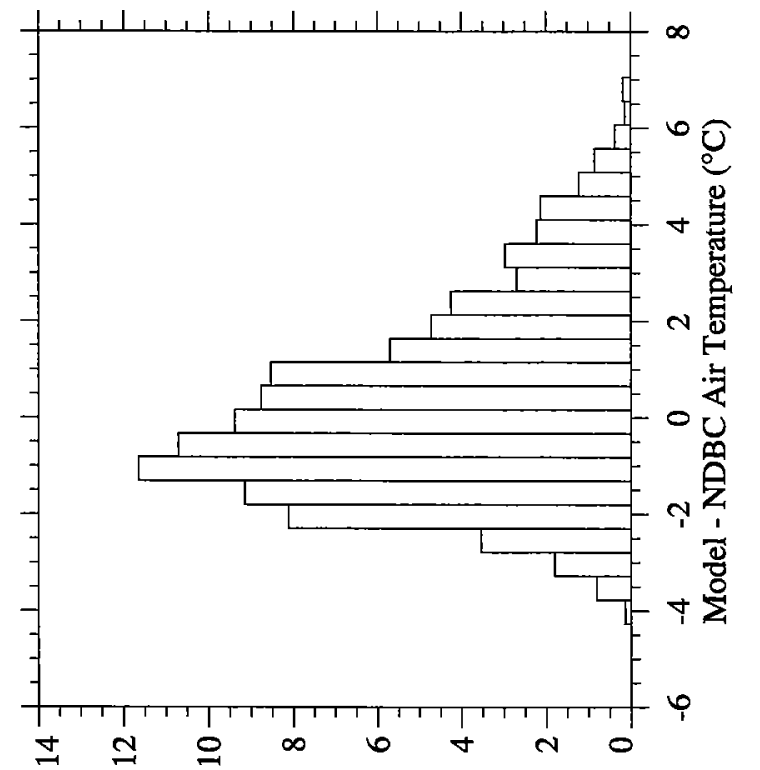

(\%) Кวuənbəఘ,

สำ

오

-

สิ

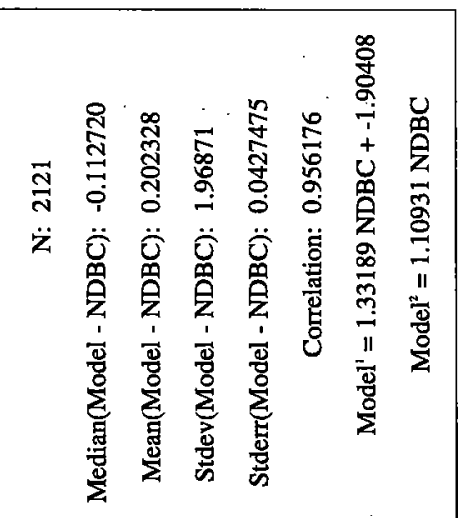

ஓ๐ั

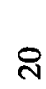

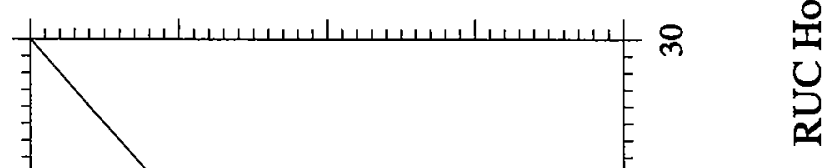

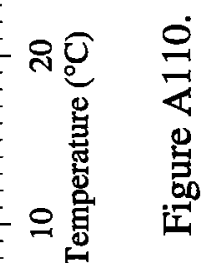

กิ

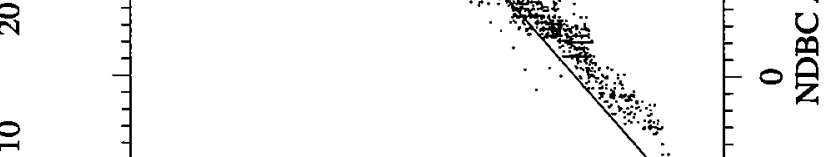

$-30 \%$

$\begin{array}{ll}8 & 8 \\ 0 & 8\end{array}$

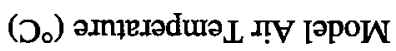

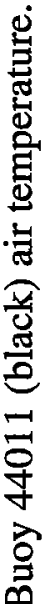

U

之

$\dot{s}$

สํํำ

क्ष 


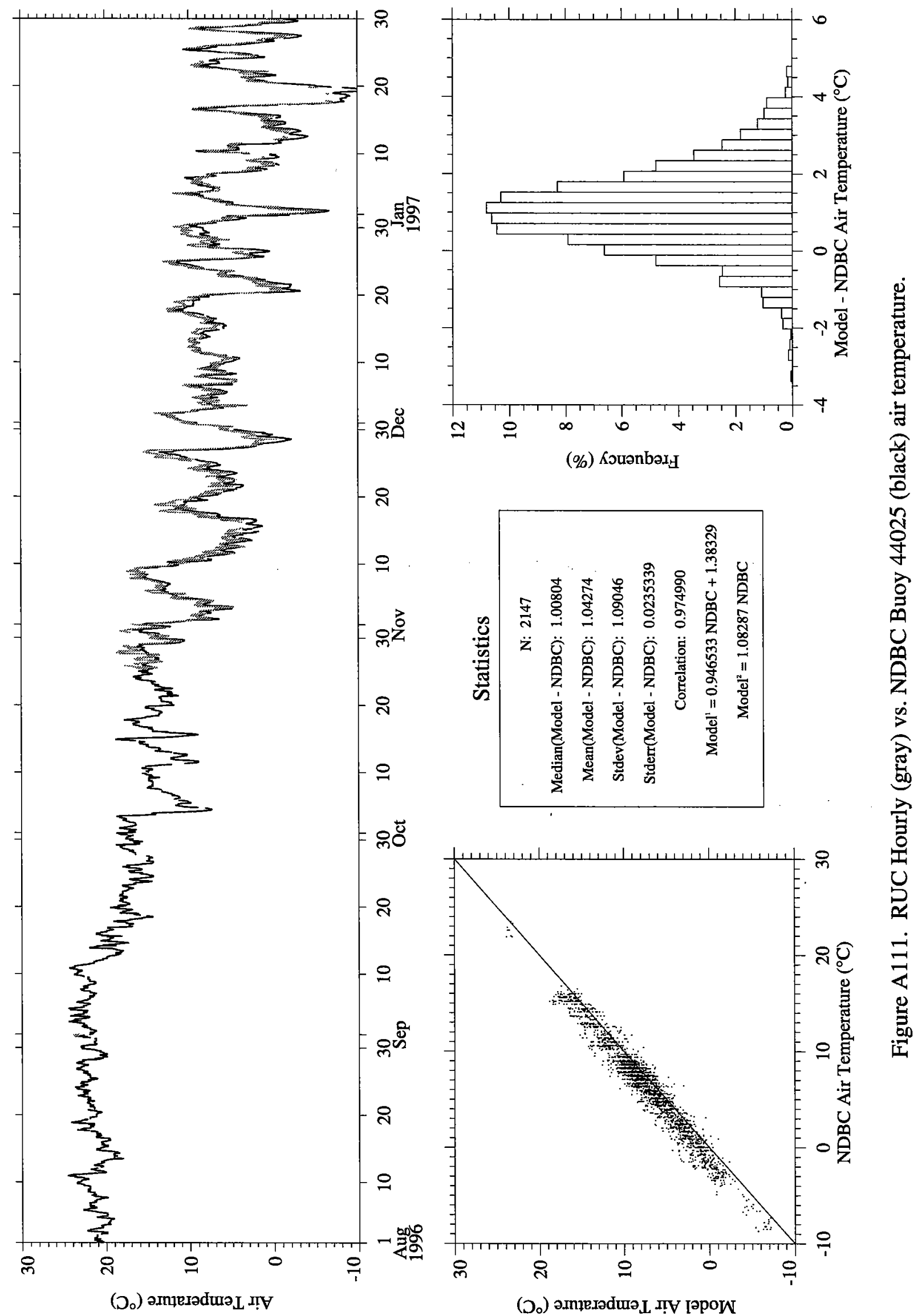




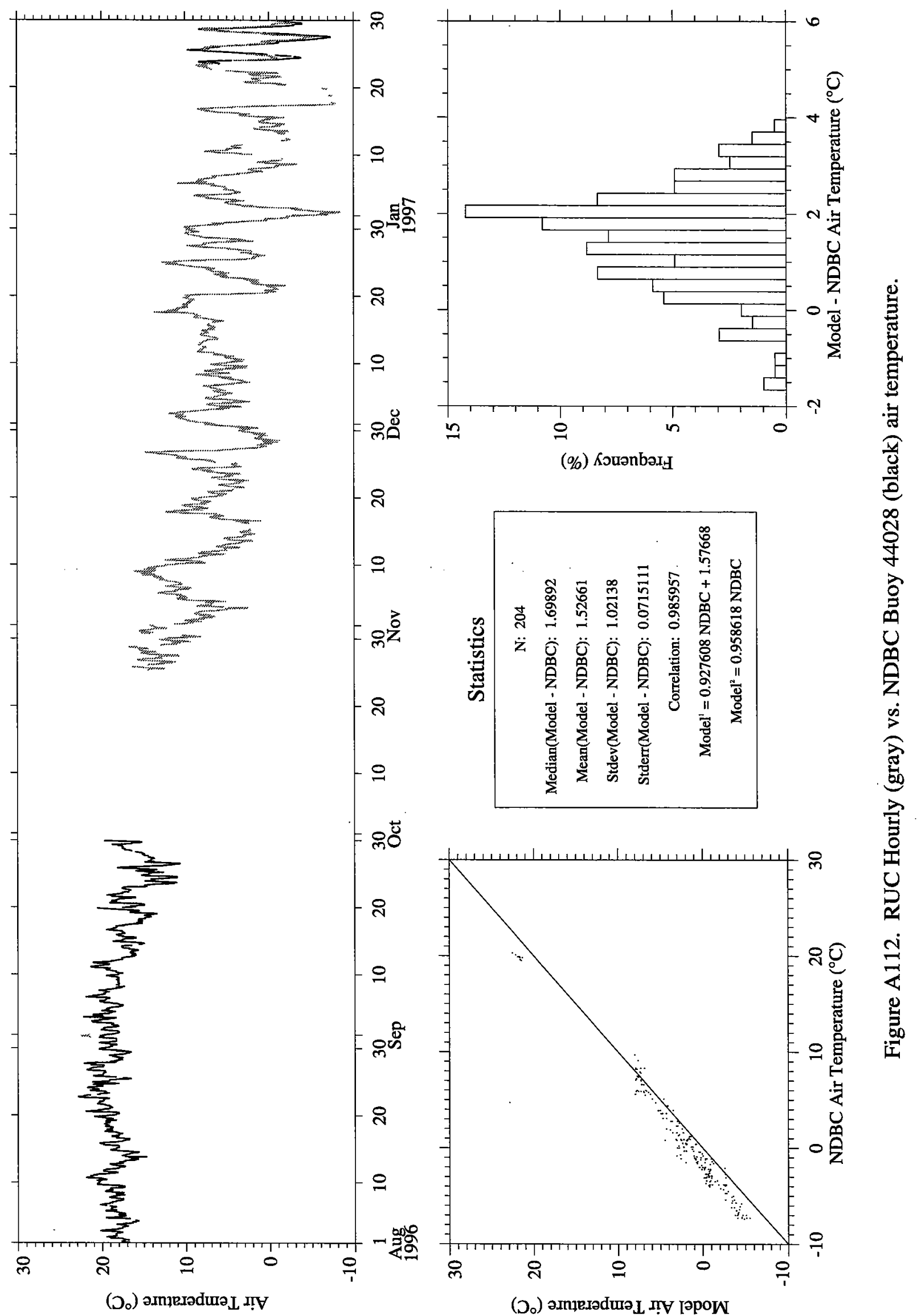




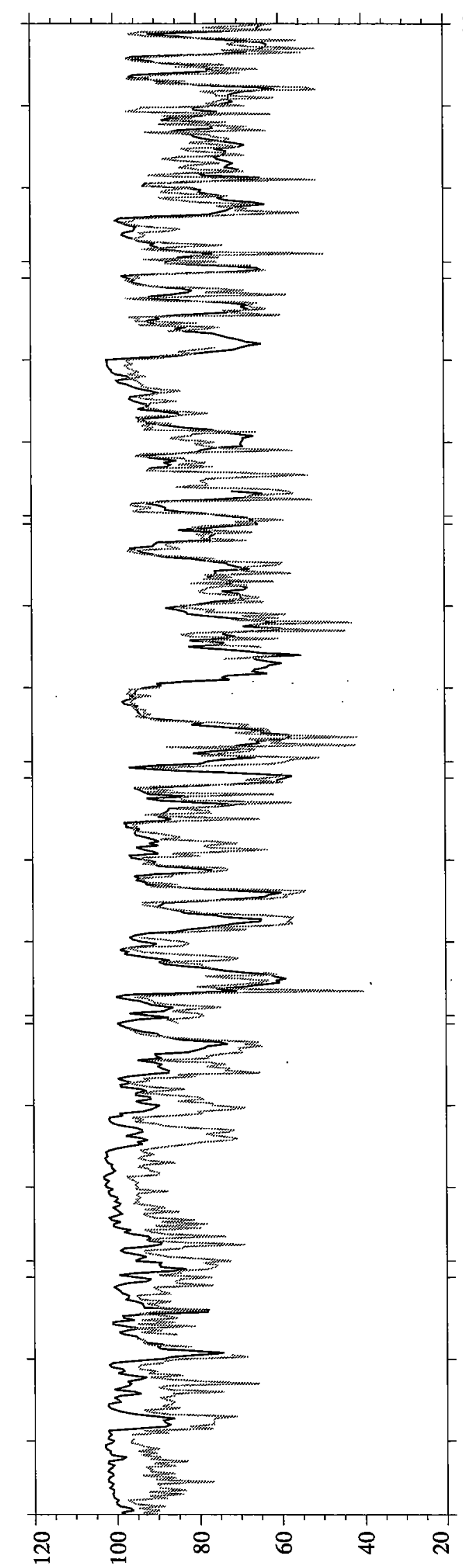

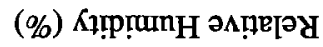

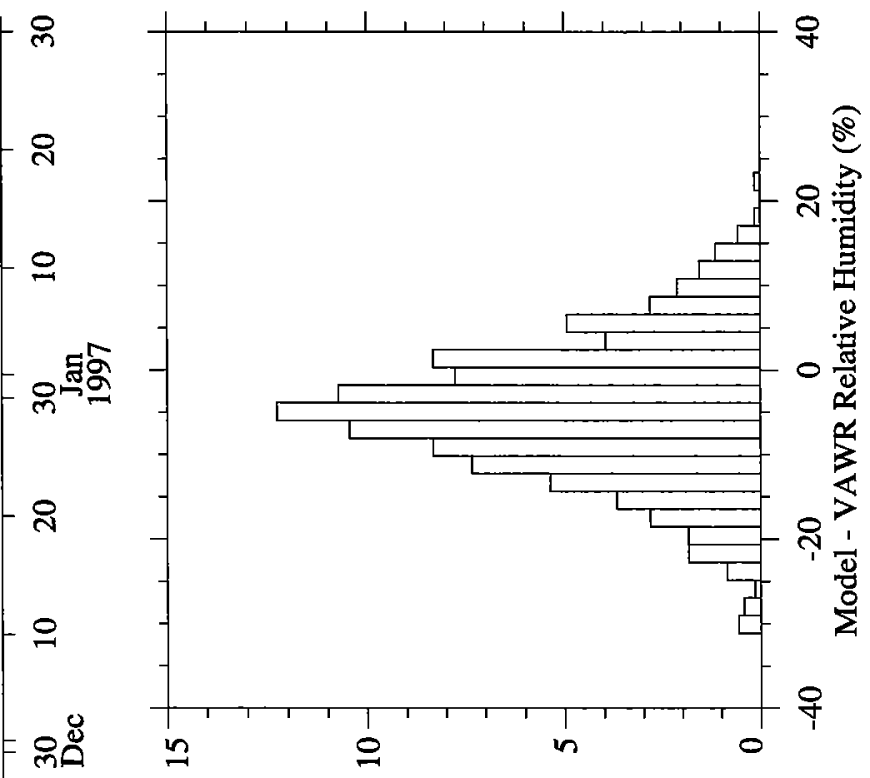

(\%) KouənbəI

กิ

은

율

㲵

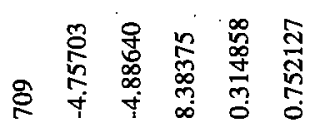

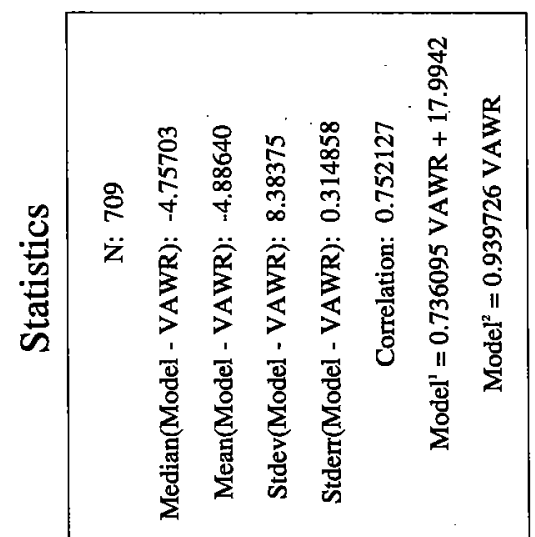

윰

สิ

量

童

3

ষ

$\stackrel{1}{2}$

$\sum_{0}^{3}$

$\dot{p}$

ลิํำ

क्ष

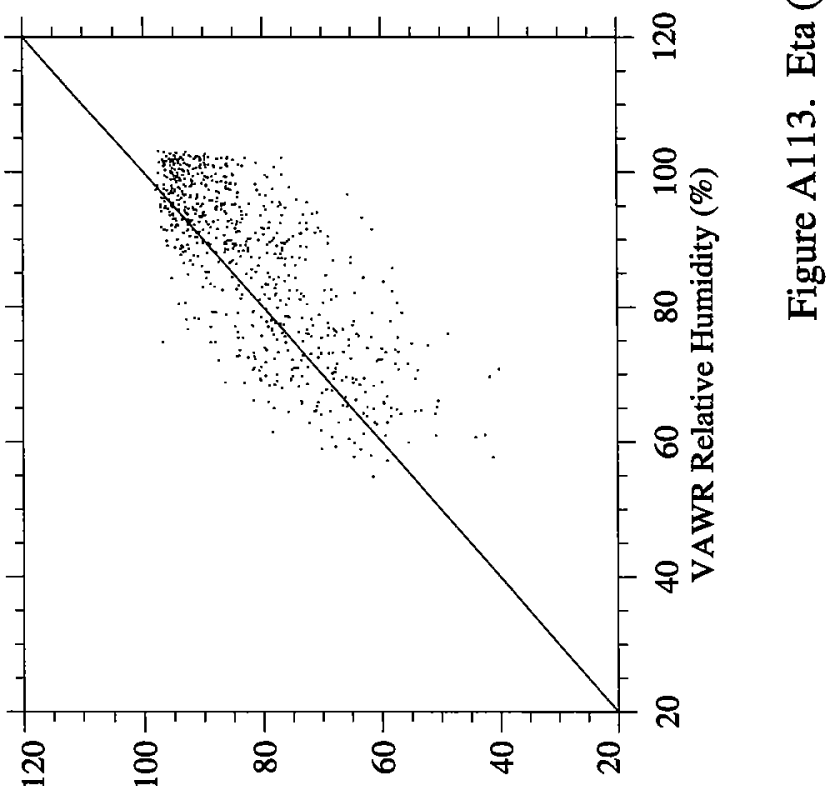

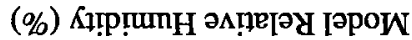




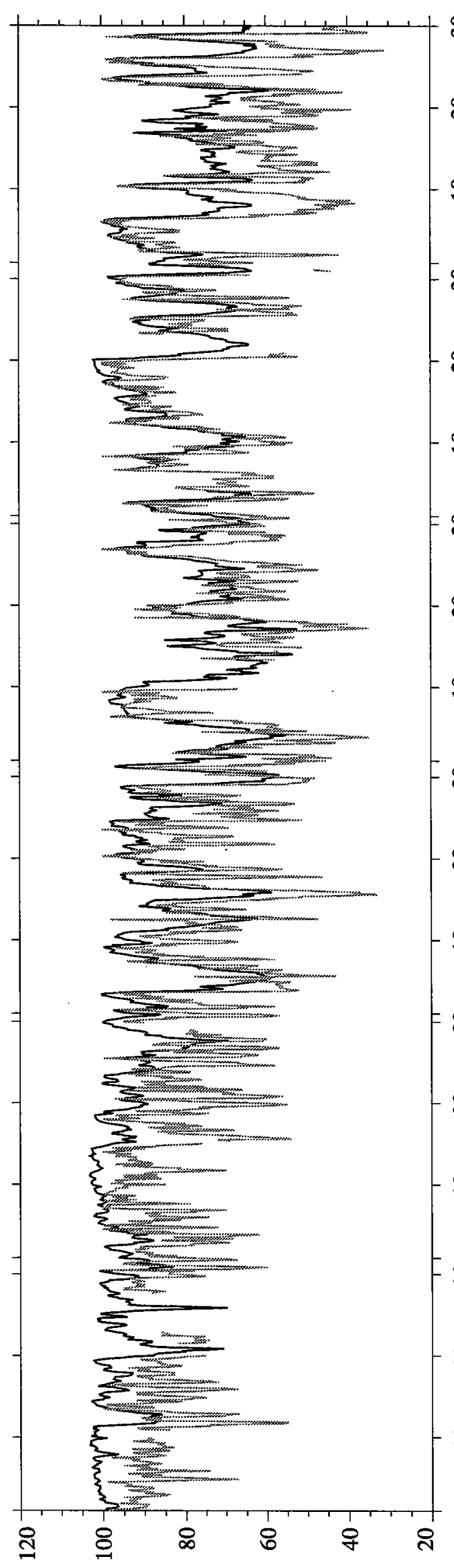

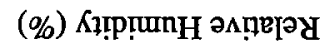
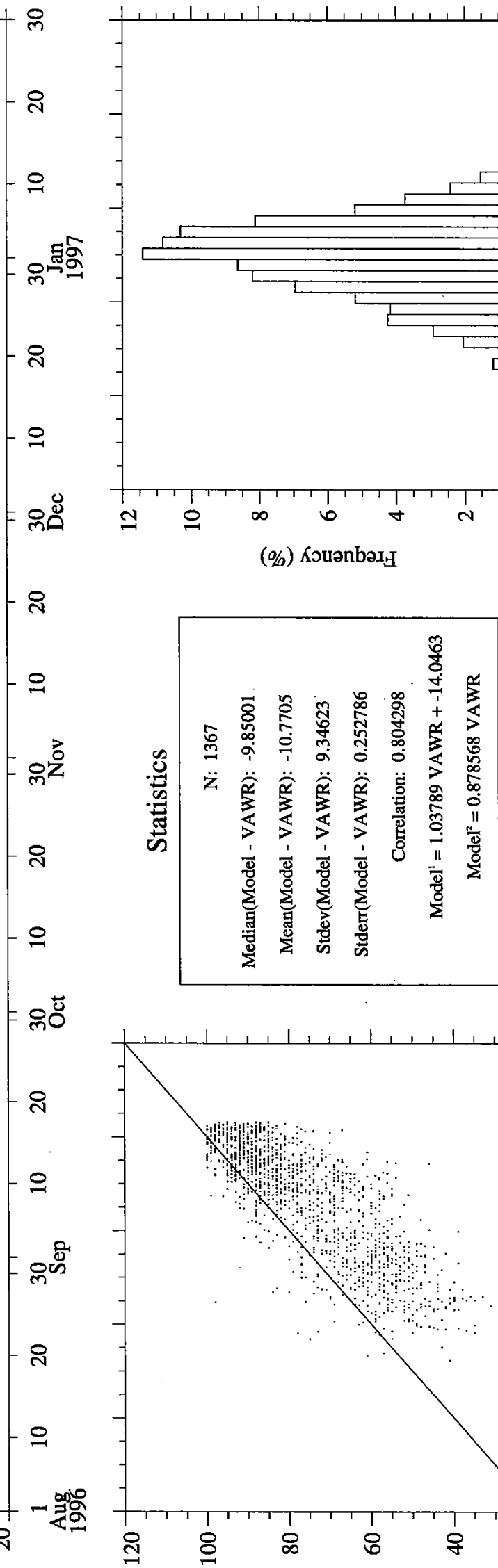

(\%) Kouənbəد,

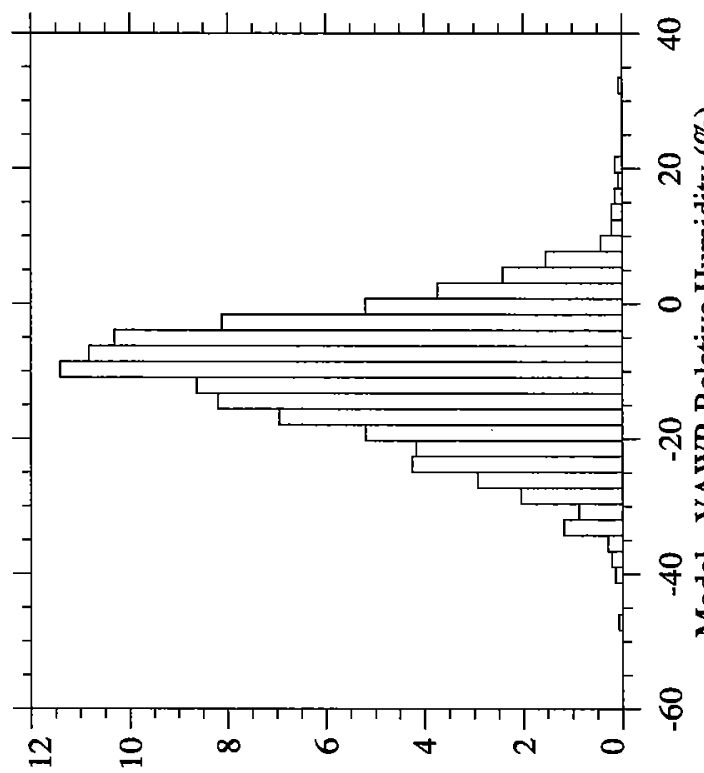

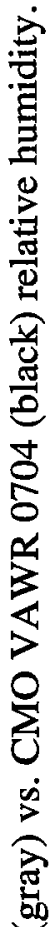

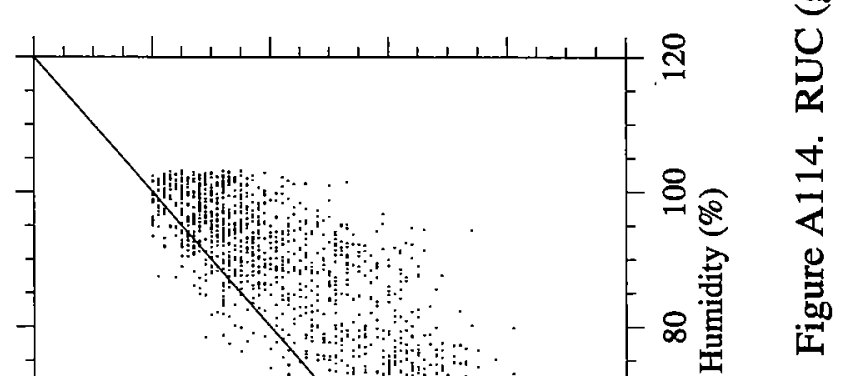




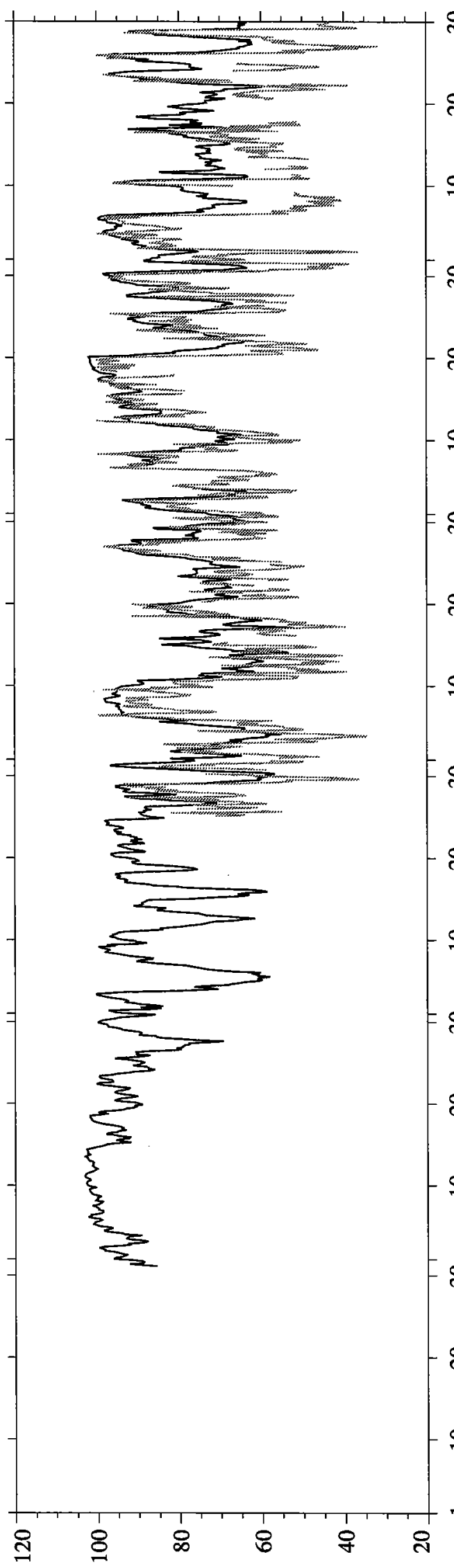

(\%) Кำp̣unн әмп̣ерәу

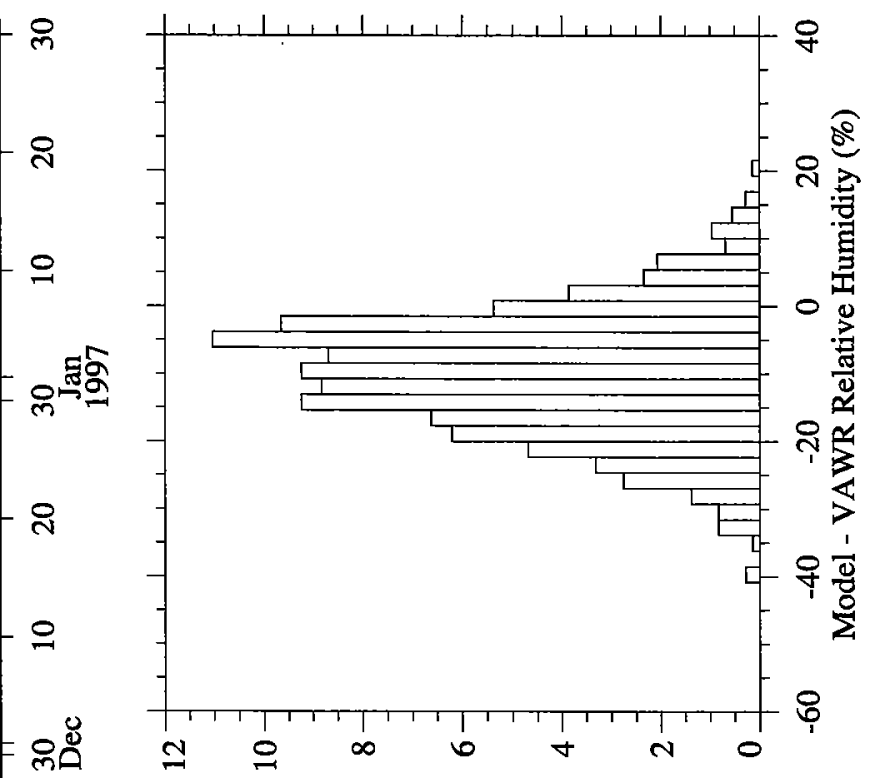

(\%) Kouənbaג

요

응

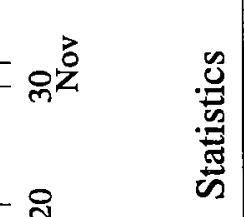

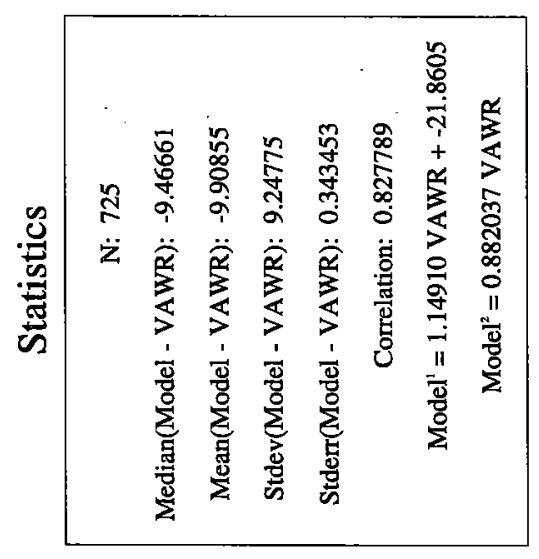

ஜீபّ

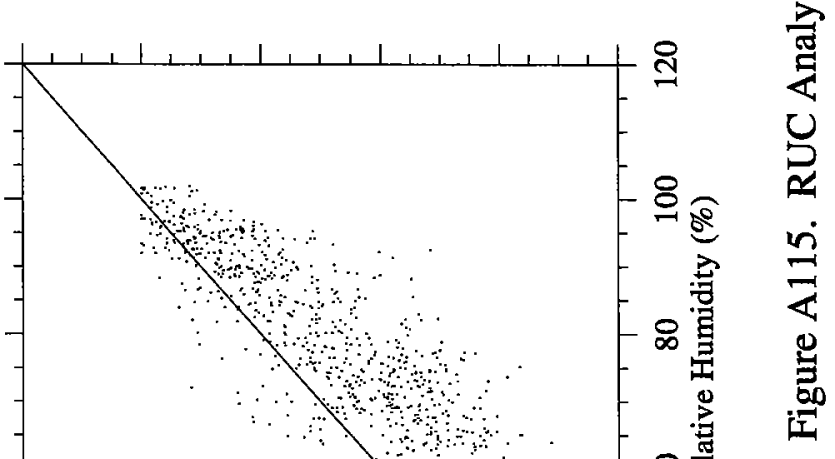

$\begin{array}{cccccc}1 & 1 & 1 & 1 & 1 & 1 \\ 0 & 0 & 0 & 0 & 0 & 0\end{array}$

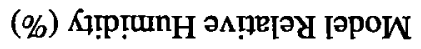

穿

苍

急

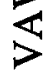

$\sum^{\circ}$

$\dot{m}$

สิ

50

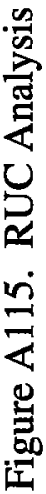




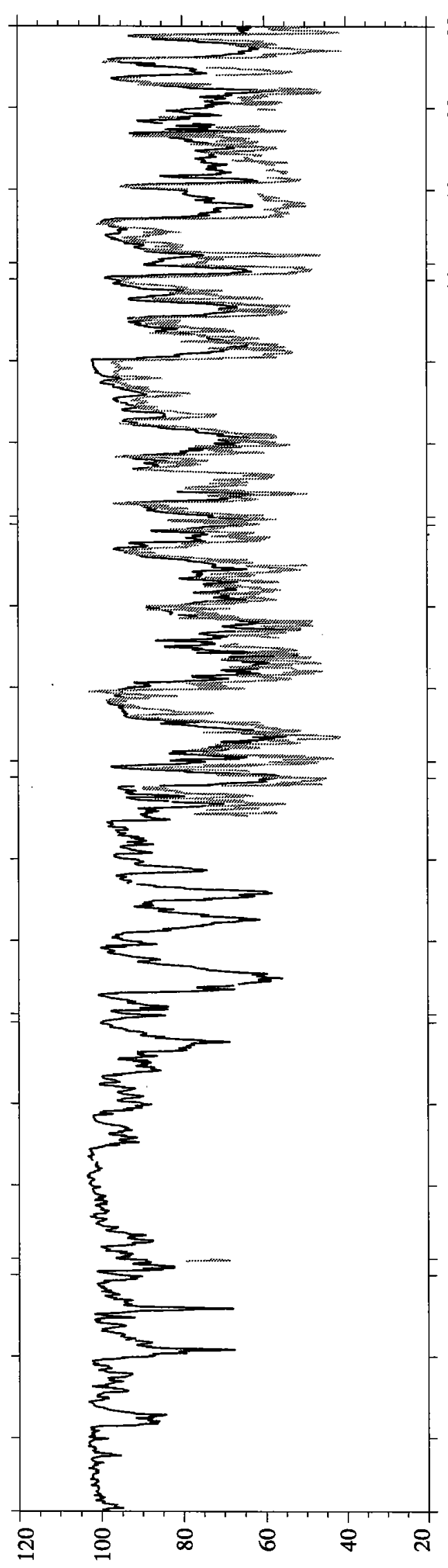

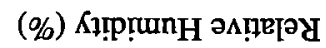

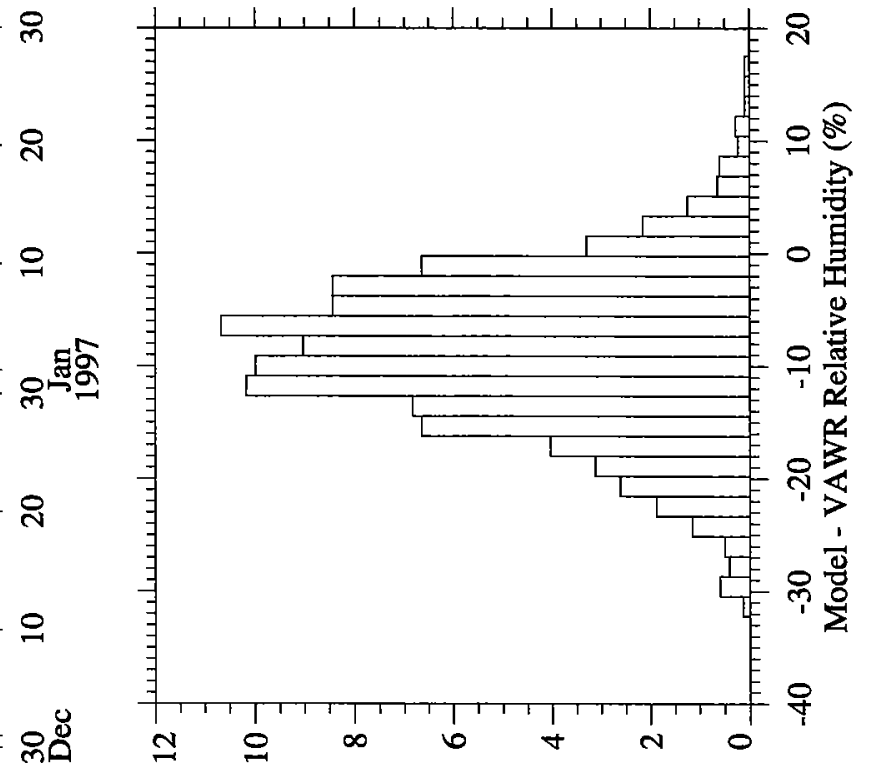

(\%) Kouənbəد!

กิ

กิ

우

ळ:

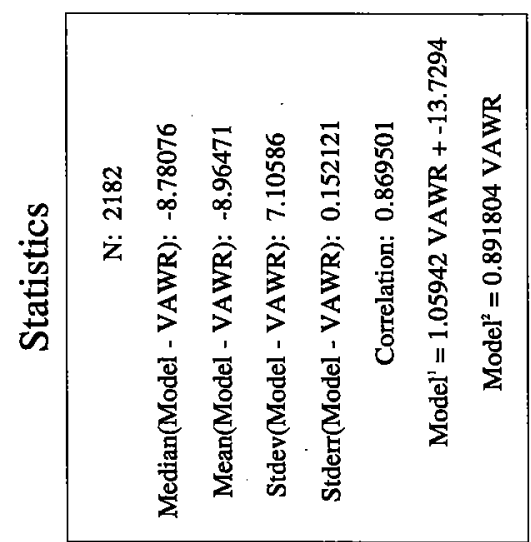

mz

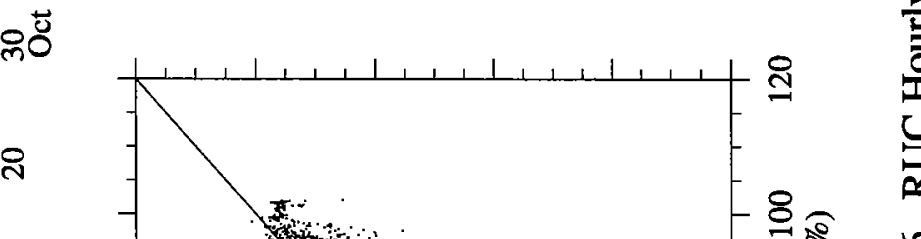

응

유

우

- 윰욤

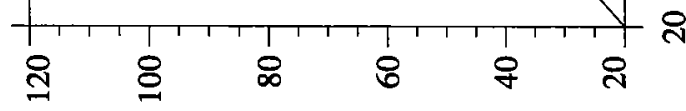

(\%) א1!p!̣un

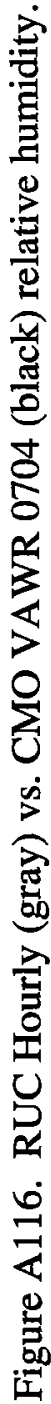



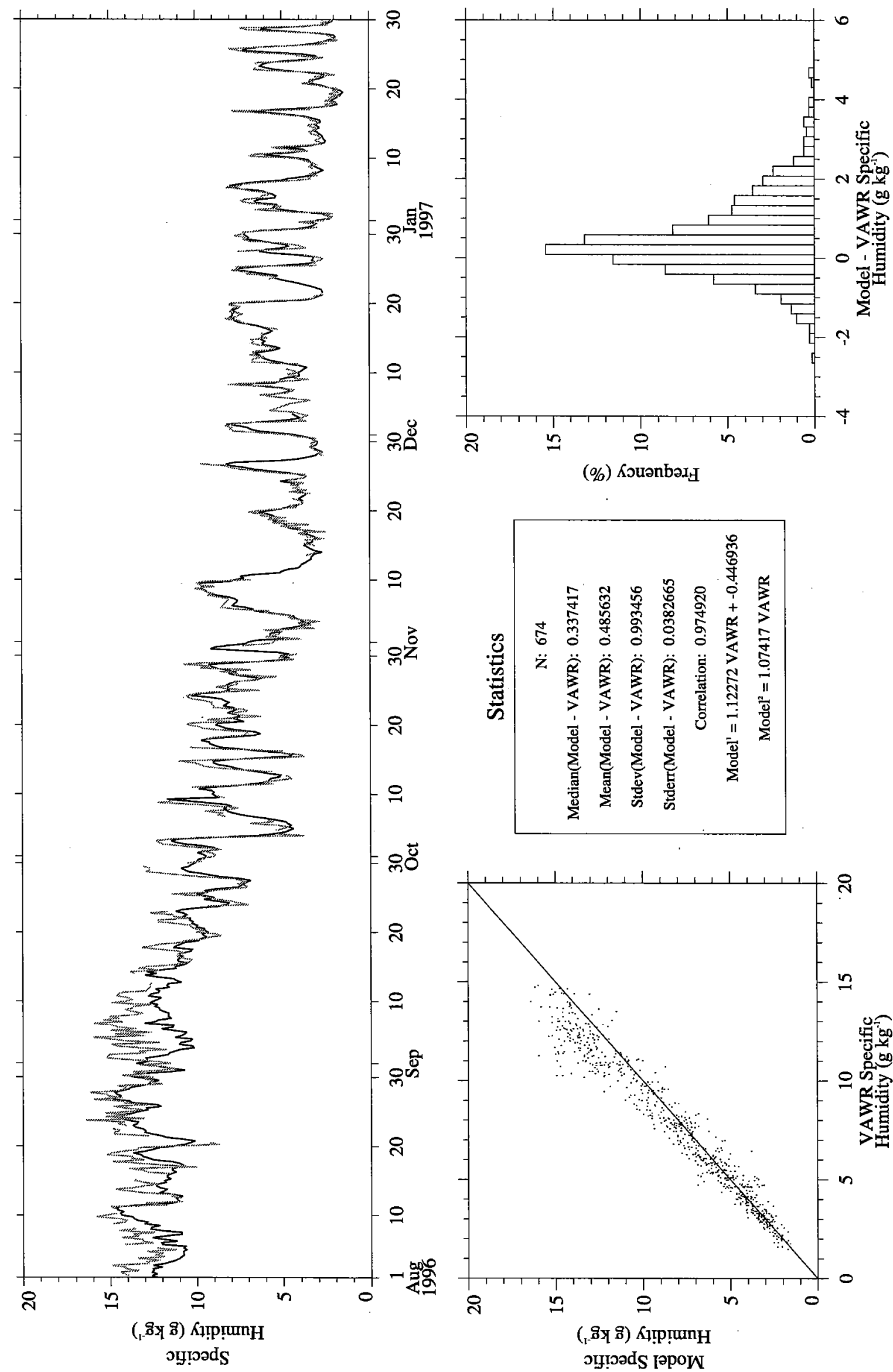

สิ

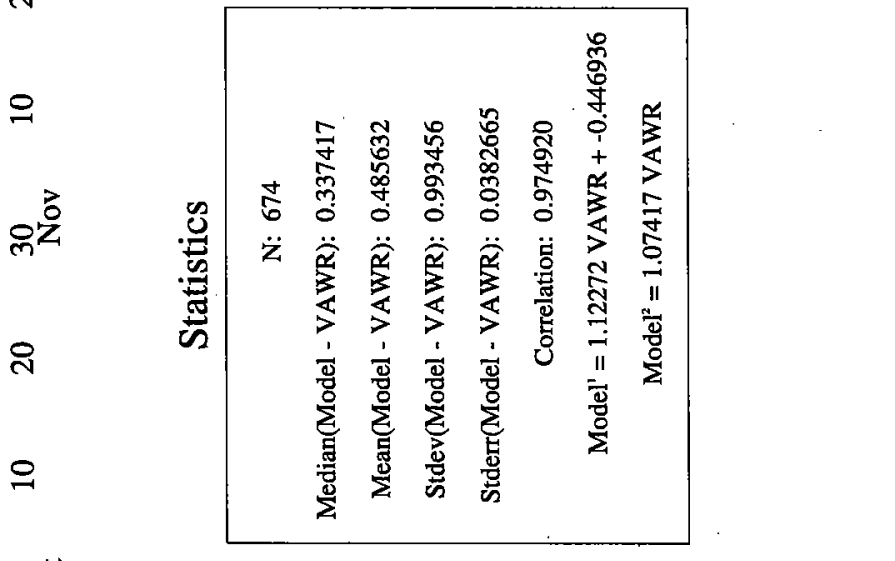

్ㅣㅇ

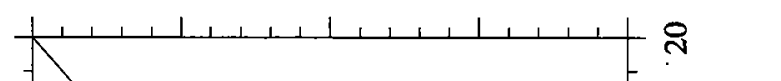

우

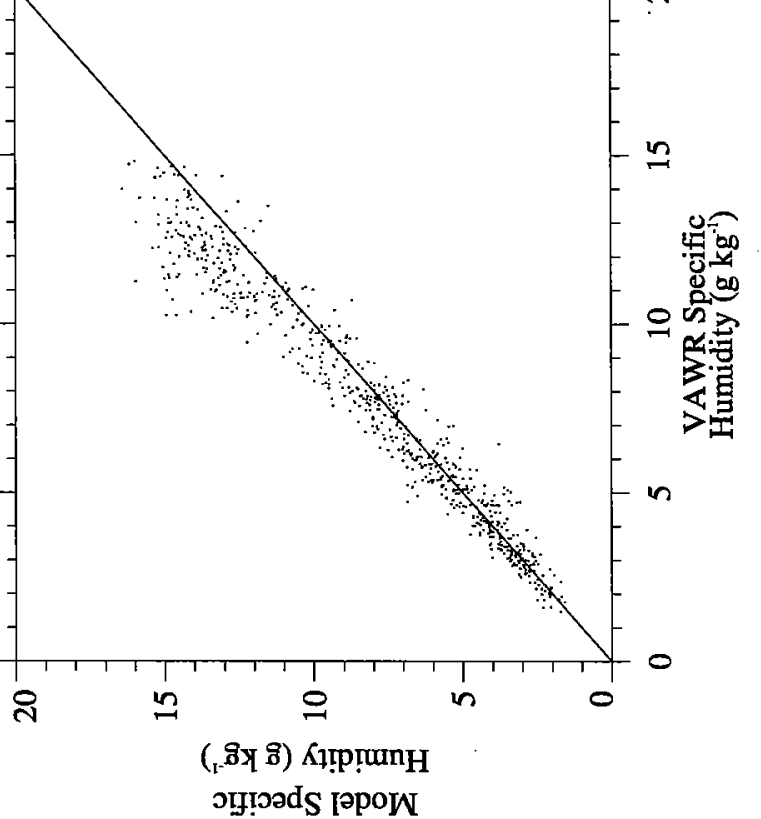

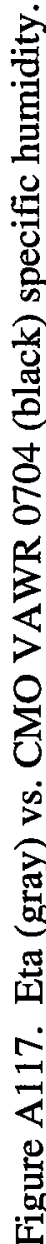




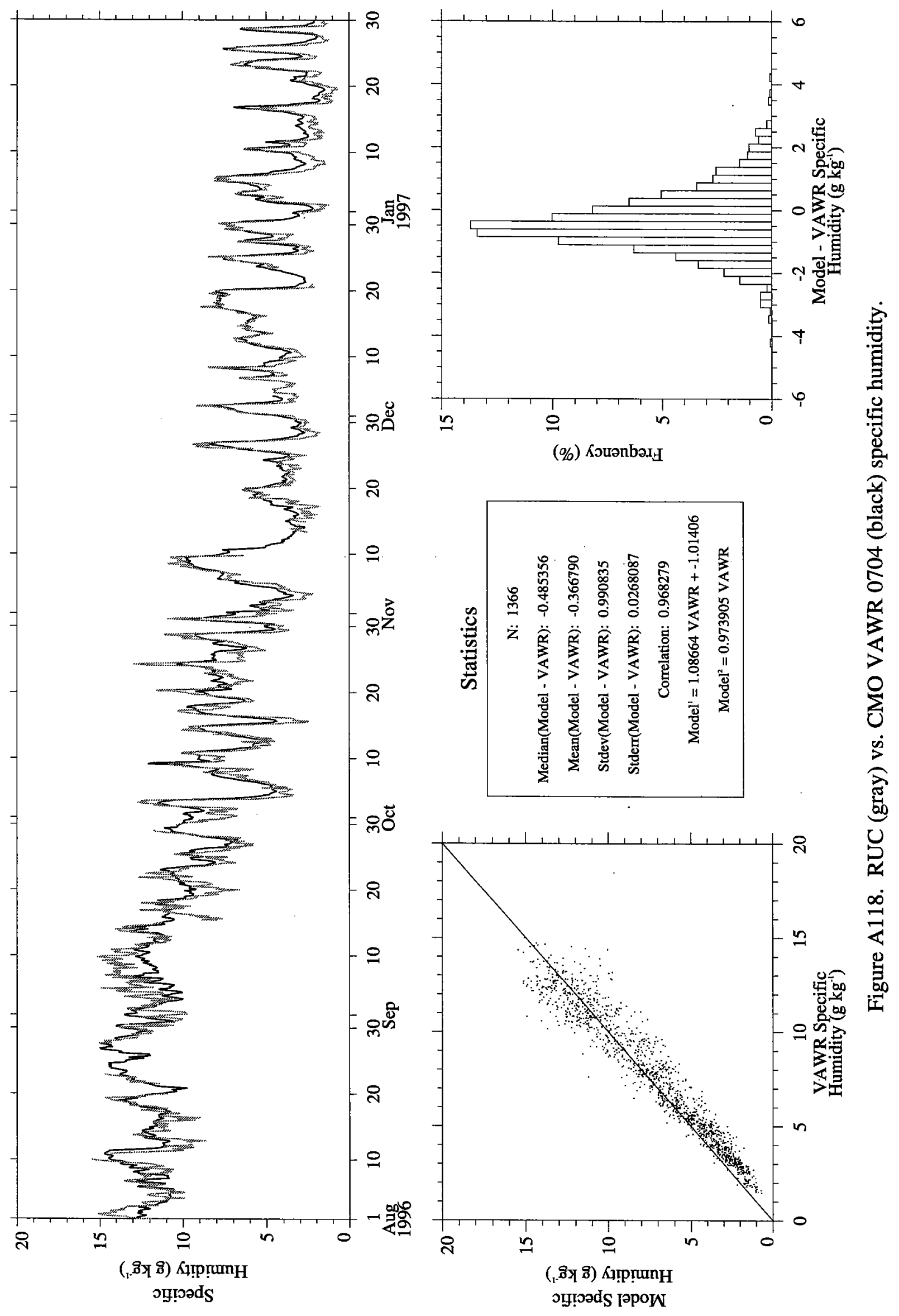



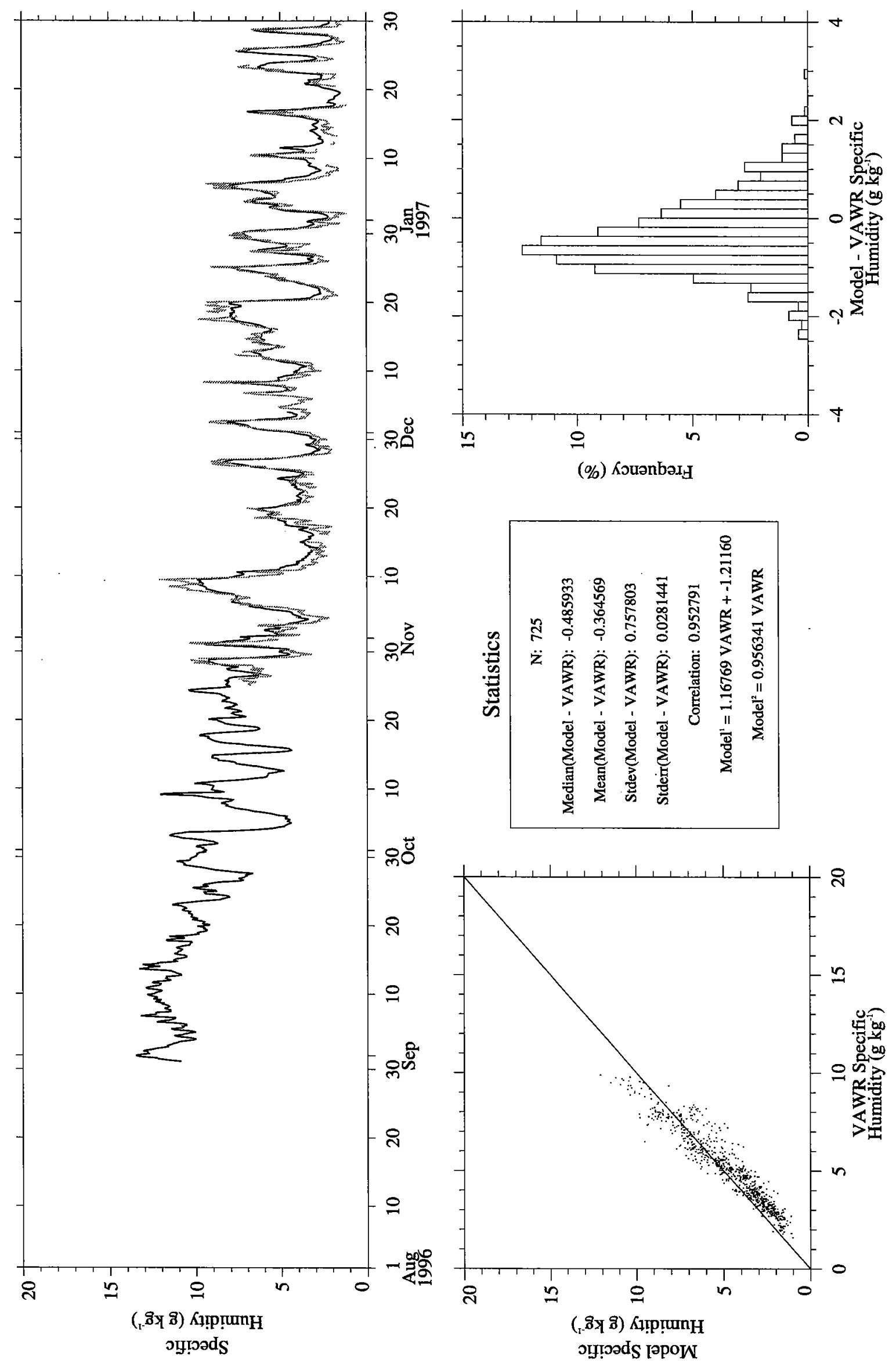

:

ำ

(\%) Kouənbəu

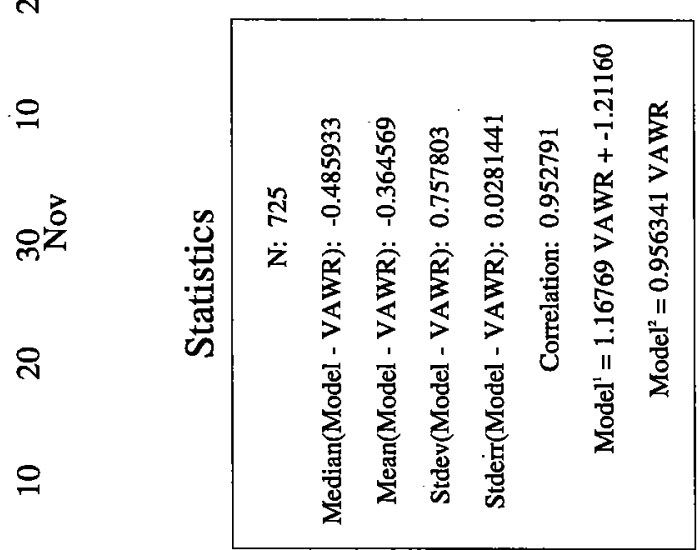

$=\varnothing \overline{0}$

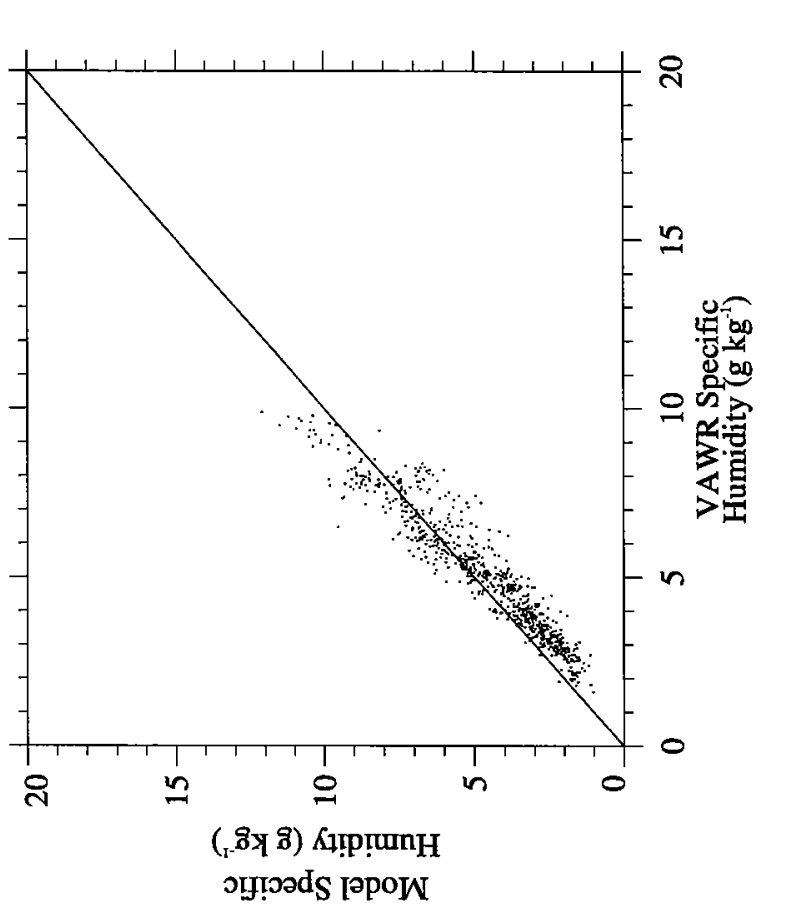

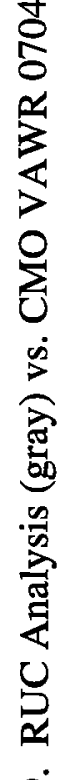

$\stackrel{9}{=}$

움

ల్లణ

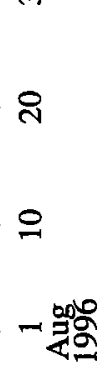



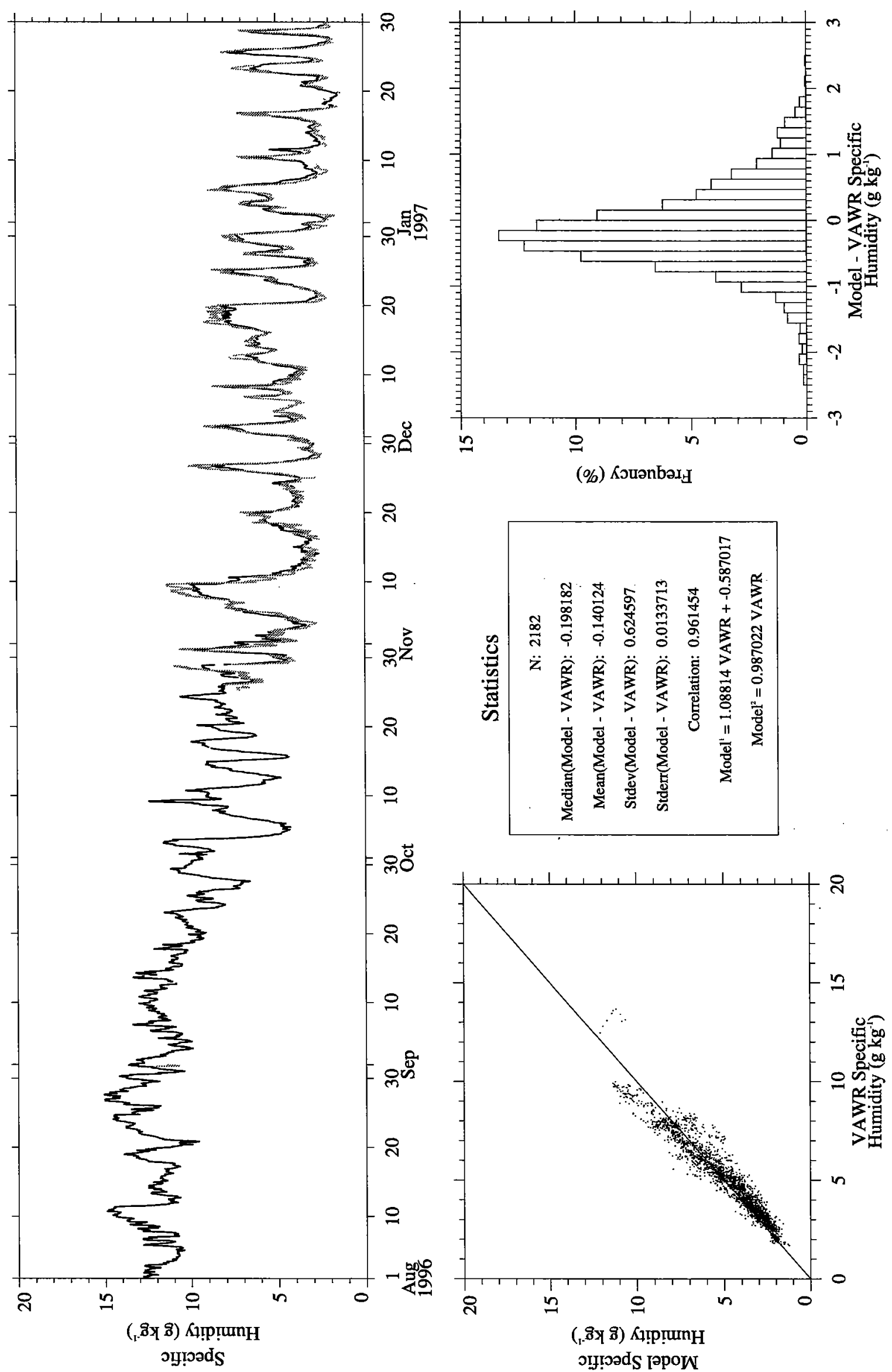

害

(\%) KэuənbəגH

유

으

유

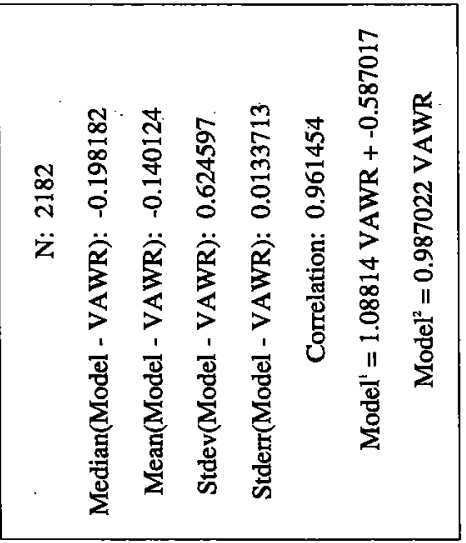

잉

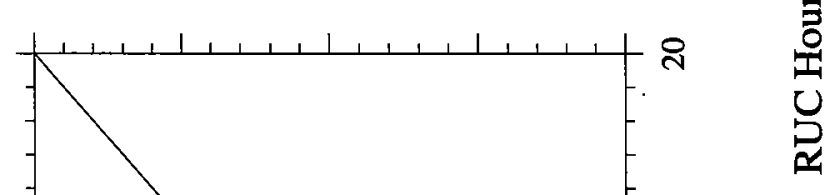

กิ

응

응

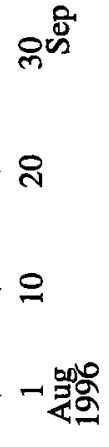

ำㅇํㅇ

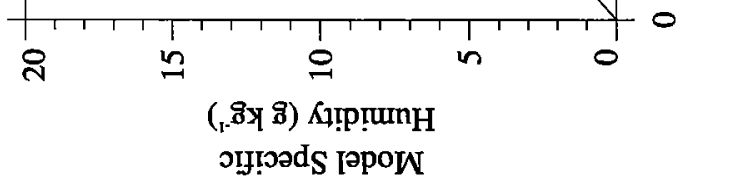




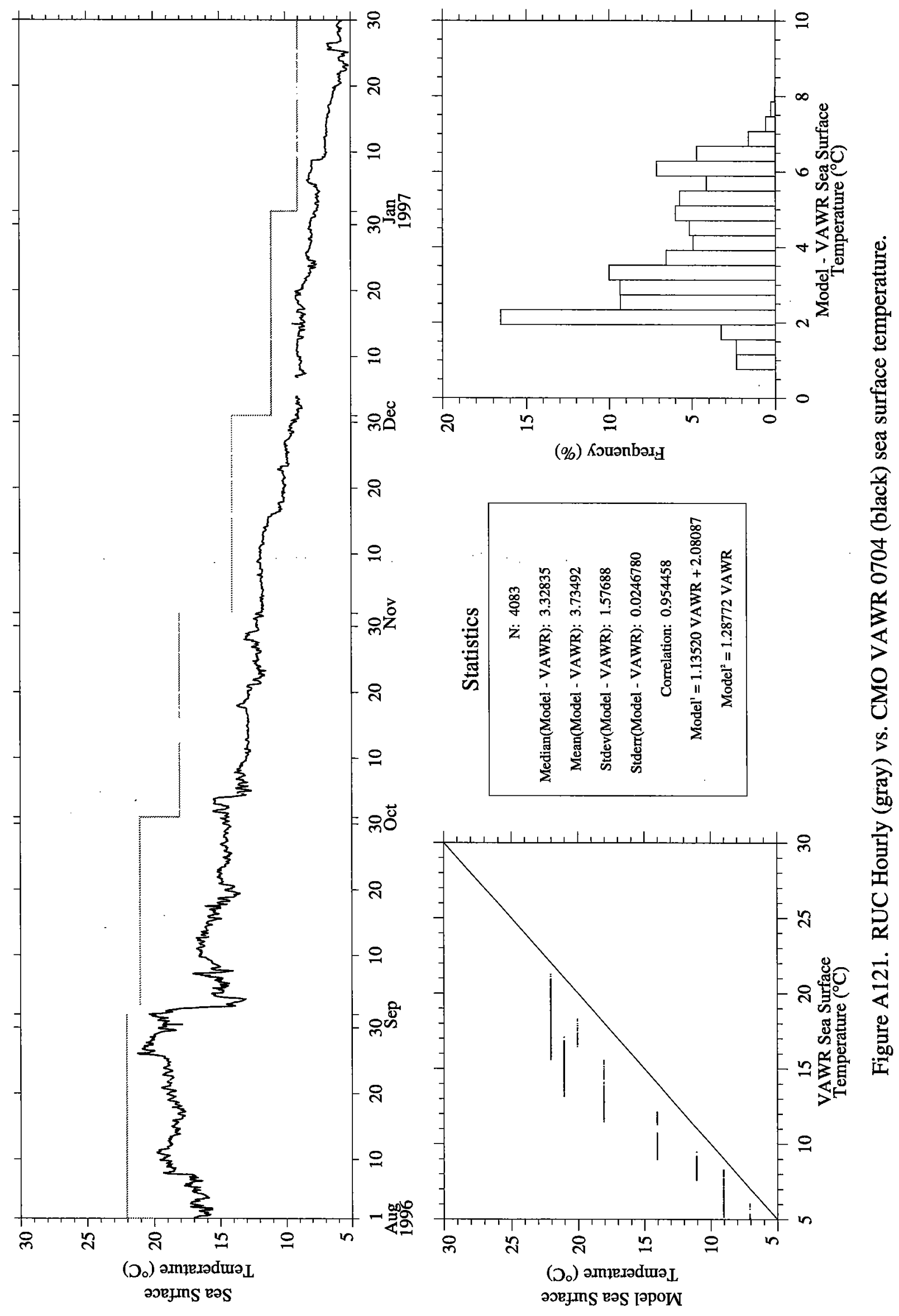




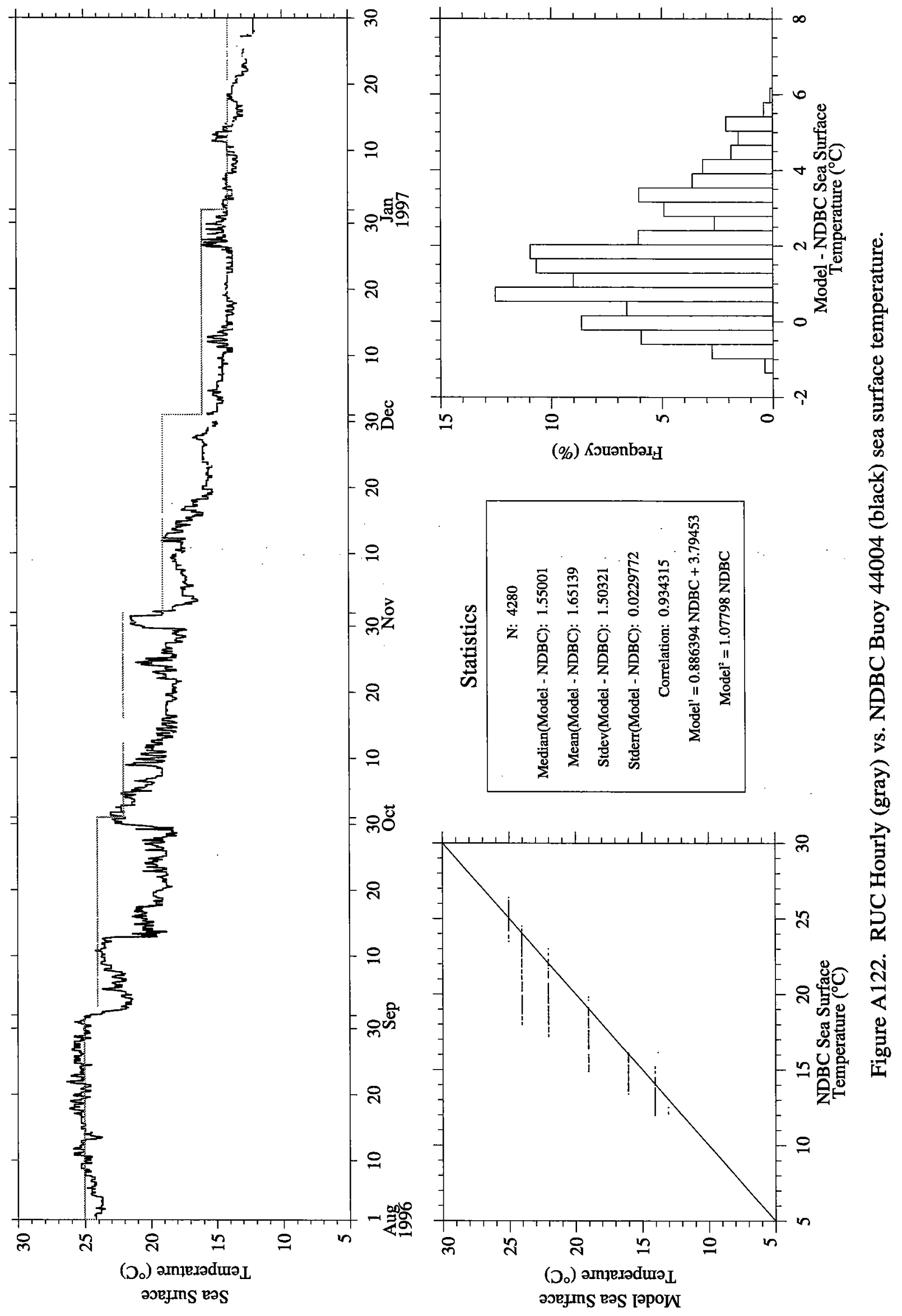




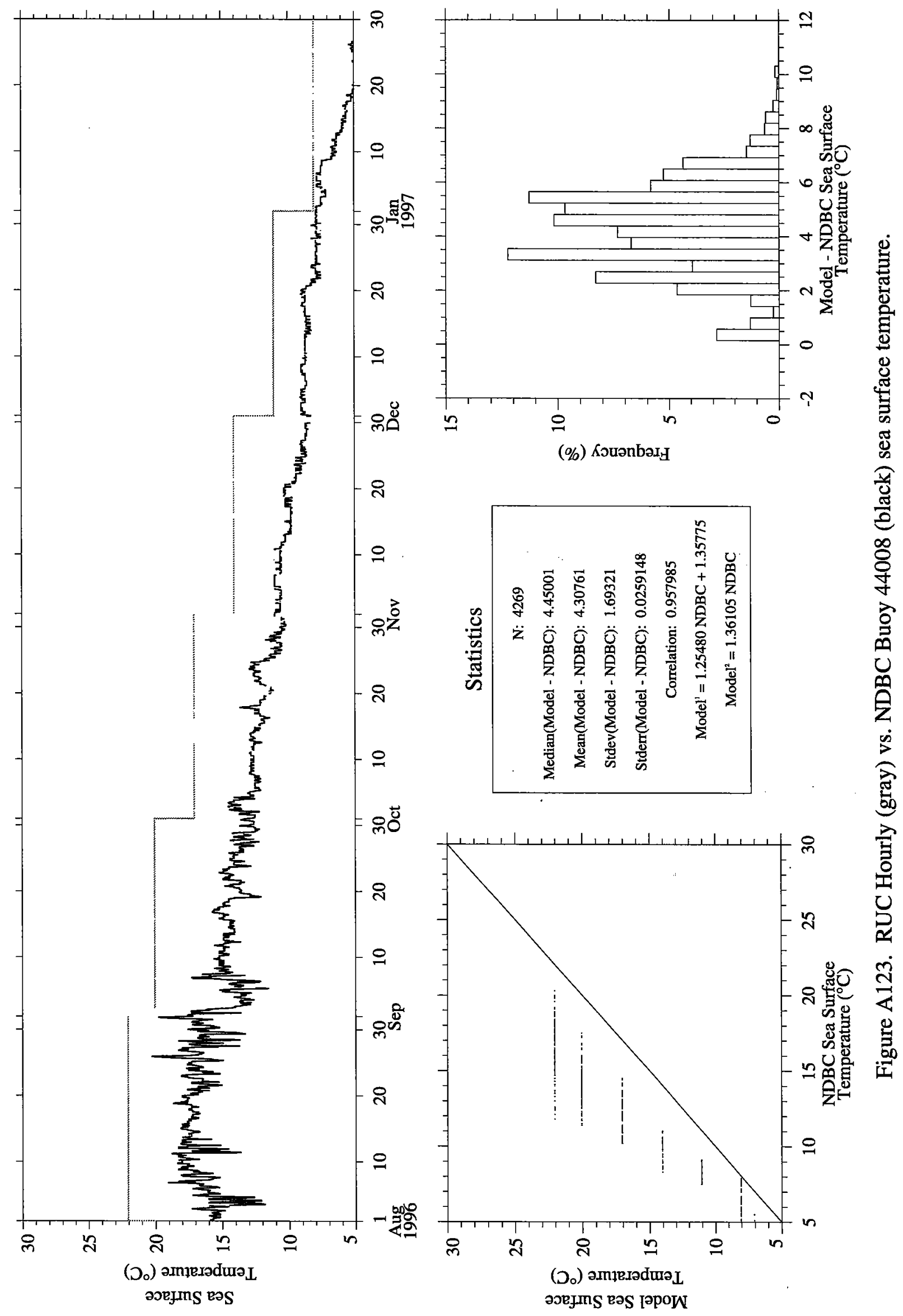




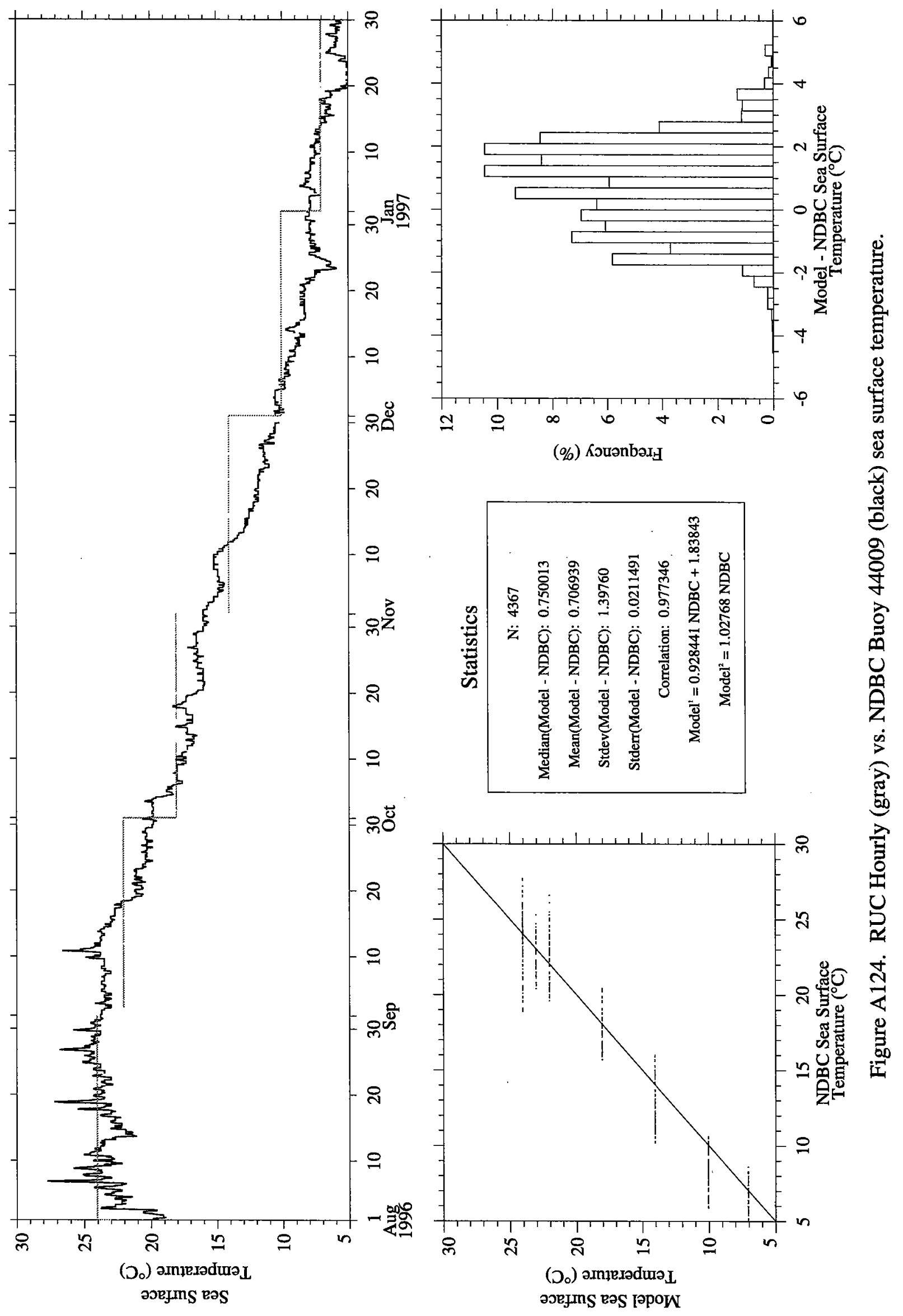




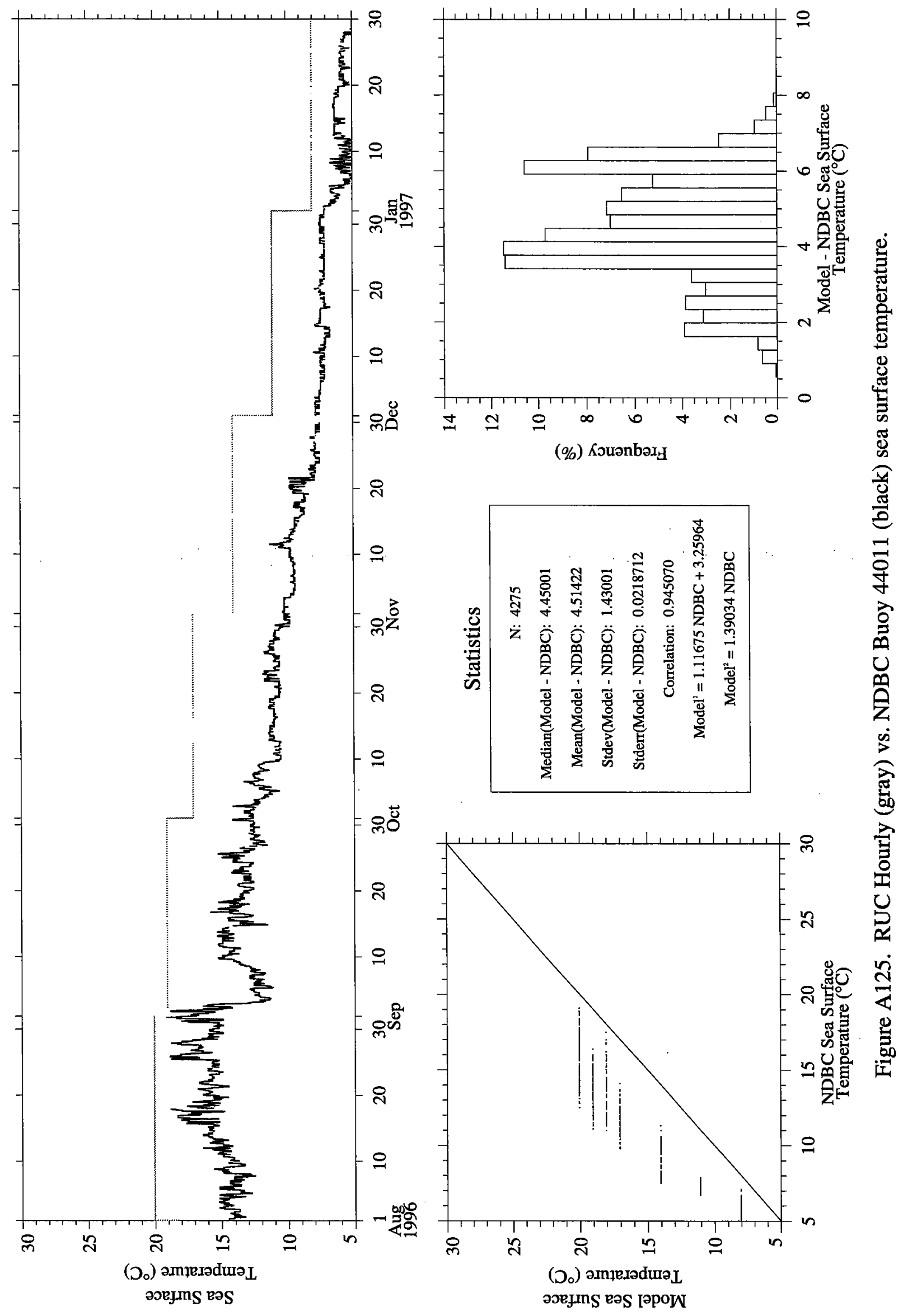




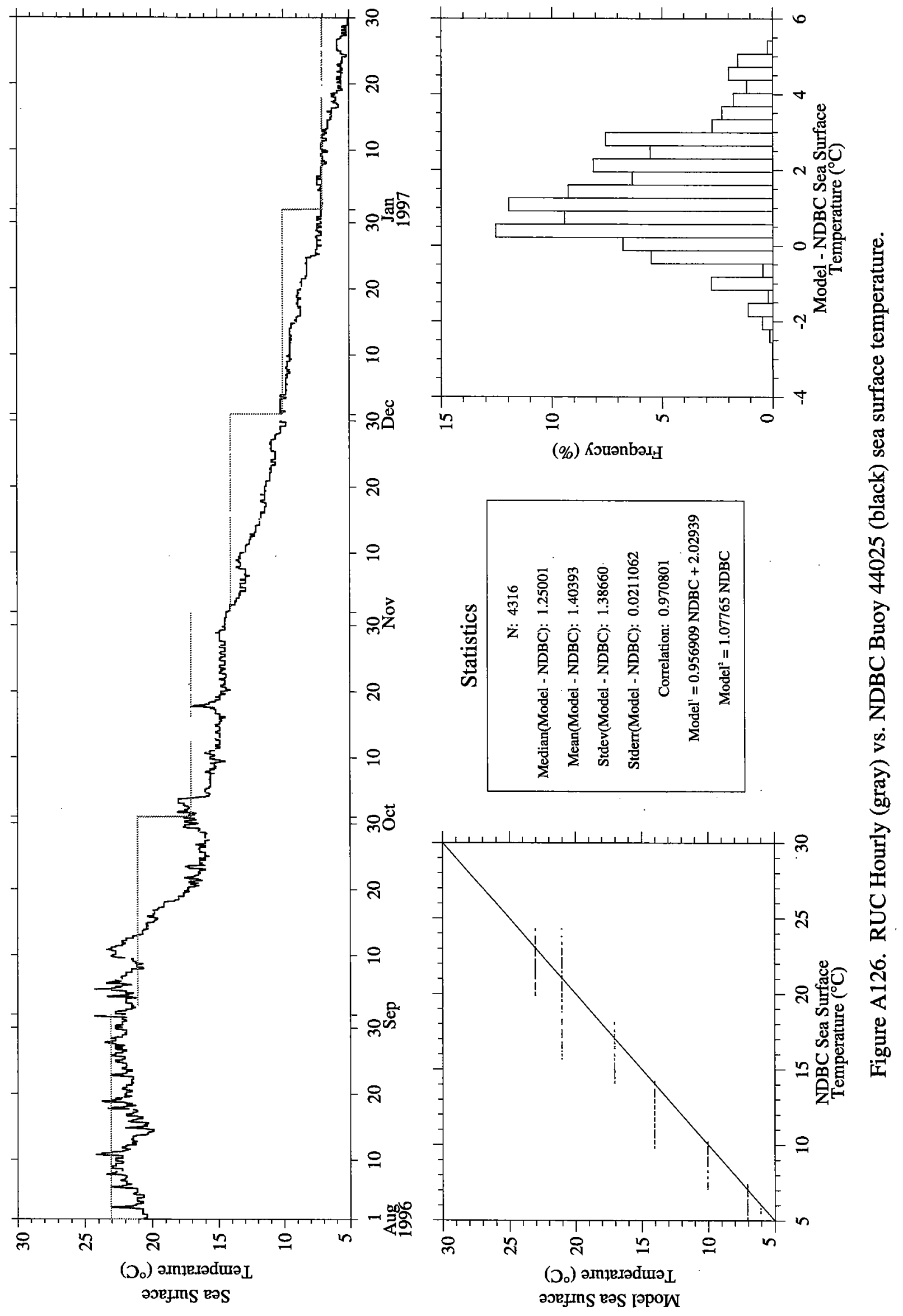



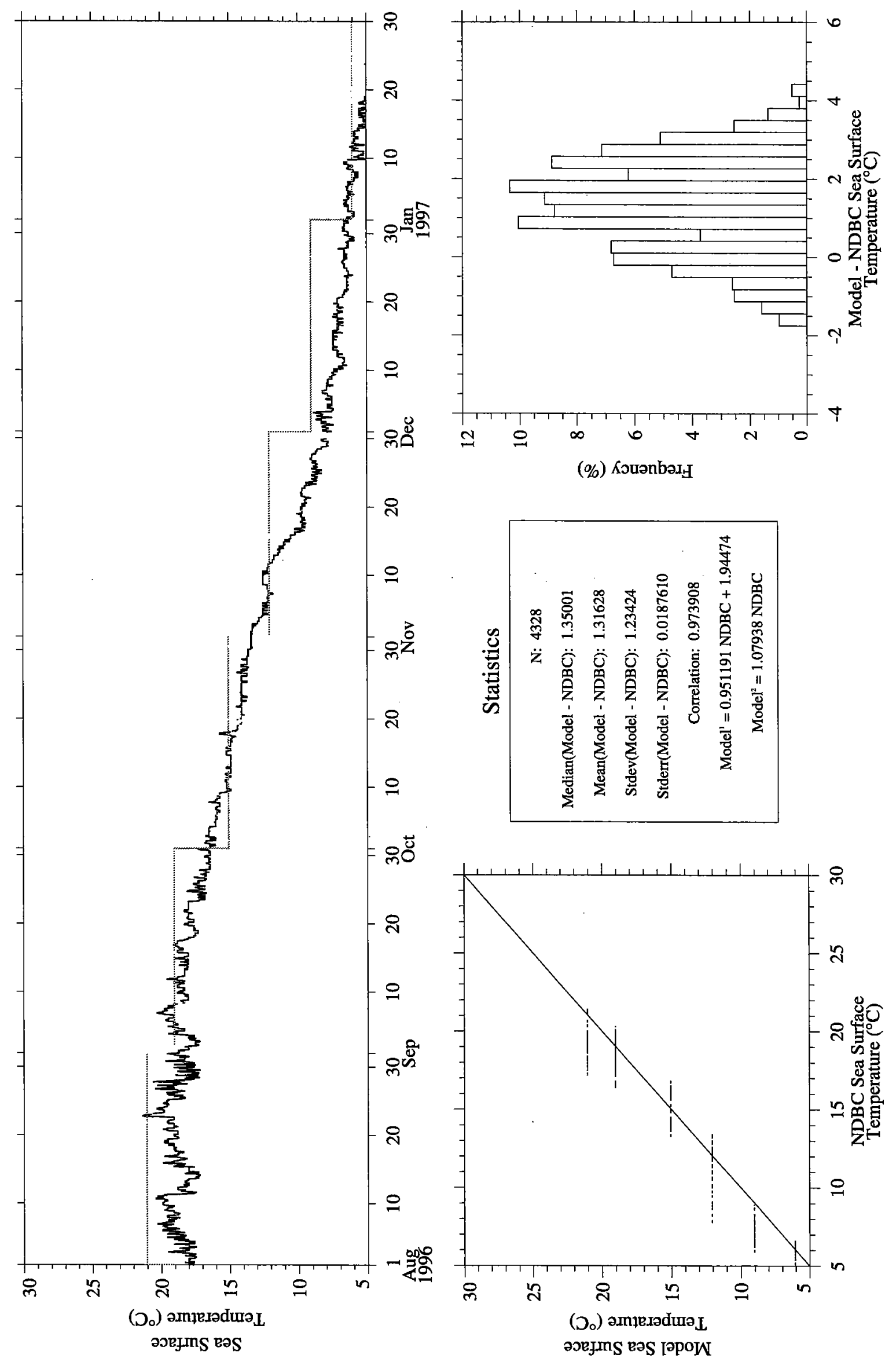

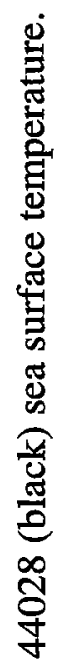
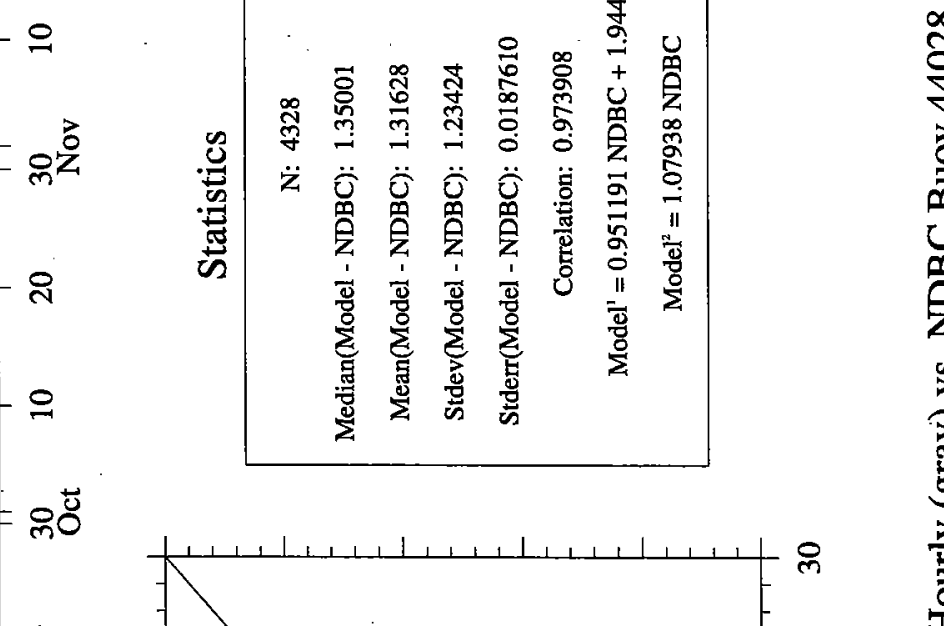

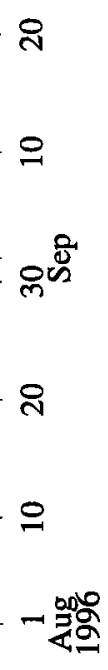

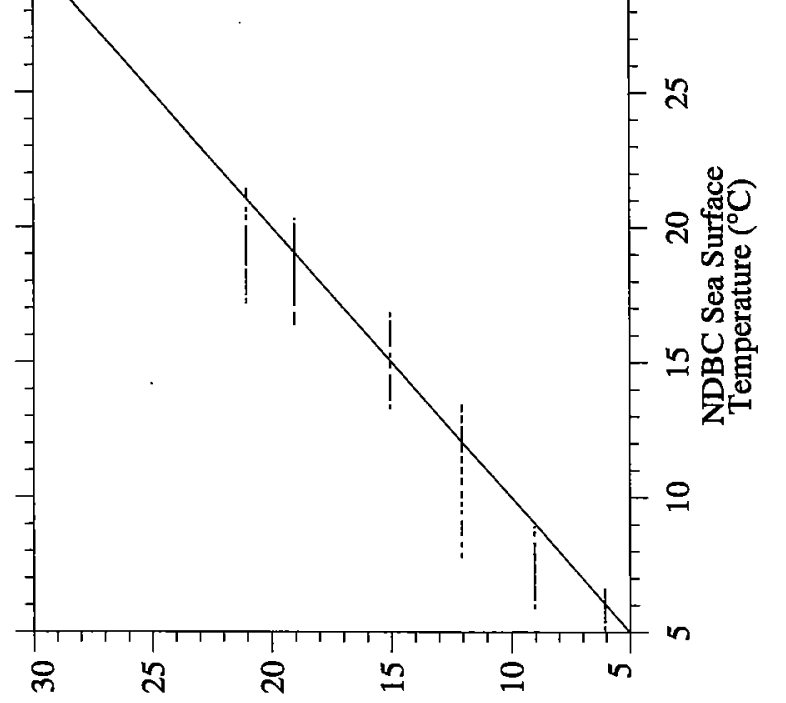

(つ०) ampłexəduว $\mathbf{L}$

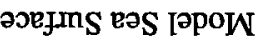




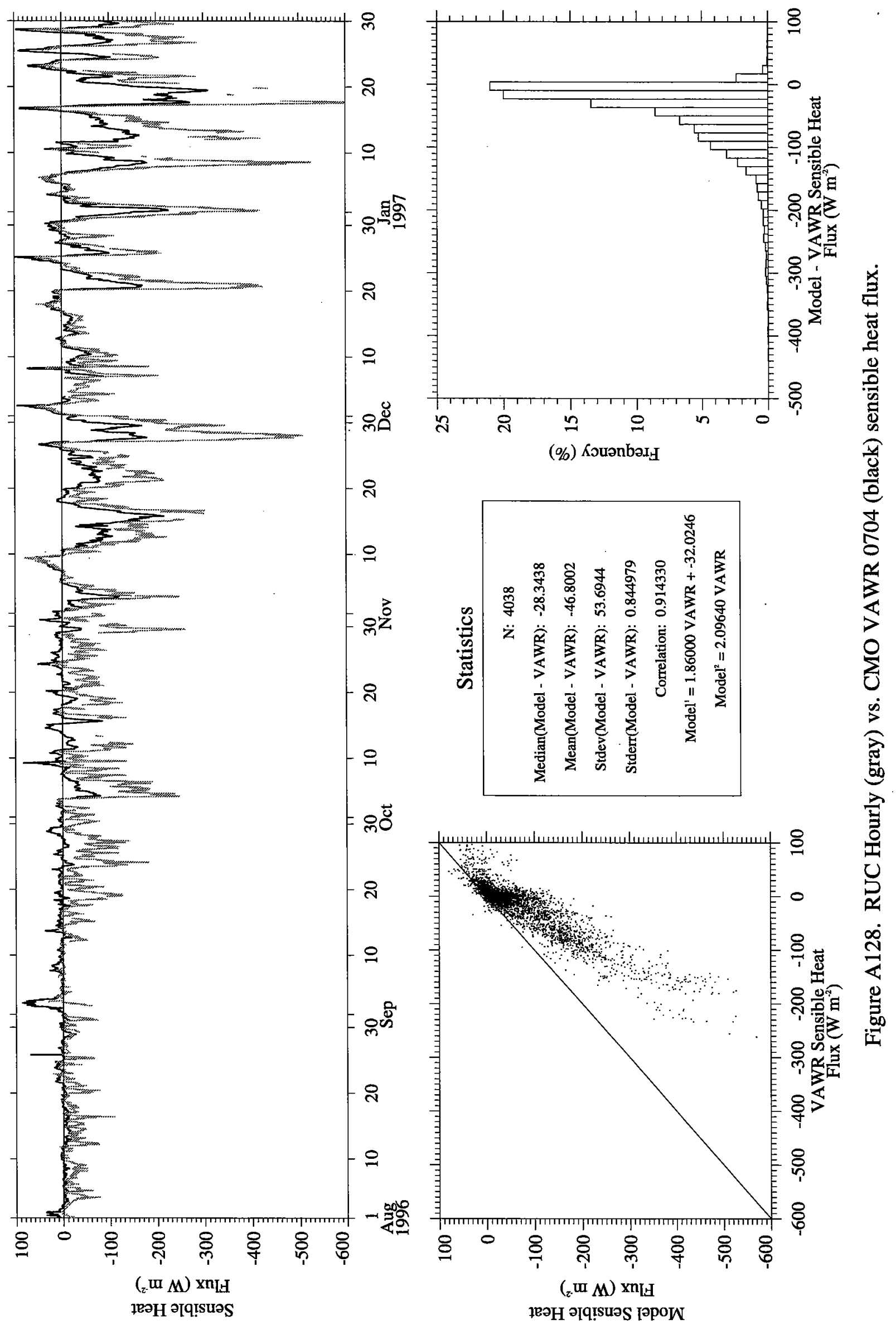




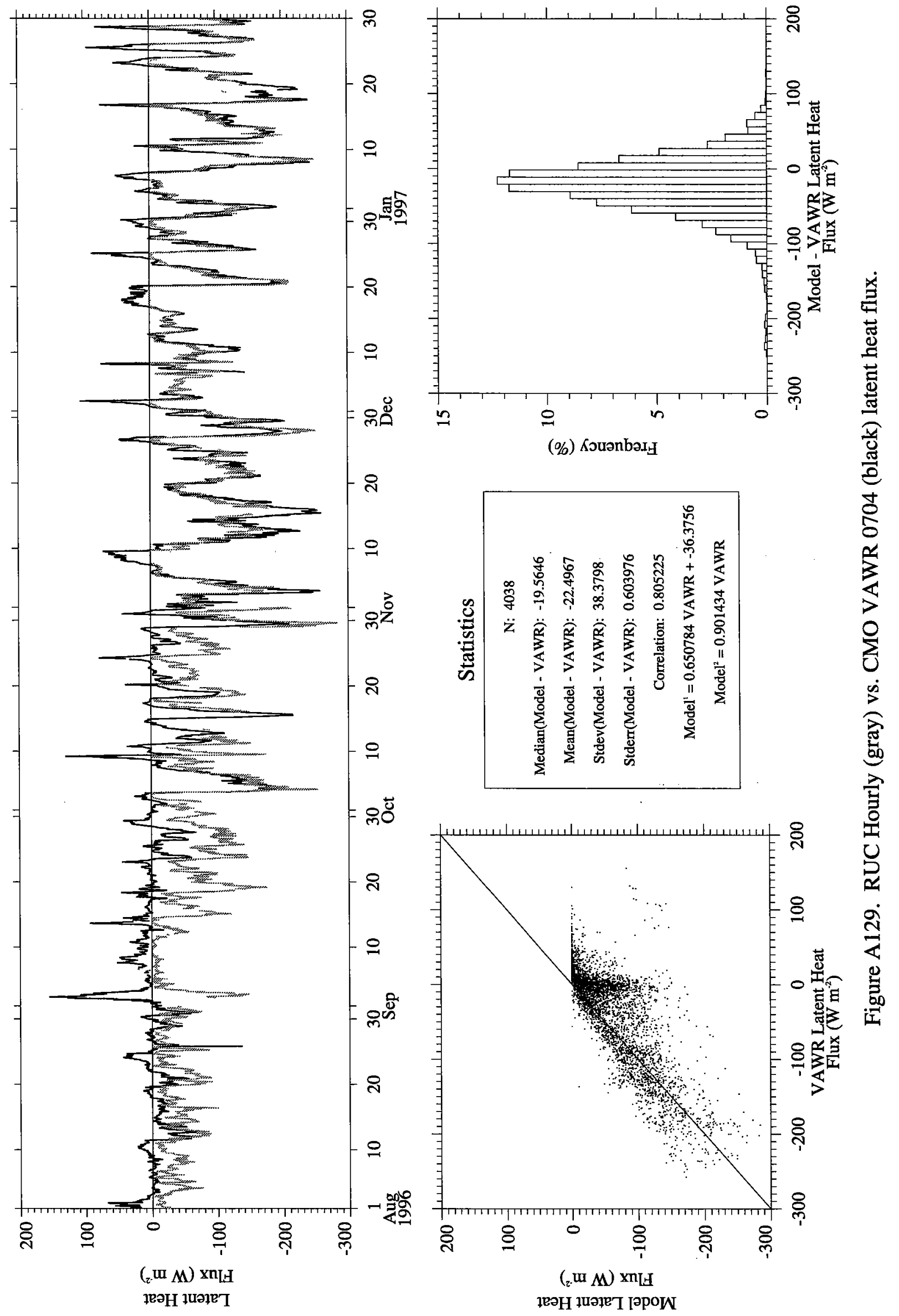




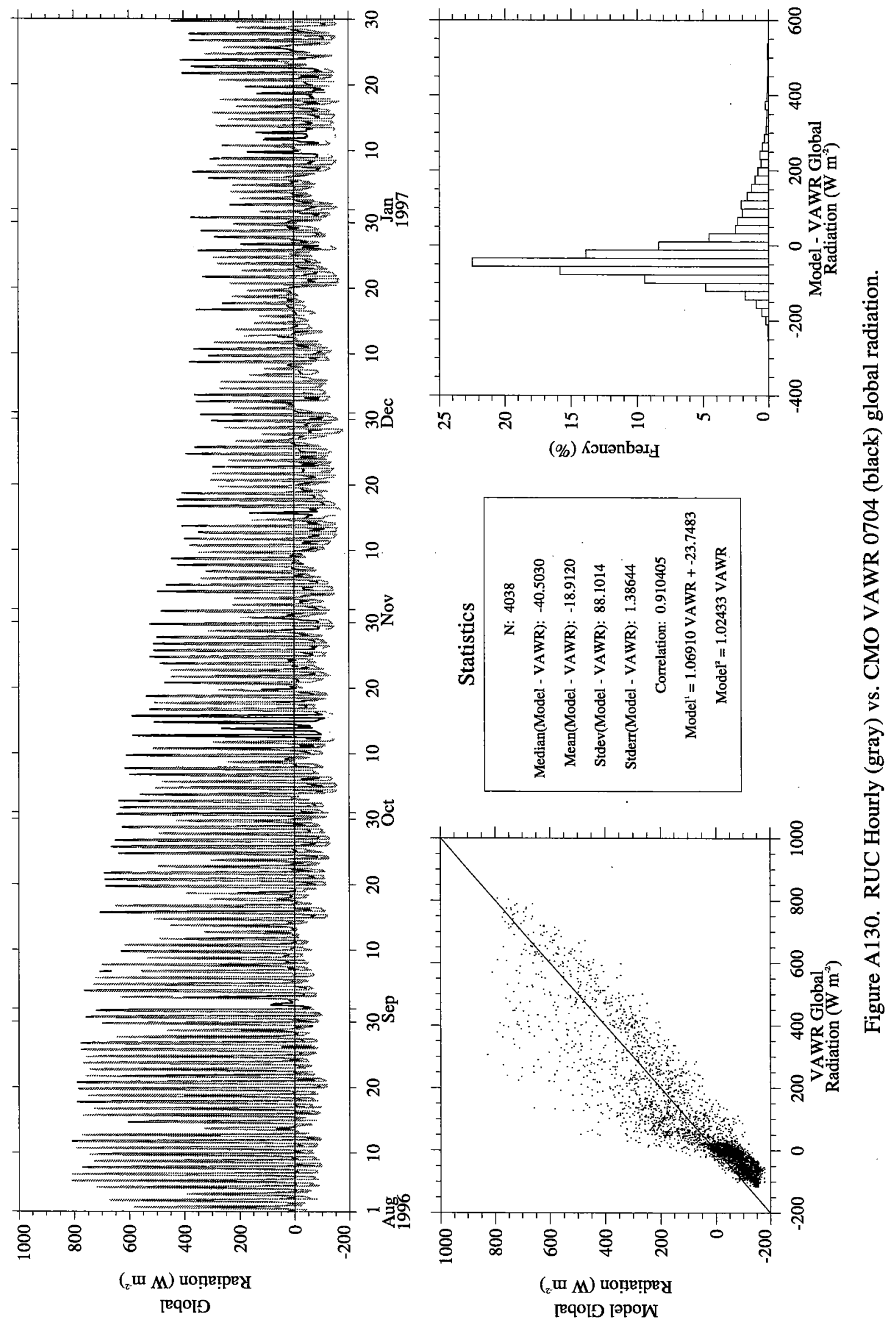




\section{Appendix B: Comparison of CMO buoy and NDBC buoy 44008}

Since NDBC buoy 44008 is only $90 \mathrm{~km}$ to the east of the CMO central buoy, intercomparisons of wind speed, wind direction, barometric pressure, air temperature and sea surface temperature from these sites are presented here. Positive differences indicate that the observations from the NDBC buoy 44008 are greater or larger than those of the CMO buoy. The figures include a time series of the NDBC buoy 44008 and CMO central buoy variables, a scatterplot, a histogram of the differences and a statistics box. The statistics box displays the sample size, statistics of the [NDBC - CMO] difference (median, mean, standard deviation and standard error), the correlation coefficient and two linear regressions. The first linear regression is denoted by a superscript 1 and is a simple linear regression. The second is forced through the origin and is denoted by a superscript 2 . 

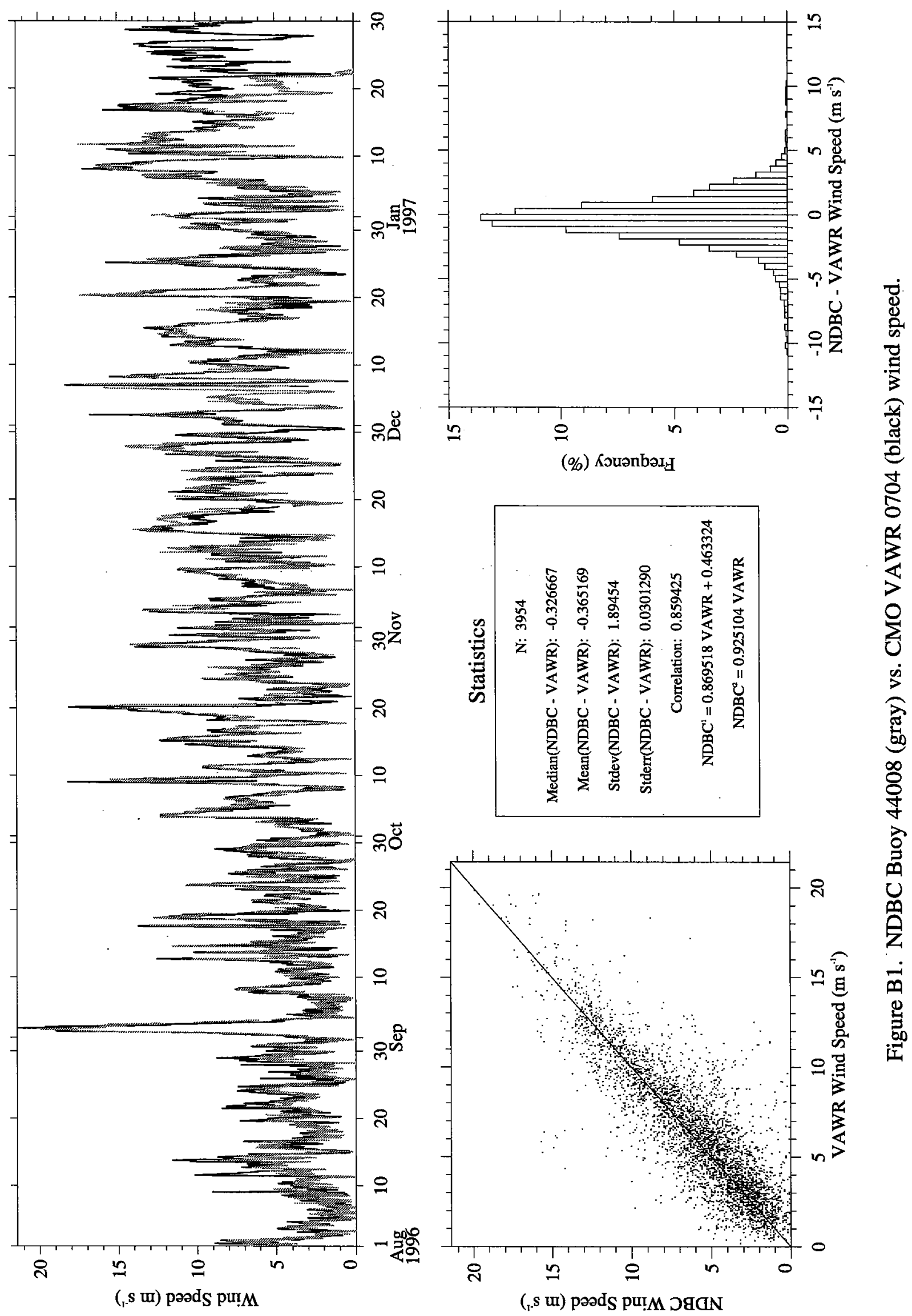


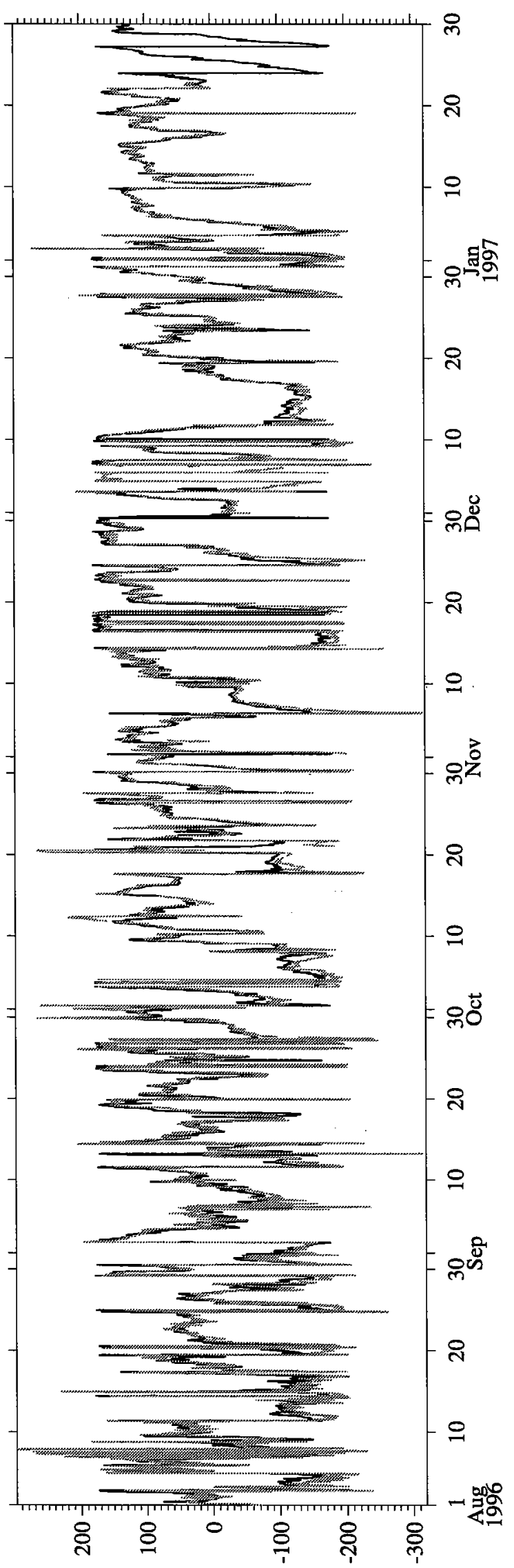

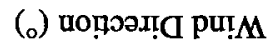
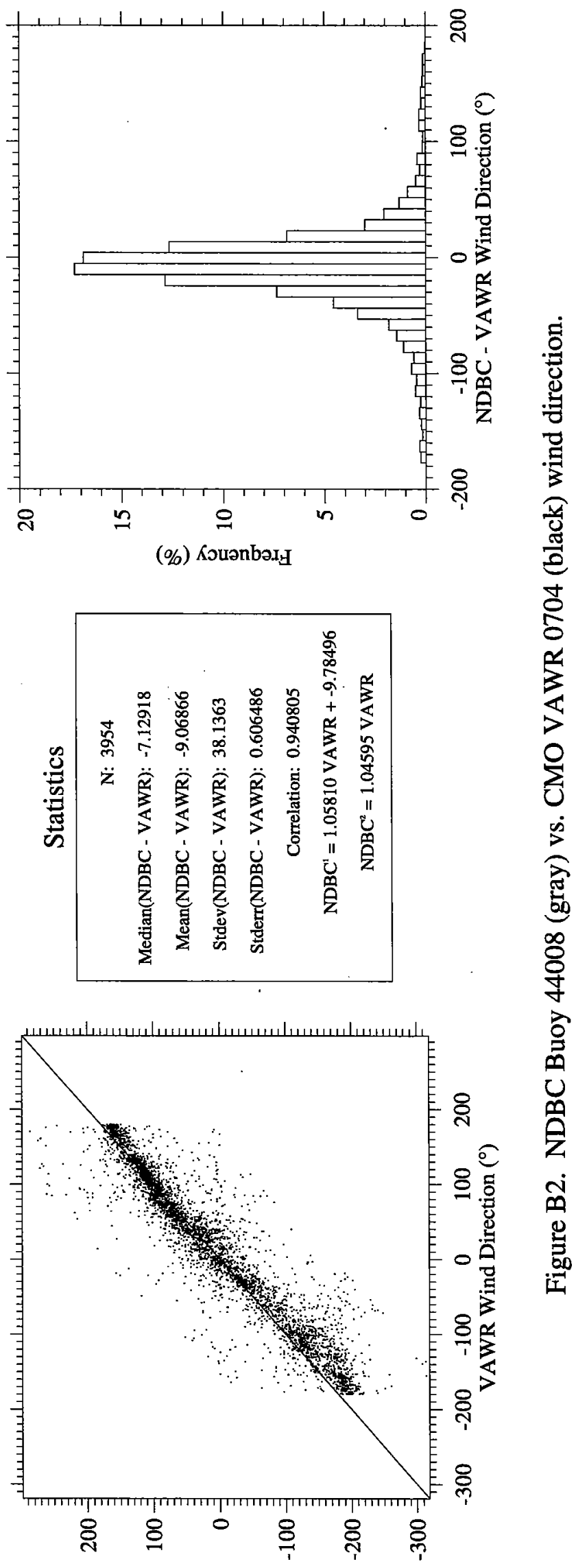

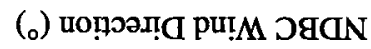




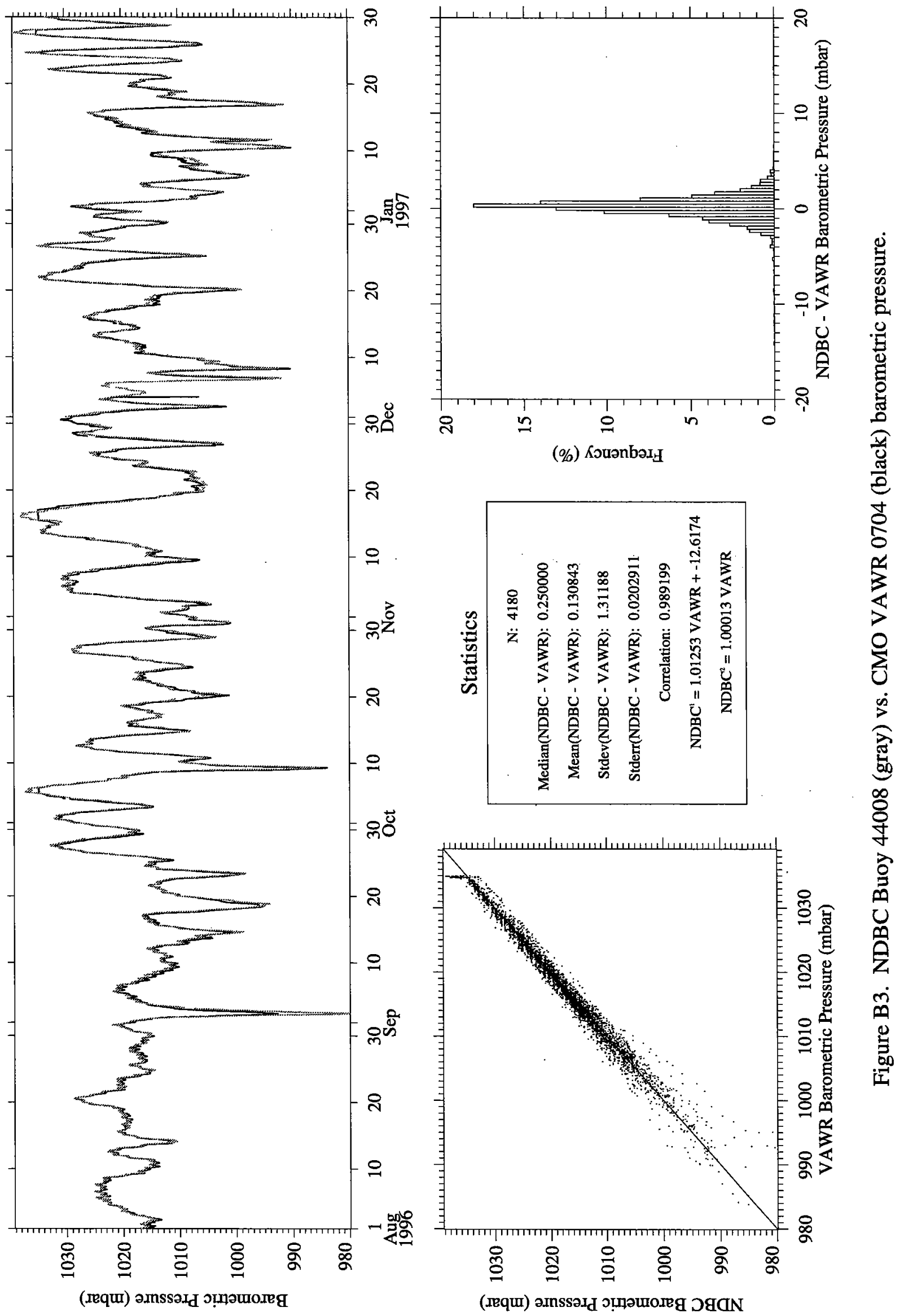




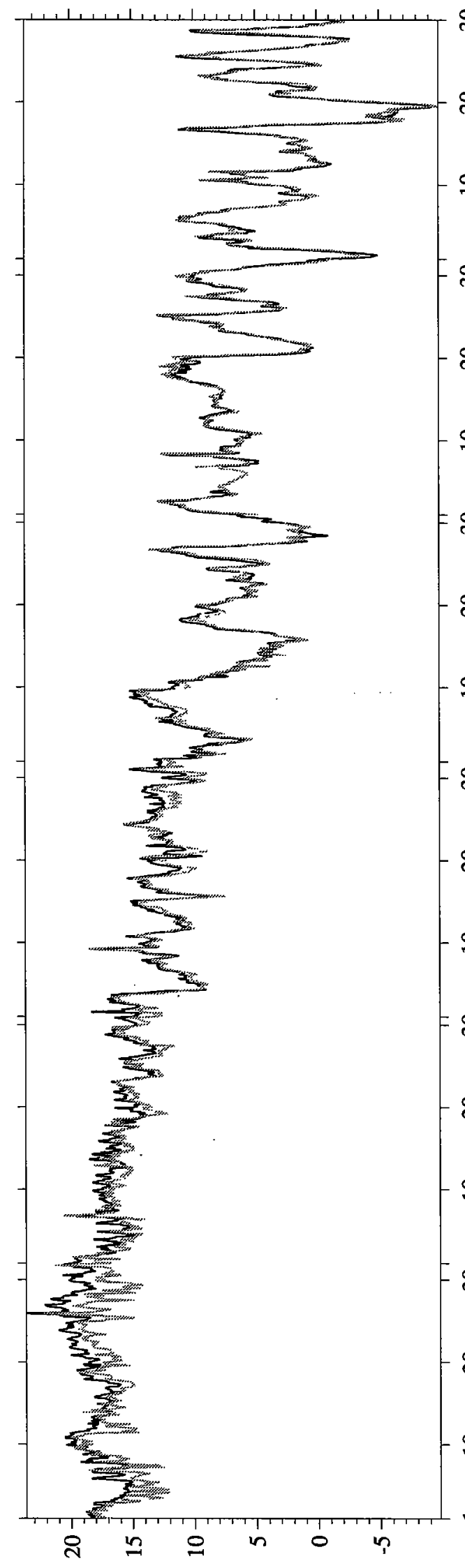

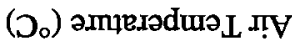
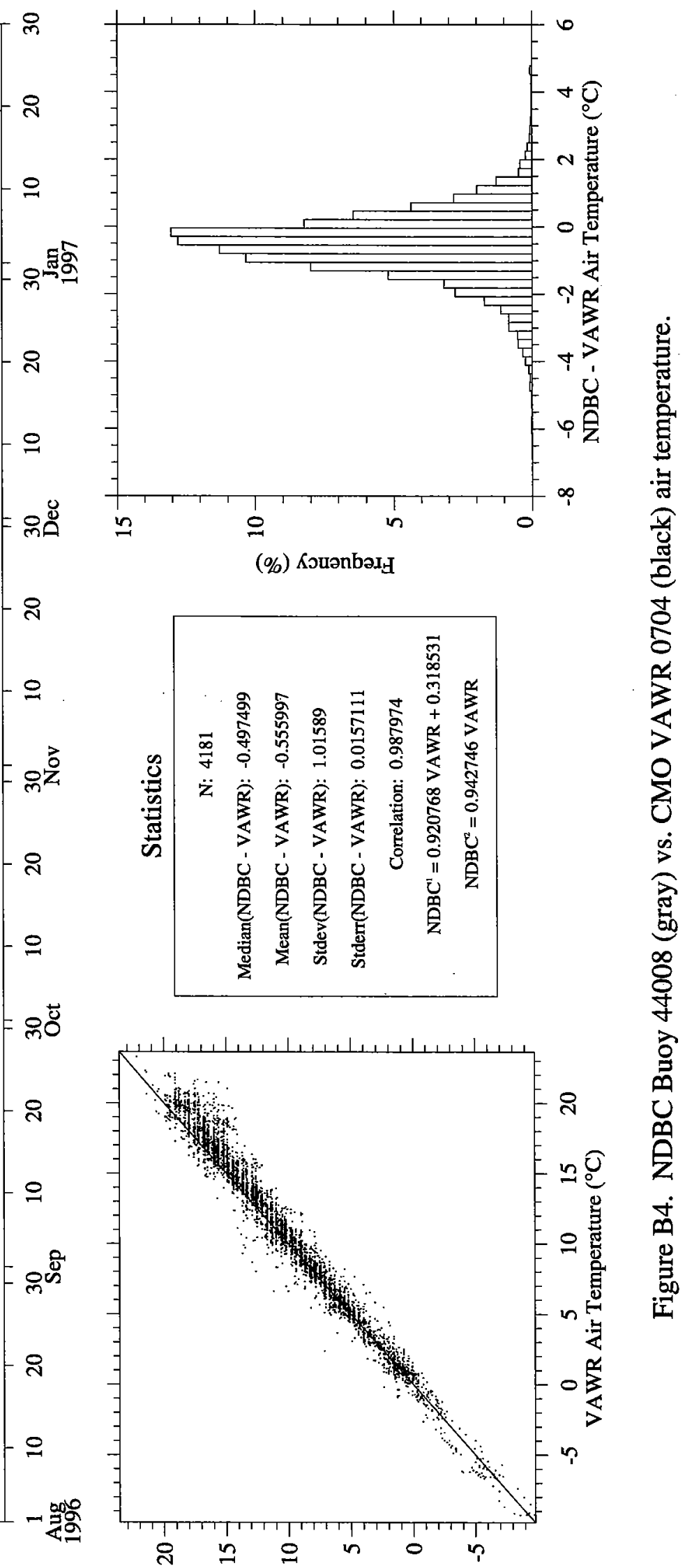

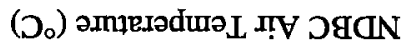




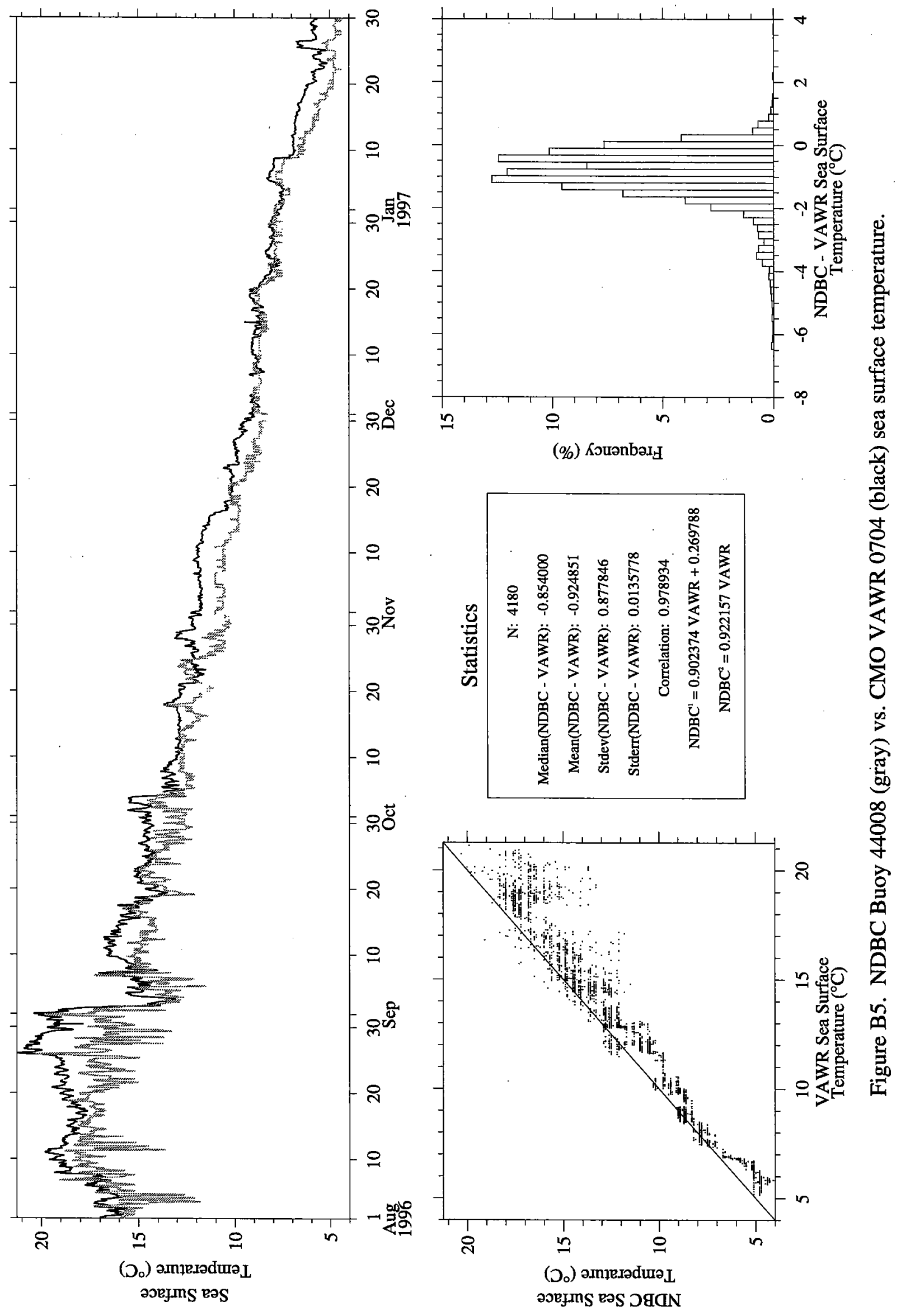




\section{Appendix C: NetCDF formats for archived model data}

\section{Eta Model}

The following is the NetCDF format (from the ncdump utility) of the Eta model archive file. This particular example is from the file 97022500 eta.nc which is the Eta model data from the 25 February 19970000 model run. The data consists of the $0,6,12,18$ and 24 hour forecast data indexed by the dimension time.

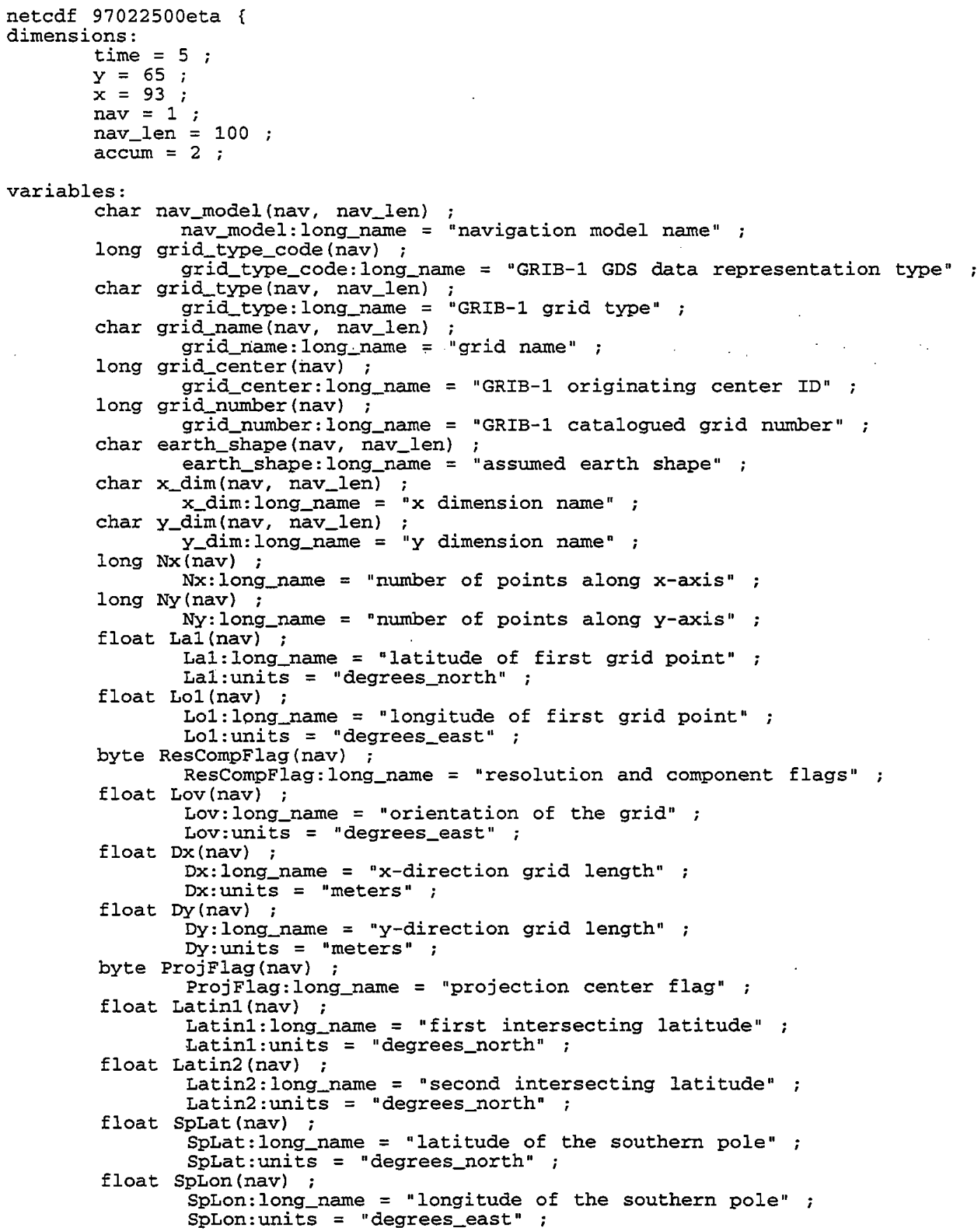




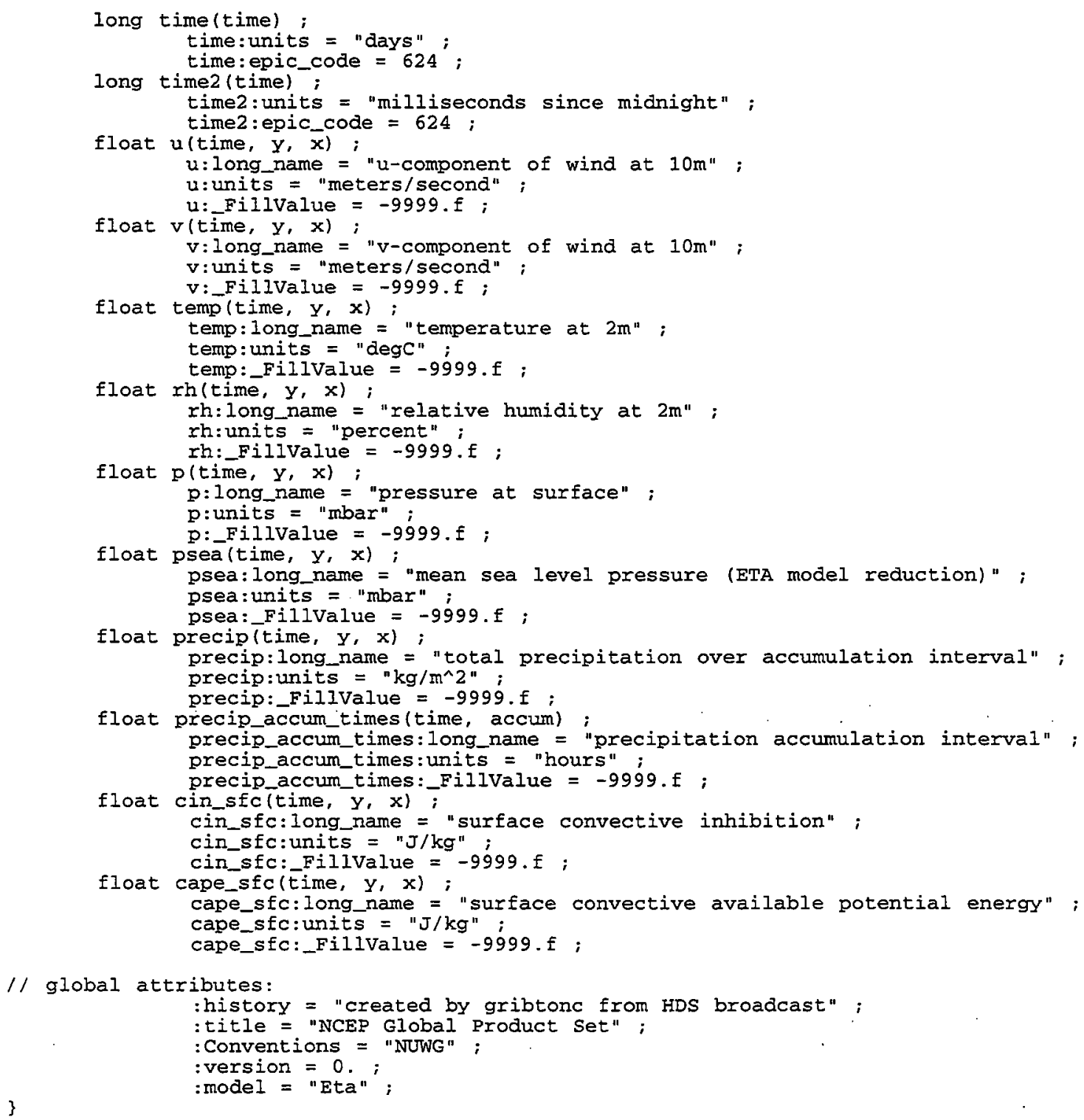




\section{$\underline{\text { RUC Model }}$}

The following is the NetCDF format of the RUC model archive file. This particular example is from the file 97022403 ruc. nc which is the RUC model data from the 24 February 19970300 model run. The data consists of the $0,3,6,9$ and 12 hour forecast data indexed by the dimension time.

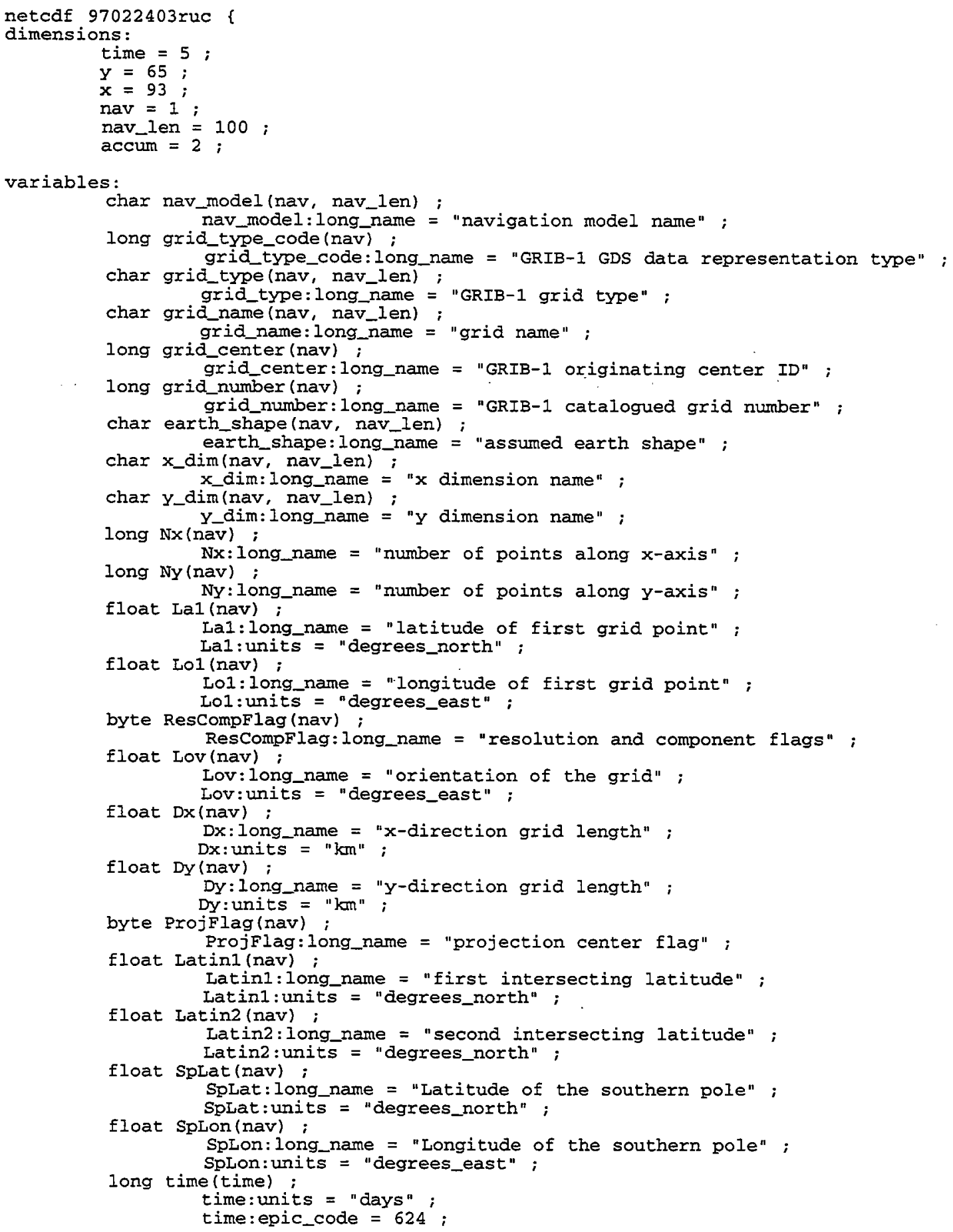




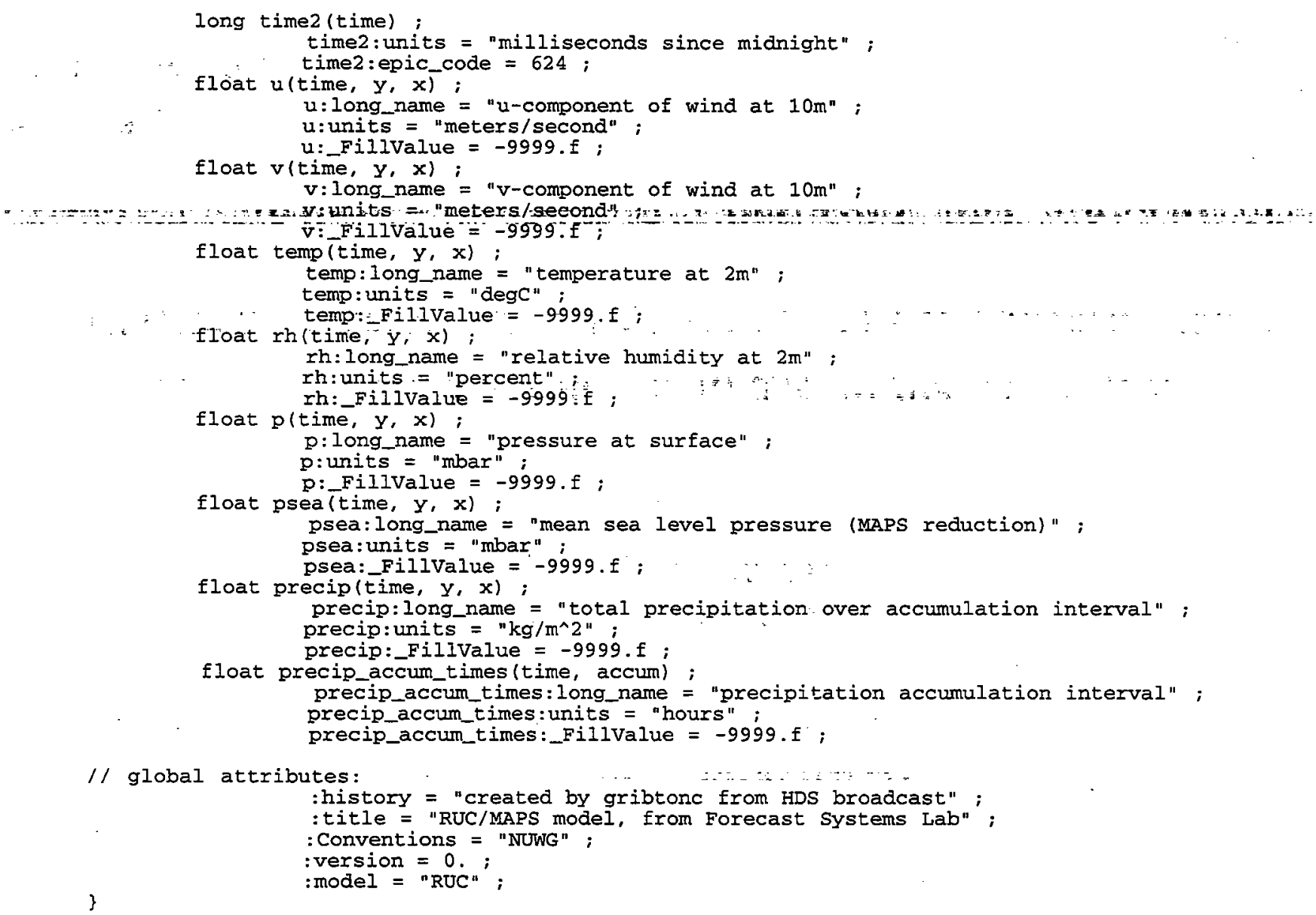




\section{RUC Analysis}

The following is the NetCDF format of the RUC Analysis archive file. This particular example is from the file 97022403 rucanl. nc which is the RUC Analysis from the 24 February 19970300 model run. The data consists of the analysis data only, which is indexed by the dummy dimension record.

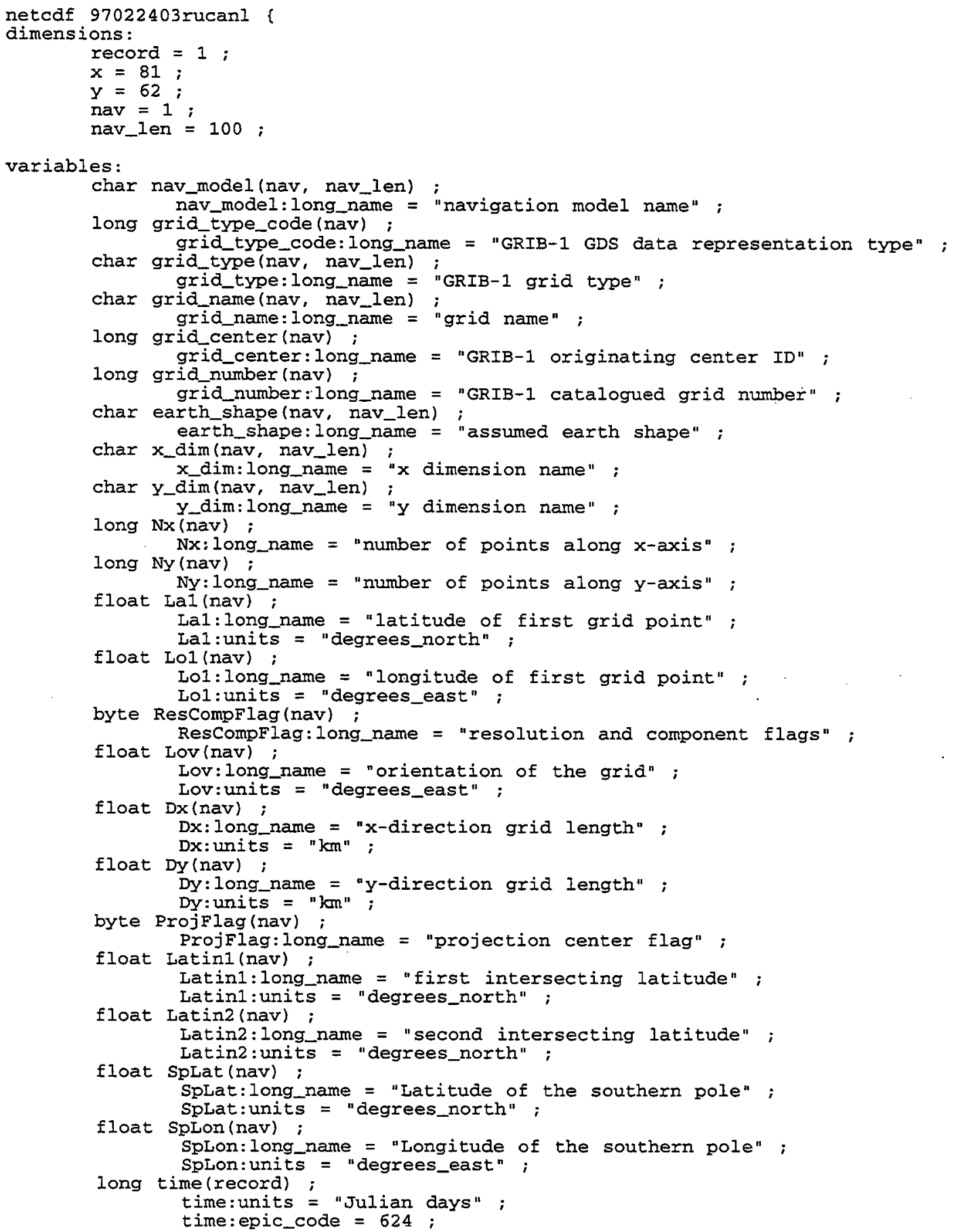




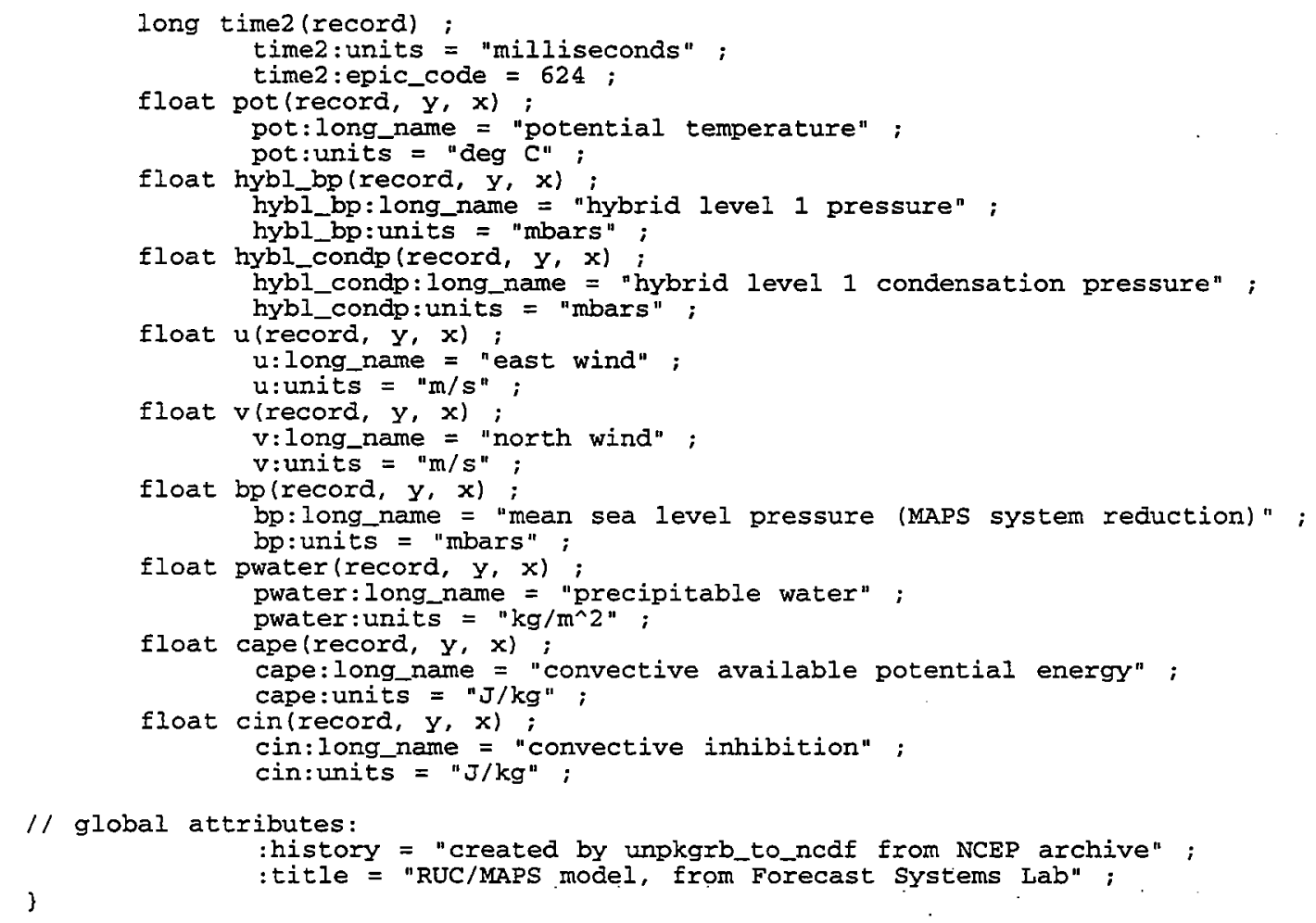




\section{$\underline{\text { RUC Hourly }}$}

The following is the NetCDF format of the RUC Hourly archive file. This particular example is from the file 97022409 rucflux. ne which contains some of the RUC Hourly model data from the 24 February 19970600 model run. The data consists of the 3 hour forecast only, indexed by the dummy variable record. For this same model run, the files 97022407rucflux.nc and 97022408rucflux.nc were also archived. These two files contain the 1 and 2 hour forecasts from the same model run, respectively.

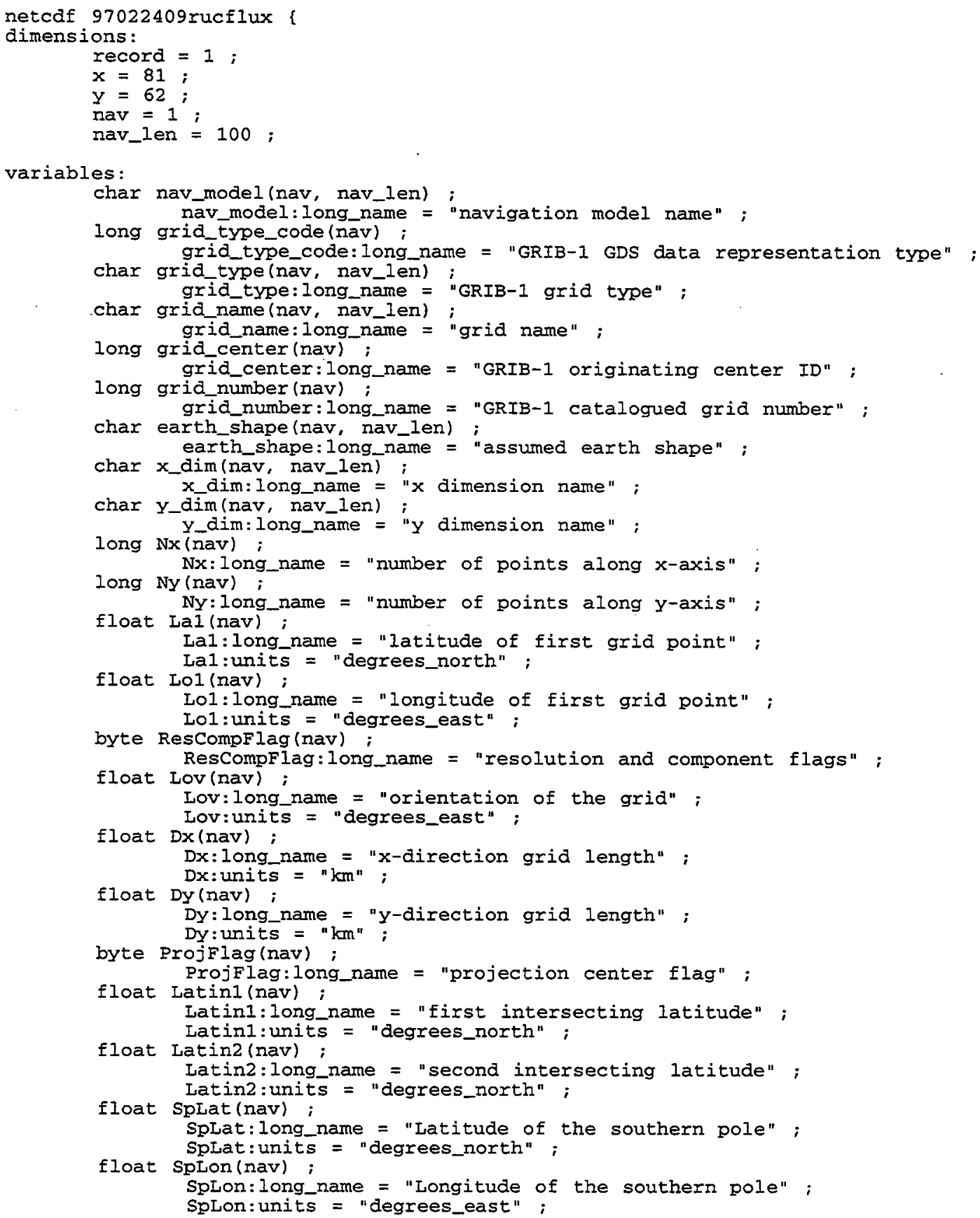




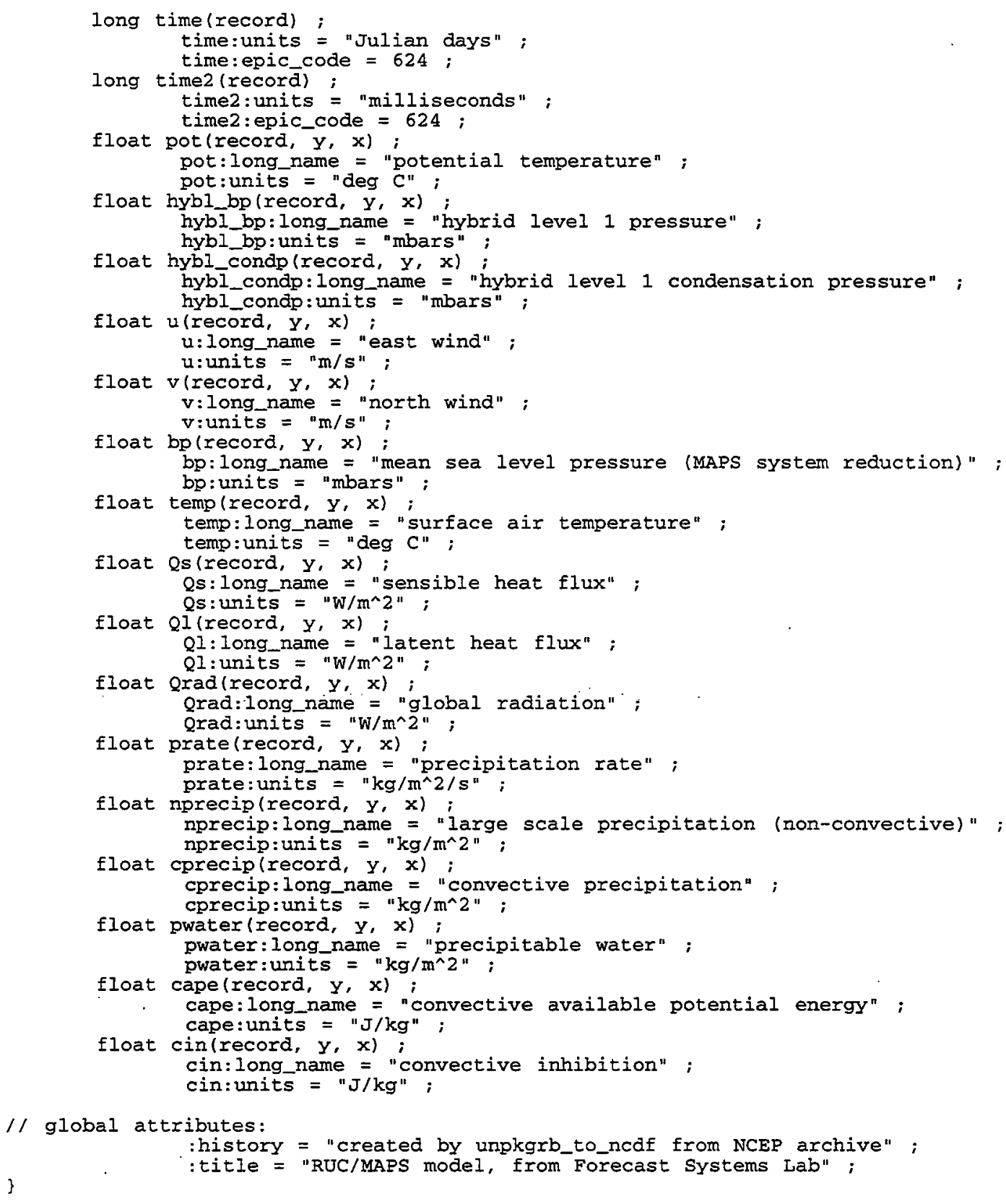




\section{Appendix D: Bibliography}

Benjamin, S.G., 1989. An isentropic mesoo-scale analysis system and its sensitivity to aircraft and surface observations. Monthly Weather Review. 117, 1586-1603.

Benjamin, S.G. and P.A. Miller, 1990. An alternative sea level pressure reduction and a statistical comparison of geostrophic wind estimates with observed surface winds. Monthly Weather Review. 118, 2099-2116.

Benjamin, S.G., K.J. Brundage and L.L. Morone, 1994. The rapid update cycle. Part I: Analysis/model description. NOAA/NWS Technical Procedures Bulletin No. 416.16 pp. [Available from National Weather Service, Office of Meteorology, 1325 East-West Highway, Silver Springs, MD 20910].

Black, T.L., 1994. The new NMC mesoscale Eta model: Description and forecast examples. Weather and Forecasting. 9, 265-278.

Bleck, R. and S.G. Benjamin, 1993. Regional weather prediction with a model combining terrain-following and isentropic coordinates. Part I: Model description. Monthly Weather Review. 121, 1770-1785.

Dévényi, D. and T.W. Schlatter, 1994. Statistical properties of three-hour prediction "errors" derived from the mesoscale analysis and prediction system. Monthly Weather Review. 122, 1263-1280.

Miller, P.A. and S.G. Benjamin, 1992. A system for the hourly assimilation of surface observations in mountainous and flat terrain. Monthly Weather Review. 120, 23422359.

Pan, Z., S.G. Benjamin, J.M. Brown and T. Smirnova, 1994. Comparative experiments with MAPS on different parameterization schemes for surface moisture flux and boundary-layer processes. Monthly Weather Review. 122, 449-470.

\footnotetext{
Also, see www.fsl.noaa.gov/frd-bin/MAPS.pubs.cgi for a comprehensive bibliography for the RUC model.
} 


\section{Appendix E: WWW Resources}

Unfortunately, there is no single source of information for describing, acquiring, decoding and using forecasting models. Relevant information is scattered far and wide. Here are a few links that will help you get started:

Model Information

Forecast Systems Laboratory

www.fsl.noaa.gov

MAPS/RUC homepage at FSL

www.fsl.noaa.gov/frd-bin/MAPS.homepage.cgi

NCEP

www.ncep.noaa.gov

NCEP Environmental Modeling Center

nic.fb4.noaa.gov: 8000

Instructions for downloading RUC data from the NIC

www.fsl.noaa.gov/frd-bin/MAPS.rucinfo.cgi

Comprehensive bibliography of RUC publications

www.fsl.noaa.gov/frd-bin/MAPS.pubs.cgi

On-line version of the RUC technical manual

www.fsl.noaa.gov/frd-bin/tpbruc.cgi

Change log for MAPS/RUCS

www.fsl.noaa.gov/frd-bin/MAPS.60changelog.cgi

LDM Information

Unidata

www.unidata.ucar.edu

Overview of LDM from 1996 LDM Workshop

www.unidata.ucar.edw/packages/dm/ws/ws.html

Data recovery from the IDD

www.unidata.ucar.edwdata/recovery.html

NetCDF Information

www.unidata.ucar.edu/packages/netcdf/index.html

Data Sources (FTP)

NOAA Information Center

nic.fb4.noaa.gov

National Data Buoy Center

seaboard.ndbc.noaa.gov

GRIB

GRIB manual

nic.fb4.noaa.gov/pub/nws/nmc/docs/gribedI

GRIB unpacking software

nic.fb4.noaa.gov/pub/info 


\section{Appendix F: Acronyms}

$\begin{array}{ll}\text { AVN } & \text { Aviation model } \\ \text { CMO } & \text { Coastal Mixing and Optics Experiment } \\ \text { ECMWF } & \text { European Centre for Medium-Range Weather Forecasts } \\ \text { FOS } & \text { Family of Services } \\ \text { FTP } & \text { File Transfer Program } \\ \text { GOES } & \text { Geosynchronous Operational Environmental Satellite } \\ \text { IDD } & \text { Internet Data Distribution system } \\ \text { LDM } & \text { Local Data Manager } \\ \text { MAPS } & \text { Mesoscale Analysis and Prediction System } \\ \text { MRF } & \text { Medium Range Forecast model } \\ \text { NCEP } & \text { National Centers for Environmental Prediction } \\ \text { NDBC } & \text { National Data Buoy Center } \\ \text { NetCDF } & \text { Network Common Data Form } \\ \text { NEXRAD } & \text { Next Generation Weather Radar } \\ \text { NGM } & \text { Nested Grid Model } \\ \text { NIC } & \text { NOAA Information Center } \\ \text { NMC } & \text { National Meteorological Center } \\ \text { NOAA } & \text { National Oceanic and Atmospheric Administration } \\ \text { NWS } & \text { National Weather Service } \\ \text { RSM } & \text { Regional Spectral Model } \\ \text { RUC } & \text { Rapid Update Cycle model } \\ \text { TOGA COARE } & \text { Tropical Ocean Global Atmosphere Coupled Ocean-Atmosphere } \\ \text { UPS } & \text { Response Experiment } \\ \text { VAWR } & \text { Uninterruptible Power Supply } \\ \text { WHOI } & \text { Vector Averaging Wind Recorder } \\ & \\ \text { Woods Hole Oceanographic Institution } \\ \text { NOA }\end{array}$


DOCUMENT LIBRARY

Distribution List for Technical Report Exchange - February 1996

University of California, San Diego

SIO Library $0175 \mathrm{C}$

9500 Gilman Drive

La Jolla, CA 92093-0175

Hancock Library of Biology \& Oceanography

Alan Hancock Laboratory

University of Southern California

University Park

Los Angeles, CA 90089-0371

Gifts \& Exchanges

Library

Bedford Institute of Oceanography

P.O. Box 1006

Dartmouth, NS, B2Y 4A2, CANADA

Commander

International Ice Patrol

1082 Shennecossett Road

Groton, CT 06340-6095

NOAA/EDIS Miami Library Center

4301 Rickenbacker Causeway

Miami, FL 33149

Research Library

U.S. Army Corps of Engineers

Waterways Experiment Station

3909 Halls Ferry Road

Vicksburg, MS 39180-6199

Institute of Geophysics

University of Hawaii

Library Room 252

2525 Correa Road

Honolulu, HI 96822

Marine Resources Information Center

Building E38-320

MIT

Cambridge, MA 02139

Library

Lamont-Doherty Geological Observatory

Columbia University

Palisades, NY z10964

Library

Serials Department

Oregon State University

Corvallis, OR 97331

Pell Marine Science Library

University of Rhode Island

Narragansett Bay Campus

Narragansett, RI 02882
Working Collection

Texas A\&M University

Dept. of Oceanography

College Station, TX 77843

Fisheries-Oceanography Library

151 Oceanography Teaching Bldg.

University of Washington

Seattle, WA 98195

Library

R.S.M.A.S.

University of Miami

4600 Rickenbacker Causeway

Miami, FL 33149

Maury Oceanographic Library

Naval Oceanographic Office

Building 1003 South

1002 Balch Blvd.

Stennis Space Center, MS, 39522-5001

Library

Institute of Ocean Sciences

P.O. Box 6000

Sidney, B.C. V8L 4B2

CANADA

National Oceanographic Library

Southampton Oceanography Centre

European Way

Southampton SO14 3ZH

UK

The Librarian

CSIRO Marine Laboratories

G.P.O. Box 1538

Hobart, Tasmania

AUSTRALIA 7001

Library

Proudman Oceanographic Laboratory

Bidston Observatory

Birkenhead

Merseyside L43 7 RA

UNITED KINGDOM

IFREMER

Centre de Brest

Service Documentation - Publications

BP 7029280 PLOUZANE

FRANCE 


\begin{tabular}{|c|c|c|c|}
\hline $\begin{array}{l}\text { REPORT DOCUMENTATION } \\
\text { PAGE }\end{array}$ & 1. REPORT NO. WHOI-97-02 & 2. & 3. Recipient's Accession No. \\
\hline \multirow{2}{*}{\multicolumn{3}{|c|}{$\begin{array}{l}\text { 4. Title and Subtitle } \\
\text { Acquisition, Description and Evaluation of Atmospheric Model Products for } \\
\text { the Coastal Mixing and Optics Experiment }\end{array}$}} & $\begin{array}{l}\text { 5. Report Date } \\
\text { March } 1997\end{array}$ \\
\hline & & & 6. \\
\hline \multicolumn{3}{|c|}{ 7. Author(s) Mark F. Baumgartner and Steven P. Anderson } & $\begin{array}{l}\text { 8. Performing Organization Rept. No. } \\
\text { WHOI-97-02 }\end{array}$ \\
\hline \multicolumn{3}{|c|}{ 9. Performing Organization Name and Address } & 10. Project/Task/Work Unit No. \\
\hline \multicolumn{3}{|c|}{$\begin{array}{l}\text { Woods Hole Oceanographic Institution } \\
\text { Woods Hole, Massachusetts } 02543\end{array}$} & $\begin{array}{l}\text { 11. Contract(C) or Grant(G) No. } \\
\text { (C) N00014-95-1-0339 } \\
\text { (G) }\end{array}$ \\
\hline \multirow{2}{*}{\multicolumn{3}{|c|}{$\begin{array}{l}\text { 12. Sponsoring Organization Name and Address } \\
\text { Office of Naval Research }\end{array}$}} & $\begin{array}{c}\text { 13. Type of Report \& Period Covered } \\
\text { Technical Report }\end{array}$ \\
\hline & & & 14. \\
\hline
\end{tabular}

15. Supplementary Notes

This report should be cited as: Woods Hole Oceanog. Inst. Tech. Rept., WHOI-97-02.

\section{Abstract (Limit: 200 words)}

Numerical weather forecasting model products were acquired for use in the Coastal Mixing and Optics (CMO) Experiment to augment in situ observations of meteorological parameters (e.g., wind speed and direction, air temperature and relative humidity) at a moored array of buoys in the Middle Atlantic Bight. In this report, the Eta and Rapid Update Cycle (RUC) regional models are described and the two methods of acquisition via the Internet, the Internet Data Distribution (IDD) system and file transfer (FTP) from the NOAA Information Center's data server, are discussed. Processing and archival of the model data are also addressed. Data from the CMO central mooring and six National Data Buoy Center (NDBC) buoys in the Middle Atlantic bight were used to evaluate the accuracy of the model products. Comparisons between model and in situ wind speed, wind direction, barometric pressure, air temperature and sea surface temperature were possible for all seven of the buoys. Since no moisture measurement was made from the NDBC buoys, comparisons of relative and specific humidity were only possible at the CMO buoy. Sensible and latent heat fluxes and global (net) radiation from the models were compared to estimates of heat fluxes and net radiation from the CMO central buoy.

17. Document Analysis a. Descriptors

air-sea interaction

moored data

numerical weather forecasting models

b. Identifiers/Open-Ended Terms

\section{c. COSATI Field/Group}

18. Availability Statement

Approved for public release; distribution unlimited.

\begin{tabular}{|c|}
$\begin{array}{c}\text { 19. Security Class (This Report) } \\
\text { UNCLASSIFIED }\end{array}$ \\
\hline 20. Security Class (This Page)
\end{tabular}

